

Digitized by the Internet Archive in 2007 with funding from Microsoft Corporation 




\section{THE, GRAND STRATEGY OF EVOLUTION}

THE SOCIAL PHILOSOPHY OF A BIOLOGIST

\section{BY}

WILliaM PATTEN, Рн.D.

Professor of Biology in Dartmiouth College, Hanover, $N$. $B$.

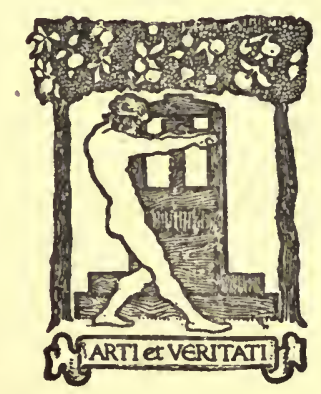

BOSTON

RICHARD G. BADGER

THE GORHAM PRESS 
Copyright, 1920, by Richard G. Badger

All Rights Reserved

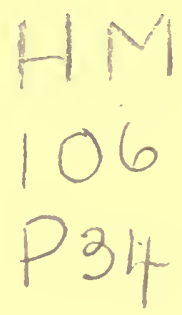

Made in the United States of America

The Gorham Press, Boston, U.S.A. 


\section{INTRODUCTION}

The Household of Man-The Philosophy of War and the Philosophy of Peace-The Purpose of a Righteous Peace-Unorganized Humanity-The Grand Strategy of Evolution.

\section{The Household of Man}

THE roof of the world shelters a common household for man and his fellow creatures. All its living rooms are occupied and all its dwelling places are public thoroughfares as well as private habitations. In this household man can have no domestic secrets for visitation and communication are available to all. Wisdom and folly are publicly proclaimed, profits and losses open to inspection. Every member of the human family quickly learns that what is "right" for one is "right" for the other; that what is "wrong" for one is "wrong" for all; that what is profitable for one may be profitable for anyone. And profit is but another name for growth, the goal of all endeavor.

While the great masses of mankind must still live hazardously from day to day, moved to meagre profits by momentary impulses and present opportunities, increasing numbers are eagerly scanning the horizon of human affairs in search of more profitable ways of living, and finding them, they shall not be denied their profits.

Eager roots may. rend the hardest rocks in search of profit. What social masonry may not be shattered by the groping roots of social life in search of happiness? 


\section{The Philosophy of War and the Philosophy of Peace}

Strange as it may seem, it was but yesterday that these eager sentinels of the human flock were gravely debating whether or no peace is more profitable than war, and whether peace or war is the "natural state" of man. The question so sharply formulated is both pertinent and logical, for it covers the whole philosophy of life. It covers, indeed, the whole philosophy of evolution and the creative conduct of $\mathrm{Nature}$. There is no other alternative.

A convincing answer, either way, will profoundly influence every phase of human life the world over, for as intelligence dictates the strategy by which it may conquer, so, in the long run, will the body act. But to satisfy the intelligence, the answer must harmonize with natural laws, for the grand strategy of man cannot be different from the grand strategy of nature. Evidently the problem lies within the domain of the biologist.

$\mathrm{He}$ who is persuaded that "warfare" is nature's method of evolution, that war is the "natural state" of man and more profitable than peace, will say in his heart: If war is profitable, then war is good; it is "right" for man to make war, and so by all means, let us have war; nation against nation, race against race, brother against brother. Every man for himself and every interest for itself; the secret or declared enemy of every other interest and every other man. Present obstacles alone shall postpone the attempt of each to master or destroy the other. If it is right for nations to war on one another, by the same token it is 
right for citizen to make war on citizen; for friends and neighbors to rob and despoil one another when safe opportunities or dire necessity arise. If there is no cause for war, invent one. A good war will hallow any cause. There are no "rights" to be respected, no "obligations" to be honored. Strategic positions and economic conditions alone are to be considered, correctly estimated, improved, and rightly utilized at the proper time for self-preservation and self-aggrandizement.

There are no such things in the naked realities of a natural life, nay there cannot be such things as faith, loyalty, honor, self-sacrifice, mutual service, and benevolence. These are but empty words invented by man for man's protective purposes; lies cunningly made to look like truth for ornamental and polite social usages. They are but conventional baits for the less intelligent; traps for sentimental fools. Pledges and truces are but resting, spells, mantles of dignified hypocrisy, to be worn only so long as they serve their purpose.

Wholesale and indiscriminate destruction, however, would be unprofitable, and unwise. Like over-greedy parasitism, it would leave nothing for the destroyer to live upon. Only that shall be destroyed which is an obstacle to the larger purposes of the conqueror, a menace to his vital interests. Only that shall endure which can be mastered by him and utilized, whose will can be bent to his will. Only the masterful can thrive, and only the strong should endure; their armor of ruthlessness is the necessary means to an end that is good; the more quickly that end is gained, the better. Pity and mercy prolong miserable lives and cumber the earth with unfit and useless beings; they are only the misguided efforts of slavish minds that draw out 
the battle but cannot change the inevitable result. All this and more, that by the struggles of war, and by the eliminations of war, the best shall survive; that the more intelligent may live on the substance and labor of the stupid; that the strong may grow stronger and prosper in the land his God has given him. Because of his skill in combat, man has thrived and gained dominion over all other animals. War is the source of this profit. It is necessary to perpetuate war in order to prevent the stagnation of an over easy life and to stimu- . late progress.

This, in brief, is the "philosophy" of war. According to many students of evolution, this kind of life is the natural one for man. It is a philosophy that still appeals to the intellect of many theologians, scientists, and statesmen, even though they cannot bring themselves to act in accordance with it.

But if any man be persuaded that a state of peace is truly profitable to man, and that war is unprofitable, then will he say to himself and to his brother: "Peace is good. Let us by all means make peace between us, and let us forever keep the peace. What is good for me is good for you; it is also good for your children, and for my children. Give me there of your strength tomorrow, and I will give you here of my strength today. Neither of us shall be a loser thereby, and each shall duly profit in the common enterprise. I will truly tell you of my adventures, of my going out, and my coming in, of my successes, and of my failures; and you will truly tell me yours. So shall we multiply our profits, for each shall profit by his own experience and by the 
experience of his brother. So shall we both grow in truth, in wisdom, and in our common knowledge. So may we better act together in our common purposes.

"I will keep the faith, even as you will keep the faith, with my life, it may be, for my goods, my life, and the lives of my helpers, are dependent on the fulfilment of your covenants, even as your goods, your life and the lives of my helpers are dependent on the fulfilment of my convenants. So shall we and our possessions the longer endure.

"Our mutual faith, our loyalty, and our honor shall be as a staff to lean upon; as girders over unmeasured gulfs of time and space; as invisible bonds binding each to each with hooks of steel, yet leaving each one free. Our honor shall not stand upon compulsion; it shall not require a witness, or a guardian, or other pledge than honor; for the virtue in honor cannot be strengthened save by honor. So shall our honor be an insurance, valid in full, at whatsoever time or place, against the fickle winds of adversity. So shall we grow in stability and security.

"Our common profits shall be as a reservoir that shall be filled in times of plenty and drawn upon in times of need. They shall be a heritage to the sons of men, freely given and gladly received, to use and to enjoy. So shall we grow in benevolence which is our assurance of continued prosperity. So shall we, and our children, and our childrens children, live long in the land and grow in happiness. Our house of peace shall be built by mutual service. It shall be founded on truth and sheltered by justice. So shall fear, and hate, and greed, not enter therein." Such, in brief, is the philosophy of peace. 


\section{The Purpose of a Righteous Peace}

When the present conflict of moral and physical forces has attained a new state of equilibrium; when hate, and fear, and greed are for the moment impotent to attack or defend; men will seek, as never before, to understand the causes of war, and to find the means of avoiding it; for no further demonstration of the futility of war for war's own sake will be required.

All the nations and peoples of the world, the conquerors and the conquered, the innocent and the guilty, will loudly proclaim the imperative necessity of a lasting and a "righteous peace."

But, if they sincerely desire to establish a righteous peace, they must first seek in their councils to reach some conclusion as to the meaning of "righteousness," and the purpose of a "peaceful" life.

Rightness may not be circumscribed by any religious creed, nor by race or color; nor high or low degree of wealth or poverty, weakness or strength, intelligence or stupidity. Indeed it cannot be limited in its scope to purely human affairs. The foundations of rightness lie deeper than man and his institutions. Rightness has its roots in the physical and animal makeup of man, in the sources of his origin, maintenance, and growth. All the evolutionary processes which have produced man must be right processes, as his actual existence, his progress in the past, and the growth and existence of his fellow creatures abundantly testify.

What then is the nature of these processes? Why do we call them righteous? What shall we say of the purpose of man? Why is he here? What is peace for? What part does man play in the grand strategy of evo- 
lution? Can science, religion, and philosophy ever come to any basic agreement on these very practical questions?

To many practical souls, the philosophy of peace is but an idle dream, an enticing but unattainable vision. They truly say: "We have no such dreams. The brothers we know have no such visions. They only are wise who deal in realities, who see mankind, and the world of things at large, as they are. Nature and her ways, man and his ways are different; they are what they are, and cannot be changed." With all that we have no quarrel. But are we quite sure of our realities? Do we surely know how nature grows and how man grows? How both create and preserve their products? Does man, consciously or otherwise, imitate nature in his constructive ways; or are his methods peculiar to himself?

Surely it behooves us to inspect our dreams and our visions more carefully. It is doubtless true that there are both peaceful and warlike ways in nature, as in man. But which ones are the more creative? What kind of things are more likely to be saved? What kind of things are more likely to be destroyed? How do those things exist, which do exist?

If our inspection is well and duly. made, we may perhaps be able to answer these questions with a greater degree of accuracy; possibly to define "righteousness," at least from the standpoint of evolution; to formulate a basic, creative law, and to define, in terms of progress, the purpose of a peaceful life. 


\section{Unorganized Humanity}

The vital interests of man are for all men the same, for all men spring from the same creative source, are servants to the same creative ends, and are dependent in the same ways upon nature, and upon one another. But there is no court language of the mind in which these interests can be intelligently discussed; no vocal organ to utter the dictates of mans intelligence; and no organic instruments to translate them into creative action. The will and the physical power greatly to serve mankind are at hand; but the elemental intelligence, and the unity of purpose essential to constructive action, are lacking. The quickening spirit of humanity awaits the birth of its organic tabernacle.

Self-appointed delegates from civic and religious domains, and from the outlying provinces of the physical and biological sciences, address the world's court of public opinion virtually as strangers, and as alien enemies to one another. Vaguely suspicious, and suspected, they grow ever more voluble of shop and of its technicalities; ever more secret, and inarticulate of heart, and of its elemental purposes. To their busy fellow men they appear to be the same old self-seekers, but in some new, still more incomprehensible disguise.

In this new Tower of Babel, church, science, and state, call in vain to one another, for each uses a code unacceptable, or unintelligible, to the other. Each thinks of different things in similar terms, or of the same things in different terms; and each emits an endless jargon of discordant notes and messages devoid of 
meaning to the body social. The deeper currents of mental life, so essential to wholesome social growth, stagnate at their sources, or their burdens putrify on their meandering way. For the carriers of truth are fickle agents; their inconstant hearts are empty, or flatulent, or too weak to drive their lessons home. Basic terms are seldom cashed at par, for the living thought of man is ever clothed in dead, or dying words. And these regal words of other days, laden with precious memories, devitalized by use, mutilated by dogmatism, or outlawed by the vital progress of ideas, are widely quoted at fictitious values. There is no standard verbal money rightly to measure the products of mental labor.

Thus the world's ambassadors to humanity, inspired though they be with the spirit of service, are powerless to accomplish their purpose. They are as strangers in their own land, as immigrants in a crowded immigrant district, mentally isolated from one another, and from their fellow men. Inestimable potentialities, pitifully unserviceable and unservable.

\section{The Grand Strategy of Evolution}

As the mental attitude of an immigrant is not without value to his fellows, I venture to express the results of my own experiences, chiefly in the world of animal life.

Let me say at the outset that I can discover no basic difference, using the term in its physiological sense, between the end or purpose inherent to all phases of vital action, and the purpose inherent to all physical or natural phenomena. In all cases, the purpose, or 
the result which is achieved, or to be achieved, appears to be the same, and the ways and means of its achievement.

The universal end, or purpose in life, and in nature, is to construct, to create, or grow. The ways and means of accomplishing that end are mutual service, or cooperative action, and rightness.

The initial constituents of any growing thing, by acting the more cooperatively, the better preserve themselves. These in turn cooperate to create and preserve other constructive agents. But these creative and saving acts cannot take place unless the right things are conveyed to the right place at the right time. When these services are performed, the creative and saving acts take place spontaneously, or automatically.

Creative rightness, therefore, is a definite function of time, and place, and of some inherent attribute.

Creative service is expressed in threefold termsconveyance in time (preservation and conservation); conveyance in space ( relative motion); and rightness. Its value is measured in terms of the things created; it is manifest in their material structure, or architecture, and in their creative acts, or functions.

There is an abiding compulsion to the action of all these factors which is cumulative, or progressive, producing that increasing architectural organization that we call nature-growth, or evolution.

Two reciprocal processes are always manifest. in this cooperative nature-action: construction and destruction; organization and disorganization. We may also call these universal processes of give and take, good and evil, anabolism and catabolism, egoism and altruism. But as this nature-metabolism, as a whole, is 
cumulative and progressive, there is but one all-pervading attribute of nature, namely, rightness, which becomes manifest to us as constructive, or creative action, or growth.

All our catalogs, which enumerate and classify nature's content according to structure and action; our histories and genealogies, which trace the course and measure the march of world events; our habitats and environments, which circumscribe the centres of cooperative activities, are our more formal ways of expressing the fact that nature is divergent, rhythmic, and spasmodic in its creative progress, punctuated in time and place by variations in the rate, kind, or degree, of things created.

In all these cases, the reciprocal egoism and altruism, the creating and saving of self in order to give self to some other creative act, is the essential process in evolution. It is the perpetual source of nature's increasing supplies and of her insatiable demands. It is the basis of man's system of ethics and morality, for in human affairs we call these same constructive processes, righteousness, cooperation, altruism, service, benevolence, and self-sacrifice.

In setting forth my own mental attitude toward nature, as a purely personal record, I shall speak, not as a scientist in the conventions of science, fortifying one opinion with another,- that I cannot do, if I would,nor yet as a biologist, bringing, in testimony, some fresh revelation of the laboratory; but rather as one at last compelled to act as secretary to his own disordered state of mind; putting into order those thoughts 
and experiences which have come from one knows not whence, or where, for the sake of a self-saving order.

Shaking "off those tangled oracles which ignorantly guide ..."

In "high neglect of what's denied or said

This way or that way, in doctrinal writ.

Troubled no longer by the priestly lore."

I have thrown the small verbal cash and other impedimenta of my native province into the melting pot, using wherever possible the irreducible sovereign terms current in all mental exchange. And if you who read will also, for the moment, lay aside your own trappings, coming foot-free with me over some neglected trails, it may be that we shall see more clearly from our new point of view-and perhaps more convincingly because of its scientific setting-that elemental truth which governs alike all the institutions of man and of nature: The right to exist and the obligation to serve are one and inseparable; for to exist is to give, and to give is to receive. 


\section{CONTENTS}

INTRODUCTION ......

The Household of Man-The Philosophy of War and the Philosophy of Peace-The Purpose of a Righteous Peace-Unorganized Humanity--The Grand Strategy of Evolution

\section{PART I. THE ETHICS AND MORALITY OF EVOLUTION}

I. Basic Factors in Constructive Action

The Influence of the New Concept on Human Conduct-The Varied Aspects of Nature as a Source of Mental ConfusionConflict and Tragedy, Competition and Destruction in $\mathrm{Na}-$ ture-Benevolence and Mutual Service as Directive or Disciplinary Agents in Nature-Action-The Continuity of the Creative Process-Evolution a Triumph of Constructive over Destructive Agencies-Cooperation and Conveyance, or Mutual Service and Rightness, as Constructive Agencies in Evolution

II. The Evolution of Individuality ............

The Individual and its Environments-The Creative DriftThe Increment of Mutual Service and Rightness in EvolutionThe Growth Purpose in Nature-Action-The Decrease of Chance and the Increase of Compulsion-Mutual Rights and Mutual Obligations and the Categorical Imperative to Existence-The Egoism and Altruism of Individuality-The Ethics and Morality of Nature-Action as a Guide to Individual Conduct-The Components of Individuality

III. Fitness and Adaptation...............6. 62-8i

The Criterion of Fitness-The Different Kinds of FitnessFitness by Design, and Fitness by Mutual Influences-Temporary and Permanent Fitness-The Measure of Organic Fitness-The Measure of Social Fitness-The Adaptation of Vital Actions to Good and Evil-The Evolution of Fitness and Adaptation-Adaptability in Nature-Action, as a Universal Creative Tropism

PART II. NATURE'S SYSTEM OF SELF-ADMINISTRATION AND SELF-CONTROL

IV. Life: Its Origin, Agencies, Habitat, and

GrowTH....................... 85-113

Preparation, Materials, and Forces-The Cosmic Formula for Life-Life's Cosmic Sanctuary-Life's Directive DisciplineLife's Freedom-The Growth of Freedom-The Instruments of Freedom-Growth: its Insistent Power; Organic Wealth, its Source and its Uses; the Demands of Growth; Checks and Releases to Growth; Development, or Simultaneous Increase in Vol- 
ume, Diversity, and Mutual Service; Limitations to Growth; Growth by Multiplication or Dissociation and by Combination, Reunion, or Association; Profitable, Cooperative Mergers; Unprofitable Mergers, Parasitism-The Creative Cadence or the Formal Accents of Organic Growth-Stability of Individual Life Essential to Social Life-The Growth Rhythm: Individual Growth, Fragmentation, Regeneration, Association

V. Nature's Dual Administrative Sovereignty. . iI 4-I 28

The Dual Sovereignty of Individuality, or Internal and External Autonomy - The Internal Administration of Life - The External Administration of Life-The Federal Administration of LifeThe Insurance of Life

VI. Benevolence and Discipline........... I 29-167

The Constructive Metabolism of Egoism and Altruism-The Merging of Egosim and Altruism into Organization, and its Emergence as the Augmented Altruism of Larger IndividualsThe Entail System in Sexual Reproduction: Life's Entailed Estates; the Entailed Habitat; the Germ, or Entailed Principal: Quick Assets, or the Endowments of Organic Capital to Embryonic Life; the Nutritive Income and Forage Dividends of Youth-Bisexual Cooperation as an Agency in Parental Benevolence: Sex, and Sexual Divergence; Female Attributes; Male Atrributes; The Functional Attributes of Germ Cells; Bisexual Cooperation-The Merging of Parental Altruism into Nature Altruism and Social Altruism: the Larger Creative Values of Bisexual Divergence and Bisexual Cooperation; the Unity and Cooperative Duality of Plant and Animal Life; the PostSexual Period of Parental Life as an Agency in Social Inheritance; Evolution as the Product of Altruistic Action; Intelligence not an Essential Factor in Altruism-Directive Discipline: Cosmic Discipline; Directive Discipline of the Germ; The Cumulative Discipline of Organized Endowments, Structural and Bionomic; Education; The Compulsion of Intelligence; Discipline in Civic Government, in Religion, and in Science-Summary of Chapters I-VI

\section{PART III. THE ARCHITONICS OF EVOLUTION}

VII. Architecture in Nature as the Expression of

Cooperative Nature-Action............ I71-I 87

Knowledge expressed in Architectural Terms-Architecture and Function-Architectural Diversity a Prerequisite to Evolution-Reciprocal Relations between the Architecture of the Individual and its Response to its Environment-Architectural Values and Cooperative Balance-The Divergent Archirecture and Cooperative Unity of Plant and Animal Life-The Compulsion of Established Constructive Methods

\section{Vital Action Versus Nature-Action as Ex-} pressed in Architectural Plans and in

Phylogeny.................... I88-210

Phylogeny-Architectural Values as Expressed in Main Lines and Collateral Lines of Evolution-Architectural Problems, and the Increase of Power through Architectural Improvements- 
The Architecture of Inorganic Growth-The Architecture of Organic Growth-The Architecture of Plant Life-The Architecture of Animal Life-Unicellular Growth (Protozoa)Multicellular Growth-Radial Structural Plan (Colenterates or Jellyfish)-Spiral Growth and False Radial Symmetry (Molluses and Echinoderms)

\section{The Triaxial System and the Great Highway of}

\section{Animal Evolution.................21 I-25I}

The Triaxial System of Structural and Functional GradientsIts Methods of Internal Readjustment and BettermentThe Material and Functional Register of Vital Betterments: The Old Mouth and the New; Gills, Lungs, and Heart; The Blood; The Nervous System-The Decline of Metamerism and the Centralization of Functions-Architectural Tropism, or the Orientation of Triaxial Organic Gradients to the Triaxial System of Gradient Action in the Outer World: The Asymmetry of the Outer World; the Orientation of Triaxial Vital Architecture to World Architecture; Tropic Action; Triaxial Architecture as a Tropic Reaction System and as a Product of Tropic Action-Other Registers of Constructive Action; Instincts, Intelligence, Cultural Implements-Cultural Registers

\section{The Architecture and Cohesive Power of}

$$
\text { Social Life.................. 252-282 }
$$

Limitations to the Growth of Man as an Individual, and the Physical Limitations to his Organic Instruments-The Distinctive Organs of Social Life, Manual, Visual, Vocal, Auditory, and Mental, and their Cooperative Unification-The Merging of Man's Sense of Self with his Physical Instruments and Material Properties-The World-wide Unification, Physical, Organic, and Mental, of the Nineteenth Century: the Completion of the Social Blastoderm; the Increment of Power; the New Receptors and Perceptors; the New Ways and Means of Conveyance; the Orientation to a New World and the New Mental Freedom-The Compulsion to Social CooperationThe Consciousness of Social Possessions as the Compelling Creative Power in Social Construction and Social Preservation-Summary of Chapters VII-X

PART IV. THE ARCHITECTONICS OF MENTAL EVOLUTION

\section{The Orientation of Mental Imagery to Nature-} Action as a Means to Constructive Conduct 285-30i

The Cooperation between Conduct, Cosmic, Organic, and Mental Action-The Egoism and Altruism of Mental Life, Learning, and Teaching-The Parallelism between Mental and Physical Evolution-Mental Imagery as a Self-Constructive Function-The Evolution of Mental Imagery-The Imagination as an Instrument of Conveyance. The New Freedom and the New World-Basic Concepts: Creation, Growth, Obedience, Service, Profit-The Tests of Veracity 
XII. The Compulsion of Nature-Action in Science,

Religion, Art and Government........302-327

The Compulsion of Intelligence-The Expression of Nature's Self-Constructive Ways in Man's Self-Constructive Social Laws-Mental Reorientation-The Militant Phase of Intelligent Action-Fear as a Counter Evil-The Conservation of Mental Rightness through Education-The Creative Value of Truth as the Expression of a Natural Creative Law-The Cooperative Factor, Mental and Moral, in Animism-The Tendency to Unify and Simplify Natural Phenomena-Rightness as a Saving and Directing Agency in Mental and Physical Action-The Community of Purpose in Science and Religion

\section{PART V. THE ARCHITECTONICS OF SOCIAL EVOLUTION}

\section{Mental Imagery as a Factor in Social Growth 33 I-357}

Conflicting Social Philosophies, Old and New-The Distorted Philosophy of the Biologists-Business Philosophy-Germany's Militant Kultur-The Permanent Mental Incentive in Social Regeneration-Mental Limitations and Unadaptive Social Growths: Primitive Social Life of the Australians; Christianity, Buddhism, and Hinduism; The Cultural Inequalities of the Greeks-Science and the New Democracy-The New Demands of the New Freedom

\section{Class Functions and Voluntary Submission to}

$$
\text { Leadership...................... } 35^{8-376}
$$

Class Differences a Necessary Condition to Social CooperationSocial Metabolism and the Conveyance of Social PowerSocial Cleavage and the Delimitation of Social Units-Social Motives and the Compulsion of Achievement-The Constructive Usage of Intelligence in Social Growth: Mental Dominion; Mental Democracy, or Equality of Authority; The Delegation of Functional Authority and Voluntary Submission to Leadership

XV. The New Leviathan.................. 377-4II

Quickening World-Life-The Mosaic of World-Life, Functional and Morphological-The Evidences of Organized World-LifeThe Ways and Means to a Purposeful World-Life-The State as a Sphere of Cooperative Action-The Evolution of Social Covenants-The Government of the State: the Autocratic State; the Democratic State-Education as a Directive Agency in Social Egoism-The State as a System of Cooperative Functions: Social Reproduction; Social Metabolism; Social Betterments-The Extension of State Functions into International Functions

Summary .......................... 412-413

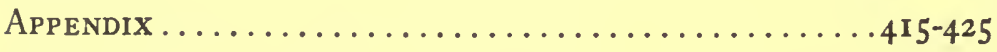

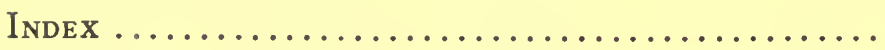


PART I

THE ETHICS AND MORALITY OF EVOLUTION 



\title{
THE GRAND STRATEGY OF EVOLUTION
}

\author{
CHAPTER I
}

\section{BASIC FACTORS IN CONSTRUCTIVE ACTION}

The Influence of the New Concept on Human Conduct-The Varied Aspects of Nature as a Source of Mental Confusion-Confict and Tragedy, Competition and Destruction in Nature-Benevolence and Mutual Service as Directive, or Disciplinary Agents in Nature-Action-The Continuity of the Creative Process-Evolution a triumph of Constructive over Destructive Agencies-Cooperation and Conveyance, or Mutual Service and Rightness as Constructive Agencies in Evolution.

\section{The Influence of the New Concept on Human Conduct}

THE theory of evolution is now accepted by all classes of intellectual leaders. Its transforming influence has penetrated society far beyond the point where the theory is formally recognized, or the meaning of the term even vaguely understood. It has destroyed old standards for the interpretation of life, erased old formulas for the conduct of life, and has compelled us to seek new standards and formulas more in harmony with nature-action; ones based on the best teachings of the old religions and on the best of the new science; and ones that shall not be in downright con- 


\section{GRAND STRATEGY OF EVOLUTION}

flict with the dictates of common sense, nor with the vision of the modern prophets who foresee the coming of a new man.

It is, therefore, time to inquire more deeply into the meaning of the processes common to the evolution of living and non-living things. What, after all, constitutes world progress and how is it accomplished? In what directions are the great evolutionary streams of plant life and animal life moving? What are the ethics and morals of nature, if indeed she has any? What has science to offer the trustees of tradition in place of that which she has destroyed? What have students of nature learned, however elemental, that shall be to all mankind a fundamental truth and a guiding principle to constructive action? Is man to live and grow by using the same methods all other things in nature use, or must he create out of his own compelling needs new methods of living, new principles, new laws of conduct, that are solely applicable to himself?

To these questions science has given conflicting answers, for nature has many different sides and science sees them through many different eyes.

\section{The Varied Aspects of Nature as a Source of Mental Confusion}

Nature, indeed, is so vast, so intricate, and in many respects so inaccessible that science can see but a very small part of her; and since no one science can long preserve its images undimmed, nor adequately utilize the vision of other sciences, man's mental picture of nature is a mosaic patchwork of flickering images; a 
changing, composite caricature, which exaggerates her most conspicuous features, her most dramatic, and most recently discovered phases.

But yesterday, nature seemed to be the unchanging product of a precipitative creative fiat; today, the still changing product of endless growth. Tomorrow, what will the image be? Which science will then throw the high lights of nature on the mind of man? Which one then will cast the shadows?

The great naturalists of the preceding generation -those brilliant students of the interwoven lives which play their various parts on shifting scenes of forests, field, and shore-gave us our first vivid picture of an ever changing nature. It was largely their testimony that won the verdict for evolution. After the great naturalists came the modern biologists, aiming to explore the source of /life, and in the seclusion of the laboratory seeking to obtain a nearer and a better view of nature in accouchement; now scrutinizing with microscope and blazing lights the minutely woven fabric of egg, and sperm, and embryo; now, watching the first throbs of nascent life in cell and organ; now, by artful and instantaneous killing, striving in their order to fix the mincing steps of life for more deliberate inspection; now striving to view the steps of life in action; and again, by mimicking the different processes of life, hoping to catch their meaning, or perhaps the meaning of life itself.

The field naturalists and the modern biologists survey a particular phase of life through a particular mental facet, and each school has evolved a more or less rigid formula for the things it most clearly sees. The Lamarckians chiefly see the inheritance of acquired 


\section{GRAND STRATEGY OF EVOLUTION}

characters, the moulding influence of habit and of the external environment. The Darwinians see little else than "natural selection" and the "survival of the fittest." The Weismannians see an omnipotent "germ plasma," the creator, mute and unquestionable of all things living. The morphologists see their own cubist diagrams more clearly than living, growing organisms. The cytologists, breeders, and experimentalists see little more than their own thumb-nail sketches of the minute machinery of life and heredity, of Mendelism, chromosomes, and eugenics.

The precise methods of modern biologists give us commendably accurate pictures of some particular point, or phase, of life as it is at the present moment. But they have not clarified man's social problems, nor given us large pictures of the processes and products of evolution. They lack perspective, and cannot take the place of the more comprehensive, descriptive, or historic sciences, such as geology, paleontology, and comparative anatomy, which show us approximately what life is now, as a whole, what it was like in the remote past, the wonderful progress it has made and the order of its accomplishment.

Thus man's mental attitude towards nature is the product of a complex mosaic vision. The very multiplicity and changing intensity of the nature-images formed by modern science have created among scientists and laymen much mental confusion, augmented by a prevalent belief that certain points of view, and certain methods of studying nature, are more truthful and trustworthy than others.

It is clear that the historic, microscopic, telescopic 
and panoramic methods of nature study have their respective virtues as. well as the defects of their qualities, for each shows important things the other fails to reveal. In their attempts to portray nature, biologists often forget the weakness of the one and fail to utilize the strength of the other. By thus limiting their field of vision, by exaggerating the minute, the local and the dramatic incidents of life, they seriously neglect the most significant teachings of nature, although they are familiarly and universally proclaimed by her.

\section{Conflict and Tragedy, Competition and} Destruction in Nature

The picture of nature painted by the field naturalists was a warring, hostile nature, "red in tooth and claw with ravin." Its merciless "struggle for existence," its wanton destruction and tragic incident deeply moved both scientist and layman and greatly influenced the conduct and the interpretation of human life.

But the attention of the naturalists was chiefly focused on the fifth act of life's drama, not on the body of the play; on the inevitable collapse of imperfect life systems, not on the upbuilding of cell on cell, and life on life, during long preliminary constructive periods.

They gave us the familiar picture of life's tragic side, and, like all one-sided representations, it was but a caricature, true, indeed, to the life they portrayed, but misleading in the omission of the larger truth. They showed us the shameless selfishness, the fruitless toil and suffering, the wanton wastefulness of life and the endless competition in strength and skill, in shifting alliance with hypocrisy and deceit; with blind 


\section{GRAND STRATEGY OF EVOLUTION}

chance in the background awarding death to the vanquished and to the victor life's bitter spoils. With master strokes, and with the convincing accuracy of the trained observer, they painted the "disastrous chances" of a tumultuous life, the "moving accidents by flood and field," the spectacular catastrophes of failure.

But they did not portray the benevolent processes of construction, the peaceful cooperation, the careful conservation, and the successful sacrifice of self to higher service. Some writers have indeed recognized the element of benevolence in the cooperation that forms such a conspicuous feature of many social organizations; but usually it has been regarded as something peculiar to a few highly organized animals and to man, not as something inherent to all stages of organic and inorganic nature.

\section{Benevolence and Mutual Service as Directive, or} Disciplinary Agents in Nature-Action

But a new phase of nature's primeval method, a new instinct, is now seeking expression in the heart of man. It demands more and more insistently the "humanitarian" methods of cooperation, altruism, and mutual service. The hand hesitates to obey the heart's command because the false prophets of science still dictate the use of nature's crudest, least effective methods, saying that progress can be made only through competition, through mastery by brute force, or by strategy, through selfishness and the license of freedom uncontrolled. I challenge this interpretation of the order. It is not the real teaching of life nor of nature. It places the 
emphasis in the wrong place and on the wrong thing. It measures the cost, but not the gain. It counts the failures but ignores the manner of achieving success.

There is nothing new in "humanitarian" methods. These methods are as old as the universe. With these methods, the universe was built. Evolution is a process of more and more effective cooperation. All manner of living is a fabric of cooperating services. In every sphere of nature, chemical or physical, organic, social, or "spiritual," and at every stage in its progress, evolution is achieved through union, not disunion; through construction, not destruction; through harmonious action, not discord; through organization, not disorganization; through cooperation, not competition; through the bondage of service, not the license of freedom; through service that leads to more service, not through dominion and freedom from service.

The processes that produce evolution, as distinct from those that do not, are essentially benevolent and moral processes; for evolution is a progressive triumph of "right," or constructive methods of self-giving. In nature every forward step in construction and conservation is a creating and saving process, whether it be the union of cosmic matter to form solar systems, or atoms to form chemical compounds, or cells and organs to form a body, or man to form society. In all cases the forward step is the result of a successful giving, or surrender of self to form a part of something that is larger and better equipped for a wider and longer service. Every living thing has its two great phases of egoism and altruism; one when it is getting or receiving all it is; the other when it is giving all 


\section{8 GRAND STRATEGY OF EVOLUTION}

it has. The broader, more elaborate, more enduring, each life is, the longer and more elaborate is the process of giving by the parents, and of receiving by the offspring; and the better all organs of both parents and offspring cooperate for a wider service of the whole.

Nor does "blind chance" rule in nature, for the dice are loaded in favor of things in the "right" time and place, as against those in the wrong time and place; in favor of those things which act constructively as against those which do not. In its broadest sense, constructive processes, even if they are due primarily to "chance," are cumulative in their results, and increasingly directive in their disciplinary influences, because of the better balance, or stability, of each new constructive product; and because the larger unit tends to control the smaller unit and to incorporate it into its own system.

Progressive union and stability, progressive cooperation, organization, service and discipline are, therefore, inherent properties of life and matter.

\section{The Continuity of the Creative Process}

Thus mutual service is the great creative, disciplinary, and saving force in nature. It tends to give community and harmony of action to her constituents, expressing itself in an evolution that inevitably leads toward the fulfilment of their inherent possibilities.

Creation then is the birth of new things through the mutual services of pre-existing things. Its product may be a new star, a chemical compound, an inanimate machine, a living mechanism with the properties of growth and renewal, or any one of the many kinds of 
cooperating groups, or associations, of men. We may not correctly use the term "Creative Evolution," for there can be no creation without evolution, and no evolution without creation. The ceaseless flow of creative services is evolution, and evolution is serial creation.

While nature's methods of creating are always the same, the qualities of her products are always different, and the extent of her creative resources are as unpredictable today as they were yesterday and as they will be tomorrow. The cooperative union of hydrogen and oxygen to produce water creates a new substance with new qualities and new potentialities for world service in no wise comparable with those of its constituents. This familiar process is no more or less mysterious than the cooperative union of a much larger number of elements to form protoplasm, with its newly created properties called "vitality."

As the chemistry of cooperating elements creates new chemical bodies, with new properties and new powers for world service, so the super-chemistry of cooperating lives creates new organisms with their new powers for world service. These new properties of the "living body," or of a group of men called a "team," a college, a city, or a state, constitute what is called the "soul" or "spirit," or attribute of that group. All these "new things" are unlike any of their constituent parts, hence they can be measured, or compared, only in terms of themselves.

The only attribute common to all of them is their inherent power to grow, or to create more new things. The only measure of their powers is the extent of the cooperative services that created them, and the creative value of the new servants they in turn create. 


\section{O GRAND STRATEGY OF EVOLUTION}

Science, therefore, finds no time, or place, or thing set apart and alone sanctified by one instantaneous, allembracing creative act. Cosmic evolution and organic evolution, the growth of suns and stars, of earth, and plant, and man, are continuous parts of one process. The more formal chemistry of earth and sea and air; the flowing chemistry of protoplasmic cell and organ; the moulding discipline of associated nerve and muscle, eye and hand ; the alchemy of associated lives in nature's household, are but different phases of one continuous, all-pervading process of creation.

Nebulæ stiffen into stars and suns give birth to drooling planets, larva smeared. Throbbing tides of sea and air, the heart beats of a planet, drive the nutrient ocean to the mountain skeleton and through the capillaries of earth, clothing her ribs in clay and spreading her first gardens of ooze. Earth labors in her kitchen and with equal skill in synthesis brings forth atoms tied in stable squads and marching regiments; crystals, straight-edged and steadfast; proteids and albumens, with rounded forms and yielding sides; dancing specks and wriggling threads, prophets of the life to come; sprawling, self-constructing, self-consuming protoplasm, free to rove, or wrapped in rigid walls, or bound in glowing brotherhoods of cells together; polyp and snail; worm and crab; fish and frog; bird and ape, and at last naked, hand-free, high-headed man, armored and armed with conscience and with vision. Scrutinize as best she may, science finds no seam in this universal fabric; no patchwork of dead and alive, honored or dishonored, in creation; no barriers between what was, and is, and shall be. 


\section{Evolution a Triumph of Constructive over Destructive Agencies}

The universal conflict of constructive and destructive agents to which we have referred has held the attention of man from the very outset of his conscious life.

It has been the theme around which he has tried again and yet again to construct a workable scheme of life; ever drawing from the furnace of his experience the bitter ashes of failure together with the golden residues of profitable adventures; ever building them into the foundations of his science, his philosophy, and his religion.

The more primitive theories of life and cosmogeny were largely the product of introspective analysis. Man freely interpreted the phenomena of nature in terms of himself, thus attributing to familiar objects, to plants and animals, superhuman powers. The heroic adventures, the arbitrary likes and dislikes of these masterful sun gods, and thunder gods, and wilful reptile devils provided both an easy explanation of nature's mysteries and an obvious source of profit. Through respectful conduct, through solicitation and bribery, it seemed possible to purchase their good will, or their allegiance, or at least their benevolent neutrality, in the battles of life. Thęreby was provided the best way, and indeed to them the only intelligible way, of avoiding that which is evil and obtaining that which is good.

But while man, from time immemorial, has carried his appeals for help, for right and justice, straight to the supreme court of nature, it was but yesterday that he succeeded in drawing from her, in the doctrine of 


\section{2 \\ GRAND STRATEGY OF EVOLUTION}

evolution, a clear declaration of general principles, and a broad outline of nature's methods. Evolution was a new explanation of cosmogeny, based on. permanent natural laws, wherein fickle, man-made gods and demons played no part.

Here, for the first time, the hope and the firm belief, so widely entertained in all stages of man's intellectual apprenticeship, that the good, or creative, agents would ultimately triumph over evil, was unconsciously placed on a firm foundation. For we now see, what was not so clearly perceived in the first excitement of the discovery, that evolution has no meaning if it is not a perpetual demonstration of the slow but cumulative triumph of right, or creative forces.

\section{Cooperation and Conveyance, or Mutual Service and Rightness, as Constructive Agencies in Evolution}

Any basic concept of cosmogeny, therefore, must assume that there is some universal creative process back of evolution, and should express that process in comprehensive terms, applicable alike to physical, organic, social, and mental phenomena.

Biologists, the chief exponents of evolution, are accustomed to think of organic evolution only, and of that largely in terms of natural selection, mutations, and germ plasma. But in the great domains of astronomy, geology, and chemistry, in science, religion, and government, and in a host of other domains, all of which are the products of evolution, these terms are inadequate, or do not aptly apply. Natural selection and the survival of the fittest are perhaps the broad- 
est terms used in the biological sciences, but the processes so designated have no creative value. The terms merely imply that a definite sequence of products ensues, or affirm the self-evident fact that something already created is selected for survival, or that it endures. They do not suggest how it was created, why it survives, or wherein its fitness lies.

I shall try to show that there is but one answer to all these questions; that there is but one creative process common to all phases of evolution, inorganic, organic, mental, and social. That process is best described by the term cooperation, or mutual service.

While the term cooperation expresses a most striking and fundamental attribute of nature, yet it is as impossible to define cooperation as it is to define gravity, or chemical affinity. In all such cases, we can affirm only what things do, not what they are. While we cannot explain why things cooperate, it would appear that all knowledge and all knowable things are the products of mutual influences, or reciprocal services. This action can be expressed only in terms of the things so created, or in the methods of their creation. The methods themselves can be expressed only in relative terms of service, rightness, and progress, that is in terms of more or less service performed in the conveying of the "right" things, to the "right" time and the "right" place, for constructive purposes.

The power to create something new, when these services are fulfilled, is something universal and inexhaustible; something standing apart, in human knowledge, from every other attribute of nature.

The law of cooperation is expressed in the simple yet marvelous fact that when two or more things, 


\section{GRAND STRATEGY OF EVOLUTION}

whatever their nature may be, are brought into a definite time and space relation to one another, and then act together cooperatively, a new thing appears, which could not otherwise exist, having new qualities, new cooperative powers of its own which did not previously exist in its constituents.

Chemical action is often set apart as something quite different from all other activities because of its familiar, instantaneous, creative power. Water, for example, which is formed. by the cooperative union of hydrogen and oxygen has no resemblance to its isolated constituents. It has very remarkable properties of its own, and these new properties are of the greatest cooperative value in world construction, for without their peculiar services, terrestrial organization, protoplasm, and vital action, as we know them, would be impossible.

The difference between the creative power of chemical cooperation and other forms of cooperation is in the agents, periods of fruition, and results, not in their basic methods. We are not accustomed to think of the creative power of mass action, because we have no convenient way of measuring its progress or its products; yet these products have properties as different from their constituents as those of chemical action. A solar system, for example, has attributes and powers that cannot be defined, or measured in terms of its members, or of its ultimate chemical elements, for a solar system is not merely an aggregate, or the algebraic sum of its various elements and qualities; it is something different from any one of them, and something more than all. It is a system, a new type of individuality with 
special creative powers of its own. In the same way, protoplasm may be regarded as a system of cooperating proteids and of other agents, within and without; life is its distinctive attribute. An animal is a system of cells and organs cooperating with one another and with their environments. A state is a group of human beings systematically cooperating with one another and with their environments. In each case, the individual is created by the cooperation of its inner parts and their outer media. It endures only so long as that inner and outer cooperation continues and only so long as the individual, as a whole, continues to cooperate with its environment. According as one or the other of these cooperative systems declines or fails, senility appears, followed by death and dissolution.

The term conveyance is used to signify the transfer, in time or place, of any material, power, or agency. Where a creative, or saving act follows as a result of this conveyance, a service to that end is performed. Conveyance may be brought about by "chance," or by a more or less elaborate series of acts which are themselves cooperative, as for instance by the transfer through space, or the conservation through time, of materials and power by means of cosmic activities; by terrestrial and atmospheric circulation; the distribution of animals and plants, of organic foods; of "germ plasma" during the process of reproduction; the circulation of the products of digestion and respiration in the alimentary, vascular, and secretory systems; by the distribution of nerve impulses and the conveyance of information through the conserving and distributing agency of science, literature, and art, and by the distri- 


\section{GRAND STRATEGY OF EVOLUTION}

bution of a host of other things, upon whose right conveyance the whole fabric of life and creative power depends.

The objection may be raised that cooperation implies a conscious, intelligent act. So it does, usually, but not always. An act may be cooperative, no matter how it is initiated, or whatever the nature of the actors may be. Strictly speaking, although preeminently cooperative, human intelligence is powerless to complete a cooperative act. Intelligence is merely a more direct and certain method than blind chance, or trial and error, of finding the "right way" to let things do the desired act themselves. It is the purposeful opening and closing of certain channels of conveyance, thereby permitting a serviceable, creative act to take place.

The chemist, for example, cannot make an atom of hydrogen cooperate with one or more atoms of oxygen, or alter in any way the nature of the cooperative act that may take place between them. All he does is to act as an agent of conveyance, a servant to remove obstructions and to bring the two elements into the "right relations" to each other. When that is done, the elements themselves automatically enter into a cooperative, or chemical union, in accordance with their specific qualities, and in so doing create something which is different from either constituent. This atomic union is a truly cooperative act, because it cannot be performed by either element alone. It must be performed in concert, by a mutual exchange of services, each element giving something of itself, we know not what, to the other, and receiving something, we know not what, from the other. Thus each in its own pe- 
culiar way, is an altruistic servant to an ulterior creative act.

Subscription to the Red Cross, to take another example, may be a highly intelligent act, but it does not fulfil its creative purpose till the whole machinery of cooperative social life has been set in motion and the right splints and bandages, the right foods and medicines are put into the right places at the right time, and the maimed and helpless in other ways are cared for. Then and not till then, the disordered organism, it may be, completes the long series of cooperative acts by healing itself. Under the compulsion of these services the ultimate saving and healing act is automatically performed by the cooperative actions of the living tissues and organs.

But the full value of this elaborate system of Red Cross conveyance does not lie alone in the resultant saving of life and alleviation of human suffering, great as that may be. It has far greater creative potentialities than that. Its chief social value lies in the potential creative power which is resident in the spontaneous or voluntary service of man to man. This spontaneous spirit of mutual service, always manifest in some measure when men are rightly brought together, is the chief attribute of man. It is the creating and saving factor of human society and of all man's social institutions.

All these creative acts, on analysis, resolve themselves into service and rightness. What we call intelligence may or may not be present. Nature's creative methods and results are in no wise affected thereby. Gravity, light, and chemical affinity, being what they 


\section{$3^{8}$ GRAND STRATEGY OF EVOLUTION}

are, could not create anything in any other way than they do, even if they were intelligent agents rightly performing creative services; and human intelligence cannot act creatively without rightly using these physical attributes. Or, to put it in another way, atoms and molecules, in their constructive processes, act as they would have to act if they were intelligent agents.

What we call benevolence is the giving of something to something else. It cannot be accomplished unless that something is first created and then conveyed across time and space to something else. If this giving and receiving is rightly done, a new creative act takes place. Human intellience cannot modify or qualify this final act in any way; it merely serves as a supplementary instrument to guide these agencies into.constructive channels.

A mother bird, a prosaic hen, for example, gives herself, her life and bodily powers, to storing up food and germ plasma in an egg, out of which, with the cooperation of the opposite sex, comes the next generation. This is altruism; something done, something sacrificed, for something else, intelligence or no intelligence. To do so is of no advantage to that particular bird, or to her mate; but nevertheless they could not have come into being without this system of mutual services. They would not have acted differently, or the result have been different, in those respects, if they had used benevolent foresight and intelligence. Perhaps the same result might have been attained more surely and economically for the hen and her chickens, if the process had been guided by a more selfish intelligence; but in that case the prodigal hen would not have been as serviceable to man, or to other animals. 
Two thousand years ago, a philosopher discovered a great constructive truth. His acts and words conveyed it to his followers. They in turn translated vital acts and verbal symbols into dead material forms, into zigzag lines on parchment, and piled up stones and monuments. And these helped to preserve the truth from generation to generation, and carried it from race to race and land to land, and then and there again made truth the guide to vital action. To convey that thing, devoid of force and substance, across the centuries and around the world, much labor and machinery was demanded. Without the services of those material instruments the philosopher would have lived and died to little purpose. 


\section{THE EVOLUTION OF INDIVIDUALITY}

The Individual and its Environments-The Creative Drift-The Increment of Mutual Service and Rightness in Evolution-The Growth Purpose in Nature-Action-The Decrease of Chance and the Increase of Compulsion-Mutual Rights and Mutual Obligations and the Categorical Imperative to Existence-The Egoism and Altruism of Individuality - The Ethics and Morality of NatureAction as a Guide to Individual Conduct-The Components of Individuality.

\section{The Individual and its Environments}

WE think of all such things as atoms, molecules, plants, animals, society, the earth, or the solar system, as more or less isolated things, or individualities, each composed of other things, parts, or units, all moved and organically held together by reciprocal, or cooperative action. As we can form no concept of action save in terms of material things, and no concept of structure without some coherent power, our impotence in the face of fundamentals is at once exposed. Matter and energy, time and space, themselves indefinable save in terms of themselves, constitute, therefore, our last mental refuge, our initial foothold and starting point for the analysis of nature's grosser creative ways.

As the universe is the environment of all it contains, so the individual is the more immediate environment of all its constituent parts. All these different environments, each one enclosing smaller individualities within itself and each one itself enclosed in larger 
ones, are merely other names for diverse spheres of enveloping conditions, or for different arrangements of matter and energy in time and space.

Each environment, therefore, includes and excludes certain things, and in accordance therewith creates and preserves, prevents and destroys. It limits and localizes the individual thing both by creating it when and where it is, and by setting the boundaries to when and where it cannot be. What therein is possible and impossible is thereby determined.

An individual, then, is a particular part of the universe in contrast with the whole. Its existence proclaims the fact that it is a localized sphere of cooperative activity in a cooperative environment. It is a resultant of both positive and negative factors. It is created and sustained by cooperative and destructive conditions within itself, and by cooperative and destructive conditions outside itself. Without these localizing creators and delimiting destroyers the individual could not exist, for without the one, it could not come into being and without the other, it would be coextensive with the universe.

Thus the distinction between the internal and external environment of any individual is a matter of mental convenience only. Both environments are continuous, and cooperatively one; each, in its own way is directive and creative.

\section{The Creative Drift}

As we grow in knowledge and experience we become more and more conscious that all the apparently separate acts of nature in reality form one con- 


\section{GRAND STRATEGY OF EVOLUTION}

tinuous creative process which flows out of an unlimited past, through the present, into a limitless future. While infinitely varied in local expression, in its larger phases this process persistently maintains a common direction, or drift, which may be expressed by the word progress. Progress, unlike time and space, is not uniform throughout, or isotropic. Like a living organism it is the expression of a graded absolute change, as well as of relative changes; it has dimensions and symmetry, a beginning and an ending, a head end and a tail end, as it were, which differ in their products. Progress, therefore, like a growing organism or a social institution, can be measured only in graded terms of things successively created.

As we extend our concept of progress by looking farther and farther into the past toward the beginning of all things, the complex and varied individualities of today appear ultimately to dissolve, setting all their constituent elements free. Cooperation, apparently, then vanishes in the nullifying conflict of universal "freedom," and all nature assumes the primordial simplicity, continuity and uniformity of elemental chaos.

Our first concept of individuality as something consisting of groups of cooperating parts then gives way to a new one, that of ultimate initial units, infinitely small and infinite in numbers, but apparently finite in kind; and yet another unit, or whole, that comprises them all.

This larger unit, or cosmos, is but an impotent, meaningless aggregate, without real unity, unless we assume that its constituents actually cooperate with one another to that end. If they do not, the unity, if such 


\section{THE EVOLUTION OF INDIVIDUALITY}

there be, must be merely the unity of universal conflict. Or, if we attempt still further to merge the infinitely small and the infinitely large into a supra-absolute one, both vanish into something wholly incomprehensible.

Here, then, our analysis of nature's beginning ends in insuperable barriers. But this brief analysis is not without value if it serves to emphasize that the present,

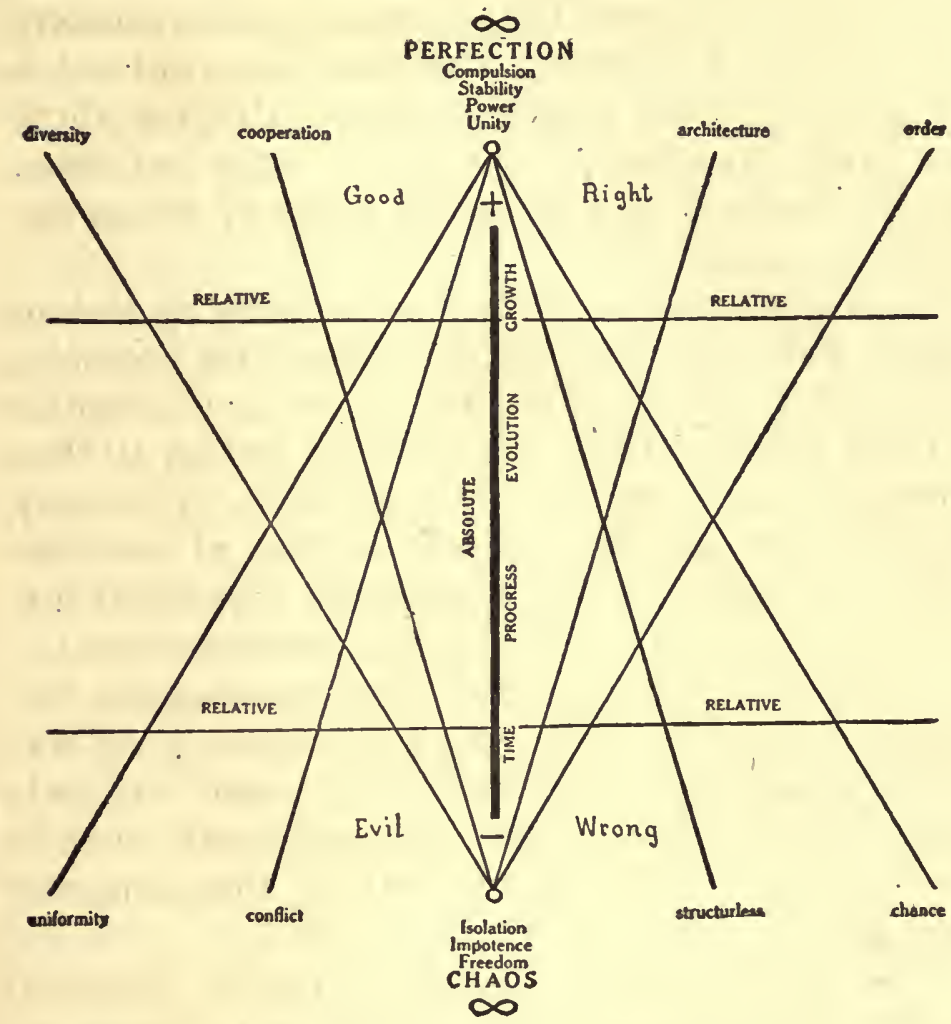

Figure 1. Diagram to Illustrate the Concept of Evolution. Note the involved dual concepts of relative and absolute, positive and negative, and the opposing gradients converging towards zero and diverging toward infinity. 


\section{GRAND STRATEGY OF EVOLUTION}

as well as the initial motive power in nature, or the very thing which everybody wants to know about, is never found. It always escapes us, or is always concealed in insoluble residues.

If we now turn our attention in the opposite direction and try to follow up the creative processes of nature farther and farther into the future, we seem to reach quite a different conclusion. In place of the contradictions and the sense of mental impotence involved in our concept of a creation beginning in universal conflict, in minuteness, vastness, sameness, and emptiness, we reach the concept of creative fulness and variety, of infinite organization and unified cooperative power, where the imagination may rest with some sense of security and familiarity. In other words, we picture to ourselves a nature which approaches nearer and nearer to a final condition where all her separate individualities merge into one stable, organic whole.

This concept of a creative drift from the futile conflict of chaos toward a more stable structural organization and unity is the central idea of evolution, and the general recognition of this phenomenon is the distinguishing characteristic of the scientific and intellectual thought of modern times.

This idea of evolution carries with it the corollary that nature herself develops, or "grows up," or progresses, in much the same way as do all her constituent individualities, such as the sun, a human embryo, or a social institution. 


\section{The Increment of Mutual Service and Rightness in Evolution}

The supreme attribute of nature, therefore, is perpetual growth, or the creation and organization of new individualities on an ever larger and more enduring scale. To that end she is ever building in advance the foundations of her enterprises; sowing abroad the ambassadors of her secret purpose; ever creating and destroying, but never falling back to quite the old levels, nor failing to surmount the new.

But wherein then is the gain? What is it which grows, and wherein is the profit? How can we express the idea of creation without running counter to that inexorable law of conservation, the bed rock of science and experience, which declares that the total content of those indefinable things called matter and energy is constant, and can neither be created nor destroyed? Even so, is not the creative power of nature equally manifest in the overwhelming fact of evolution and organization? Does not better "organization," which is the physical expression of better cooperative action, always create something new, some architectural individuality, which could not have existed without it, and which did not previously exist in the cooperating agents? Gain, then, there is, if life and organization and architecture is an advance over chaos.

But the gain which springs from the organization of materials and forces, which otherwise were mere aggregations, is due primarily to some "improvement" in their relative distribution, resulting in what we can only designate as the "right" distribution for creating

${ }^{2}$ See Rita, (Hindoo) way of the world, and Tao, a Chinese equivalent. 


\section{GRAND STRATEGY OF EVOLUTION}

that particular product, or individuality. On the other hand, we must designate every other condition as the "wrong" one for that particular purpose. Hence no other general term, in spite of its misleading connotations, so aptly expresses those conditions essential to creative returns as rightness.

The profit, then, in evolution is rightness, or the finding of the right way to convey the right thing at the right time to the right place. The tangible architectural profit of this mutual service and rightness is the thing thereby created. The universe is, therefore, an organism only in so far as there are in it righteous conveyors of materials and power to creative ends. Nature's potential creative power, its power to grow, is infinite and insatiable; and growth proceeds in all its individualities as fast as they can find the right vehicles to supply their demands.

There is a graded substratum, so to speak, of rightness and cooperative action which is cumulative, or wherein the gains have been more permanent and absolute; and a more superficial stratum which flickers like a flaming atmosphere with the rise and fall of the newer creative products, or with the success, or failure, of the newer creative enterprises.

It is the finding of more stable, balanced or enduring constructive ways that lays the more permanent foundations for new constructions, making further evolution possible, and ultimately making that possibility a reality.

We may readily imagine the basic qualities of nature to be different from what we believe them to be and then in our minds construct a consistent sys- 
tem of philosophy, or mathematics, on that basis. But nature cannot build in that way. She has no makebelieve systems. She must create with things as they are. Man cannot build a bridge, nor does nature create a living organism, on a four dimensional system of geometry. This constructive test is our test of reality.

Hence apparently every new creative process, every forward step in evolution, is the product of finding a better way of conveying materials and power from a less useful to a more useful condition, from a non-cooperative to a cooperative one. The very fact that growth and progress is a reality is, in itself, a declaration of creative dividends; it is nature's proclamation of that righteous, pathfinding attribute which glorifies matter.

\section{The Growth Purpose in Nature-Action}

This process of nature-growth is "purposeful" in the same -sense that the physiological acts of a plant, a worm, a frog, or a human being, or any of their parts or organs, may be purposeful, or self-constructive acts; for nature-growth is the product of the cooperative acts of many different things, the purpose of which, or if you prefer, the end, or result of which, is the creation, preservation, and growth of nature's individuality and of all her constituent individualities. In this broader concept of nature-growth, light and gravity, vitality, genes, and gemules, heredity, intelligence, "selection," social conduct, and all the rest of the growth-machinery of life portrayed by the physicist and biologist may be regarded merely as local, or special manifestation of a common creative agency. 


\section{GRAND STRATEGY OF EVOLUTION}

\section{The Decrease of Chance and the Increase of Compulsion}

In all these cases, whether in nature as a whole, or in any one or more of her constituent individualities, the prevailing characteristic of growth, progress, or evolution, is the decline of chance, isolation, and uniformity, along gradients which converge more and more, and for longer and longer periods, toward a vanishing point in zero; while the gradients which represent the increase of diversity, cooperation, law and order and compulsion rise more and more toward a maximum in infinity.

It is the local, as well as the general progress of these constructive processes over the destructive ones, which we speak of as the triumph of "good" over "evil," or of the "right" way of doing things over the "wrong" way, and the goal toward which this progress moves we speak of as perfection.

In the initiation of new individuals, it may well be that finding the constructive way is largely due to the "chance" distribution of creative elements and forces. The result, when the way is found, cannot be due to "chance." It was determined by some previously established virtue in the cooperating agents.

When, for example, elements unite to form compounds, or cells to form organisms, or men to form society, the union may or may not be due to chance, according to the limitations we put on our definition of "chance." But the inherent capacity in each case so to unite, and the inherent qualities of the products of union, are definitely determined by the pre-established gualities of the cooperating units. 
With the onward march of evolution, therefore, "chance" is always a diminishing factor, determination, or compulsion, an increasing one, because cooperative ways once found, thereby create new units smaller in numbers but larger in content than any of their own constituent parts, and these units have special directive qualities of their own and more comprehensive influences.

A hundred million people, for example, each one living, so far as it is possible to do so, a free and independent life, will expend their vital energies selfishly, that is to no common purpose. Each one will exhaust itself in beating against the walls of its narrow environment; in haphazard, balanced conflicts, like so many peas in a hopper, or like atoms bombarding one another in a gaseous medium.

There let life be as fast and strenuous as it may, it will still remain local and futile. So long as it is not increasingly cooperative, there can be no accumulation of power, no summation of influences, no organized instruments of conveyance, for the influence of each individual is immediately neutralized by that of his neighbor.

But when those hundred millions are organized into a cooperative social unit, as, let us say, in our own country, the fleeting, insignificant powers of many separate individuals are summed up into great currents of activity, or into great unified social functions, such as commerce, science, literature, and art, which ever draw to themselves new agencies, and grow in power until their determining influences become world-wide and permanent.

This diminution of "chance" and the increase of 


\section{GRAND STRATEGY OF EVOLUTION}

compulsion and of specific opportunities, or what we call law and order, is one of the chief characteristics of evolution. It is due to the cumulative stabilizing power of cooperative action. It is an automatic, progressive process, growing by incorporating into itself its own profits.

\section{Mutual Rights and Mutual Obligations and the Categorical Imperative to Existence}

The very factors which create one individual, in doing so may prohibit, destroy, or create many others. Thus "good" and "evil" always have a limited, or tentative value when applied at a particular time or place, or to a particular individual. But since all these individualities, large or small, simple or complex, are nature's sole instruments for the creation of other, larger, or still more complex individualities, their creation and preservation is an essential preliminary to progress, or to the attainment of a larger end by more comprehensive methods. The larger values of good and evil, therefore, are revealed only in the larger creative results.

Thus the "rights" of all the varied individualities of nature to security and to the full expression of their individuality rest on the fact that their power of selfexpression represents nature's accrued creative profits in those investments. The aggregate of those profits, at a given time, represents nature's only available capital for constructive services in other enterprises. An essential condition to progress, therefore, is the creation of diverse individualities, and the safe-guarding of their 


\section{THE EVOLUTION OF INDIVIDUALITY 5 I}

"right" to existence. Otherwise there would be no constructive agents with which to build.

On the other hand, as the existence of every individual thing depends on the services of its constituent parts, so the power of those constituent parts to exist, and thereby to fulfil their purpose, depends on the receipt of services from their colleagues. Therefore, to give and to receive service, or the fulfilment of mutual rights and obligations, is the categorical imperative to existence.

\section{The Egoism and Altruism of Individuality}

The prevalent belief that selfishness and dominion play the chief creative rôle in nature growth is an error which springs partly from the laymans shallow estimate of evolutionary values, and partly from his failure to recognize the creative and saving processes of social life.

This error has been greatly strengthened by a similar lack of discrimination on the part of the biologists, for it might well appear from their analysis of life at large that chance, competition, selfishness, and aggression, were the chief factors in organic evolution, and the real causes of a successful life wherever it may have been achieved.

Following these suggestions, real or implied, statesmen, philosophers, and scientists, as a rule, have assumed that the altruistic methods involved in the ethics and morality of man belong to a different domain, or differ fundamentally in origin and in character from those utilized by nature in her creative processes.

The rapid growth of evolutionary doctrines in the 


\section{GRAND STRATEGY OF EVOLUTION}

past generation, while liberating religious thought, initiated a strong intellectual movement away from the "impracticable idealism" of an "artificial" social system, toward the so-called "realities" of a larger world life, and led to the widespread worship of a new God, a fictitious Nature-God, created by the biologists in the image of their own distorted mentality. The present over-emphasis of selfishness and the clashing of moral and intellectual purposes in social life are chiefly due to this error. The violation of the finer moral instincts incident to the practice of these teachings is condoned on the ground that selfishness is a necessary condition to social progress, and the misuse of power is justified by an appeal to the ruthless struggle for existence and the dominion of force in nature. But there is no justification whatever for such an appeal. Ruthlessness and selfishness there is in nature, on every hand, but they are no more creative and preservative there than in human society. In fact, as we shall presently show in more detail, in all her constructive processes nature is preeminently altruistic and benevolent. Her creative power and her power of sustained progress is wholly dependent on her multitudinous systems of organized endowments.

Every living thing, for example, is dependent on the mutually beneficial acts of its own internal organs. Every living thing receives from nature at large and from its forebears the initial impulses and germinal materials that give it life and being. Every living thing is insured against the inevitable hazards of a complex world by the measure of food given to it in embryonic life by its parents; by the measure of parental foraging, protection, and foresight devoted to it during the 
youthful stages of its existence; and by the measure to which it can draw upon the profits of its colleagues and upon the reserve capital of the world at large.

The destruction of a thousand, or tens of thousands of eggs, that one may live and grow, is not, as so often assumed, evidence of nature's ruthlessness in methods or purpose. No animal can be justly convicted of selfishness, that devotes, consciously or otherwise, the most active periods of its life to the preparation of thousands of food-laden eggs, the better to insure the welfare of another life yet to come. Rather is it the convincing evidence of lavish parental benevolence to a future end, but a benevolence, it may be, as yet undiscriminating in its methods of administration. Every living thing is absolutely dependent on endowments of this character, endowments which are nothing more or less than the organic surpluses, or profits of individual life, conveyed with variable precision from one life to another. The countless eggs and young that fail of their more specific purpose, devoured by predatory life, may still be regarded as residuary legacies to life at large, unwilling though it may be, nevertheless a legacy of otherwise unusable increments from one life to another. This undiscriminating benevolence is one of those universal interlocking devices by which every individual life is in some measure sustained, devices without which the larger unity and continuity of nature life would be impossible.

Power itself, whether physical, organic, or intellectual, is always a product of the cooperation of smaller powers, and wholly meaningless except as an endowment to further cooperative enterprises. And so also it is with the altruistic idealism of man. It is a spir- 


\section{GRAND STRATEGY OF EVOLUTION}

itual endowment from the one to the many, for its fruits mature for those who have it not rather than for those who do. Idealism is in truth based on realities and endures because of its saving services and creative power. It is their clearer vision of the creative drift which impels the leaders of men to take their characteristic expectant mental attitude, rightly oriented to face the life-giving currents of world events. This positive orientation of leadership to world progress, this idealism, is the mother of practicality, for it is the explorer, the pioneer, the long-range director, and hence the benefactor of mankind in all creative intellectual movements. But egoism, or self-aggrandizement and self-preservation, the effort to attain the fullest freedom of self-expression, always has been, and doubtless always will be, the primary law of evolution. It is a basic condition to progress because in that way only can the necessary instruments to progress be preserved. Self-sacrifice and benevolence, or the giving of self in cooperative action to a larger end, is a secondary law; but secondary in sequence only, not in dignity, nor in creative power. Self-sacrifice is a higher law only in that it pertains to higher levels of progress; for it in turn depends on the utilization of the fruits of egoistic action. In other words, self-preservation is not the end and aim of creative power, but merely the necessary means to a larger creative result. The individual saves itself in order that it may give itself to a larger purpose. The fulness and variety of these products of self-preservation constitute the constructive endowments of nature.

In the social life of man, commerce, literature, and art, as well as science and religion, are all common car- 
riers in a benevolent creative service. They are vehicles which know no barriers, individual, local, racial, or national. Their limitations are in their own powers of conveyance and in the power of the recipients to utilize their gifts. But that does not mean that the idiosyncrasies of time and place, of race, or quality, or nation, can or should be dissolved, or equalized. On the contrary, they should always retain that egoism which gives them individuality. For if different social or national units are not preserved, and their unlike qualities emphasized, or given adequate freedom of selfexpression, they cannot be utilized as cooperative parts of larger individualities; there would be no resources for future reorganizations on an international scale.

From this point of view, "fitness" has a new and a deeper meaning. The "fittest" is not merely the one most likely to survive because it cooperates best to its own selfish ends; it means something more than that. In this deeper meaning of the term, the fittest is the one which, in its survival, provides the means to a new and a still larger end. The "struggle for existence" is a struggle of the individual to find the right way out of the obstructive conditions created by its own growth and by that of other individuals, in order to give itself to a larger life.

Thus the larger purpose in life and evolution, the ever receding goal of all endeavor, is escape from the older bondage into the newer bondage of a larger service.

This universal give and take for some ulterior constructive act; this self-surrender of individualities in order to make larger and more enduring individualities; this investment of self in a purpose beyond self, 


\section{GRAND STRATEGY OF EVOLUTION}

which cannot be realized till self is swallowed up and consumed in posterity, is a basic attribute of natureaction, the ethical and the moral factor essential to all phases of growth and evolution.

Whether all these acts are conscious or intelligent acts is here immaterial. The outstanding fact remains that in this universal system of reciprocal egoism and altruism, where common profits are endowments to the future, lies the secret of nature's creative power, the explanation, so far as explanation is possible, of her strategy.

VIII. The Ethics and Morality of Nature Action as a Guide to Individual Conduct

It is not without significance that man's chief desire is to accomplish something, and his chief satisfaction in life is the feeling that he is in some way a creative power and an instrument to progress. To best satisfy that desire, man must look to nature for instruction. $\mathrm{He}$ must seek in nature his guide to constructive and saving conduct, for the age-long processes which have created the multitudinous forms of life are thereby standardized as righteous and moral processes.

$\mathrm{By}$ the intelligent contemplation of this long series of creative events, man may best hope to gain some insight into the constructive conduct of nature, and to find some index to her standards of rightness. In the final analysis, her creative methods alone can give him a secure basis for his own systems of ethics and morality. They will be to him his guide to profitable living, not only as an individual, but also as one of nature's asso- 
ciated creatures, and as a member of human society. For the unity and continuity of nature, and the interchangeability of her agents, excludes the presumption of multiple standards of ethics and morality, one for the living, another for the non-living world; one for plants and animals, and another for man.

Intelligence is the product of evolution. It has no power to alter the methods that created it. It may accelerate them, for it is quicker and surer than blind trial and error in finding the right way to growth and progress. To live more profitably than a plant or an animal, man must use his own distinctive instrument to find the creative way, and, finding it, he is compelled to obey its dictates. He cannot refuse if he would.

But yesterday, speaking of evolution, a distinguished, but an evidently perplexed biologist said to me that he was satisfied to study life on a plot of ground big enough to stand upon. That kind of intensive study will doubtless keep some biologists happily engaged as long as life is worthy of contemplation. But it will be of little profit to him or to any one else, unless some one stands over him, aids him, and directs him in the common interests. For rightly to appraise a point, or estimate the constructive value of a chromosome, man must needs have perspective.

And when we do survey the world of varied things about us on a comprehensive scale of time and space, much of the meaningless detail and the apparent waste vanish in creative investments. The fact which stands out with convincing clearness is that nature in her evolutionary convulsions always makes some permanent constructive gain; that evolution is a progressive crea- 


\section{GRAND STRATEGY OF EVOLUTION}

tive process. The monuments to nature's creative strategy, wherein victory is expressed in growth and organization, are in us and all about us.

To say that evolution is unethical or unmoral is to destroy the basic value of the terms by arbitrary limitations to their meaning. It carries the assumption that human conduct stands in a domain apart and that the agencies which influence man to his own welfare and profit are different in kind from those which control the constituents of his body, or those of animals and plants, or those of inanimate nature. And if rightness and morality are divorced from all physical agencies, or from the results of their acts, then the terms have no tangible meaning whatever.

We are therefore compelled to assume that since evolution is a progressive creative process, the things that do act constructively act rightly. That, it is true, gives us no definition of what rightness really is, other than that it is the constructive, or creative way of doing things. That is the way in which we shall use the term.

We shall use the terms morality, behavior, conduct, or constructive action in the same broad way. It may sound strange to speak of the morals of an atom, or of the way in which a molecule conducts itself. But in the last analysis, science can draw no fundamental distinction between the conduct of an animal, a bullet, or a freshman, although there may be more unknown factors involved in one case than in the other. The things that chiefly concern us, as scientists, or as teachers, or as laymen, are the questions: What makes things act as they do? What are the acts they in turn produce, and how can man profit by that knowledge? In so 
far as all such acts, or conduct, are constructively right or wrong, and take some part in the destruction, or construction of something else, they cannot be divorced from the domain of ethics and morality.

\section{The Components of Individuality}

As every constructive process necessarily requires services of various kinds, rightly performed, the essential factors at every stage of evolution are service and rightness, and the things or agents in which these qualities are resident. Everything newly created, every forward step in progress, or evolution, must therefore be the product of service, and in turn must represent some addition to nature's system of serviceable things. And these new services cannot be performed without some new discovery, or invention, or achievement, in doing things rightly. The greater the creative progress, the larger and more intricate in structure things become, so the more varied and supplementary are the services required, the greater the number of things that must be rightly done, and the more surely and persistently they must be executed.

Everything in nature, therefore, every molecule, star, animal, or social group, is the product of various services to that extent rightly performed. And each one of these things is itself an instrument to further service, a promise of new things to be created by them, and by their products.

Thus the services and rightness involved in the creation of any particular thing always present a more or less pyramidal series, the more general, elemental, and enduring phases of the creative process at the be- 


\section{6o GRAND STRATEGY OF EVOLUTION}

ginning, or base, the more fluctuating and special, at the end, or apex.

In the construction and preservation of a worm, for example, the chief sets of factors involved are: (I) the constructive action of the physico-chemical elements of matter and force; $(2)$ the solar system and other heavenly bodies created by them; (3) the earth and its various components and activities, such as climatic and other changes, its various habitable media and provincial qualities; (4) plant and animal life, as a whole, and particular kinds, or groups, of individuals; (5) the parts and organs which constitute the bodily structure and internal life of the worm itself; and (6) conduct, or behavior, or the external life of the worm as an individual unit, in relation to all its cosmic, organic, and social surroundings. All these interwoven constructive agencies are essential to the creation and preservation of the worm.

Man is built on the same broad pyramid of mutual services and constructive rightness, but a great many more have been added to them, notably those of the higher plants and animals, and of his more complex bodily functions and organs, specially his hand, intelligence, and articulate speech. By their instrumentality and by the accumulated services of countless human beings rightly performed, the new systems of servants were created, such as science, literature, art, government, by which the man of today lives and has his being.

These countless supplementary services, rightly performed for the individual man by the social institutions of mankind, are as much a sustaining part of his individuality as those of his own brain, or of his own 


\section{THE EVOLUTION OF INDIVIDUALITY 6 I}

eyes. Take away from the man of today his science and he would fall to the level of the witch-doctor, and his protection against disease, or the vicissitudes of nature, would be reduced to incantations and a bag full of amulets.

Take from him the knowledge of the right way to make fire, and he would fall below the level of the cave man; the mantle and the sword of his culture would vanish, the arteries and nerves of his social life wither away. Rob him of his cerebral hemispheres, and he would fall below the intellectual level of the frog 


\section{FITNESS AND ADAPTATION}

The Criterion of Fitness-The Different Kinds of Fitness-Fitness by Design and Fitness by Mutual Influences-Temporary and Permanent Fitness-The Measure of Organic Fitness-The Measure of Social Fitness-The Adaptation of Vital Actions to Good and Evil-The Evolution of Fitness and Adaptation-Adaptability in Nature-Action, as a Universal Creative Tropism.

\section{The Criterion of Fitness}

THE familiar phrase "Survival of the fit and elimination of the unfit," has played and still plays an important rôle in evolutionary theory. But it is an elusive verbal formula whose imposing garment of unessentials and its silence as to what we really want to know make it so comprehensive and self-evident, its emptiness so dangerous. It is virtually but another way of saying that whatever is exists because it was so created, and the thing which survives is that which is fit to survive. What the creative and preserving factors are, the questions of real significance, are left unasked and unanswered. Hence all the theories of evolution upbuilt on selection, such as germinal, physiological, or natural selection, are fundamentally evasive and of little scientific, or moral, value, in so far as they contain no general implication as to what constitutes "fitness," how things are created, how they are saved, why destroyed, and to what end, or purpose, they do, or do not, exist. 
But these difficulties vanish, and the familiar concept of evolution, as an aimless, unethical process, disappears, when we recognize that cooperation to that end is the creative and saving power of individuality. That cooperation is always expressed in terms of service and rightness, or the conveyance of the right thing to the right thing, at the right time and place. That the fittest is the one whose component parts cooperate best, and that his struggle for existence is a struggle to find a better cooperative or constructive way. That things endure because they continue to cooperate, and are eliminated, or disappear, when they do not. That structure is both the material and dynamic expression of cooperative action. That growth, or progress, is merely cooperation on a larger and better scale. That the rate and extent of evolution is measured, not in terms of change or power, but in terms of service and rightness, or in terms which express the creative value of those changes. That cooperation is right because it is constructive, creative, preservative, and progressive. And that finding the right cooperative way to create. and preserve larger, or more complex, individualities is the essential preliminary to each and every stage of evolution.

Thus mutual service and rightness are the creative and preservative factors in evolution. Therein is the index to the universal end, or purpose, in life, and in nature; the criterion of "fitness" and the basis of man's ethics and morality.

\section{The Different Kinds of Fitness}

Fitness and adaptation are the conjuring terms with which the biologist performs his most deceptive tricks; 


\section{GRAND STRATEGY OF EVOLUTION}

and they are performed so convincingly that he often deceives himself, as well as others. Like many other exhibitions of the conjuror's art, the illusion is due to the unobserved substitution of one thing, or of one value, for another; in this case, by substituting one meaning of the terms for another. This is the more difficult to detect since fitness and adaptation may be very broadly applied. They have very subtle, as well as very obvious meanings; they may be variously qualified by chance, incidental results, and designs; and the fitness and adaptation may be fulfilled either beforehand, or presently, or at some future time, or in some other place.

Using the terms in their broadest sense, we may say with equal propriety:

(I) That wheels, cogs and axles, springs, pawls, and catches; steam, fire, and electricity are fit to make certain kinds of machines; that such machines are fit for man's use and profit and that man himself is fitted for the profitable usage of machinery.

(2) That the atoms in a grain of starch, by virtue of their own peculiar attributes, are fitted beforehand to cooperate with one another and thereby produce a substance called starch; and that starch is fitted beforehand for human food in the sense that it was one of nature's standard products long before man appeared on the face of the globe; and that subsequently, man was fitted for the consumption of starchy foods.

(3) That the stream is fitted to its bed, and the bed to the stream, and both fitted for profitable usage by plants and animals, and by man.

(4) That plant life, as a whole, is fitted to animal life as a whole, both living thereby cooperatively, each 
serving the other with materials and forces that could not otherwise be provided; and that on and around this broader mutual fitness and mutual service are built many minor fitnesses and services. That both plants and animals, at all times, are fitted to live in a very narrow stratum of terrestrial conditions between earth and air, and these narrowly prescribed conditions are eminently fitted to sustain life.

\section{Fitness by Design and Fitness by Mutual Influences}

In this usage of the terms fitness and adaptation, the idea may be conveyed, or implied, that there is a premeditated design and a designer involved; that man, for example, was expressly made in such a way that he can and does utilize machinery to his own profit, and that man himself designs and makes machines expressly to that end.

Whether man was designed to use machines, we do not know. But we do know that, in that sense, no machine ever purposely designed and made another machine for its own uses, although machines, as contingent parts of human life, grow like living organisms, by the summations and adaptations of countless mutually serviceable constructions and inventions. All that man does, in any case, is to select certain fitting materials and forces already in existence, the qualities of which are already established and which he can in no wise change, shape them, and put them rightly together. If they are rightly moulded and rightly put together, the various parts will cooperate just the same, whether put together by accident or by design. Each part will per- 


\section{GRAND STRATEGY OF EVOLUTION}

form a service for the other, and all together may perform a common resultant service which man still further supplements by using it in cooperation with his organic mechanism, to enlarge his own life.

Or it may be implied that fitness and adaptation is the mutual moulding of one thing by the other, so that each thereby becomes better fitted to act cooperatively with the other and so acting produces something which finds a place in the world where it may exist.

In the case of the river and its bed, many creative and cooperative factors are involved. On the one hand there are the chemical and physical properties of water, and the volume and rate of precipitation. On the other hand, there are the physical and chemical characters of the terrain, its elevation, slope, and vegetation. And back of all these are the more fundamental cosmic conditions of heat, light, gravity, daily, seasonal and other periodic changes. All these factors acting together have produced, at a particular time and place, a particular stream of water, in a particular channel, each adapted to the other, and both, it may be, adapted in a particular way to sustain life. In this case, while the course of the current may be in part determined by the terrain, and the terrain more or less sculptured by the current, so far as we know, neither the attributes of water, nor those of the constituents of the terrain are modified, or moulded, in any way thereby. The fitness of the river to its bed is chiefly and more immediately due to the mutual influences of water and terrain whereby both the direction of the stream and the contours of its bed are modified or changed. This process may be checked, or accelerated, extended or diminished, by the cooperative action of many other 
forces and agents remotely connected with that particular river, or its terrain.

If it is difficult here to trace the chain of cause and effect to the sources of fitness and adaptation, how much more difficult is it to trace them in the rivers and streams of life?

It is evident that in forming our judgments of vital processes, we cannot limit the scope of our vision to any one aspect of life, or to purely vital phenomena only. The windows of our mind must look in all directions upon the world about us. The reader may be assured that the biologist, with such an outlook, studies even the simplest problems of life in no other attitude than one of profound humility. But he jealously guards his provinces, and is chiefly moved to dogmatism by the petty dogmatism of others.

\section{Temporary and Permanent Fitness}

In the larger sum of more elaborate adaptations, it is easy to confuse secondary, incidental, or perhaps even for the moment useless, fitness with that which is more fundamental and universal. In the case of man and his machines, for example, it is evident that while iron is fit for many cooperative mechanical 'uses, it is also fitted to form the chief constituent of the earth nucleus. It is also fitted to form a vital constituent of all living tissues. It cannot readily become unfitted for these basic purposes, owing to the stability of its qualities. But by the very same tokens, in a rapidly advancing life, iron may quickly become unfit for many mechanical uses when a better material to these ends becomes available, or when man himself becomes capable of 


\section{GRAND STRATEGY OF EVOLUTION}

making better usage of different materials. Wood, flint, bones, copper, iron, steel, and aluminum are materials which in this way may become fit, and ultimately unfit, for special constructive purposes.

It was, doubtless, a happy combination of chance events that led someone, somehow and somewhere, to discover the right way to make fire. But there is nothing, in that sense, accidental in the attributes of fire, or in the attributes of those things influenced by fire, or in the ways they are influenced by it. Nor is there anything accidental in the fact that once the right way of liberating fire was discovered, the latent fabric of civilization itself was set free and progressively upbuilt by its services. Through the more or less durable fitness and adaptability of such agencies, and these cumulative cooperations, the great currents of nature's creative power have themselves been profoundly influenced, and new kinds of fitness and adaptability successively created.

\section{The Measure of Organic Fitness}

It may be urged that the bacteria are just as fit and well adapted for self-preservation and growth as the elephants; or that a yeast plant is just as successful in its way of living as an orchid is in its way. That is true. But the measure of life.is not in efficiency alone, or in size, or in fitness. Every cooperative system must be efficient to the point of self-preservation, else it would not exist. The question is, what kind of fitness and adaptation leads or has led to larger constructive results, to a greater sum of cooperating services; to a more extensive system of conveyance; to better contact 
with, and cooperative response to the world at large; and still endure. These methods are measurable only in the sum total of organic services rightly performed.

The yeast cell is no doubt an extraordinarily complex system in miniature. It produces something like a score of different enzymes, or about all of these remarkable substances known to science, and some of these enzymes have a profound influence, for good and evil, on the social life of man. But the yeast does not appear to profit directly, or in due proportion, from its own products. It has no neuro-muscular mechanism, like that of animals, by which it can move about, or respond to its environments; and yet it is more widely distributed over the earth's surface than any of the higher plants or animals.

On the other hand, the orchid is a much larger, and on the whole, a much more elaborately constructed plant. Its methods of fertilization have long been the stock examples of cooperative fitness and adaptation for special purposes; and yet the orchids are not especially abundant, nor widely distributed, nor vigorous plants, nor very serviceable agents to life at large. The brilliant and varied colors of its flowers, their bizarre shapes, their perfumes and nectars which lure the "buccaneering bee," or some other unwilling agent, to concealed traps and time-set springs, finally letting him go his way, besmeared and bepollened in the service of the plant, are indeed marvels of adaptation. And yet the humble potato gets the same service performed, at least as efficiently, if not in such a flamboyant manner.

Thus the fitness and adaptation of the yeast plant, potato, and orchid, are not measured by the constructive and saving services performed for themselves 


\section{GRAND STRATEGY OF EVOLUTION}

alone. It includes their larger cooperative values. Man receives far more basic services from yeast and potato than from the orchid and gives far more thought and labor to them in order to provide the ways and means to set their powers free.

In spite of its extraordinary adaptations, the orchid does not have a particularly strong hold on life. Its profits and losses are apparently too evenly balanced to endure except under most favorable circumstances. Its most characteristic inventions for living suggest the marvels of the patent office rather than the homely devices of approved utility. These wonderful inventions work, sometimes, but not surely, nor economically.

Sexual life abounds in these bizarre inventions, for sex, especially in social life, must carry an enormous, and ever growing amount of baggage, and heavy draughts must be made on the resources of life to keep this baggage moving and self-supporting.

When these properties of sex grow too cumbersome for the essential journeys of life, or their administration too costly, they become self-destructive burdens, defeating the very purpose they serve. If, under such conditions, the organism still endures, it is in spite of their extravagances rather than because of them.

The subtle influence of sex is felt in all phases of life, high and low, constituting a basic and all pervading vital motive. Indeed the consummation of the sexual function is the primal obligation of life, and in its services are enlisted, as propaganding lures and stimuli, the chief pleasures and ornaments of life. Nor would we have it otherwise. But when these secondary characters and functions usurp the resources of life to no effect, when they pervert, or inhibit, the primal func- 
tion of reproduction, life automatically returns to a more primitive, or a more economic level.

\section{The Measure of Social Fitness}

We can readily imagine a kind of human society in which the basic principle of the orchid's invention is fully utilized. Let us picture to ourselves how it might work out. In such a society, over the gateway to his domicile, the advertising lover displays his erotic symbols, and from his windows discharges alluring and suggestive perfumes. Wafted up the community avenues, conveyed by servant light and air, his missiles cross the pathway of some official receptive agent called, let us say, a guardian of the peace. In most human communities this constituent normally has a positive reaction to such stimuli. That is, he automatically orients himself to their line of propagation, and, with unerring instinct, follows their sensuous trails to their source. So it is in this case. Passing under the gateway, still led by servant eye and nose, he enters the lover's chamber. Overcome by the splendor of his surroundings, he is temporarily diverted from his purpose and pauses a moment to survey the repast, expressly fitted, apparently, for himself. In making a preliminary examination of the nectars set before him, he inadvertently presses a concealed button, which automatically regulates the movements of a trap door beneath the spot where the investigations must necessarily take place.

As the inclination of the trap door quickly changes in response to the pressure on the button, the investigator, moved by a stronger will than his own, falls into a refreshing bath. Here, one of the chief purposes of 


\section{GRAND STRATEGY OF EVOLUTION}

the mechanism is accomplished, for in the momentary confusion which follows, the astonished official is anointed with resinous materials, one of the by-products of the household, and by this fitting instrument are attached to his person, as it were by accident, the lovers' tokens.

The whole reaction of the official is now reversed. What formerly attracted now repels. He suddenly becomes what is known to the experimental biologist as negatively thigmotactic. Under the influence of this reaction he hastily leaves the house and seeks the shelter of more familiar surroundings, incidentally conveying the virile tokens to an expectant lover in his own household. Thus a regular channel of conveyance may be established between two imprisoned lovers; for the innate reactions of these state officials are not seriously injured, or permanently destroyed by the performance of their incidental functions. In fact, their experiences, on the whole, are enjoyable and profitable to them, and they are not overburdened by the consciousness of their incidental services.

Judging from the way similar devices in the organic world are exploited to the limits of their capacity, it is not perhaps impossible that out of some such ingenious aid to sexual conveyance, a new class of animals might arise, and on it a new kind of civilization be upbuilt, not greatly different from our own. In that case every detail in the maze of events might be highly elaborated and beautified through the process of natural selection. Lyrics might be sung in their praises; comedies and tragedies written to caricature their inevitable incidents; scientists might earn their pittance in measuring and cataloging its civilizing materials and 
forces; statesmen solemnly enact international laws for the regulation of the laws of nature, and great defensive wars might be heroically waged over some menace to ancient prerogatives, over freedom of action, or over local differences of opinion as to which particular variation of the procedure was right and which was wrong. There is no limit to the chain of cooperative fitness and adaptation, that might be linked up in this way, so long as every link in the chain was self-sustaining.

But the naturalist is familiar with many cases in the organic world of reality, where the machinery that develops around a given function ultimately outgrows its purpose and defeats its own aim, like "vaulting ambition that o'erleaps itself and falls on the other"; or like an animal whose defensive armor, by overgrowth, becomes a prison, or a killing burden; or like one that destroys itself and the sources of its own maintenance by over-greediness; or as in man where over-physical, or over-intellectual development, may each destroy the other and thereby defeat their individual and their common purposes.

So in the case of the hypothetical society we are considering, it would be of little moment which social group was right, and which was wrong on any particular question, or which nation had evolved the more "kultur," or had the more elaborate civilization, art, science, or literature, if one of them concealed within itself some basic moral, ór cooperative, defect. Only that one could endure, wherein the real purpose of all this social machinery of mutual services is rightly accomplished, that is, in this particular case, when lovers are cooperatively united, and the ultimate messengers of love safely reach their destination. 


\section{GRAND STRATEGY OF EVOLUTION}

The same principles govern the evolution of all phases of social life. Human society, as it is in reality, in spite of all its social fretwork and its orchid-like conventions, must remain a mere shell, hollow of heart, so long as social conventions and social trappings are over magnified, and enjoyed solely for their incidental products, while their real purpose in life is ignored, or not fulfilled. And civilization itself will collapse, over and over again, in partial death, crushed under the weight of its own super-structures, destroyed down to its more stable foundations by domestic and foreign wars, and by failures in the conveyance of vital necessities, so long as it is not supported by the girders of mutual faith and mutual service. For the extent of its growth and the measure of its self-sustaining power is wholly dependent on the extent to which mutual rights are protected and mutual obligations fulfilled. And in human society, where intelligence is the chief constructive instrument, these services must not be left to chance; they must not be wholly incidental, trap-door services; nor the unwilling services of unconscious agents; but the deliberate, joyous acts of those who have the will to create social institutions, and know how their purpose may be accomplished. Therein lies the real test of social fitness and the creative possibilities of social adaptations.

\section{The Adaptation of Vital Actions to Good and Evil}

The chief difference between animate and inanimate things, between plants and animals, high and low, is in the degree of profitable response to their environ- 
ment. This response is expressed in constructive, cooperative actions, and may be measured in these actions only. That is, in the relative change of form and position of various parts, and in the architecture and movements of the whole organism from one time, or place, to another.

These constructive actions of the physical and organic world constitute the currents and counter currents of nature's perpetual flux. Science has no means of measuring them except in terms of themselves, for there is no absolute standard of value, either for direction, length of time, or extension in space. The north star, the radius of the earth, or the revolution of the earth in its orbit, which we use as our standards of measurement, are themselves the expression of changing action in things already constructed.

The terms commonly used to indicate these constructive processes and their opposites are good and evil. These terms are rarely used by scientists in their more formal discussions, nevertheless no other terms can quite fill their places. Substitute terms either mean precisely the same thing, or conceal beneath a cumbersome, unfamiliar terminology the very idea the scientist wishes to convey.

When we say, for example, that something is good or evil for an animal, all we mean is that it is more or less constructive and preservative for that animal; or more or less destructive. So it is with all our measurements, they always express in some way the degree of constructive or destructive action, in positive or negative terms, in reference to that particular thing; that is, in terms of good and evil.

Thus in spite of the infinite variety of nature-ac- 


\section{GRAND STRATEGY OF EVOLUTION}

tions, there is no way to measure, or define, or classify them except in terms of what they do constructively, or destructively. For that reason, every one is ultimately compelled to use the basic, all-embracing terms, good and evil, or their equivalents, to express the results of his experience. Science will gain far more than she will lose by including these elemental terms in her vocabulary.

In animal behavior, there are but two really significant classes of acts, or movements; one leading up to what is good for the animal, the other away from what is evil. One kind of action results in growth, or the enlargement of the individual; the other, in saving it, or by avoiding or preventing its destruction. One kind of action, in the main, leads up the supply lines to their sources, the other down the danger lines, away from destructive agencies. In one kind, the increasing stimulus of food and the increasing attainment of wellbeing and power lead the animal directly toward the source of the stimulating constructive agencies; in the other, the increasing stimulus of ill-being and the loss of power, lead the animal away from the source of that particular stimulus, into neutral territory, but otherwise in no particular direction, nor into any particular place. Thus one kind leads from many'directions to a few good things; the other, away from a few evil things, in many directions. One, therefore, directs and centralizes; the other distributes. One ultimately unites the animal with its bodily materials and powers, such as food, light, and oxygen, or with its complemental sex; the other repels it, or divorces it from destructive, or offensive agents. One ultimately leads it in the pathways of further cooperative action, increas- 
ing profit, and a larger and longer life; the other leads it away from those things that prevent cooperative action, and that diminish life and power. All other reactions are neutral, or of secondary value. The persistence of these reactions tends to open or uncover the pathways of constructive living, and to hold the animal to its dual course, a course which more and more surely leads toward that which is good and away from that which is evil.

In other words, the fundamental tropism of plants and animals to things that are good for them is positive, and to the things that are bad for them is negative. This dual reaction, or behavior, is cumulative in its effects, and inevitably leads to the discovery of better ways of doing things; to more adaptive reactions to the external world, and thereby to a longer and more certain tenure of life. The same principles apply to each part and to each organ of any animal, or plant, and to each member of any social aggregate.

The local growth, for example, of fur, or feathers, gills, or lungs, of valve, muscle, or nerve, which thereby better aid and protect the animal; and the increase in numbers, and in power, of soldiers, laborers, bankers, preachers, and scientists, which thereby better aid and protect society, is in each case the resultant of this dual response of individual parts to their environment, the resultant of their successful avoidance of what is evil to them and the attainment of what is good for them.

Each part, or organ, of every cooperative system thereby tends to grow indefinitely. But when it attains the maximum of growth consistent with the welfare of the whole, upon which it ultimately depends, its growth is checked automatically. 


\section{GRAND STRATEGY OF EVOLUTION}

Thus all response, or movement, or growth, is measurable in the sum total of many constructive and destructive processes. The actual condition attained in any given case must represent, therefore, a positive, or plus, quantity in the attainment of good, or of constructive profits, else it could not exist.

Hence that which is good for any organism is precisely and adaptively directive, giving it more power and stability. Evil is indiscriminately distributive and tends primarily to decrease power and stability. The good which resides in evil is the spur which impels things within the influence of the good. Good and evil, therefore, are the reciprocating functions of rightness, and both are essential to progressive adaptation and constructive action.

\section{The Evolution of Fitness and Adaptation}

The evolution of mutual service and rightness and the evolution of fitness and adaptation are coincident; in fact, each is a manifestation of the other. That is to say, the prerequisite to every evolutionary process is the creation of the fitting things to that constructive end; and coincident with growth or evolution, progressive adaptation must have taken place, or the right ways must have been successively found to perform those constructiye services.

What we call fitness and adaptation in reference to any particular thing, or circumstance, may be something: ( I) fundamental, absolute, and enduring; or (2) transitional, serving as a stepping stone to higher constructive levels, and then gone forever; or (3) immediately constructive; or (4) apparently encumber- 
ing, neutral, or sterile of immediate results, but yielding its products in deferred dividends. These adaptive fitness are the by-products of something else or of other constructive acts. They can be measured only by their creative power, actual or potential.

Man, as an individual, is more or less fitted to his social and physical environments, as a flower, or a nation, is fitted to its physical and social surroundings. But the number and complexity of the fitnesses is much greater in one case than in the other. Man, for example, is made up of a greater number of internal parts than the plant, all of them marshalled in groups, and classes, and organs, mutually moulded and fitted to one another in one cooperative, bodily service; as a constituent of nature-life, he is fitted to a greater variety of external things, and to more subtle, more fleeting external events; and, as a member of human society, he is fitted to his brother members for a great variety of social services wholly lacking in every other phase of nature-life. Hence he does a greater variety of things; his life is larger and quicker, more resourceful than that of any other organism, and he is a living part of a much larger cooperative system.

\section{Adaptability in Nature-Action, as a Universal Creative Tropism}

The world of action is revealed to us as an architectural system, a universal network of physical and chemical organization; it may be on a gigantic, enduring scale in terrestrial and cosmic affairs, or on an infinitesimal, more fugitive scale in the affairs of atoms and molecules. In every direction, these graded, struc- 


\section{8o GRAND STRATEGY OF EVOLUTION}

tural series lead to fathomless depths, far beyond the reach of human knowledge. And within this worldwide, physico-chemical system, apparently apart from it, but in reality blending with it, and supported by it at every point, are the various series of plant and animal organizations called life.

Pervading both these living and non-living systems, like a corrosive or consuming atmosphere, is an ever present disorganization; a universal incompleteness of administration, and a mocking instability of purpose, where chance creates and chance destroys, or nips in the bud the tender shoots of new-sprung enterprise.

But in this universal strife, constructive action always wins, always increases its power by holding on to some of its gains. For evolution, as we can clearly see in retrospect, is not a process of creating something out of nothing; but a process of mutual moulding, giving and receiving, yielding, and advancing into new relations, and thereby constructing new things, themselves adjustable to new constructions. It is the finding of the right way through the shifting maze of nature-action, out of a nullifying chaos into a more dynamic order, and the incorporation of its profits into larger units, or individuals. This universal attribute of adaptation is in reality a universal creative tropism, or a turning toward the right ways of constructive action, and using them constructively.

Nature-life, as a whole, is the resultant product of the mutually adaptive life of plants and animals, high and low, large and small, to one another and to inanimate nature. From its beginning, nature-life has grown in volume, in security, in power, and in freedom; but 
at various rates, because its innumerable constituents, at different times and places, have attained different degrees of fitness, and have made adaptive discoveries and inventions of very unequal value.

Science is a fourfold record of these actions. Her historians describe their sequence in terms of past events; her morphologists, the products, in terms of architecture, form, or structure; her physiologists, the acts in the process of consummation; and her prophets affirm, or deny, the continuity of these acts into the unexplored, or inaccessible domains of nature-action.

In the forward look of prophecy, science sees the continuation of the same processes; that is, a gradual increase of concerted, automatic action, and a decrease in the destructive power of chance.

This universal adaptability of nature's content makes the consummation of her creative ends inevitable. It is an inexplicable power, but one ever manifest to us as growth and progress. 



\section{PART II}

NATURE'S SYSTEM OF SELF-ADMINISTRATION AND SELF-CONTROL 



\section{LIFE: ITS ORIGIN, AGENCIES, HABITAT, AND GROWTH}

Preparation, Materials, and Forces-The Cosmic Formula for Life-Life's Cosmic Sanctuary-Life's Directive Discipline-Life's Freedom-The Growth of Freedom-The Instruments of Freedom-Growth: Its Insistent Power; Organic Wealth, its Source and its Uses; the Demands of Growth; Checks and Releases to Growth; Development, or Simultaneous Increase in Volume, Diversity, and Mutual Service; Limitations to Growth; Growth by Multiplication (dissociation) and by Combination (reunion or association): Profitable, Cooperative Merges; Unprofitable Mergers, Parasitism-The Creative Cadence and the Formal Accents of Organic Growth-Stability of Individual Life Essential to Social Life-The Growth Rhythm: Individual Growth, Fragmentation, Regeneration, Association.

\section{The Preparation for Life. Its Materials and Forces}

LIFE is not an act apart, nor is it the product of any specific time, or place, or material. It is the offspring of the physical world; a transient phase of creative power in the universal whole.

To make way for terrestrial life, nature labored on a universal scale. Matter was the warp and energy the woof of her growing fabrics; constellations were the patterns.

Elements joined in elemental forms, and with elemental motions harried the fields of space, growing in power. Mass grew in mass, and momentum in momentum; each drawing the other to itself in mutually regulated rotations; sweeping the heavens on their en- 


\section{GRAND STRATEGY OF EVOLUTION}

circling course; clearing the pathways of light for future generations.

Out of the nebular pull and thrust, and meteoric collision came the germs of celestial spheres and a measure of celestial order. In the wide womb of the cosmic night commingling, nebular gamites the germ plasma of the sun and her family of planets engendered.

From the sun, the earth its substance inherited, and received in her household its nurture. In communion with its mother sun, and with its twin sister, moon, the fœtal earth acquired its form, its features, and its motions; was cradled in its orbit, bathed by the recurrent light of day, disciplined and caressed by the changing seasons, till the initial cleavage of its growing substance divided the assembling airs, the lands, and the waters, into serried layers and graded masses, according to their attributes.

Thereby was built for life a home terrestrial, and stable. And there in rightly tempered beds, in nutrient nooks and sheltering crannies, quickening plasmas grew, and multiplied, and overflowed, tincturing the shallow seas with their opalescent swarms, and spreading their verdant flush over the face of the rising earth; and there life was nourished and sustained by the income from a brotherhood of stars.

The flesh of the earth, the flash, and the pull, and the grip of the sun, the moon, and the stars, is the steadfast substance of life and its unfailing power.

\section{The Cosmic Formula for Life}

As the germ-plasma of the egg, subject to its environments, determines the nature of its ensuing life, 
so in like manner the earth's initial ingredients, and their environments, determine the nature of the earth's issue. The elements which constitute the land, the sea, and the air, and those larger celestial forces which regulate the earth's activities, were established in, and around the earth-egg in fixed proportions; and their distinctive attributes were insured to the germinating earth as life's heritage, long before protoplasmic life could exist thereon, or endure. These agencies determine the nature of terrestrial life today, and they will determine the nature of that life which the earth shall bring forth in the fulness of time.

The cosmic formula for the evolution of life was, therefore, explicit and imperative. To compound that formula, time and space, materials and power in abundance were demanded, with stability in foundations, exactitude in the quantity of ingredients, everlasting integrity in their qualities, and unremitting service.

\section{Life's Cosmic Sanctuary}

But life occupies a very small place in the universe. It stands on a meagre franchise of the elements, a frail terrestrial film in an infinite sea of death; a beneficiary of stability and order in a tiny sanctuary. For life could suffer but little deviation in the sun's radiant power, or in the moons tidal pull, and still endure; but little change in the size, position, and movements of the earth; or in the volume, and composition of the earth's atmosphere; or in the proportion of land to water; or in the upheavals, and circulating movements of its substance. Nor could life suffer any omission of its constituent elements; nor the substitution of one 


\section{GRAND STRATEGY OF EVOLUTION}

for the other; nor any fickle fluctuations in the basic qualities of heat, light, and electricity, of hydrogen, oxygen, nitrogen, and carbon dioxide, her chief agents and constituent which for untold ages have passed in and out the gates of life and death, unchallenged and unchanged.

\section{Life's Directive Discipline}

The immutable barriers that confine life's fluttering excursions express but the stability of its habitat. Because the inexorable whole faithfully preserves the exact terms of its franchise, it is possible for life to endure within its narrow habitat. As this habitat is narrow, and flanked with death, it disciplines and directs the life it shelters. Since life is hedged about with restrictions and unfailing discipline, every living thing is forced to retreat from the road that leads to destruction, and again begin the search for a better way to live. It is compelled to give and to receive that service which creates and preserves, or be exterminated.

\section{Life's Freedom}

But within the boundaries of its cosmic sanctuary, and beyond its primal obligations, life is free to act, free to grow, free to appropriate what and where it may to its own salvation and aggrandizement. And within this common sanctuary are many smaller sanctuaries, wherein every living thing and every living part finds its measure of seclusion, of freedom, and opportunity for self-expression. Freedom to vary in. form and motion in response to its changing structure 


\section{AGENCIES, HABITAT, AND GROWTH 89}

and environment; freedom to play, to experiment, or explore, and to follow the never-ending labyrinth of life and hope renewed that opens up before its progress. It is this special franchise of individual liberty, within a universal prison, that is the joy of life and its guiding hand.

Thus each atom and each cell has a specific measure of freedom within the sanctuary wherein it exists. Through the exercise of that freedom of action it tests and explores its environment and finds the ways that lead to more constructive action. The same freedom, for the same purpose, is given to the organ, individual, species, family, state, and nation.

Thus in all stages of life, freedom and bondage, variation and stability, the radical and the conservative, work together for progress. Discipline and restraint conserve the old ways; freedom finds the new.

\section{The Growth of Freedom}

But the barriers within which life resides are not impregnable. In its traffic with nature, life is free to look beyond its tenement walls; free to receive directive agencies from afar, and thereby free to enlarge its heritage. By this universal attribute of profitable exchange, life grows in volume and complexity. Its increase in volume by assimilation is merely the increase of its servant organs; and the greater the precision and the power, of life's organic machinery, the freer are life's bodily movements, the wider is the range, and the more rapid the rate of its exchange. And as they increase, the prison walls of life recede. The windows which look out on the universe, and which admit 


\section{GRAND STRATEGY OF EVOLUTION}

its messengers, grow larger and clearer. By strengthening its servants of sensory response and bodily motion, life works its way to physical and spiritual freedom.

"For Nature, crescent, does not grow alone In thews and bulk; but, as this temple waxes, The inward service of the mind and soul Grows wide withal."'

\section{The Instruments of Freedom}

Thus there is no freedom without service given and service received. Freedom without the one or the other is but another name for death. Freedom grows only so far as the instruments of service grow in power to serve, and only so far as they actually perform their services.

To the amœba, the jelly-fish, or the worm, the "world" is the franchise of an hour in a drop of water; a niche in the rocks for a season; or a home in the sea for a decade. To man, the "world" is the universal whole of time and space, for their content are his to explore and to utilize. And therein lies our measure of freedom and attainment. For what we call the higher animal is the one which lives in a larger world; the one with more discriminating organic instruments for the discovery of good and evil, instruments of greater power and certainty in getting the good things and avoiding the bad ones. These are the chief differences between the jelly-fish and the worm, the worm and the crab, the fish and the reptile, the monkey and man, the herd and the clan, the state and the empire. 
The growth of freedom ever awaits the growth of service.

\section{Growth}

I. Its Insistent Power. Self-enlargement, as we have seen, is a universal property of matter. It is primarily dependent on the attributes of the agents whose cooperative union produces individuality and growth, a basic fact which lies beyond explanation. But growth is most commonly associated with life. It is indeed its most fundamental attribute, for all living things, such as protoplasm, cells, animals, plants and human society, ever tend to increase in volume by the capture of more constituents, whenever and wherever they come into appropriate contact with them.

This lurking, ever insistent power of growth resides in every living thing, and in all its constituent parts. It is ever straining against the bonds which temporarily hold it in check; ever producing the overflowing abundance of life's machinery; ever creating and recreating the infinite number and endless variety of plants and animals; pouring out with lavish hands the apparently useless wealth, the ornament, the beauty, and the luxuries of life.

2. Organic Wealth. Its Source and Its Uses. It is this primeval bounty and savage waste which is so confusing to a narrow, utilitarian philosophy; which leads one to wonder what it is for; to envy the wealth bestowed on others; to look with suspicion on every structure not frankly created for some obvious specific purpose; or to assume too readily that structural wealth was created by its owner for himself; or that it must 


\section{GRAND STRATEGY OF EVOLUTION}

be in some way immediately made use of when created. Nature, however, does not move in such petty and obvious ways. On the contrary, the newer properties and working capital of life are invariably the by-products, or surplus products of life. They may, or may not find a use. In any case, while they may or may not be of immediate harm, they cannot, at the very outset of their being, cooperate in giving aid and comfort to the whole. That comes, when it comes, later, and then only by mutual adjustments to a new end, or purpose.

It is the readjusted part, or organ, which has at last attained a fitting place and function in the organism; and the perfected plant, or animal, which has at last found a fitting place in the maze of social life, on land or sea, which excites our admiration; amazing us with its stability and the perfect adaptation of means to a given end. On the other hand, the wealth of nature in living things, and the overloading of animal life with armament and ornament, still confounds us by it apparent lack of present usefulness, or future purpose. But this constant over-production, and the accumulation of reserve organic capital, releases life from a too rigid hand-to-mouth existence, giving it, as it were, a leisure margin of safety, which, sooner or later, is utilized to explore new fields, and to find therein the ways and means for a larger life.

3. The Demands of Growth. So far as the biologist is able to determine, all vital action depends, primarily, on the cooperative response of protoplasmic constituents to one another, and to their outer world. This response is manifest in the changing chemical composition of protoplasm, in its internal streaming, change of form, and locomotion. 
This characteristic vital action is the visible expression of a reciprocal exchange; certain materials and forces from the other world, entering the protoplasm, usually through specific doors or passageways, and ultimately reaching every living part. Certain other things are discharged from these parts into the outer world, through their own specific exits. Life endures only so long as this cooperative exchange endures. On the whole, it is a profitable one, that is, more is received and retained than is given off; otherwise growth, the chief manifestation of living things, could not take place.

All vital processes, therefore, require for their continued being definite materials and forces from the outer world. Every living point, however minute and remote that point may be, must receive within a definite period its due share of food, air, and stimuli; and harmful agents must be excluded, or removed, else it will cease to live or to grow.

Thus all living things, and all their organs, by means of this process of self-insulation and assimilation, tend to acquire a definite localization, and structural individuality. That is, they tend to grow in their own likeness through their power to select and add to themselves other things like themselves; they are protected against contamination, or dilution, or perversion, by their power to reject and exclude.

This process of growth tends to go on indefinitely, subject to the new demands created by growth.

4. Checks and Releases to Growth. But just there a new factor inevitably arises; for growth cannot take place without changing the original conditions under which growth was initiated. This change is brought 


\section{GRAND STRATEGY OF EVOLUTION}

about: (I) by reducing the more available supplies; (2) by making it more difficult for constructive materials to reach all the growing points in the larger organism; (3) by making it more difficult to remove waste, or encumbering, materials. (4) Some points, or organs, must necessarily be more favorably situated for this give and take than others, and they will grow differently, or faster than the others. In this way, the initial internal cooperative balance of the whole organism is sooner or later upset, and this organic unbalancing produces a fourth check to growth. Growth, therefore, in all kinds of growing things, however great and inexhaustible the potential power of growth may be, is inevitably checked by its own success. Growth will go on, provided some improvement in mutual services takes place, or "happens," or is found, due either to betterments in the instruments of exchange, or to a better arrangement of them in time and space. If not, disorganization increases, and death or disintegration inevitably ensues. Growth may then take a new start with somewhat different materials, or under somewhat different conditions, and the whole process may be approximately repeated, possibly with better success than before.

5. Development, or the Simultaneous Increase in Volume, in Diversity, and Mutual Service. Thus no conceivable method of growth can proceed in the same manner, nor can it continue to produce the same results. With each increment in mass the modifying effect of the whole on each constituent part is more and more effective; and with each increment in volume, the distance from one extremity of the growing body to the other, the differences in age between the 


\section{AGENCIES, HABITAT, AND GROWTH 95}

youngest and oldest constituents, the differences in environment between the central and peripheral parts, become greater and greater, and the time required to serve the more widely separated constituents becomes longer and longer.

Hence the longer growth continues, the more the original conditions of growth are altered, and the more the rate of profitable exchange is diminished and the expenditures in exchange increased. Conditions are constantly arising, therefore, where, in order to meet the local difficulties of distribution and exchange, either new kinds of materials must be added, or new methods of growth adopted, or both, if growth is to be maintained.

Thus, however simple or elemental the method of growth may be in the beginning, or whatever may be the initial character of the growing materials, increase in mass and volume automatically creates development, or the unfolding of new characters. In other words, growth inevitably proceeds from the simple to the complex, from the homogeneous to the heterogeneous, because the progress of mere aggregation inevitably creates more complex and heterogeneous conditions for the associated units. Conversely, all methods and stages of development, in their origin, rest on the ultimate simplicity of the cosmic germinal stuff.

All problems of growth and exchange must be solved, as indeed they are, in the order in which they arise, the earlier ones in a more and more precise and certain manner, otherwise there would be no later ones to solve. Hence in every growing body, the growth of new parts, and the formation of an adequate and dur- 


\section{GRAND STRATEGY OF EVOLUTION}

able service of conveyance for them must take place simultaneously, and along approximately parallel lines. For growth and conveyance automatically control each other, since the point, or cell, or organ, or individual, not properly supplied, either ceases to exist, or does not come into being; and the one unhindered in its self-expression, and freely served, grows up to the full capacity of its distributors.

The members of a growing community of cells are subject to precisely the same kind of conditions as human beings in a growing city, or nation. In both cases, the conditions inevitably created by growth approach nearer, and nearer, to an ultimate balancing point which lies somewhere between the minimum rate of local consumption and the maximum efficiency of the available conveyors.

The rise and fall of this point marks the oscillation in the progress of evolution and organization. It rises as the ways and means of conveyance increase, and falls as they diminish. But while there is no limitation to the potential power of growth, or to the demand for constructive materials, there are very definite limitations to the available supply and to the rate of their conveyance.

In other words, all kinds of growing things demand more supplies and better protection. The additional requirements for income, outgo, and exclusion cannot be provided without better administration in the system of conveying supplies to the sources of demand, the removal of waste, and the exclusion of harmful agencies.

It is this ever present potentiality for growth, which is perpetually checked, or thwarted, by its own suc- 
cesses, and again liberated when better ways of supplying its demands are found, that produces that orderly progression from simple to complex, from disorganization to organization, which we call development, or evolution. This eternal conflict of growth with itself; this right readjustment of vital administration to its own demands, and its failure to meet them, constitute life and death, good and evil. It is the consistent triumph of constructive methods over destructive ones which makes growth and development the dominant characteristics of life and nature.

6. Limitations to Growth. At each succeeding stage of growth, the keeping out of harmful agents, the removal of those produced within, the discovery, and the capture of supplies, and their equitable internal distribution, demand more and more elaborate cooperation and exacting service. Moreover the variety of possible ways in which these vital constructive problems may be solved gradually becomes more and more limited, or compulsory, while the constructive processes of growth follow one another in more definite sequence and with a greater degree of stability and regularity.

But in spite of all the varied combinations and readjustments that may be made, ultimately every growing thing reaches a more or less definite balancing point between supply and demand where further growth is impossible. This is clearly indicated by the fact that all the most familiar objects in nature, such as atoms, molecules, chromosomes, nuclei, cells, polyps, insects, man, etc., never grow beyond well-defined limits in mass, volume or organization. It may be assumed, therefore, that it is impossible to maintain the con- 


\section{GRAND STRATEGY OF EVOLUTION}

stituents of such bodies in a self-sustaining cooperative union beyond those limits.

In plants and animals, this balancing point between supply and demand is fixed within comparatively narrow bounds; it cannot rise above a certain level because of the following limitations: (I) the limited variety of those things it is possible for living bodies to appropriate, to assimilate, or to utilize in their internal economy; (2) the limited structural strength of their necessary constituents, such as protoplasm, muscle, cellulose, chiten, or bone; (3) the limited power of response to the outer world, in the organs of sense; (4) the limited range and speed of transmission in nerves; (5) the limited power of the alimentary, circulatory, and excretory organs to overcome the increasing resistance to distribution and exchange; and (6) the limited power of life to conserve its gains.

In human society, owing to new and very exceptional conditions, the balancing point between supply and demand is rising rapidly. The rate at which society has grown, or the rate of profitable exchange between man and man, and man and nature, has increased with extraordinary rapidity in modern times because these inherent disabilities of life's organic instruments have been rapidly overcome by the invention of countless new physical instruments, of far greater power and precision, made of wood, stone, metal, glass, and other materials of like nature; and because man has utilized his science, literature, and art, the immortal conservatories of human experience, in an elaborate process of cooperative social life. Everywhere, coincident with this social growth, appear the arteries, the veins, and the nerves of domestic and foreign commerce and of 
social intercourse. They are the new agents which convey the nourishing and sustaining agencies of social life; they are the essential instruments for the distribution of diversified local products to the ultimate growing points; they lengthen, ramify, and enlarge with social growth, and society grows only so fast as they better penetrate the great barriers of time and space which separate man and nature, race and color, the living and the dead, and establish between them the life-giving channels of exchange.

7. Growth by Multiplication (dissociation) and by Combination (reunion or association). The balancing point in protoplasmic life is quickly attained within the relatively narrow limits familiar to us in unicellular life. When a cell reaches its maximum size and complexity, no further growth in volume, or in organic development, can take place except by subdivision, or fragmentation; these fragments then grow up to the same individual limitations as before, thereby producing more cells, distinct from one another, but of a similar kind. This is what we call growth by multiplication, or regeneration. But there is still a third method of growth both in volume and complexity, due to various amalgamations, or associations, of multiplying cells. Two or more cells may be completely amalgamated with one another, as in the case of germ cells; or many generations of cells may remain in touch with one another, still retaining their individuality, and thus forming colonies, or multicellular bodies, composed of millions of cooperating cells definitely arranged, it may be, into cooperating systems of tissues and organs. Then these multicellular organisms may multiply, and their offspring combine again and again, 


\section{IO0 GRAND STRATEGY OF EVOLUTION}

in many different ways, to form still larger, less coherent groups, thus leading up to the many different kinds of cooperative social growth, social multiplication, and social amalgamation.

These three basic methods of vital growth: (I) growth in unit volume and in unit organization; (2) by multiplication or dissociation, and (3) by cooperative union and organization, or association, are familiar ways of growth and development, every phase of the process having its own peculiar limitations.

Justly to appreciate these larger methods of growth, we must clearly recognize that individuality and unity do not depend on the existence of different parts either at the same time, or near the same place, or on their bodily contact and cohesion, but on the cuntinuity of their cooperative action and mutual services.

There are invisible avenues of exchange which everywhere permeate nature, knitting separate lives together into a complexly woven fabric. They are of infinite variety, of the most subtle and enduring character, and as intangible as life itself. Like wireless impulses, they may have no fixed abode, nor substantial boundaries, yet they are as sure and effective in their services as blood-vessels, nerve fibres, or ocean cables.

These ways and means of upbuilding nature life are overshadowed by the more obvious isolation and conflicting interests of highly individualized lives. It is only when animals and plants live in more immediate relations with one another, or when they are held closely together by common physical bonds, or when they are merged with one another in the more intimate 
communion of social life, that this phase of growth stands out with unmistakable clearness. Nevertheless this merging of life with life through connecting systems of conveyance and mutual service is one of nature's most common and effective methods of growth.

There are a great many different ways of bringing this about; but the creative value of the mergers always depends more on the duration and cooperative efficiency of the system than on the duration of the cooperating individuals, or the intimacy of their union.

8. Profitable, Cooperative Mergers. In the commensal merger, for example, different kinds of animals, such as a jelly-fish and a worm, a vertebrate and an invertebrate, may be united in life-long companionship under a common menage.

In the symbiotic merger, widely different kinds of plants, such as algæ and fungi, are so interwoven in a life-long physical contact as to form one inseparable organic body (lichens).

There is also the merging of all the offspring from the same parents into a single vital system. In such cases many sister cells, or polyps, or zoids, form compound organic units, or colonies, held together, under a common system of self-insulation, in life-long unity by common physical bonds, and sustained by living channels of communication and exchangt.

Then there are innumerable cases where different kinds of life are partly blended into one through domestication. Although there may be no physical contact, or intimate communication with one another, yet the life of one has become largely dependent on the life of the other, as in the man-dog, man-wheat, and manhorse association. 


\section{IO2 GRAND STRATEGY OF EVOLUTION}

There is also the union of one life with another in marriage, and in the many other cooperative associations of individuals, that constitute herds, flocks, families, tribes, and states.

There is also the fruitful nuclear exchange, or the mingling of the substance of two individuals into one, common among lower plants and animals, called conjugation. And finally, in sexual reproduction, there is the alinost universal method of uniting the male and female germ cells, and their chromosomes, to form a new being, or ovum, whose greatly increased powers of life and growth are doubtless due to some adaptive reorganization of its constituent parts.

We may regard this universal merging of male and female cells in sexual reproduction, and the cooperative association of male and female organisms in the higher phases of life, as an attempt on the part of each to capture and assimilate the other for its own aggrandizement, or growth. This attempt results, like so many others of like nature, in mutual adaptation and mutual service, or in united action for a larger creative result.

In all these cases, the individual profits and losses of cooperative living are fairly equally divided, and the methods of living are such that each constituent life becomes largely, or wholly, dependent on the other. The transaction is mutually serviceable and profitable, for each one gives the other, through a great variety of channels, some of its own powers, and the combined lives thereby acquire new capacity for world service which the constituents alone could not possess. It is one of the larger phases of growth.

9. Unprofitable Mergers. Parasitism. But this is 


\section{AGENCIES, HABITAT, AND GROWTH IO3}

not the case in the familiar parasitic unions where one animal, usually a lower one, lives on or within a higher one, and largely at its expense. The association may be a temporary attachment, or a life-long union, as intimate as that of different organs of the same animal. But it is never a profitable partnership; it is not cooperative living, or mutually serviceable; the net constructive result is always something lost, never something gained.

Parasites, as a rule, are of good antecedents; the degenerate descendents of animals which once possessed the means of living free and independent lives. As parasites they live at the expense of some more active and more highly organized animal than themselves; immerșed, it may be, in the food its host has captured and digested for its own use, and dependent for transportation and protection on its host's superior freedom of movement, and its superior power to fight the battles of life.

The only important functions to be performed by such an animal as a tapeworm, for example, are to make sure of its own position in life, and by not completely destroying its host, to insure a similar sinecure for its descendants.

The methods by which such highly specialized parasites maintained their position in life are exceedingly intricate and cunning devices, more elaborate in some respects than those utilized by their more highly organized hosts. But nothing is really gained thereby, for the methods are not broadly constructive. They are based on the robbers' doctrine, and the gamblers', of how best to gain something for nothing. But the successful parasite, after all, does pay too large a price 


\section{IO4 GRAND STRATEGY OF EVOLUTION}

for what it gains. It does, indeed, gain a relatively secure position, and acquires enormous powers of growth and reproduction. But the more its system of parasitic living is perfected, the more it loses through degeneration. In extreme cases, it may lose its digestive organs, sense organs, brain, and appendages, and thus practically all its powers of responsive movement, and its freedom of action.

Whether the degeneration, in a given case, is wholly due to the parasitic mode of life, or whether an already crippled organism is compelled to adopt the only method of life by which it is then possible for it to survive, is not altogether clear. Both factors have doubtless played some part. But the point is immaterial here, for in any case the degeneration is both the index and the product of diminished cooperation. Viewed from the standpoint of growth and evolution, it is clear that the combination of two lives, one acting as host, the other as parasite, is an unrighteous, nonconstructive act, because the product of previous constructive action is thereby in part destroyed, and the possibilities of further construction greatly diminished, or prohibited.

Thus all parasitic mergers are inherently non-creative, and tend toward mutual destruction, rather than toward mutual growth and mutual self-preservation; for the more successful the robbery of one member by the other, to that extent the power of service in both members is diminished. And the attainment of better defensive and offensive means by one, against the other, means correspondingly bad conditions, or death, for both. 


\section{AGENCIES, HABITAT, AND GROWTH IO5}

This growth principle applies to any aggregation of units held together by more or less equitable give and take, and common interests. If cooperative action is increased through mutual adjustment and mutual benefit, it binds the group more firmly together into more stable, organic unity. If it decreases, resulting in mutual disadvantage, the group inevitably breaks up into smaller groups, or partnership in it is wholly dissolved.

In the man-dog, or man-wheat, combination, and in many others of like nature, the conditions are very different. Here the components have interests in common. The union, although not organic or physical, is nevertheless highly constructive, or creative. Each constituent, in proportion to its own development, serves the other so much the more, and creates new powers in it. Thus the product of the union grows, and tends to acquire larger powers for world service, which could not have been acquired separately.

In the man-dog combination, for example, the dog is given a share of the greater security and larger freedom acquired by his human partner, and new powers are created in the dog through his association with, and his service to, man. On the other hand, man receives additional security, stability, and freedom of action, through the peculiar physical and sensory powers, the affection and the intelligence of the dog; and new and broader mental powers are created in man through his service, sympathy, and affection for his faithful comrade.

The cooperative union of these two lives, therefore, creates a growing power for world service. The po- 


\section{Io6 GRAND STRATEGY OF EVOLUTION}

tential powers of life are thereby enlarged. and its larger possibilities in a measure realized.

The same thing is true of the man-wheat combination, even though its constituents are so unlike in all which concerns their origin and the conditions which surround their individual lives.

Thus organic progress can never be achieved through any form of parasitism, wherein the parasite purchases a cheap, momentary success of assured place and volume of growth at the expense of a more highly organized host, and the loss of its own organic structure and freedom of action. Even if a condition is established, that permits the continuation of both lives in unison, where one does all the giving and the other all the receiving, no new power of service is born of the union. A man-tapeworm association is in no wise a more widely serviceable or effective instrument than a man and a tapeworm not in association. It is clear that parasite and host do not yield a common profit. It is always a losing game for both participants.

The same conditions underlie all forms of associative competition. Complete success of either competitor tends to create a condition of dominion, or slavery, ending in the extinction of the other, or of both competitors. The competitor that grows, and earns his survival, always does so because there is better cooperation in his own affairs than in the one that failed. Neither competitor can survive and continue to grow, without improving its self-saving, cooperative system; and both can do so only through concessions and mutual service in their common interests. 


\section{The Creative Cadence and the Formal Accents of Organic Growth}

All the phenomena of development to which we have referred are ultimately expressed in organic architecture and organic action. But the force behind all these phenomena, the force which compels the marching and counter-marching, the structural balancing and unbalancing, is the basic power of growth, and the cooperative action upon which it depends. This cooperative action is manifest in all bodily movements, in the functioning of vital organs, and in their rhythmic checks and releases. Its accumulated achievements in constructive rightness are impressively displayed in the unswerving leadership of germinal materials, and in the long procession of upbuilding, constructive acts in the growing embryo. It is because each system of cooperative action tends, sooner or later, to attain a relatively balanced condition of income and outgo, that definite forms, and more or less stable structures, are produced, which may be recognized by the morphologists, and classified by them into branching, graded series, roughly indicating the historic sequence of their creation, and the relative creative value of the various ways of cooperative action.

Nothing more clearly shows us, or more concisely, the real unity of nature-life, and the way life has grown, than the great phylogenetic trees of the animal and plant kingdoms, as they have been reconstructed for us, in their main outlines at least, by the biologists. When we have fully grasped what they signify, we shall not so much question whether one phase of life is higher than the other, or lower; whether the stem is more im- 


\section{I08 GRAND STRATEGY OF EVOLUTION}

portant than the root, the egg-germ than its food-yolk, or the leaf than the flower. Rather will it be our chief desire, both as laymen and as biologists, to discover how each life serves the other; how each one comes, and how it goes; what are the expanding buds and what the withered fruits; and what, to us, is the message of the whole.

But such condensed, graphic representations of biological knowledge show us something more than a mere genealogical tree of animal and plant life. So far as it is an approximately correct record of what has taken place, it also represents the successive rise and decline of internal organs coincident with the rise and decline of new kinds of animals and plants, and new ways of living. The knowledge of that historic sequence is just as firm a basis for the interpretation of causal relations as the observed order of events in a laboratory experiment.

For life cannot grow in vacuo. It must climb, if at all, step by step on the solid footing of stabilized cooperative improvements which permanently sustain life at each higher level. A definite sequence of progressive steps, each one rightly made, is therefore imperative.

This serial order in nature-rightness is the basis of all our interpretations of natural phenomena. It carries its own explanation-all the explanation that can be given. Science aims to ascertain, as nearly as may be, what that sequence of creative rightness was in order that she may infer what it shall be. For genesis is the logic of science; the source of all intellectual sympathy with nature-action, and the sole justification for prophecy. 
But evolution cannot be uniformly progressive, for organic innovations have widely different creative values, and produce widely different rates of growth, giving rise to that deceptive appearance of discontinuity which leads us to classify events or objects into larger or smaller categories according to the degree of their resemblance.

After making due allowance for irretrievable losses, and for our fragmentary knowledge, it is still evident that the things we are trying to express in our classifications are these very differences in the rate of constructive action, upon which the rate of evolution depends. In others words, the unequal creative values of the various improvements in organic service are the punctuation marks in nature-growth, and the cause of its creative cadence. The periods of more rapid progress, which follow after these improvements, appear, in perspective, as larger or smaller gaps in the flow of creative events. The more stable cooperative readjustments give visible expression to the more enduring anatomical characters which are the distinguishing marks of species, genera, classes, etc.

For that reason, every large class of animals is necessarily separated from its nearest of kin by what, to the discriminating eye of the morphologist, may appear to be a wide structural gap. But, on analysis, it is seen that the real difference is not in itself a large one, although it is always a highly cooperative one, carrying with it, of necessity, a multitude of other changes.

Whenever, therefore, the right ways, or better, or more serviceable ways, of conveyance are worked out, or "happen" more growth and higher levels of devel- 


\section{IIO GRAND STRATEGY OF EVOLUTION}

opment are quickly attained. Hence this onward march of organized growth is divided into many unlike stages; into epochs, eras, and periods; into units, organs, systems and classes; and into longer, or shorter, genetic series, such as embryonic, phyletic, and orthogenic, in accordance with the constructive value of some particular improvement in service. Moreover the development of every system must wait the passage of stormy events, or the coming of their fruits. It must wait for the growth of new parts; till the new and the old are cooperatively adjusted to one another; till the stronger are adequately served by the weak, and the weak by the strong.

Thus while the flow of creative processes is uninterrupted, the creative rate is modulated by various creative phrases and cadences; breaking up into what we call different kinds of living things, created at different times and places, endowed with unequal opportunities, and with unequal constructive values.

\section{Stability of Individual Life Essential to Social Life}

It is evident, therefore, that reunion and associative growth, whatever the value, or nature, of the associated units may be, cannot be definitely established until the possibilities of cooperative improvements in these units approaches its limitations, and their structures and organization have acquired some measure of stability. Conversely, no association can endure unless it is built on a degree of stability, or integrity, in its constituent units sufficient to insure continuity of associative cooperation.

Hence all growth and progress is concerned pri- 
marily with the stability and welfare of the constituent unit, or the individual; secondarily with that of the aggregate, or system; ultimately with both in equal measure.

If we would trace the evolution of organic growth, or analyze its forces, or control its results, we must fix our attention on the individual units and on the administration of their internal and external affairs, as they are successively submerged in larger and larger compound units. We must always bear in mind that the highest living organisms are composed of innumerable individuals of various grades and orders, each living within its own circle of internal and external environments; and that the most primitive individuals, the minutest and humblest parts at the bottom of the whole fabric, are the foundations on whose integrity and welfare the entire super-structure is built.

It would be as impossible to produce protoplasm out of chemical elements without fixed attributes, or a living body out of cells devoid of functional stability, as to upbuild a social body out of human beings without some basic stability in their physical organization and some assurance of their moral integrity.

\section{The Growth Rhythm: Individual Growth, Frag- mentation, Regeneration, Association}

In our final survey of nature growth, we wish to emphasize the fact that growth always proceeds in definite rhythmic order, or in repeated sequences of four progressive phases. In the first phase, through the agency of its internal and external system of profitable exchange, the individual ultimately attains its 


\section{II2 GRAND STRÁTEGY OF EVOLUTION}

maximum development, or growth, in volume, complexity, and stability. In the second phase, growth tends to attain its maximum by increase in numbers, or by division, fragmentation, or dissociation. In the third phase, these subdivisions, or fragments, again grow up, by regeneration, to their respective limitations. In the fourth phase, these individualities unite to form cooperative associations, or new growing individualities of a higher order. And so on indefinitely, into the highest phases of social growth. Although these four phases of growth overlap and interlock in many ways, they necessarily follow one another in the order indicated.

To give specific examples. Cells, as individuals, have their specific growth phases and limitations, followed by their fragmentations, regeneration, and associations. Then follows the development of the bodily product of these associations; their ultimate subdivision, their regeneration, and their association into colonies, or social aggregations. On a higher scale, man has his own limited growth phase as an individual; growth by sexual fragmentation, fertilization, and regeneration, and so multiplication in numbers. Then follow the combinations of human individuals to form various social aggregates, followed by their growth, their dissociative divisions or multiplications, and their cooperative unions, etc.

But if growth proceeded in this way indefinitely, all the available materials essential to organic growth would soon be exhausted, or tied up in the lowest stages of growth. It cannot proceed indefinitely, because each individuality has only a temporary hold on its possessions, and because there is a perpetual exchange 


\section{AGENCIES, HABITAT, AND GROWTH II3}

between high and low, the new and the old, the living and the dead.

Since growth always tends to outrun its administrative inventions, every growing system ultimately reaches the limit of its capacity for conveyance and self-maintenance. When that point is approached, the growing system hesitates in its career, and with diminishing power and increasing disorders, declines, through senility, into that more complete fragmentation we call death or dissolution. But since the basic power of growth is in no wise destroyed by death, and because the profits of individual life are in some measure conserved after death, life still maintains its continuous rhythmic progression; an alternation of partial death and complete regeneration and, it may be, the surpassing of all previous records of achievement. For every new life, as a rule, starts on a little higher level than its predecessors, and with greater resources at its command. 


\section{NATURE'S DUAL ADMINISTRATIVE SOVEREIGNTY}

The Dual Sovereignty of Individuality, or Internal and External Autonomy-The Internal Administration of Life-The External Administration of Life-The Federal Administration of Life-The Insurance of Life.

WE have seen that growth is a basic attribute of nature, the expression of an inexhaustible latent power, ever waiting a new birth of freedom in the performance of some specific service. It is manifest in the automatic construction of nature's individualities; its working capital is the accumulated profits of past services dedicated to further constructive enterprises. These processes are administrative in character, and are used in common by the organic and inorganic worlds of supply and demand; growth itself creating the new means to fulfil the new demands.

Nature's administrative system necessarily involves, therefore, some way of insuring the integrity of her individualities, their conveyance through time and space, the usage of them as endowments to larger ends, and the attainment of those ends through restrictive and directive discipline.

I. The Dual Sovereignty of Individuality or Internal and External Autonomy

Growth depends primarily on what we call "chance," or accidental combinations, which, after all, 
merely mean that ultimately the right constructive things come into the right constructive relations. But why is it that there is so little evidence of chance in the products of growth; that is, in the constructed, or growing things? Why is it that with the progress of evolution, all the constituent parts of a living thing become more stabilized in structure, and regulated in their functioning, if the fate of these constituents was originally governed by chance? The biologist is constantly confronted and confounded by this dilemma, for nature offers him an equally pointed denial and affirmation of freedom and repression, mechanism and vitalism; spontaneity in the new, determination in the old; of internal autonomy, and external control. He clearly sees the reign of disorder in the smaller affairs of life, and with equal clearness the reign of order in its larger affairs; the initial lack of direction in elemental parts, and the ultimate direction of elemental parts within the resultant whole; the lack of purposeful action in life's constituents, and the intelligent, purposeful conduct of the living organism. $\mathrm{He}$ is an expert witness to the perpetual contradiction of life by death, and to the perpetual contradiction of death by a recurrent life.

Here we touch the very heart of nature-connduct, and if we look intently we may catch some glimpse of her methods of self-construction and self-control.

These apparent contradictions are due to the fact that at every stage of growth, there is created within every growing thing some new phase of communal life, some new phase of environment, which governs the action of these constituent parts. For since no growth can confine its products to a single point, and since all 


\section{II6 GRAND STRATEGY OF EVOLUTION}

growth is consecutive, not instantaneous, it is impossible for all parts of a growing body, or all members of any social institution, to be precisely alike in relative location; or in their relative time of advent; or in many other conditions incidental to growth. These conditions inevitably determine what these parts are, what they must do, and the things they may, or may not do. The same laws govern the growth of the outer world in which these individuals must live. That is, nature-growth successively imposes on itself its own directive discipline, giving to each individuality a sovereignty of its own, and a different sovereignty to its outer world.

This sovereignty of the inner life enables the individual to find a place in the outer world where it may live and grow. On the other hand, the outer world invites the peaceful penetration of its domains; but it subjects all additions to its own resources to its own sovereignty. Thus the administrative system of nature is always expressed in dual form. Apparently its sovereignty is always divided against itself; the individual for itself, and all the rest of the world for itself.

But this dual selfishness and independence is ultimately mutually serviceable and mutually directive. In reality, it is cooperatively unified into one creative process.

As each component part of any individual, and each component part of its outer world, exists under different conditions, all of them necessarily grow in different ways, bringing internal interests into perpetual conflict with one another, and the individual, as a whole, into conflict with the changing conditions in its outer world. 
Every living thing, therefore, must make its progress, if at all, in three principal ways: ( $\mathrm{I}$ ) by better cooperation in its inner life; (2) by better cooperation in its outer life; and (3) by better cooperation between its inner and outer life. These betterments liberate individual growth, enlarge the individual, and increase its directive influences on its outer world.

\section{The Internal Administration of Life}

The chief problem for the internal administration. of life is how to create the best internal environments for the conduct of its own affairs, or the most effective machinery for the internal distribution and assimilation of its constructive materials and forces. It does not change the nature of these problems, if the life in question is that of a single cell, a flower, a worm, or a society of human beings; or if the requisite constructive materials and forces are molecules, or proteids, or petroleum, or ideas.

The historic and descriptive sciences, such as paleontology, comparative anatomy, embryology, and physiology, tell us with unmistakable clearness that all these internal improvements in life are brought about by so reconstructing and rearranging the various bodily members, such as nerves, blood vessels, appendages, etc., as to produce more economic and equitable bodily services, and the better to carry on the increased traffic these improvements both create and demand.

The chief point to be observed is that each administrative improvement, no matter how it is initiated, whether by some change in the position or structure of organs, or by some addition or subtraction, or by 


\section{8 GRAND STRATEGY OF EVOLUTION}

new combinations of germinal materials, inevitably quickens or releases some new form of growth, local or general. These new products may, or may not, be of immediate constructive value, but in any case their presence upsets preexisting relations, and inevitably creates, elsewhere, new checks, or releases, to the lurking power of growth. Moderate impact, stress, and strain modify the growth of the parts so affected, and thereby modify their resistance, or their response, to these strains and stimuli. All actions and reactions tend to take the shortest route, and the easiest way. The pathways of exchange are laid out, cleared, and strengthened by using, and they are preempted, or commandeered for service, according to their cooperative value and prior constructive necessity.

Thus growth itself creates a diversified internal environment, and this internal environment controls the progress of growth, because it controls the administration of supplies to its constituent parts. Each point that is better served promptly responds by increased growth, and increased power of service. It dwindles when poorly served; and as it dwindles, so do its demands for service. Thus the service of the served flourishes apace; and the servant is fortified by his own service. But the servant that is unserved perishes, and his power to serve perishes with him.

\section{The External Administration of Life}

Thus while the internal environment of the individual is self-created, this is by no means the case with its external environment. Life cannot create, nor can it modify, except to a very limited extent, its external 
environments. It cannot temper the seasons; nor control the physical nature of its habitat; nor radically change the character and distribution of its food supplies; nor alter the basic attributes of its fellow beings.

Life itself must seek out and find the best environments to live in, rightly using its instruments of discovery, and its machinery of response, to keep in touch with those constructive agents, mental and bodily, which the external world holds in readiness for the service of life.

Life can endure only so long as it yields to these larger agents upon which it depends, and builds itself up in harmony with the more rigid medium in which it exists. The chief problems in the administration of its external affairs, therefore, are how to avoid, or exclude, those things which are harmful; how to seek out, and appropriate, or associate itself with, the things which are serviceable; how to submit to the counter currents and turbulent eddies created by the unequal progress of the world at large; and thereby itself make progress in the performance of its services.

Hence whatever progress life actually has made in its external affairs has been made by better usage of the products of world-growth, and by improvements in the ways and means of self-insulation, or protection against them. That means better response to them; better locomotion toward them, or away from them; better communication, and more profitable exchange with them.

All these improvements have their origin in the shifting conditions of the outer world, where each part grows, as best it may. The improvements exist, and 


\section{GRAND STRATEGY OF EVOLUTION}

are improvements, because they are more cooperative, and more constructive in their effects. They cannot come into being, or at most but temporarily, if they are destructive to the internal organization of life; and they cannot endure without still further improvements, keeping pace with the progress of the external world, which itself moves onward, in its own way, with irresistible momentum.

The long story of these manifold adjustments and devices is partly told by those branches of science, familiarly known as natural history, and by the more modern science of œcology.

\section{The Federal Administration of Life}

When these two administrative systems are approximately balanced, a definite rate of growth or, exchange, ensues, constituting for the time being what is called fitness, or adaptation for existence.

But this rate is never uniform, in whole or in part, because the internal and external improvements are never of equal creative value; because other conditions, within and without, are constantly changing, and these changes are not necessarily dependent on one another.

There must be some ways and means, therefore, of restoring the cooperative balance between the inner and outer life whenever it is unduly upset. For lack of a better term, we shall call these ways and means the federal administration of life.

The two systems control each other in something like the following manner: As we have already indicated, better internal administration produces either 
more growth, or more rapid exchange, making heavier demands on the external administration, or commissary side of life, and more quickly exhausting the attainable supplies. If they cannot be obtained, internal improvements will be of no avail. To meet these new internal demands, the external administration must invent, or find, new ways and means to supply them. That is, there must be some improvement in the power of capture, either by increasing the surface exposure relative to volume, or by increasing the powers of discovery, or locomotion, or orientation, or the power of discrimination between good and evil.

Locomotion is an expensive function. To be profitable, it must yield returns something over and above the costs of transportation; and the larger the body to be moved, the greater the required velocity, and the more that velocity must be changed, or regulated, the more it costs.

When such improvements in capture are made, and the internal demands are for the moment satisfied, a new state of equilibrium between the two systems will be attained, only to be again upset by some new gain, or loss, in supply or demand.

Thus there is a perpetual see-saw between the commissary department of life, and the assimilation department. The system for the capture of supplies is always under compulsion, as it were, to meet the new demands of growth; and growth always uses its surplus supplies to create new things, which themselves provide new ways and means of consumption and which consequently create new demands.

According to the rightness of the federal administration, a rise in the rate of exchange, or the volume of 


\section{I22 GRAND STRATEGY OF EVOLUTION}

growth, or both, will ensue, with longer periods of balanced income and outgo.

As losing systems of exchange cannot come into being, the systems that actually do exist are either balanced systems, or profitable ones, or those that have been profitable.

Thus the administrative problems of self-construction are everywhere the same; the same for a college, a city, a nation, a factory, or for a human being, that they are for the humblest plant, or animal, or for the world of life at large. They are problems of the ways and means to liberate the latent creative powers in the inner and outer life of each constituent part. These ends are always attained by the same means, by mutual services, by self-imposed discipline, and by constructive rightness.

A college, for example, is a unit, or organ, within a still larger unit, the state. Each of these units has its own peculiar structures and functions, subject to its own internal sovereign conditions. Each unit helps to create and preserve the other, and although each is a distinct individuality, both are cooperatively one.

The quality of the college is always manifest in what it does; by what it selects, or draws to itself in selfconstruction; and by what it eliminates, or excludes in self-protection. Its inner life is expressed by the life of its constituent elements, or in the digestion, conveyance, and assimilation of constructive agents, bodily and mentally, drawn from the outer world. The constituents themselves create the restrictive and directive influences peculiar to its internal environment; upon their mutual services, and upon the right construction 
of its machinery of service, the life and growth of the college depends.

The external life of the college is largely expressed in parental solicitude for its offspring and in the capture of new supplies. To these ends the state invites invasion of her opportunities and forage on her resources, subject always to her sovereignty. The college neither creates these opportunities and resources, nor controls their character, distribution, or requirements, although it may contribute something to them. It must find these opportunities with its own instruments, and use these resources as they are.

Any marked improvement in the inner, or outer, administration of the college will at once liberate growth in some particular, and thereby create some disturbance in its system of give and take, supply and demand. Something comparable with the federal administration of life may then intervene to restore a more equitable balance of cooperative services. In that case, the criterion of equity, and the effect of the readjustments, if rightly made, will be the betterment of mutual services between the college and the state, and thereby the better welfare of all their constituents.

Man upbuilds all his social institutions in this manner, and in doing so he merely follows, consciously or unconsciously, the same administrative methods everywhere used by nature in her constructive processes. How far "chance," compulsion, and intelligence enter therein, no one knows. In any case, the constructive results would not, nor could not, be greatly different from what they are, without some radical change in the whole constructive system. In human society, a great 


\section{I24 GRAND STRATEGY OF EVOLUTION}

many different constructive and directive agents are utilized, and while man is more discriminating in his selections and exclusions than any other animal, he brings to his labors no new materials or forces, and no other franchise than a little freer usage, through his intelligence, of nature's resources in constructive rightness.

\section{The Insurance of Life}

What we sometimes call natural phenomena, or nature-action, is the weaving of many different kinds of events and materials, springing from infinitely remote sources, into a moving-picture fabric, whose larger, more stable patterns we may sometimes see and feel, but never the smaller, or more fleeting ones; nor the basic things which make the web, and do the weaving. Each element of the fabric is subject, on its way, to variable incidents; and when that occurs, something within ourselves may be sensibly modified; some pattern may abruptly change, or disappear.

We are so accustomed to the apparent stability of natural phenomena, that it is the change of pattern, the "accident" and the eclipse, which most command our attention, making minor incidents appear the major. We see the threads of life vanish, swallowed up in new constructing; but we may not see the new constructions, nor the way in which they are constructed. Thus we often mistake the making of chips, for the making of buildings. Because a thousand fish eggs die where one survives, does not mean that their destruction was the motive, or that it was useless, or that it was necessary, in order to make the survivor any better, or more fit to live. And it does not mean that, seeking to 
imitate nature, we should make, let us say, a thousand pairs of shoes, and destroy all but one pair in order that a good pair may be saved. The misfortunes of life are not the essential things. Organic evolution consists in utilizing the scraps; in reducing the percentage of error by the actual performance of the process of living and dying; making one in a million, one in a hundred, or one in a still smaller number fit to survive by more surely finding and preserving the right way to live. This progress in rightness can only be attained by accumulated improvements in the administration of the vital processes; improvements in mutual services which insure a larger and larger percentage of survivals by reducing the waste and the liability to error.

The unbroken continuity of life through untold ages is due to the basic security and the well-ordered life which has been assured to its individuals and to all their subordinate parts. The continuity of life, and its future progress depends on the perpetuation and the improvement of this method of insurance.

In all phases of life, the liability to errors of internal adjustment, and the liability to uncontrollable accidents from without, is directly proportional to the extent the scaffolding of life and nature has been erected. That is to say, the rate of liability to errors, and to accidents, gradually increases with growth until a point is reached where life becomes impossible, or death inevitable.

On the other hand, life is insured against these errors and accidents inversely to the extent of its progress. All the initial, fundamental processes of life have been so effectively covered by the protective in- 


\section{I26 GRAND STRATEGY OF EVOLUTION}

surance of right living that they have acquired great regularity and stability. It is along the frontiers of an expanding life, or wherever young life is experimenting with new combinations, invading new territories, and adopting new methods of living, that life fluctuates most rapidly, or flickers with its minor successes and failures. There its aims are exploratory, the failures are many, and the gains may be exceedingly small, or fleeting. Once perhaps in an æon, or in a great geologic era, is some unusually constructive innovation crowned with a new class of enduring progeny.

The internal administration of every individual life is insured by several sets of mingled, or overlapping agencies: (I) In part by better "heredity," or by the conservation and usage of right constructive materials. (2) In part by better self-insulation and self-protection, or by that discriminating appropriation, exclusion, and expulsion which tend to create and maintain a better internal medium for the conduct of life. (3) In part by larger endowments. The endowments may provide an active capital for consumption during the early stages of life, or a regular income in the form of parental and social services rightly performed for the individual at prescribed periods in its development. (4) In part by a more rigid discipline which begins in the egg and extends throughout life. This discipline is the product of definite physical and chemical conditions established within the growing body, which compel life to follow approved channels in a prescribed manner and in a prescribed sequence.

Thus the internal administration of all forms of life, as for example a plant, an insect, a human being, a city, or a great institution, is very largely self-insured, 
because it is very largely self-created and self-controlled. That it is not wholly so, is due to its dependency on its external environment.

A molecule of water, for example, is self-constructed, self-controlled to the extent that it is created through the cooperative action of its constituent parts. But it cannot exist or endure unless it happens, or is placed in, or finds, the right environmental conditions to that end. So it is with a living thing, or any other object. Hence the administration of the external life is not and cannot be self-insured or self-determined, for no individual life either creates or controls, except to a very limited degree, the world in which it lives.

The external life is insured, like the internal life, by several sets of agencies: (I) In part by the long established order, and the basic quality, of the cosmic and terrestrial environments of life. The nature of these environments, their universality and durability is insured by their own constructive methods; over them, life has had, and can have, no measurable control. (2) In part by life's self-constructive and self-saving usage of the varied ways and means provided by nature as the legitimate and compelling heritage of life. (3) In part by the directive discipline of the external world which irrevocably prescribes when, and where, and how life may, or may not, exist. It is only by avoiding that which is evil; by seeking, and finding, that which is good; by yielding, not breaking, under superior forces; by obedience, or submission to the dictates of the established physical, organic, and social order, that individual life can attain cooperative conformity with nature action, and rightly use her resources in a common creative purpose. 


\section{I28 GRAND STRATEGY OF EVOLUTION}

These external conditions are of infinite variety. They insure to every individual specific opportunities for self-aggrandizement, and thereby insure its usefulness. They also impose upon every individual specific restrictions. 


\section{BENEVOLENCE AND DISCIPLINE}

The Constructive Metabolism of Egoism and Altruism-The Merging of Egoism and Altruism into Organization, and its Emergence as the Augmented Altruism of Larger Individuals-The Entail System in Sexual Reproduction: Life's Entailed Estates; the Entailed Habitat; the Germ or Entailed Principal; Quick Assets or the Endowments of Organic Capital to Embryonic Life; the $\mathrm{Nu}$ tritive Income and Forage Dividends of Youth-Bisexual, Cooperation as an Agency in Parental Benevolence: Sex, and Sexual Divergence; Female Attributes; Male Attributes; the Functional Attributes of Germ Cells; Bisexual Cooperation-The Merging of Parental Altruism into Nature Altruism and Social Altruism: the Larger Creative Values of Bisexual Divergence and Bisexual Cooperation; the Unity and Cooperative Duality of Plant and Animai Life; the Post-Sexual Period of Parental Life as an Agency in Social Inheritance; Evolution as the Product of Altruistic Action; Intelligence not an Essential Factor in Altruism-Directive Discipline: Cosmic Discipline; Directive Discipline of the Germ; the Cumulative Discipline of Organized Endowments, Structural and Bionomic; Education; the Compulsion of Intelligence; Discipline in Civic Government, in Religion, and in Science-Summary of Chapters $I-V I$.

BACK of all evolutionary processes lies a universal compulsion to constructive action. It is manifest in three definite ways: ( 1 ) by increasing restrictions; (2) increasing guidance; (3) increasing freedom. That is, nature always forbids the constructive usage of some ways; inexorably compels the usage of others; and leaves still others open to trial, subject, however, to contingent gains and losses, or rewards and punishments. Or, to express it in still another way: nature 


\section{I30 GRAND STRATEGY OF EVOLUTION}

compels all her constituents to follow certain constructive ways temporarily open to trial; but they are ways which must be retained and further followed, if those means which the right way provides are utilized. All other ways she guards with destruction. These predetermined possibilties and impossibilties constitute nature's directive discipline.

\section{The Constructive Metabolism of Egoism and Altruism}

Let us consider, in somewhat more detail, the way in which life takes advantage of its opportunities; how it creates a working capital; and how it preserves and augments that capital through reciprocal egoistic and altruistic action. For egoistic and altruistic principles are everywhere present in nature's constructive processes. We have already referred to them as two phases of world service, or as self-service and superservice.

Social life, using the term in its broadest sense, is merely an enlargement, or extension of protoplasmic life. In both cases, vital action is expressed in metabolism, or the mutual exchange of products. In protoplasm, it is the exchange of protoplasmic products between protoplasmic constituents and between them and the outer world; that is, between the anabolic, upbuilding, or egoistic parts, and the catabolic, breaking down, up-giving, or altruistic parts. In social life, it is the exchange of social products between social constituents; between up-building and up-giving human beings; between plants and animals; old and young; the living and the dead. In human social life, we call 
this traffic in constructive materials between man and man, and man and nature, commerce, or culture.

If growth results therefrom, there must be some profit in the transactions; something must have been gained. What is that gain and where does it come from?

We may recognize four different phases in vital growth: (I) increase in the mass, or volume, of the individual in question; which merely means an increase in the number of its constituent parts; (2) multiplication, or increase, in the number of individuals, which means an increase in the total number of constituents; (3) increase in the power of each individual, which means better organization, or the summation of mutual services between their constituent parts; (4) increase in the power of the aggregate, or of the social group, which means its better organization and the summation of mutual services between the constituent social individuals. This process of growth may proceed indefinitely, but not necessarily to the same degree, in any two or more of its phases.

All this increase in living constituents, in their volume, numbers, and power, represents, at any given period in evolution, the world's supply of organic capital, which in turn represents the total product, or the accumulated profits, of countless individual lives and of their constituent parts.

Whatever vital power this aggregate of organic capital may have is dependent on the range and volume of its exchange in time and space; its endurance depends on its power to preserve its gains; its growth, on its power to add new gains to the old.

All these gains, material and directive, must come 


\section{I32 GRAND STRATEGY OF EVOLUTION}

primarily from without, either from cosmic agencies previously constructed, or from other parts, or members, of the social aggregate, previously constructed. And when we say they "come from without" that means that there must be some adequate machinery, or ways and means of conveying these constructive agents from their own creative, or initial, source, to that time and place where they play their respective parts in new constructions.

This whole process is in effect an organized system of benevolence, or of cumulative endowments, the only difference between its more primitive and its more specialized stages being in the kind of profits conserved, and conferred by one individual on another. It is nature's way of giving something previously constructed, and conserved, to some other constructive agency. It will be evident, on careful consideration, that benevolence of this basic character must be present in all kinds and phases of growth.

For benevolence is the giving of self to some other self. It always implies some previous creative, or selfconstructive act, the possession of the thing so created, and its conveyance, or transfer, from a previous possessor to another agent for further constructive usage. This possession of a thing implies the opportunity for usage of it in self-construction. When its creator, or possessor, fails to use it in self-construction, it automatically ceases to be a part of his system, or individuality, and becomes the property of some other system, it may be with better opportunities for its constructive usage.

Hence a gift is commonly valued for its durability and its utility. But it is especially valued for the source from which it comes, because in addition to these values 
it is a token of cooperative sympathy, and the assurance that a larger unity of purpose exists between the giver and the receiver than in either one.

Every gift carries with it its own compulsion and directive influence to these larger purposes. Benevolence, therefore, has a disciplinary value, as well as an additive one.

Thus all benevolence has a dual aspect: self-creating and self-giving; the receiving of endowments for self-construction, and the giving of self to new constructions. This is egoism and altruism. Egoism, which in its nakedness we call self-aggrandizement, self-preservation, and self-service, is the primary obligation of every individual; the initial source of nature's constructive capital. It is a prerequisite to altruism, for the larger and more righteous the self-constructing service of the individual, the more the individual will have to give; the greater will be his directive influence on other things.

Thus the profit in evolution is some gain in the rightness of self-construction. That power cannot be preserved except it be rightly added to, or conferred upon some other constructive agent which rightly uses it. The profits will be cumulative, or nature's capital in organized agencies increased, provided the cost of conveyance does not exceed, or wholly consume, the constructive gains.

This rhythmic exchange of power between individuals; this metabolism of self-constructive egoism and self-giving altruism, is nature-life. If it increases in intensity and stability, if the social life of nature actually grows in possessions; or if, as we say, evolution takes place, it must mean that on the whole individual 


\section{I34 GRAND STRATEGY OF EVOLUTION}

life profits by its living and confers on its colleagues and offspring something more of constructive rightness than it received. It must mean that the system of conservation and endowment, that the constructive value of gifts and the range of their influences, and the power of conveying mutual services, grows, or increases.

This nature-growth, or evolution, is not so evident in the increased power of the individual itself, great as that may be, as it is in the accumulated endowments of nature's organized capital thereby made available for its uses.

II. The Merging of Egoism and Altruism into Organization, and Its Emergence as the Augmented Altruism of Larger Individuals

The reciprocal process of self-creating and selfgiving merges imperceptibly into cooperative action, into organization, and the creation of larger individualities. The giving and receiving tends to react profitably upon the giver and receiver and to unite more and more intimately the ego and the alter, into one.

When benevolence attains its higher stages, it becomes more and more difficult sharply to distinguish between its different phases and their constructive results, or purposes; that is, between the self-creating and the self-giving; between the gifts and their conveyors, or their possessors; between the creating, the receiving, and the using of the gifts; between the common profits derived from the transaction and their constructive value to any one or more of the agents involved. 
Every living thing displays this blending of selfcreating agents and their gifts into one organic structure, and their mutually benevolent acts into one cooperative, or vital, process, in a very intricate, but most convincing way.

In a highly organized animal, for example, the different kinds of cells, nerves, muscles, glands, etc., create and give up, receive and utilize, their respective gifts without any clearly- defined break, or interruption, in the process. The whole complex of things possessed in common we then unhesitatingly look upon as one thing, or the body of the animal, and all their cooperative services as one process, its life.

By these ways and means the animal lives and grows, and itself becomes a source of benevolent services to its own world of living and non-living things. The altruism of the individual animal is merely the overflow of its constructive profits, the extension of the internal altruism, of its internal system of metabolism and profitable organic exchange, beyond the formal limitation of its own body into the outer world of other things.

We should not allow our analysis of these basic processes to be confused by the thought that human, or animal intelligence is a necessary, or an essential factor in them. The creative power of benevolence is the same, with or without intelligence, provided the right constructive way is found. Intelligence is merely a name for a quicker, more certain, more highly organized method of finding the right way to use egoism and altruism constructively.

In the great world of nature-life, with its countless lives on different structural levels, benevolence flows in hidden streams, or openly cascades from over- 


\section{I36 GRAND STRATEGY OF EVOLUTION}

flowing lives to other lives in different times and places. Where the fountains and the tributaries of benevolence are thus exposed, they may be more easily analyzed. This is especially true of life's reproductive rhythm, and of all those intermittent springs of life and death which fill the reservoirs of nature's vital capital and maintain their brimming measures.

\section{The Entail System in Sexual Reproduction}

Sooner or later every individual organism meets internal conditions which automatically check and ultimately prohibit the continuity of life in that particular individual. These conditions inevitably produce those disabilities of maturity which culminate in senility and death.

Life as a whole is sustained, and has been sustained through ages past, by countless renewals, that is by the generation of new living individuals to take the place of those about to die. But these new individuals do not start from the very beginning, or from an initial condition like that whence the first life sprang. They start from a new base, from a definitely attained vantage point, the germinal cell, the egg, or seed, far beyond the initial one, and aided, it may be, by an elaborate equipment for the nourishment, protection, guidance, and discipline of the new life.

From these new starting points, it is possible for such things as a flower, a polyp, insect, fish, or human being, to reproduce with unfailing precision, in a few days, months, or years, new individuals very much like themselves, although it required many millions 
of years to produce the kinds of things to which they belong.

Why is there such an enormous difference between the time required to produce a particular kind, or class, of animals or plants, in the first place, and the time required for that class to reproduce itself?

The difference undoubtedly lies in the starting points; in the fact that one had to create its own means and to find out the right ways. The other had its means given to it ready made; its ways were so prescribed, so directed, and so enclosed, it was compelled to follow them. This means that life is able to conserve its ways and means of living, and to make its discoveries and inventions in constructive rightness an accumulative property, a material, or structural endowment and a guiding hand to a future life. This rhythmic parental egoism and altruism is a basic form of benevolence.

Life, like science, literature, and art, creates for posterity an ever growing heritage which gains in stability as it gains in rightness. It creates an essentially immortal endowment of physical properties and directive discipline which insures the progress and continuity of life, despite the death of its producer. Individual life uses these endowments as stepping stones, or as advanced points of departure for the creation of a new life on a higher level. By means of these immortal endowments, the constructive processes of life make their permanent gains over the destructive processes of death. On these permanent foundations are erected the super-structures which make for progress and immortality. 


\section{I38 GRAND STRATEGY OF EVOLUTION}

We may never know precisely how this is done; it is one of the great mysteries of life and nature. But we know it is done. We know that nature has prepared a place where life exists, endures, and becomes enlarged. We know that the germinal principle of life with its increment, a working capital and fixed income with their increments, and the beaten pathways of constructive conduct, straightened by restrictive discipline, and approved by success, are its dower.

There are always three great overlapping phases in the life of every individual organism: (I) That of receiving all that the individual has and is; (2) that of preserving and augmenting these endowments; and (3) that of giving them with their increments to their offspring, or to life at large.

The first may be called the entail phase, the second the growth phase, or the phase of self-enlargement, and the third, the phase of self-giving.

Life's Entailed Estates. In recent years we have gained an inspiring insight into the correlation between the acts of fertilization, the architecture of germ cells, and the products of selective breeding. These dramatic revelations have led some biologists, and many laymen, to exaggerate the significance of genetics, in the narrower meaning of the term, and dangerously to neglect the larger aspects of life and nature.

But there are many other factors which have an equally significant influence on the reproduction and the evolution of life, and so far as possible all these factors, in due proportions, should be borne in mind. The chief factors are as follows:

I. The Entailed Habitat of Life. The habitat common to all life, with its provincial variations, is 
the gift of cosmic agencies to life. To these previously prepared habitats, and their prescribed order, life must conform all its activities, and from their resources derive all its materials and forces.

2. The Germ, or the Entailed Principal of Life. These estates are the parental and racial germ-plasmas, or chromosomes, or whatever they may be, which constitute the more stable organic basis of life. Each life receives them, ready made, from a long line of ancestors, shelters and husbands them temporarily, and then gives them up, reimpressed, to posterity. They are the immortal, vital sparks, tended by mortal fires, which ultimately leave the parent body and, reenkindled by cooperative union with one another, initiate a redirected life.

In the higher animals, the larger part of this germinal material is doubtless of the same physical and chemical nature as that which has been the common heritage of animal life for many millions of years. Its constructive power has been gradually enlarged by successive changes, additions, or improvements, and each enlargement has become definitely stabilized, in the sense that under widely different conditions it always grows up, if at all, in very much the same ways, and produces the same kind of things as those from which it came, with, it may be, something more.

The germ plasma of the human egg, for example, is man's heritage from the whole gamut of animal lives. It is very largely the product of their fostering care, and at every stage of its growth into a human being it bears the stamp of their impressions. It always grows into a living thing, at first fundamentally like all other living things; and then in its further up-growth takes 


\section{I4O GRAND STRATEGY OF EVOLUTION}

on, in definite succession, the more and more particular semblance of a jelly-fish, worm, arachnid, fish, reptile and mammal; and finally the semblance of its more immediate human ancestors, more or less qualified throughout by its own personal peculiarities.

In all cases, a very small part of this material, perhaps a small fraction of one per cent, if we may so estimate it, is less stable. Its fluctuations are visibly expressed in those minor details which constitute the last finishing touches, as it were, to a particular stage of development, or which distinguish one particular species, race, or individual, from another. It is these relatively minor variations which now so absorb the attention of the specialists in genetics, narrow their horizon, and envelop their teachings in obscurities.

Although the germinal material plays such an important part in the upbuilding of the animal body, and there has been a very great increase in its directive and constructive power, that increase cannot as yet be directly measured in terms of germ-plasma, that is in its structure, or volume, or quality. The germ-plasma of the simple animals and plants is not recognizably different in kind, or less complex in structure, or less voluminous, than that of man. In all cases the germinal material itself is microscopic in volume, its basic structure and its basic mode of action inaccessible. The differences are measurable only in terms of growth, or in the things they ultimately produce. These properties are in marked contrast with those of all the other estates which form a part of life's heritage.

3. Quick Assets or the Endowments of Organic Capital to Embryonic Life. An essential part of the 


\section{BENEVOLENCE AND DISCIPLINE I4I}

endowments to a new life is the active working capital, or quick assets, in which the vital spark is laid.

It is a highly concentrated food, freely available for immediate consumption, and specially prepared by the parents (not intentionally of course, although the result is the same) to meet the first demands of the new life. Although stored up inside the egg in the form of fats, and oils, and proteids, etc., and although it may be mingled with the germ, it does not form an organic part of the germ, at least not more so than with man, buildings, food supplies, and bank accounts, form an organic part of the heir that makes use of them. Like man's inherited estates, it represents the conserved surplus products, or profits, of organic parental labor; it is a parental surplus which, rightly utilized, insures the continuity and progress of its own life. This transfer of parental profits to the egg ensures the otherwise helpless embryo against starvation and accidents. It facilitates the processes of self-construction; rectifies and accelerates growth by placing beforehand the right materials in the right places for the constructive usage of the embryo. To each new life, it obviates, for the time being, the necessity and the otherwise insuperable dangers of having to discover, by itself alone, the right way to live.

There is no more impressive aspect of evolution than the progressive increase in the volume of this working capital, as well as in its rightness, or in the improvements in its timeliness, placement, and qualities. In its mere volume and in its power to provision a long developmental journey, the food materials which are stored up in the egg of the higher animals, a bird 


\section{42 GRAND STRATEGY OF EVOLUTION}

for example, or those which in the mammals are regularly supplied to the fœtus by the circulating maternal blood, may be some millions of times greater than that in the lower ones. The difference in the rightness is not so easily measured, but consideration of all the numerous factors involved may convince one, perhaps, that it is of a commensurate order.

4. The Nutritive Income and Forage Dividends of Youth. To the working capital deposited in the egg, or provided for the embryo by placental nutrition, may be added further endowments in the form of post-natal income and forage dividends. They are derived, in part, from secretions of the parent body, such as mammary glands and other organs, cooperatively adjusted to cosmic, climatic, and germ cycle periods; and in part from a percentage of the raw materials captured by the parents, or by the social group. All these resources are subject to draft at sufficiently frequent and regular intervals; and the income from them is better insured, increased in volume and variety, and spread over a longer and longer period of growth, with the progress of evolution. Here also the great increase in the volume and rightness of parental endowments is one of the most striking phenomena in evolution, and long familiar to even the most casual students of nature.

IV. Bisexual Gooperation as an Agency in Parental and Social Benevolence

I. Sex, and Sexual Divergence. Let us consider for a moment the respective rôles played by sex in the growth and organization of life.

The characteristic differences between males and 
females have their origin at the very roots of the animal and plant kingdoms. But whatever causes may have initiated these differences, as they increase, the power of either sex to perpetuate itself is gradually lost. Sexual cooperation then becomes the only way to preserve the dual life.

Individual life may be regarded as definitely initiated with the cooperative union of the male and female germ-cells respectively contributed to the new life by male and female parents.

A part of the combined germinal fund is used in constructing the body of a new parent; the remainder is domiciled within that parent till it may be safely surrendered to its complementary germ-cell in the construction of the next generation.

The intervening period constitutes the period of parental growth, a period which begins in the youthful egoism of acquisition and self-construction, and passes over into the period of parental altruism when all its powers are utilized in the interests of its germinal ward. For each sex ultimately draws on all its resources to guard its respective trust funds, and to convey them to a time and place where they may best live and grow. Each sex also contributes to these germinal funds it own special endowments in the form of foods, containers, and administrative labor.

The almost universal distinction between male and female parents rests on the basic fact that each one is the product, as well as the conveyor, of a special kind of germ plasm, each kind producing a different type of metabolism, and consequently differently constructed bodies. Thus the organic profits, which respectively accrue to males and females during their lifetime, are 


\section{I44 GRAND STRATEGY OF EVOLUTION}

expressed in different terms, or in different parental powers, which ultimately serve different purposes in the reproductive act.

2. Female Attributes. In the female type of organization, there is usually a marked tendency to conserve the surplus products of vital labor in relatively durable compounds, such as fats and oils, starches, sugars, and albumens. These products accumulate in the maternal tissues; some of them are ultimately conveyed by the bodily fluids to the ovaries and deposited in the ova as an initial food supply to meet the first demands of the growing embryo. From time to time, further contributions may be made to this initial supply which are conveyed by the blood, or other parental agencies, directly to the offspring.

Generally speaking, the food supply stored up in the egg is greatly increased with the progress of evolution, till in birds and reptiles, for example, it reaches an enormous volume. In these animals, the heavily provisioned eggs are largely left to themselves; or nests and shelters are built for their reception, and the parents intermittently guard, or incubate them, as best they may, while attending to their own welfare.

But in the highest vertebrates, like the mammals, a fundamental improvement is made in the administration of parental benevolence, which opens up an entirely new field of progress; for it largely obviates much of the inevitable waste and inherent dangers of the old system. In this more economic system of the mammals, the eggs and young are not heavily provisioned beforehand. Instead they are kept within the body of the mother at a constant optimum temperature; and supplied with nourishment directly, and continuously, from her own blood, which also carries away the waste 
products of the embryo. Thus the mother is left with a greater freedom of movement in her own behalf, while at the same time all her vital resources may be quickly mobilized in behalf of her young.

This elaborate, direct action system of parental altruism, in which parental nutrition, respiration, excretion, incubation, protection, and transportation are effectively combined into one prolonged organized service, is still further supplemented by suckling the young, and feeding them in other ways, for a considerable period after birth; by carrying them about from place to place; and by guarding and guiding them, without stint or limit, up to the full extent of parental powers.

3. Male Attributes. The male on the other hand is generally a physiological spendthrift, expending, as fast as they accrue, his organic profits in bodily activity, and in exuberant local growths. Hence, as a rule, the male is smaller, more active, more profusely ornamented, than the female.

These initial defects in his character, so to speak, are the sources of his virtues; the means by which he ultimately makes his own peculiar contributions to life. His persistent extravagance in architectural details, in color, and in action is in reality a recurrent investment for the discovery of more particular phases of constructive action. It provides him with the varied equipment essential to a life of exploration and adventure. Ultimately many of these apparently wasted efforts and useless properties, find their constructive outlets, and are utilized as cooperative instruments not only to a larger life for himself, his mate, and for his offspring, but for life at large. 


\section{I46 GRAND STRATEGY OF EVOLUTION}

4. The Functional Attributes of Germ-Cells. Similar differences in size and in locomotor activities are also the distinguishing attributes of the male and the female germ-cells, or spermatozoon and ovum. The ovum, with its stored-up energy in material form, is larger, in many cases millions of times larger, than its complemental sex cell; but the number is smaller. This costly endowment cannot be economically moved on its own power. Its great weight and volume forbid extensive locomotion; its great organic value forbids its use in hazardous explorations.

The sperm cells, on the contrary, are never large depots for food. They are always very small, very numerous, and very active; taking advantage in numbers, and in locomotor powers, to seek out, find, and unite with its complemental germ.

5. Bisexual Cooperation. Sexual divergence is a good example of what is meant by the term "finding the right constructive ways." It is evident that improvements in parental benevolence demand the creation of a greater organic surplus, greater storage capacity for it, and greater power and freedom of movement in its instruments of conveyance. But these attributes are mutually incompatible; for combined in a single individual each tends to defeat the other. The only way to develop all these attributes is to separate them, develop each one on its own resources, and then recombine them, by means of cooperative action across longer reaches of time and space, into a single function. Nature has discovered this way to increase parental benevolence, and she exploits it to the highest degree in bisexual divergence and bisexual coopera- 
tion. It is another phase of subdivision and reassociation applied to functional attributes.

The peculiar qualities of the female parent are always the first ones to be drafted by evolution into the service of the racial germ plasma; for her associations with the new life, by virtue of those qualities, are necessarily more intimate, her gifts more substantial and of more immediate constructive value than those of the male.

The male qualities are secondary, or supplementary in character, although not necessarily of secondary value. Hence the smaller size of the male and the wider range of his activities was from the very outset utilized in finding the female, and in conveying its germ plasma to its destination. For, obviously, this is the most economic way of bringing the two kinds of germ plasma into cooperative relations.

The more subtle powers of the male, as an administrator of foreign affairs; or as a vagabond explorer, and knightly ambassador to an outer world far beyond the reach of female activities, was not primarily available as an asset to the new life. These potential powers of the male were drafted into the service of life at comparatively late periods in organic evolution, after the peculiar structures and properties of the masculine body had found the cooperative ways better to direct his guardian and exploratory activities.

Thus, in the main, femaleness sets apart and conserves a fraction of her germinal estates; provides for them quick assets in adequate amounts out of her own bodily surplus; makes the ova safe depositaries for these endowments, and then secretly advertises their location. Maleness answers the advertisement, 


\section{I48 GRAND STRATEGY OF EVOLUTION}

and out of his own resources provides the means, and finds the ways, to add his powers to hers. The transaction is profitable; but the common, or resultant profits go elsewhere than to the partners in the undertaking, chiefly to their common offspring.

V. The Merging of Parental Altruism into Nature Altruism and Social Altruism

I. The Larger Creative Values of Bisexual Diverg: ence and Bisexual Cooperation. It is evident that bisexual divergence and bisexual cooperation are essential factors in the constructive processes of evolution, or nature growth. For heredity, in its broader sense, is the reproduction of individual life out of specific germinal materials, supplemented by all the administrative acts of a bisexual life. But not in that alone is comprised the whole creative significance of sex.

The creative value of a bisexual life, in contrast with asexual life, cannot be limited to the mere function of fertilization; to sexual commerce in chromosomes; or to the resultant expression of that commerce in Mendelian terms of form, color, and numbers. Its full significance is to be found in its ultimate extension into much larger social functions.

Primarily, better cooperation between the two sexes depends on better mutual services, and mutual aggrandizement in those secondary sexual attributes essential to the perpetuation of themselves in their own immediate offspring.

Secondarily, this parental aggrandizement finds larger outlets for its altruism than family life; for all kinds of individual profits, not merely germinal ma- 
terials and strictly parental functions, have their constructive value and find their altruistic outlets as social assets. But even in the highest forms of animal life there is no formally organized machinery for extending this altruistic action beyond the immediate offspring into the social phases of life at large.

2. The Unity and Cooperative Duality of Plant and Animal Life. Something of this kind, on a very large scale of time and space, is accomplished by the familiar commerce between plant life and animal life. It will serve to illustrate what we have in mind when we speak of the larger creative value of dual functional divergence.

The functional unity of these two great divisioins of the organic world is based on the mutually profitable exchange of their characteristic products.

The conservation of organic power in starch, sugars, wood, coal, and oil, and the peculiar nutritive, respiratory, medicinal, and constructive properties of many other products of plant life, are indispensable to animal life. On their part, many plants, especially the higher ones, are largely dependent on animal life for their nutrition, distribution, or fertilization. In this dual functioning, there is a prevailing tendency mutually to strengthen and accentuate the characteristics of each other, and thereby to make each one more dependent on the other. In these respects, the peculiar attributes of immobility and conservability in the plant kingdom, and of instability, locomotion, and exploration in the animal kingdom, have the same divergent, complementary, and cooperative relations to each other as the male and female attributes in sexual cooperation.

On this more general exchange of plant and animal 


\section{I50 GRAND STRATEGY OF EVOLUTION}

gifts and the common usage of each other's powers depends the existence and unity of the great social life of nature. Its continuity is wholly dependent on the ultimate fruition of this individual self-constructiveness and self-surrender to this larger purpose.

3. The Post-sexual Period of Parental Life as an Agency in Social Inheritance. In animal society, parents are of little value after the reproductive period, except as food for life at large. The prolongation of life after it has reproduced itself is to be regarded primarily either as a necessary margin of safety which, for economic reasons, must be, cut down to the narrowest margin, or as a vital surplus for which no profitable investment for saving, or enlarging, racial life is for the time being available.

There are many cases, familiar to the biologist, where, for a relatively long preliminary period, the parents are elaborately equipped for voracious feeding, and wholly devoted to the rapid accumulation of an organic surplus. Then all this equipment rapidly changes and they become wholly devoted to reproduction and the surrender of their surplus to a new generation.

But when this second purpose is accomplished, the specialized machinery of sex, such as wings, legs, copulatory organs, glands, sense organs, and nervous system, which have so well served to discover each sex to the other, and to bring them and their respective germ-cells into cooperative action, is disorganized and lost in death, it may be with the sexual act, or shortly after that act is consummated.

In many invertebrates, in mammals, and in primitive man, the older members of the social group, or 


\section{BENEVOLENCE AND DISCIPLINE 15I $^{1}$}

those which normally have fulfilled their reproductive functions, are deliberately destroyed by their former associates; or they are excluded in various ways from the giving and receiving of social services. In these 'cases the prolongation of the post-sexual period of life is determined, apparently, not by insuperable organic difficulties within the individual, but by external conditions, or by difficulties in social administration, which, so long as they are unsolved, prevent the further utilization of the sexual equipment as an altruistic agency.

Here, as in so many other cases, the power of growth outruns the power of administration, and this surplus of an over-long life, with its potentially valuable equipment, awaits its creative opportunity.

But, broadly speaking, with the progress of evolution, the increasing momentum of highly organized growth tends to save, or prolong parental life more and more beyond the period requisite for the mere consummation of its self-repeating function, or the endowment of its offspring with necessary reconstructive materials and moral resources. In man, the post-sexual period is of considerable duration, and under modern social conditions it is finding specific outlets into larger fields of altruism, and its value as a creative social factor is rapidly increasing.

This is chiefly due to man's more recently discovered ways of conserving the profits of his vital activities, and to his innumerable inventions for conveying them to mankind as material, mental, or spiritual gifts.

By these inventions and discoveries, the creative possibilities of mental and physical labor were enormously diversified and multiplied; the social value of 


\section{GRAND STRATEGY OF EVOLUTION}

man's activities, other than those of his mere muscular, or combative, or reproductive powers, was greatly increased; and human society, rather than the family, or the class, became the beneficiary of these labors.

That is to say, in human society the expenditure of parental labor to construct a home, a storehouse, highway, or machine; to domesticate the land and make it safe for family life is so much vital power conserved in human properties, as maternal labor is conserved in egg-yolk, or as sunlight is in coal.

This over-constructiveness of parent life survives, locked in the reservoirs of social culture, long after the producer has ceased to be. It is then no less a vital part of the body social, than it was a part, before, of parent life. And in due season other workers add more constructions to it, whereof the identity of the giver, like a grain of starch in the granary of seed, is lost in the assembling of the common store. These material properties therefore are to social life, as are to racial life the fats and oils assembled round the germ. They are the mingled, unspent profits of individual laborers; their surplus constructive capital overflowing into social reservoirs as a social heritage. Accumulating in the tissues of the body politic, they insure stability and continuity to social life, and a rising level of constructive capital to build upon.

So also it is with man's discoveries of nature's constructive capital in the bounteous outer world, the inventions for its better usage, and those betterments in social conduct which add to social life new powers of regeneration. All these rare fruits of exploration and experience are discoveries in constructive rightness made by individual human beings, chiefly in the ex- 
ercise of their respective sexual functions. They are discoveries of the right ways and means to do things; of enlarging their individual lives. But the creative power of that rightness lives in the records of the events, and in the things discovered, or created. These material symbols by means of which science, literature, and art have grown; these libraries, monuments, and instruments, which by themselves are but dead things, waste pigments of nature-action, unmeaning shapes and noises, in vital union with the hand and mind of man, are subtle agencies of spiritual conveyance in social life, as man's organs are the instruments of his intelligence.

The special value of this social heritage is in its stability and democracy; in the fact that its elements are not conserved in perishable protoplasmic form within the narrow limits of parental bodies, or for the benefit of their immediate offspring only. On the contrary, they may have the strength and durability of stone or steel and may be perpetually renovated by eliminations and additions outside the living body of man. And so far as they represent discoveries in constructive rightness, or truth, they are not exhausted, or impoverished, by general usage, but multiplied thereby.

But the highest creative powers of man, that is his technical skill, his wisdom, and social vision, attain their culmination toward the close of his sexual life, and may endure beyond it into the period of his greatest freedom of thought and action. This period of his fullest development, which the narrow utilitarianism of primitive life would minimize, or destroy, has been unconsciously retrieved by a growing feeling of fellow sympathy; by a purposeless and apparently wasteful social benevolence which knew not the creative power 


\section{I54 GRAND STRATEGY OF EVOLUTION}

of its own altruism, nor the nature of its returns to posterity.

For when man, or woman, is released from all but the more immediate demands of egoism, from the more imperative summons of sex and the purely reproductive obligations of parenthood, then further expressions of the distinctive attributes of sexual individuality become social assets of the highest value. They become, indeed, spiritual endowments expressed in the disciplined and chastened idealism of the mature artist, or the social worker, or whatever his, or her profession may be called, whose creative purposes extend far beyond self, or family, or race, or nation, and whose overflowing constructive powers are the supreme gifts of life, freely given to life at large.

4. Evolution as the Product of Altruistic Action. From this brief survey of the chief factors in parental and social regeneration it is evident that animals and plants grow upwards and outwards by means of many cosmic, racial, parental, and social endowments. These endowments are always the outgoing products of constructive action in the physical world, and in the great world of life at large. They are in part real gains; something absolute, inevitable, and final; not only in the material things actually constructed by nature, but in her ways and means of constructing them. Without this basic accumulative attribute of nature, wherein profits are expressed in better mutual service and in rightness, there could be no evolution, or progressive organization. There could be no structural gain other than mere aggregation. No individual thing could contribute to any other thing. There could be no benevolence, or altruism, because there would be nothing 
to give. Each thing would wholly spend itself in egoism. The system of exchange would be nothing more than a universal system of mutual robbery; a mere passing of properties to and fro between thieves, the agents, the process, and the products, either remaining forever on the same level as at the beginning, or sinking to a still lower level dissipating whatever power there might be in futile action.

There is no way to estimate, or to measure this growth except in terms of service and rightness; or in terms of something constructed and preserved; something rightly given, and rightly received.

5. Intelligence $N$ ot an Essential Factor in Altruism. That this creative system is not based on individual consciousness, or on the purposeful acts of intelligent beings, so far as that is true, merely emphasized its significance. For any act, to be intelligent, must be profitable in purpose. That purpose can be realized only when it is, in effect, a cooperative, selfconstructive, or self-creative act.

Man's existing social system is in no sense a product of previous deliberation on his part, or the mere fulfilment of his purposes, however intelligent they may have been. In fact, man has always been unconscious of what he was building, and doubtless always will be, for the seed can never know its own fruit. As a professed philanthropist, or as a would-be benefactor of his fellow creatures, man is not an innovator, but an unconscious imitator of a universal creative method, using, under its compulsion, whatever intelligence he may have as a special instrument to accelerate the accomplishment of natures purposes.

The three great agencies of social benevolence: 


\section{GRAṆD STRATEGY OF EVOLUTION}

science, literature, and art-were not primarily the products of a conscious necessity, nor primarily benevolent in purpose, although apparently from the very outset of their evolution they have been strongly impregnated with idealism. As idle amusements, as aimless exploratory activities, they sprang spontaneous from the soil of masculine and feminine leisure. But today they contain within themselves the riper elements of altruism and benevolence; for they are distinctly creative and preservative in purpose; both the instruments of conveyance, and the conscious missionaries of their own products.

Commerce, their sister system, stands on a lower level, for it is rarely creative, or altruistic, in purpose, and was ever lacking in idealism. Its conscious purpose is self-profit, frankly seeking larger opportunities for unequal exchange. It is, as yet, in the egoistic stage of self-construction, and as yet largely unconscious of its altruistic social function. But it cannot prevent, even when it would, the overflow of its profits into social benevolence.

That man in his supreme moments, has attained to even this degree of comprehensiveness in his altruism; that he is conscious of his own creative power and is moved, in spite of himself, by a deliberate will to world service, is perhaps the most significant event in organic evolution.

\section{V: Directive Discipline}

Mingled with the material endowments to the new life are other assets, less tangible to be sure and not so easily measured, but some of them at least of equal im- 
port. It will be convenient to consider them as a whole under the above heading.

The directive influence of an old and well established business on the partners to it increases with its organized momentum and that of the social system in which it has developed. He who holds an inherited position in that business is thereby subject to certain negative restrictions and positive compulsions, and endowed, perforce, with a part of the constructive rightness of both systems which he and his forbears helped to create.

So also it is with the momentous creative business of nature. Every individual endowment, or addition to that system, is subject to its directive influence; and the endowment itself carries with itself its own restrictions and compulsions to constructive action.

I. Cosmic Discipline. In this sense the cosmic system imposes its corrective discipline on life at large, and from the very outset rigidly defines the limits of its habitat, and the scope of its activities. Within these broad restrictions and compulsions, physical and chemical, provincial and climatic, life is free to grow as best it may, subject only to those ever narrowing limitations which life itself imposes on itself with increasing precision. But otherwise the cosmic environment is a blunt tool that has little or no power to direct the internal structural plans of life, or to interfere with the detail of its domestic economy; for plants and animals, when subject, for age-long periods, to either essentially the same, or even to widely different provincial conditions, still preserve the same wealth of variety in structural details, as well as the constructive peculiarities of their class and order. 
2. The Directive Discipline of the Germ. That thing which the germ tends to become, depends first on its own peculiar attributes of structure and quality; and second, on the time and space relations to one another the products of its growth are compelled to assume at each successive stage. The germinal materials, apparently, impose this directive discipline on their products, as long as growth continues.

But the volume, or quality, of the final product cannot depend on the number of such germinal units originally present in the germ, for if that were so the same results would sooner or later follow from the growth of one unit, or a hundred, or a thousand. Neither can the variety of unlike structures in the final product depend on the variety of initial germinal units; for otherwise there would be no progressive organization, no successive change in form and structure and quality, and no unlike creative values in time and space.

The changing internal conditions created by growth, and which govern all the constituent orbits of conduct, cannot be conveyed from one generation to another in the same sense that the initial germinal materials with their attributes are conveyed. They are conditions, however, which must necessarily arise in some definite sequence, and to which the actual hereditary materials must submit, or in accordance with which they are compelled to express their own activities.

3. The Cumulative Discipline of Organized Endowments, Structural and Bionomic. The germinal endowments of life cannot exist by themselves alone. They are wholly dependent on other endowments, such as rightly constructed foods, right kinds of protecting 
envelopes, and the right placement of them in time and space, which in varying degrees always go with them. What the new life then becomes is not merely a larger germ product, but a resultant serial product due to the cooperative action of the germ with all these initial and serially added contributions.

The influence of specific containers, more voluminous yolk mass, and a constant food supply, to which the germ must adapt its growth, is very considerable, to say nothing of other modifying conditions; and their directive influences and compulsions may continue long after the agents themselves have bodily disappeared.

And when at last the embryo is hatched, or born, it comes under the directive compulsion of another set of agencies, that of the great world of plant and animal life. These external, bionomic environments were created by the growth and multiplication of all the constituent members of life at large. They regulate and control the individual in much the same manner that its internal environment regulates and controls the life of its constituent parts, but in a less rigorous degree.

It is evident that the internal environment of every individual thing, whether it be a molecule, an animal, or a social aggregate, is more directive and exacting than its external environment, for it is more homogeneous, it contains fewer conflicting elements, fewer enemies and neutrals; all its constituent parts have a narrower common interest, and all of them cooperate better to a common end, than those of the outer world.

But, as we have already seen, there is no definite boundary between these inner and outer environments of life. The two are always bridged by channels of 


\section{I60 GRAND STRATEGY OF EVOLUTION}

cooperative exchange; and the inner environment is constantly encroaching on the outer. It is always enlarging its domains and increasing the range and power of its directive influences by enlarging its altruism, by merging more and more intimately and completely one life with another by the better performance of mutual services.

In this way the older external environments of germ units, the gifts contributory to them, and their products, successively pass over into the newer internal environments of a larger organism, and the external environment of the individual into the internal environment of society.

4. Education. All these enveloping spheres of influence, which are the products of the life that has passed, take on the rôle of creating and directing factors in the life to be. In other words, the dynamic reaction of the conditions created by the growth of life at large on the life of its individual constituents assumes the function of a moulding discipline that forbids and compels; that educates, and persistently leads the individual life into established pathways of self-saving and self-constructive action. It thereby tends to make what were originally free, or voluntary actions, and the successive chance discoveries and inventions in constructive and self-saving rightness, compulsory.

Whenever we follow the long sequence of unerring, self-constructive vital processes in any growing individual, we clearly see this directive discipline at work; for there the compulsion of rightness is displayed in miniature, summed up in quick development; its accumulated gains epitomized in lawful, creative action. We see it in the rigid discipline of the cloistered em- 
bryo, safely insulated, and secretly schooled in a special environment of its own; walled up in egg-shell, nest, or uterus; shut off from the minor incidents of the outer world; locomotion and practically all other movements, or functional responses to outside stimulants prohibited; subject to a constant, prescribed diet, and subject to the fixed chemical and physical conditions essential to its growth.

To this rigid, intra-cameral discipline of the sequestered embryo is added from time to time throughout the ascending scale a larger and larger measure of parental care, and social guidance, which extends over longer and longer periods. When the embryo ultimately breaks the walls which held it in solitary confinement, and as larva, tadpole, or infant escapes, it is only to enter a larger school, under the broader shelter of parental care, and with the greater freedom of parental and social discipline; and thence, still treading a fixed, invisible maze, it is led by instinct and lured by sense, up to the still larger freedom of maturity; into the larger cage of life, barred by circumstanding death.

5. The Compulsion of Intelligence. In the higher animals and in man, these compulsions are still expressed by life itself, in its more intricate self-saving, or intelligent reactions to them. Intelligence then becomes the medium of compulsion to righteous action; truth and knowledge, the agencies of that compulsion.

6. Discipline in Civic Government; in Religion; and in Science. No man can escape the directive discipline established for him by the evolution of life at large; nor from the more particular discipline imposed upon him by the momentum of social growth. The re- 


\section{I62 GRAND STRATEGY OF EVOLUTION}

sult of these restrictions and compulsions are tangibly expressed in more or less growth, or in terms of life and death. They may be wholly unrecognized, or manifest only in the degree of organization, or in certain saving instincts, habits, and customs, which are automatically, or involuntarily obeyed; for to obey them augments and preserves; to disobey, destroys. What we call man's science, religion, and government is the more or less formal recognition of this naturediscipline. They are the attempts to express it in human terms of profit and loss.

Hence with the growth of intelligence, self-regulating restrictions are formulated briefly and broadly to define the limits within which the human individual may, or may not act without detriment to himself. Within those self-imposed limitations to conduct, real or imaginary, lies his freedom.

But to fulfil its function as an instrument of social evolution, using nature's methods as a guide to selfconstruction, human intelligence must also formulate constructive social mandates.

7. Civic Discipline. Man's system of self-government, as expressed in civic, or social laws, is primarily broadly prohibitive, and broadly permissive; rarely explicitly mandatory. Out of this common legal basis, two opposing tendencies periodically arise and decline in varying degrees; but on the whole, both make some permanent gains, for profit is the common goal of all endeavor.

One tendency is to impose more and more specific mandates on the many for the exclusive profits of a few. The other, to eliminate all mandates, that in more equal freedom for all there may be more equal 
profits for all. In purpose, both tendencies are wholly egoistic; but the one, unchecked, leads to death in despotism; the other, unchecked, to social chaos, and to death in social disintegration.

But democracy is always open as a way of retreat from despotism to the more stable basis of equal rights; and despotism is the way out of disintegration to the more stable basis of unity in compulsory service. Neither tendency can wholly accomplish its purpose. The resultant of both is some gain for each, in unity, stability, and mutual service.

This resultant increase, or common profit in better cooperative action through the striving of the few with the many and the many with the few, in alternating partial failure and partial success for each, is a universal creative law, applicable to all constructive processes.

It is not surprising that the Constitution of the United States, formulated as it was with the spirit of democracy in the ascendent, contains no specific mandates; while individual freedom, and equal rights before the law, are strongly emphasized. In that respect, it does not constitute an organic contract between men comparable with that contract which is inherent in every natural object, or organized body in nature; for in all such bodies, each and every constituent part of that body must give to the other constituents and must receive from them, specific services to a common end, otherwise that object cannot exist, or endure. In other words, the constitution is not a purposeful cooperative covenant, or compact, wherein each and every citizen agrees, and thereby recognizes his obligations, to perform specific services for the state in return for specific services performed by the state for him; or 


\section{GRAND STRATEGY OF EVOLUTION}

one wherein the partners to the agreement are purposefully cooperating for a specified common result. No specific obligation to contribute services to the other under penalty of diminished returns from the other is therein laid upon either state, or citizen. Certain ways in which either the state, or the individual citizen, may act without liability to legal penalties are specified; and the penalties are specified that may be legally imposed upon either one if either acts in specified ways. But otherwise no specific obligations are recognized by them in legal terms, or can be legally exacted from them; no common purpose in civic law is defined; and no specific system of morality, or of constructive conduct, is legally required. It is often assumed, not without protest, that these moral omissions in civic law are adequately provided for in ordinary intelligence, or may be supplied by universal education in the elements of science and religion, and the duties of citizenship.

8. Discipline in Religion. Religion is more specific in its mandates, less specific in its restrictions, than democracy.

In early Christianity, the concept of religious discipline is said to be based on a cooperative covenant between Jehovah and his chosen people in which there was recognized the obligation to serve God in return for his blessings. At a later period in the evolution of Christianity, the covenant was expressed in the promise to save all those who believed in Jesus. The basic concept of Christian morality was mutual service, under the directive discipline of a superior power, and with the prospective alternative of receiving the greatest possible reward, or the worst possible punish- 
ment. That mutual service carried its own creative rewards was not so strongly emphasized. "Ye shall serve the Lord, thy God, and He shall bless thy bread." "Be thou for the people." . . . "Thou shalt teach them ordinances and laws and shalt shew them the way wherein they must walk, and the work that they must do." "Six days shalt thou labor." "Thou shalt love the Lord thy God with all thy heart, and with all thy soul, and with all thy mind." "Thou shalt love thy neighbor as thyself."

The democratic state does not make corresponding demands on its citizens. A citizen of the United States, it is true, may not legally work on Sunday, and he must pay taxes, if he has taxable property; but, except perhaps in times of the greatest emergencies, his civic laws do not compel him to labor on any day; or to accumulate taxable property; or to love and honor his country; nor do they show him the way wherein he must walk and the labor he must do.

9. The Directive Discipline of Science. Science is more explicit in its restrictions and compulsions than either civic or religious governments; for science comprises all man's knowledge of nature-action, and all man's intelligent efforts rightly to obey her dictates the better to profit thereby. It seeks to define in its lawgiving, not only what may and what may not be profitably done, but precisely what must be done, if it be done profitably. It aims to measure the rewards of rightness, as well as the punishments which follow every violation of nature's constructive ways. Science, in a passing stupor, is the new Moses, receiving out of the black and angry clouds of political dissension, nature's more explicit dictates, to be translated by science 


\section{I66 GRAND STRATEGY OF EVOLUTION}

into terms of human conduct. In this new covenant with nature, made with man through the agency of his larger experience and larger intelligence, therein again is expressed the promise that nature will serve him, guide him, and bless him with all her powers if he will but believe in her, and serve her, and obey her. That promise is made in the axiom that the right to exist and the obligation to serve are one and inseparable. It carries with it the categorical imperative to create and grow in power through mutual service. For nature has but one purpose in all-growth; and but one government — of all, by all, for all.

\section{Summary of Chapters I-VI}

All the currents of constructive nature-action are subject to the same directive discipline. Whatever the agents may be, stars or corpuscles, man or cell, physical, social, or spiritual forces, the cumulative compulsions and restrictions of time and space, mass and quality, progressively limit their spheres of operation, unify and stabilize their combinations, and guide them in gradient sequence to creative action.

Cooperation is manifest, both statically and dynamically; the one in more stable structure, form, or substance; the other in change of form, in conveyance, and exchange of properties. Exchange that is profitable, or constructive, that stabilizes and preserves, is serviceable. The profits are in constructive rightness. When these profits are localized and cumulative, they are expressed in egoism, or in self-growth, or in the progressive creation of some new individuality.

Mutual service is organization. It thereby creates 


\section{BENEVOLENCE AND DISCIPLINE I67}

a larger unity, and a larger individuality out of smaller ones. Service that flows out of one individuality to another we call benevolence, or altruism. When a constructive way is found, we call it the right way, or rightness, because it is creative and preservative to that extent.

The increase of organization, or of mutual service, mutual restraint, and mutual adaptation, is what we call progress, or evolution. It is expressed, not only in the growth of individualities, but, in a larger way, by the increase of their fitness for mutual service; by that rhythmic sequence of egoism and altruism, of give and take, of life and death, of gain and partial loss, which constitutes the metabolism of nature-life, and which is the source of nature's accumulating profits in constructive rightness and creative unity. 



\section{PART III}

THE ARCHITONICS OF EVOLUTION 



\section{ARCHITECTURE IN NATURE AS THE EX- PRESSION OF COOPERATIVE NATURE- ACTION}

Knowledge Expressed in Architectural Terms-Architecture and Function-Architecture Diversity a Prerequisite to EvolutionReciprocal Relations between the Architecture of the Individual and its Response to its Environment-Architectural Values and Cooperative Balance-The Divergent Architecture and Cooperative Unity of Plant and Animal Life-The Compulsion of Established Constructive Methods.

\section{Knowledge, Expressed in Architectural Terms}

IN nature, form and action, matter and energy, past and future, internal and external, are one and inseparable; each is a reciprocal manifestation of the other.

Hence statics are no more, and no less, significant than dynamics; morphology than physiology; observation than experiment; history than prophecy. In any case the biologist must interpret all vital action in architectural terms, or in terms of material things variously distributed in time and space; and all material structures in terms of past or future action. The astronomer, chemist, statesman, and philosopher, and the so-called practical man, or layman, are subject to the same mental compulsion. One has no different mental instruments to work with than the other.

Man's stature, mental and physical, is his formal reaction to his own outer world of nature-action; his 


\section{I72 GRAND STRATEGY OF EVOLUTION}

understanding is the measure of himself, in fractions of the whole, which he himself is compelled to express in architectural terms of history and prophecy, massed in gradient vanishing lines around a centre within himself where past and future join.

\section{Architecture and Function}

A house, for example, is a sturdy skeletun of walls and beams, rightly resting on and holding up each other. Its base is stable earth; it is held to earth by gravity. Gravity is also the orienting, directive power which chiefly limits and prescribes its architectural plan and the usage of its structures; for acting in rectilinear, radial paths, it points the chimneys to the skies, and dictates where cellar, chamber, and attic shall be, and where the exit and entrance.

Subject to these basic conditions, a house may grow in serviceability, if new constructive elements are rightly added to it. But the extent to which it may be enlarged by man, still serving as a safe and fitting dwelling for him, will depend on the kind of materials utilized, and on the structural plan followed in its construction. That is, on the points and angles of additions; on the possibility of uninterrupted renewal, strengthening and remodelling appropriate to its increasing size and more varied uses; on its resistance to enemy attacks, to shifting sub-soils, to earthquakes, vagrant storms, and other perturbations of nature's more normal action. Rightly done, a hut may grow into a city of enduring palaces; otherwise it must forever remain a hut; a temporary shelter, crumbling in adversity, perhaps to be at once rebuilt, but always sub- 
ject to its inherent architectural limitations, which in turn strictly limit the upbuilding of its inhabitants.

So it is with all the housings of life. To preserve its integrity, to insure its continued growth and the continuity of its shelter, every living thing must itself make its own additions to itself of definite things in definite ways, and its own eliminations. It must rightly orient itself to the more stable cosmic agencies, such as heat and light, and air and gravity; provide for its necessary renewals and remodellings; lay out its own internal lines of incoming and outgoing products; and keep itself in touch with the shifting lines of world traffic all about it. That all this really is done, is clearly displayed in the architecture of living things, that is in their structural plans, and in their functioning, or their ways and means of handling their constructive materials.

This constructive action is less in evidence where it is most constant and most evenly balanced, as, for example, in a crystal, or stone; here the minute contributory acts, and the multitudinous actors cannot stir our sensibility; only the sum is sensible, producing in us the preponderant impression of solidity and unchangeability.

It is most impressive where the actors, or functioning organs, are visible, or tangible bodies, themselves moving in measurable orbits under mutual influences, as the planets and satellites of our own solar system, or the cilia, heart, blood corpuscles, legs, or wings, of a living organism, moving with monotonous, rhythmic repetition in definite channels, or pathways.

These orbits of moving planets, organs, or corpuscles, may be swayed by passing influences, the imme- 


\section{I74 GRAND STRATEGY OF EVOLUTION}

diate sources of which may or may not be recognizable, producing, according to the degree of disturbance, or control, what we call determination, perturbation, conduct, or behavior; or, briefly, more or less constructive, or destructive, action.

When the pathways are less distinct, less frequently, or less regularly utilized; when moving objects are widely separated in time or space, and mutual influences are less in evidence, as in the great social system of plant and animal life, or in the narrower social life of man, the impression of architectural unity is reduced to the vanishing point, and no longer commands our attention. Each individual thing then appears to act independently, or in ways peculiar to itself; yet the cooperative coherency and structural unity is still there, as inexorable as ever.

It is because of the infinite variety of architectural details, precise and definite in each individual thing, and in all their subordinate parts, that this apparent freedom and precision of movement is possible.

It is evident that no one individual thing can contain all the necessary functions, or instruments, of construction. Hence, whenever one method of growth attains its own constructive limits, its products must then themselves become constructive instruments, or agents, playing their respective rôles on a more comprehensive scale.

If a jelly-fish had all the wisdom of Solomon, it could not utilize that wisdom in self-saving or self-constructive acts. The external agencies necessary to intelligent action cannot gain access to a jelly-fish; but even if they did, the jelly-fish could not respond to them 
in a helpful or self-saving way. Neither the receivers, nor the conveyors, nor the other actors, rightly constructed to that end, are present.

A creative genius, with nothing but gelatinous instruments to work with, could not rise above the physical limitations of his instruments, or above the creative power of the things which he is able to give and to receive.

III. Architectural Diversity a Prerequisite to Evolution

Thus life cannot advance in the same directions, nor at the same rates, nor to the same degrees. It thereby acquires the structural diversity on which its cooperative action depends. If all the constituent parts of an animal were exactly alike, or on the same dead level of structure, the animal could not exist. This is like assuming the impossible to be possible, for the very essence of vitality is the cooperative action of an infinite number of parts in multitudinous variety. And just as these diversified powers are essential to the creation and preservation of each individual life, so also are many different species, orders, and classes of living things essential to the creation and progress of life as a whole.

Life, therefore, had to bide its time, and await the vital and social organization of its countless armies of animal and plant life progressing on a world-wide front; wait till its pioneers had themselves constructed the organic instruments that would enable them to find the ways and means which nature keeps in reserve, or 


\section{I76 GRAND STRATEGY OF EVOLUTION}

provides, in due season, for life's usage. And today life still bides its time and awaits the performances of specific social services.

\section{Reciprocal Relations Between the Architecture of the Individual and Its Response to Its Environment}

But how is it possible for such a great variety of living things to exist side by side in what appears to be the same external environment? Why is it that many of them live on the same structural level in different environments; and again, why do some advance in structure, others fall to lower levels, and still others remain practically stationary for indefinite periods? It will help us to answer these questions if we bear in mind the difference between the nominal habitat of the individual and the real one; between the architectural materials which are utilized, and the structural plans which have been adopted in each particular organism.

The environment of any living thing, using the term in its commonly accepted meaning, does not represent the whole content of the place wherein it exists. It comprises only those parts of it to which the living thing responds, and with which it comes into constructive relations. In this sense, two things may live side by side in the same habitat, and yet have their being in different environments because they do not react to the same agencies in them, and because they are not active parts of the same system. The tree does not live in the same environment as the bird that nests in its branches; nor does the dog live in the same environment as his master, even though he lives in companionship with 
him; nor does the boy live in the same environment as his father, even though he dwell with him in the same household.

This functional isolation, independence, and distinctive behavior of individual life is due to its distinctive internal architecture. That is what, in effect, limits and defines the content of its outer world, not the presence, or absence, of things actually in it. In other words, the sources of individuality are internal, not external; and the infinite diversity of nature-life lies primarily in its multitudinous variety of individuals, not merely in their environments. Therein lies a special significance in numbers, giving to them something more than a mere summational quality. This diversity of life is based on the axiom that two things can not occupy the same space at the same time; conversely, no two individuals can be alike. The increasing diversity in individual life, which inevitably follows increase in numbers, is a perpetual invitation to make profitable usage of it. Only when the invitation is accepted, and cooperative action with qualitative subdivision of labor takes place, does the possibility of creating a higher life become a reality.

Thus it is that an animal, like any other balanced system of cooperative action may endure in a world of many changes and yet take little or no part in them. On the other hand by virtue of some apparently insignificant internal readjustment peculiar to itself it may move rapidly onward and upward leaving its fellows behind in the old life and environment. So changing, it may enter a new world without changing its nominal habitat because these internal structural changes bring it for the first time into cooperative re- 


\section{I78 GRAND STRATEGY OF EVOLUTION}

lations with things it could not before utilize, or with new agencies which for it did not before exist.

\section{Architectural Values and Cooperative Balance}

From every main line of progress, many side branches or collateral lines of evolution arise. The point where a larger or smaller branch diverges from the main stem represents a period when some particular method of growth, or building material, or habitat, was definitely adopted; and the number and extent of the secondary branches arising therefrom represent the constructive products of that experiment, and testify to the creative possibilities of the change.

Any estimate of these gains must be based on all three of the fundamental requirements of organic progress, i.e. (I) increase in content, or volume; (2) improvements in internal administration; and (3) improvement in external administration. Increase in any one respect is largely dependent on the other two; but increase in volume is the less restrained, the more primitive, or the initial one of the three processes. It tends to exceed the other two, and in excess automatically checks their progress. On the other hand, successful inventions in administration accelerate growth in volume which ultimately neutralizes the effects of the invention and restores a new cooperative balance.

Thus any condition which disturbs the pre-existing methods of cooperative action checks or releases the ever-lurking powers of growth, and leads to over-production or under-production, the result of which may be either organic stability, or decadent evolution, or extinction. 
In the development of a tunicate, or a barnacle, for example, there is evidence of unusual internal changes in the rate of growth and the character of its various organs, which necessitate a return to a simpler mode of life than that of its progenitors. The administration of its purely digestive processes is little impaired; but the secretion of thick cellulose walls, or of lime-filled chiten, is developed to an extraordinary degree, so that they no longer act as protective envelopes, but as prison walls, or sinkers, or cumbersome anchors, thereby compelling these animals to adopt a sessile, or stationary, life. Moreover the blood vessels and excretory organs fail to complete the normal measure of their growth, greatly reducing the efficiency of internal exchange; and the degeneration of the eyes, brain, and locomotor organs cuts down cooperative contact with the outer world, and reduces the external administration of life to a minimum.

Organic degeneration of this character, as well as organic progress, involves many changes and effects difficult to distinguish from one another; and some of them no doubt are due to remote changes in the constructive germinal materials. But whatever the causes may be, a simpler life is always a necessary result of the lack of organic instruments, or a disturbance of their cooperative balance; while increased freedom of action is an inevitable accompaniment of better organs and better organic cooperation.

That the architectural materials used by growth have far-reaching effects on the life of the organism is also shown by the difference, as a whole, between plant life and animal life. Animals, as a class, stand on a higher cooperative level than plants because of 


\section{I80 GRAND STRATEGY OF EVOLUTION}

their greater freedom of movement, and their profitable response to more subtle internal and external actions.

This is very largely due to the fact that all plant cells are enclosed in cellulose walls, often of great thickness and rigidity. Plants have never been able wholly to shake off this element in their make-up; and this element has persistently restricted their mode of growth, their nutrition, and their power to receive, and respond to, external stimuli. Plant cells, coated with cellulose, apparently cannot be spun into nerve fibres, or muscles, or blood corpuscles, or eyes and ears, like those so almost universally formed from the naked cells of animals; and all the resources of time and place, heredity and environment, have been powerless to remove this firmly established disability. Nevertheless, this very disability has been widely utilized at every stage in the evolution of plant and animal life.

A pig stands on a much lower level, architecturally, than man because, among other reasons, the administration of its commissary functions is largely dependent on cloven hoofs, and on the rooting efficiency of a blunt and clumsy implement. The traditional methods of the pig, while not exclusively his own, have helped to perpetuate a flourishing race of highly organized animals. But his hoofs and snout, as purely mechanical instruments for the administration of foreign affairs, cannot compare in efficiency with the hands and tongue of man, because owing to their anatomical position, structure, and internal organic connections they cannot bring the animal into cooperative contact with the outer world in as many different ways or do as many different things. No conceivable improvement in in- 
telligence, environment, or morality could remedy these individual defects, or enable these organs to sustain such a free and diversified life as that of an ape, or a human being.

In all these cases and in many others that might be cited, a fixed cooperative balance between all the vital processes of life is never attained. Organic balance is constantly fluctuating, the threatening deflections indicating unequal progress in one or the other of the great vital functions; the return toward a more stable norm, indicating the restoration of equality in the progress of all. In other words, the organic balancing point of individual life is never central; the living organism is always longer on growth than on administration. The latter is always behindhand, and by readjustments and compromise is constantly striving, as it were, to catch up with growth in order to meet the demands of its increased content.

But it is a familiar fact to the morphologist that there are inherent limitations to the modifications and readjustments that can safely be made in a given structural plan, or method of growth, after it is once established.

The nature of these limitations can be but roughly determined, if at all; but their existence is clearly indicated by the limited development of their products after a prolonged period of trial; and by the fact that another method, under apparently similar external conditions, and in a very much shorter time, gives infinitely larger returns. 


\section{I82 GRAND STRATEGY OF EVOLUTION}

\section{The Divergent Architecture and Cooperative Unity of Plant and Animal Life}

In its upbuilding from a common beginning, life has found, strangely enough, but two main lines of architecture open to it, the plant line and the animal line.

This basic duality of life is the more impressive in view of the multiplicity of structural types in the domains of purely physical and chemical phenomena. In no other domain of nature are there two such distinct classes of phenomena, each standing so much apart architecturally, yet each so complemental functionally to the other. Therein lies the secret of this architectural duality, for the mutually sustaining attributes of plants and animals, like those of the male and female sex, are of such a character that neither could exist without the other, and neither could alone perform the work of both. Thus plants and animals create a common life, held together, not in formal architectural unity, but in labile cooperative action.

The distinctive inventions of plant and animal life have been persistently followed up, and apparently exploited to their utmost possibilities.

For every plant and every animal, blindly or otherwise, seeks to avoid that which is destructive to it, and failing, dwindles away, or vanishes in extinction. Every plant and every animal, aimlessly or otherwise, seeks out and tests every nook and cranny of fitting opportunity for further growth, and finding it, the further grows, the more firmly holds to the more enduring help, to the more saving shelters of the world at large, and to their more bounteous conveyors; fitting itself to 


\section{ARCHITECTURE-NATURE-ACTION 183}

them, as roots to the texture of the soil, or as leaves to the temper of the wind and sun; clinging to them as a child clings to its mother and moulds itself to her larger ways; or as a fish clings to the waters and fits itself to the idiosyncasies of their life-giving pools and currents.

Thus what we carelessly call the "vital" organs, or living tissues, of a given plant or animal are in reality but a very small part of its sustaining resources; for every organism is a pensioner to the labor of its outer world of living and non-living things; and is tied to its beneficiaries by countless visible or invisible architectural bonds. These bonds may be cancelled, in our more direct discourse, but they should never be forgotten.

We may picture this process of animal and plant evolution as a growing tree with two main branches, and a common stem representing the common stock in which the two great lines of plant and animal life have their origin. The two main lines of growth become more and more widely separated in character, because plants and animals utilized in their architecture widely different constructive materials, and different methods of assimilation and growth.

As the whole animal kingdom and the whole plant kingdom are come from the same common stock, are of equal age, and have had equal rights and equal opportunities to utilize the franchise of earth, and sea, and air, whatever difference there may be between them must be in architectural methods and constructive materials, not in opportunity. That is, the difference, let us say, between a flowering plant and a mammal must 


\section{I84 GRAND STRATEGY OF EVOLUTION}

be due primarily to the difference in the potential powers of the materials and methods utilized in growing, not to any extrinsic circumstance.

But the incomparably larger results attained by animals individually are by no means wholly due to the creative powers of their own germinal materials or methods of growth. They are due in large measure to the supplementary activities of the whole plant kingdom, for plants supply, and they alone can do so, the essential structural materials for animal life. And animals reciprocate by performing indispensable services for plant life. In fact, each supplements the other and both act like two different organs performing their respective functions in unison for the common body of nature life.

From this point of view, there is no reason to assume that somewhere, or somehow, the plant made $\dot{a}$ mistake, so to speak, in the adoption of an inferior, or vegetative, method of living, one that can never attain the freedom and versatility of animal life; and one whose highest product is a fruit, or a flower, beautiful, it may,be, and serviceable to both plant and animal, but without intelligence. But even so, the fruit and the flower play but a minor part in the service of plants to animals. It is the plant's basic method of living which is the more fundamental and important thing, as essential to the evolution of consciousness and intelligence as sense organs and nerves. For plants are the living bridges which unite man constructively to the sun and the soil; over these busy bridges, nature sends her merchandise from the inorganic to the organic world, from the physical to the spiritual and back again, tying all nature traffic into one. 


\section{ARCHITECTURE-NATURE-ACTION 185}

We need not enter into a technical discussion of the differences between plant and animal life. They are fully described in most text books of biology. Very briefly stated, and without reference to well-known exceptions that do not seriously affect the general rule, they are as follows: In plants, the living protoplasm is enclosed in woody chambers, or cellulose walls, through which only soluble foods may pass. In animals, these woody envelopes are absent and solid foods may be taken into the body, and particles of suitable size may pass freely into the living cells. Plants have certain instruments, which, in cooperation with light, transform inorganic solutions into living protoplasm. Animals cannot do this. They must live on the products of the plant, or on other animals that live on plants; and their foods must be broken up, dissolved, and distributed in roundabout ways before they can be utilized in the construction of animal protoplasm. Plants use carbon dioxide and liberate oxygen. Animals use oxygen and give off carbon dioxide. Plants have no muscles, nerves, and sense organs. These are the chief instruments of animal life.

These characteristic instruments of plants and animals rigidly restrict their respective manners of living, but open to each resources unavailable to the other. To the plant, they open to self-constructive usage the physical powers of heat and light and the chemical materials of air and soil, but bind them to the soil, and to the sun, for they are the sources of their nourishment. The animal is restricted to plant products for its foods; but it is free to move from place to place, sustaining itself by rightly following the trails of countless subtle influences which have no existence for the plant. 


\section{I86 GRAND STRATEGY OF EVOLUTION}

The plant, in the main, is nerveless, senseless, and stationary; enclosed in wooden chambers and fed by a cosmic circulation which delivers its products at the tiny doors of expanding leaves and groping roots. The plant is essentially inert because it is impervious to the more complex events in the world outside-itself. It cannot quickly move into the pathways of profit nor away from destruction. The tree cannot respond to the inviting valley, the threatening axe, nor the oncoming fire because it does not possess the architectural resonators requisite to these ends, nor the other internal machinery requisite for the purposeful application of its own power. It cannot, therefore, receive the warning messengers from the outer world, nor answer their invitations in self-benefitting, or purposeful movements. It can only drift with the currents and eddies of the outer world; a passenger of the winds, the waters, and the bees; or cling to the stable shores of recurrent cosmic events, dependent on their flotsam bounty.

But the animal in the main is nervous, sensitive, and active. Moving from place to place, it seeks out its own salvation, largely impelled by its own internal powers, guided by its own instruments. Its inner life and structure is upbuilt in exact conformity with particular external acts of a very complex and subtle nature, or with the dimensions and energy of a multitude of specific vibrations and forces. Its distribution in time and space tends to follow the distribution of these agents. Its coming in and going out is in profitable response to the source, and the line of propagation, of a particular perfume, a cry, a flash of color, a song, a sign, a word, or an idea. 


\section{ARCHITECTURE-NATURE-ACTION I87}

\section{The Compulsion of Established Constructive Methods}

It is evident that as these two lines of life become more firmly established, all further progress, or improvements, must be built on and around the basic principles of these two inventions. For the plant, therefore, the problem of life is to discover a better use for its own peculiar instruments; to find a more fitting place for itself in the sun, or soil, or water, and to enter into more profitable relations with other forms of plant and animal life. In so far as it succeeds in doing so, in those respects it grows and so becomes more specialized, its structure more specific, or divergent. The same is true of animal life in all its varied phases. 


\section{VITAL ACTION VERSUS NATURE-ACTION AS EXPRESSED IN ARCHITECTURAL PLANS AND IN PHYLOGENY}

Phylogeny-Architectural Values as Expressed in Main Lines and Collateral Lines of Evolution-Architectural Problems and the Increase of Power through Architectural Improvements-The Architecture of Inorganic Growth-The Architecture of Organic Growth-The Architecture of Plant Life-The Architecture of Animal Life-Unicellular Growth (Protozoa)-Multicellular G*owth-Radial Structural Plan (Coelenterates of Jellyfish)-Spiral Growth and False Radial Symmetry (Molluscs and Echinoderms).

No individual can contain within itself all the different instruments, or do all the different things, essential to a higher life. That is clearly shown by the evolution of plants and animals. Historically these two towering life-kingdoms have been upbuilt side by side on a united front. Each kingdom follows its own distinctive structural plans and uses its own distinctive materials, but both progress by common agencies, and both are everywhere strengthened by interlocking bonds of mutual services.

The same is true on a smaller scale within each kingdom, for at every level of their respective upbuilding, divergent outgrowths are formed of unlike architectural value. According to the nature of the materials utilized, the patterns they form, and the manner of assembling their materials, these varied genetic growths 
may form the minor parts, the wings and flying buttresses, of social life, or the walls on which the superstructures stand. For the better ways of construction must ultimately yield the larger returns; and, conversely, the actual products of a particular constructive method must be a measure of its constructive rightness.

\section{Phylogeny}

Using this basic principle as our guide, we may recognize two chief kinds of evolution: (I) the great phylogenetic trunk lines which lead more or less directly upward from the lowest to the highest achievements in the plant and animal world; and (2) the numerous collateral lines, or side branches, with their countless ramifications which end in organisms on a similar, or lower structural level.

In the evolution of animal life, with which we are here particularly concerned, it is not always easy to distinguish these collateral lines from the main line of evolution. But it is very important that we should be able to do so, for the ways and means of progress utilized by the different classes of animals will have for us the utmost scientific and moral value. They alone can tell us why or how, the greater constructive powers attained by man and his predecessors have been achieved, and how we may best utilize that knowledge for our future guidance.

We have elsewhere ${ }^{1}$ discussed this problem in a technical way; we shall here briefly discuss some of its broader aspects.

'See "The Evolution of the Vertebrates and Their Kin." 


\section{I9o GRAND STRATEGY OF EVOLUTION}

\section{Architectural Values as Expressed in Main Lines and Collateral Lines of Evolution}

Under the term collateral evolution are included all the multitudinous bypaths of creation; the groping, exploring, trial-processes which arise as divergent offshoots from the main lines of evolution and lead through branching and narrowing paths into the wilderness of created things. Each major offshoot represents the automatic working out, under the influence of various external environments, of some particular internal condition. In the organic world it is the resolution of some particular plan of internal organization into a suite of different kinds of plants or animals, each individual being the combined result of minor variations in its own constituent parts and in those of its environment.

The various conditions which may arise, and be expressed in organic structures, are due to two fundamentally different sets of causes, namely: (a) to the internal conditions created in a definite sequence as a result of growth, or the accumulation of newly formed parts; and (b) to the slower, more widely diffused cosmic and social changes arising outside of the organism, whose influence on organic structures is fleeting, or general, and whose specific local effects may appear only after a prolonged period of action.

The march of events in the internal and external domains of life takes place, therefore, under very different influences and at very different rates, and they may have widely different constructive values.

Each offshoot, or phylum, may resolve itself, in the 
course of ages, into classes, orders, and families, and some of them, it may be, into a great number of species, or varieties, which differ among themselves in minor details of size, form, and color, or in their mode of action. But even when subjected to widely different external environments, for many millions of years, the basic structural plans, the modes of growth, and the vital processes peculiar to the larger classes never change. Hence it is clear that material constitution and a rchitectural plans may have great stability and far more influence in determining the character of lineal descendants than any events likely to take place in the world external to them.

All these side branches to the great tree of evolution, these divergent types of structure and modes of growth, with many of which nature has been experimenting since the very earliest recorded periods, have either ended in defeat, or are doomed to defeat, in the sense that they are themselves forever excluded from attaining the highest phases of organic development; although they may serve and have served as constructive agents, or as subsidiary aids, to a higher evolution along other lines.

Some leads have been fruitful, as the octopus, the ant, and the bee. For a while, their progress in structural and psychic evolution was rapid and promising, but they soon reached the fulness of their possibilities, and their further progress now appears to be definitely limited. The different types of structure represented respectively by the oyster, the snail, the worm, and by other less familiar forms, began their periods of trial many millions of years before the first fish-like verte- 


\section{I92 GRAND STRATEGY OF EVOLUTION}

brates appeared, yet they and all their descendants are still moving in essentially the same cycles of growth and reproduction, and on the same low level of vital organization, as before, while the descendants of the tribe of arachnids, and fishes, out of like environments of seas and shores, have soared into man.

The tunicates, the sea-urchin, and the sea-lily are still leading a semi-vegetative existence, doing essentially the same kind of things, with essentially the same kind of organs, in much the same kind of surroundings, that they did many millions of years ago, standing examples of organic defeat through too successful stability. Still other types of organization have long since ceased to exist. Their dead frames are living evidence that "that way madness lies," for extinction is nature's "reductio ad absurdum" to all upright enterprises.

Failure of individual life to make sustained progress is due, therefore, to some defect, or failure, in internal organization. With further growth, these defects are revealed; the weaker bonds are severed; cooperation fails, or service "o'erleaps itself and falls on the other."

Nature's highways and byways are strewn with the wreckage of dead, stalled, or stranded enterprises that have been checked, or defeated, through failure to meet some one of the fundamental demands of a sustaining unity. We may not be able to detect the flaws in methods, or materials, nor for our present purpose is it incumbent upon us to do so, for the specific enterprise which reveals no measurable progress on the clock of ages sufficiently testifies to its own defeat. Destruc- 
tion may not immediately follow error, or the failure to attain these larger ends. The sentence, so to speak, may be suspended, and a term of probation allowed under the restrictions entailed by the error, till a new sphere of usefulness is found.

In many cases, however, the sources of failure-are patent enough. It is the old story of little victories big with defeat. Stories of over-service, or misdirected service, or service that excludes cooperation, or will not combine to give more service. Of unbalanced. growths that clog the channels of conveyance and shut out the access of service. Armor of overgrown spine and coat of mail that no longer support or protect, but imprison, or crush to earth, or suffocate. Weapons of overgrown tooth and nail, of hoof and claw, and horn and spear, that no longer rightly strike, but compromise with vain threats and useless lowerings, and culminate, at last, in monstrous self-destroying burdens. Service sinking to servitude, and acquisition to rapacity, destroying both the master and the slave, the robber and his prey. Cooperation swerving into competition, and friendship into enmity, those fruitless cycles of unending struggle between the pursuer and pursued, seeker and hider, aggressor and defender; that have no outlet but mutual destruction, or a deadlock of perpetual reprisal. Over-stability that stagnates in immobility, and over-freedom that rots in license.

These types of organization were doomed to defeat at the very outset of their career, for their methods of cooperation were economically unsound, and incapable of sustained progress. Their possibilities were soon blockaded, or exhausted, resulting in endless repe- 


\section{I94 GRAND STRATEGY OF EVOLUTION}

tition; in labyrinthine meanderings through a maze of shifting, short-lived opportunities; in vain flutterings against a dead wall of circumstance. They never have found the open road to progress, and if youth, after untold millions of years and opportunities, could not find the way through, over, under, or around, it is not likely that old age will be able to do so; for organic evolution stiffens with age; it never can shake off its past, nor change its initial structure and manner of doing things. It is, therefore, life's cooperative response to the outer world through the medium of its own specific architecture, not the architecture of the external world, that primarily determines the duration and efficiency of organic life. Cosmic environment, from the earlier phases of organic evolution, has been practically stable and broadly permissive for all kinds of life, provided life could find the right ways to use it. But the economic, or social environment has greatly increased in complexity as a result of the increasing numbers and internal development of individual life. Hence all living things must first conform to the demands of their cosmic environment, next to the demands of their own internal structure, and ultimately to the demands of their social environment. But social environment is more plastic, its demands are less imperative, more yielding, and more readily avoided than those of the other two. Hence all the older structural types have survived great social changes; few could survive a considerable change in internal organization; and no form of life could survive a radical change in its cosmic environments, such as heat, light, oxygen. diameter of earth, etc. 
III. Architectural Problems, and the Increase of Power Through Architectural Improvements

The instruments of animal life are of special significance to us because through them man has acquired his own distinctive powers. We shall therefore endeavor to show in this and the following chapters: (I) how man's distinctive powers have been upbuilt by means of his organic instruments. (2) Wherein the power of those instruments is permanently limited. (3) How science has added to them a new order of physical instruments. (4) How these new physical instruments have opened up to man's constructive usage an inexhaustible source of world power, thereby creating with unparalleled rapidity a wholly new phase of world life.

The basic invention of animal life, as we have already indicated, was one which gave to it greater freedom of movement and the power of profitable response to the activities of a larger world. To that end, the chief bodily instruments of animal life are discriminating receivers and conveyors. That is to say, they are specialized sense organs, such as smell, touch, taste, seeing, and hearing, so constructed that they respond to particular agents of the outer world, and to no others; connecting nerves to convey the impulses so received to their respective terminals; and muscles and other organs which, on receipt of these impulses, in turn act in such a way as to assist in the conveyance of requisite materials to and from the bodily sources of supply and demand; and also to assist in the conveyance of the whole body (locomotion) toward what is good and 


\section{I96 GRAND STRATEGY OF EVOLUTION}

profitable for it, and away from what is evil, or destructive to it.

The evolution, or enlargement, of this neuro-muscular mechanism of animal life cannot take place, however, without a corresponding increase in all those other instruments which minister to them, such as the supporting, protecting, alimentary, respiratory, circulatory, and excretory organs. Provisions must further be made for a sinking fund, or for organs of reproduction, by means of which the whole system may be rebuilt when the old one has become too rigid, or has exhausted its power of profitable adjustment.

The basic problem in the evolution of animal architecture, therefore, is to find a method, or plan, of growth and repair which may be continued indefinitely. That plan must provide the maximum number of different bodily sites, or locations, for the necessary organs, and at the same time permit unlimited alterations and improvements in the position and size of these organs, as occasion may favor or demand. All this must be accomplished without serious interruption of vital processes, and must always yield a sufficient margin of profits to be invested in new adventures and new construction. As we shall presently show there is but one method of growth, the triaxial system, which meets all these requirements. That system is utilized throughout The Great Highway of Organic Evolution which leads from the lower forms of animal life up to man.

\section{The Architecture of Inorganic Growth}

There are many different methods of growth in inorganic, as well as in organic, or living things. We 
will briefly consider some of those more pertinent to our discussion. Many inorganic things, crystals, for example, grow by accretion, or by the addition of successive layers, rows, or chains, of similar molecules to a relatively fixed outer surface, like the addition of bricks in regular sequence to a wall. The resultant form of the wall, or the crystal-whether or no it be flat, rod-like, polygonal, or spherical-will depend, among other things, on the initial form of the structural elements, the points and angles of their placement, and the degree of their stability.

A physical body like a sun, or a planet, may grow in volume, mass, and diversity, by capturing, in its movements through space, other cosmic bodies, or particles, which then become the architectural elements of itself. They may form relatively fixed parts on its outer surface, or they may be digested by chemical and physical agencies, distributed by circulatory movements, and their elements finally rearranged in graded, concentric layers, according to their respective attributes, the developmental stage of the celestial body, and the cosmic environment in which it is growing.

These so-called "dead bodies" and all their constituent parts are held to their orbits, or in their respective places, by overpowering, interlocking forces, both within and without. The very conditions which give them their peculiar architectural stability, prohibit their labile organization, or at least prevent the profitable usage of their own powers as in an animal or plant.

Thus a crystal may grow in size by accretion, or by the superficial addition of other individualities to itself, cnly when other powers outside itself bring the 


\section{I98 GRAND STRATEGY OF EVOLUTION}

right constructive materials to it, or overcome its stability and compel it to move into right constructive environments. Even then its growth does not measurably alter, or disturb, in any essential respect, its previous structure, or action; nor can the crystal utilize its own increase of power better to orient itself to its outer world and to move into a more saving and self-constructive environment.

But, so far as science can now determine, this difference between the methods of growth, or in the selfconstructive power of "living things" and "dead things" is not in the presence or absence of any particular materials, or quality, but in their architecture; that is in the formal ways their elemental powers are organized; for all the nature-powers science can recognize, or identify, are apparently universal and interchangeable.

\section{The Architecture of Organic Growth}

In all living things the new and the old are continually coming and going, or shifting their relative positions. In the inmost recesses of living protoplasm, the older structures are not merely eroded and new chemical elements added to the eroded surfaces, but new corpuscles, or atoms and molecules, interpolate themselves, by intussusception, between the old, either taking the places of those removed, or crowding those that remain into new places. The process of intussusception is like the removal and addition of the members of a family, or fraternity, or the inhabitants of a city, or nation. The same methods of internal readjustment, removal, or repair also prevail among the 
larger structural units of the living body, such as cells, blood vessels, nerves, and other organs, except that these changes take place more slowly. They are comparable to the rearrangement of streets, service pipes, and houses, which is constantly going on in a developing city.

Thus one of the basic attributes of living things, as distinct from dead things, is their relatively greater freedom of self-constructive action, their more labile, purposeful organization. The constituents of a living organism are free to move about among themselves, and the organism itself, such as an animal, a family, or a tribe, may move from place to place on its own power, subject to definite restrictions; but the internal method of organization, and the constitution of the system, which alone can give this freedom of action must and does remain relatively stable.

But a living plant, or animal, like a village, city, or nation, never grows at the same rates at different times, or in all its different parts to the same degree, because all their constituent parts have a distinct individuality of their own. By virtue of that individuality, growth always takes place faster in some places, or in some directions, or in some qualities, than in others.

A village may grow into a city in many different ways. But in whatever manner it may grow, its industrial and other vital centres, however conveniently they may have been located and cooperatively balanced in the beginning, will become unbalanced and very inconveniently located with the growth of these various centres, or with the mere increase of popula- 


\section{GRAND STRATEGY OF EVOLUTION}

tion. If readjustments in the ways and means of conveyance are rightly made to meet these new conditions, growth may safely continue indefinitely; if not, it will be automatically checked by unbalanced, or inequitable exchange, or something may "yield of itself," or break, or some more general catastrophe may occur.

A village, for example, may grow in length along both sides of a common road, in single storied houses. Or, as the population increases, it may expand right and left, by the more or less regular addition of successive cross streets with their supplementary lines and channels of conveyance; or up and down, by the successive additions of deeper cellars and successive stories. The relative rate and direction of growth will thus determine the shape and structure of the city as a whole, and the distribution of its chief lines of conveyance; or it will determine, as we say, the architectural plan of the city and the way in which its vital services respond to the demands of growth.

But the older the city, and the more firmly its method of growth is established, let us say along radial, parallel, zigzag, or vertical lines, or if built of stone in place of wood, the more difficult or dangerous it will be to make radical changes in it. Although the more imperative readjustments and improvements may be made at subsequent periods, the original materials and methods of growth, and the location of its great civic centres will long remain, affecting the economy of its life in varying degrees; a permanent check, or an invitation to further growth; a serious handicap, or a potential source of profit, as the case may be.

So it is with the growth of all living organisms. 


\section{The Architecture of Plant Life}

Beauty in architecture is the manifest rightness in the ways and means of accomplishment in the face of adversity. Nowhere in nature is this structural beauty so apparent to the casual observer as in a growing plant or flower. Its very existence, every àspect and attitude of form and color, the inmost texture of leaf, and stem, and root, and branch, is the triumphant expression of a fundamental rightness of being; of a successful resistance to the stress of nature-action, and a right usage of nature-action in self-construction.

In its architecture and well-being is sharply displayed that dual sovereignty to which we have already referred; that is, the existence, in the plant itself, of a definite vital purpose, so far successfully accomplished, and the existence, in its outer world, of a lawful, compelling action to which it must submit. It is this beauty of a triumphant vitality, so clearly expressed in the stability, economy, and utility of every growing thing, that man is forever trying to express in his own architecture.

Thus the housings of mankind, when rightly built, display in the position, shape, dimensions, and durability of their walls, roofs, doors, windows, chambers, and passage ways, the vital, sovereign purpose of their inhabitants, as well as the sovereign action of gravity, heat, light, wind and rain; the sources from which they come; the directions in which they act; man's usage of them and his defense against them. Man's life and art is beautiful only so far as it manifests this rightness of usage and defense. More or less than that is ugliness. 


\section{GRAND STRATEGY OF EVOLUTION}

It is not our purpose to discuss the various architectural plans utilized by plant life. Their ways and means of growth are comparatively uniform and bear less directly on our problems than those of animals. It will be sufficient to indicate, in one example, how their achievements, as individuals, are definitely limited by their initial constitution, the sources of their profits, and the methods they must use to gain them.

The more highly organized plants, for example, have been compelled to adopt a distinctly dual, or double ended system of growth, one set of organs in the soil, a different set in the light and air. Thereby special administrative difficulties are incurred in the. conveyance and exchange of their respective products, the receipt of their supplies and the storage of their surplus.

The roots must build their defensive lines against the poverty, and the varied texture of the soil, and draw from the soil its nourishment. The leaves must spread their receptive fabrics to the sun and air, and construct, or seek, their own defense against them. To these ends, the plant makes large usage of its own dead and waste materials, and preserves them within itself for support and transportation.

All these exigencies of the plant's inner life and outer world place definite limitations on its powers of growth, that cannot be exceeded without disaster. The weight and area of leaf and branch cannot exceed the sustaining power of stem and soil; nor can the excursions of the roots and leaves in search of profit exceed the limits of profitable exchange between them.

The rightness of its living, the degree of its free- 
dom, the usage of it, and the ways in which it meets the demands of the outer world, and the limitations laid

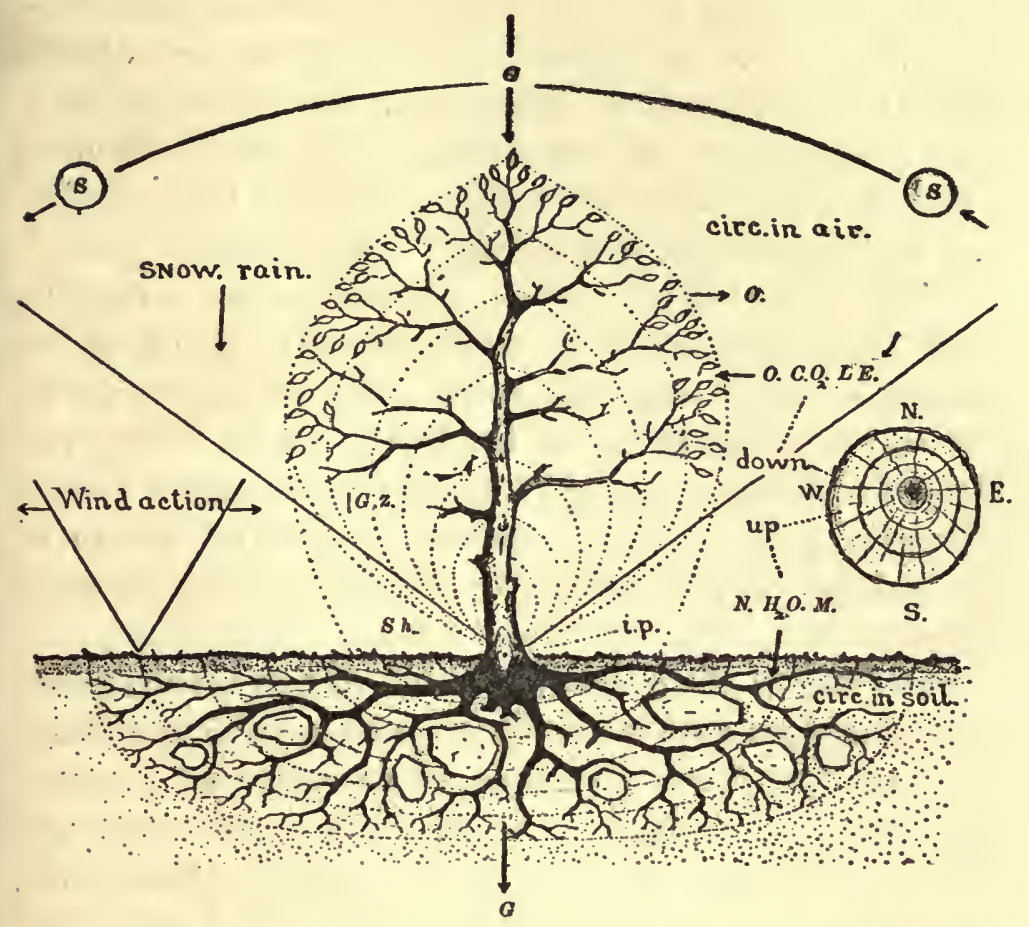

Figure 2. Diagram to Illustrate How the Architecture of a Plant (supposed to be located in the northern hemisphere) Is THE Formal ExPression of a DUal Action SYSTEM, one internal, the other external. It is intended to show that the thing we recognize as a growing tree is the tangible expression of a profitable differential exchange between rootlets at one extreme, leaves at the other, each located in a different circulating medium, air and soil. The chief actors are the sun, air, weather, and gravity, on the one hand, and on the other the new conditions successively created by the progress of growth from an initial point, such as shading, imprisonment, support, and the necessary extension of the lines of exchange. The chief compelling and limiting factors are indicated, their lines of action, and the conformity, or orientation, of the whole vital action system to them. Social factors are not indicated.

upon it by its own over-shadowing growth, is, and must be, displayed in all its architecture, if we could but see it and read it rightly. See diagram, fig. 2. 


\section{GRAND STRATEGY OF EVOLUTION}

\section{The Architecture of Animal Life}

Animal structure is exceedingly complex and difficult to visualize without long experience and familiarity with it; nevertheless, so far as it is accessible, it affords us the most tangible record of vital achievement and the best measurement of its progress.

The progress of life, for example, is more convincingly shown in the structure of an amœba, jelly-fish, worm, crab, fish, mammal, and man, than it is by their actions, methods of living, or in their manifestation of intelligence, because in all living things the basic purposes and functions of life are the same, growth and self-preservation. We cannot picture, or measure, naked acts, or purposes, or intelligence. But physical structures may tell us how far acts are constructive, and to what extent purposes have been accomplished; and the ways and means of their accomplishment must always be expressed in terms of structure.

\section{Unicellular Growth (Protozoa)}

The simplest form of animal life is a single cell, a tiny speck of cooperating proteids, and other substances. With little apparent distinctions of parts and organs, it performs all the essential acts of animal life, such as moving, feeding, growing, respiring, excreting, reproducing, and dying. Now stirred by the passing incidents of riotous surroundings; now driven in rhythmic cycles by waxing and waning heat or light, and atomic migrations. Or swirling air, or water, sweep it here and there; bringing the vital agencies of the world to its very doors, or conveying it to the world's commodi- 
ties; penetrating its inmost recess, cleansing and healing its secret fabric.

All the chief architectural forms and structures possible to a one-celled life have doubtless been realized; and apparently the best that nature can do within such limits is shown by the minute, unicellular organisms called Protozoa. Wherein lie all those limitations which prohibit their individual increase in volume, in organization, and vital power, we may only surmise, and need not argue here; but the existence of those limitations we may not question.

\section{Multicellular Growth}

One of the great innovations in the methods of animal life was the union, or the cohesion, of the offspring of parent cells to form social aggregates, or multicellular organisms. This simple innovation opened up a new world of possibilities, produced a larger unit of life, and gave rise to a new order of animal life on a much higher level of organization than before. The very act of union took something away from the old freedom of the cell; restricted its power of individual action, and conferred upon it new powers, and a new freedom common to all. The groups of cells thus formed had common interests, common dangers, and a common external environment. A new stability was acquired through action and reaction in unison; new powers were gained through sub-division of labor, and by greater economy in the performance of vital processes.

Every further increase in the number of cells created a more and more particular and exacting environ- 


\section{GRAND STRATEGY OF EVOLUTION}

ment for its members as regards contact, pressure, distribution of materials, and the nature of the stimuli received from within and without.

Such cells acquire, therefore, a more constant, or fixed, relation to one another, and definite physical and chemical conditions are established in and about them, which henceforth determine many of the things they may or may not do, and what they must do. Hence cells, which may be potentially alike, when separated, must become an organized society of different kinds of cells, if united. Otherwise they must disband, or never could have united.

\section{Radial Structural Plan (Coelenterates, or Jelly-fish)}

If we assume that a certain group of cells is growing in a homogeneous medium, or environment, and that the increase in numbers is approximately equal in the three planes of space, spherical bodies will be formed, in which unlike conditions for cell life appear along concentric rings and radii, in accordance with the geometric properties of spherical bodies. As a result of these local conditions, special kinds of cells should arise locally, such as muscles, nerves, and sense organs, arranged in more or less regular geometric patterns, fig. 3. And this actually does take place in all the coelenterates (jelly-fish); and something similar to it in the corresponding stage of growth in all the higher organisms (gastrulation and germ layers, ectoderm, mesoderm, entoderm).

But a symmetrical sphere, if it is ever formed, does not persist. The aggregate always presents some 
asymmetrical modifications, or unlike poles, oral and aboral, and with peculiar zonal and radial growths. Some phases of these bodily specializations are doubtless correlated with the peculiarities of special environments, or modes of life, and above all with the fact that the external environment, as a whole, is never

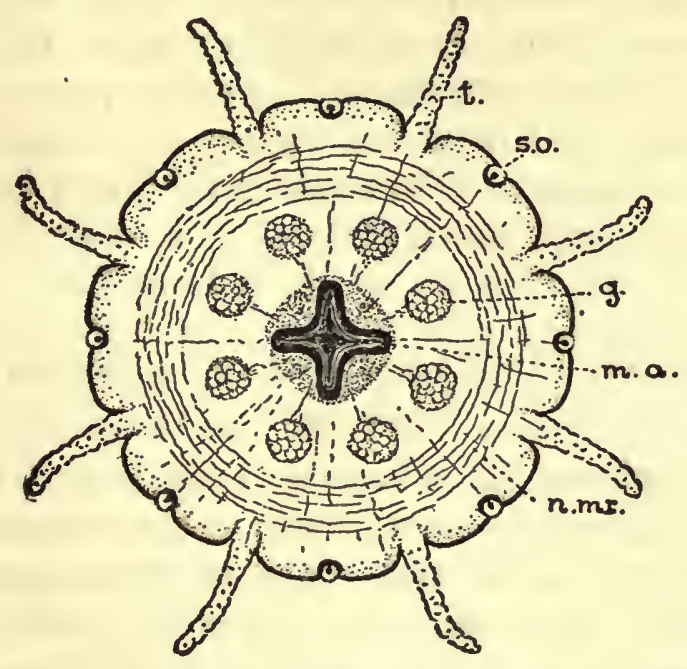

Figure 3. Diagram of the Radial Architectural Plan (Coelenterate, or jelly-fish, $t$, tentacle; s.o., sense organ (eye or ear); $g$, germ cells; m.a., common opening for mouth and anus; n.m.r., neuro-muscular ring.

either homogeneous or symmetrical. It has a permanent asymmetry and a gradient differentiation of its own, in four important respects: (I) as regards the lines of gravity; (2) the source of light; (3) the rotation of the earth on its axis, and (4) the marked difference between its underlying and overlying media, or solid earth below and atmosphere above, with their consequent effects on circulation and diffusion.

These asymmetrical, gradient constants of the outer world are the same ones which play such an impor- 


\section{GRAND STRATEGY OF EVOLUTION}

tant part in the architecture of plant life, fig. 2, but animal life makes different usage of them.

In any case, the jelly-fish, and all others of their class (at one time the super-animals of the organic world) are upbuilt on this so-called radial plan, with a common central opening for intake and discharge, and with multiple structural elements appearing according to definite laws along radial lines, like spokes to a wheel, or in circumferential lines and zones, like the hoops and staves to a barrel.

Thousands of species of jelly-fish have been produced, differing among themselves in a great variety of minor ways, but all of them have this relatively simple organization, and still have their organs arranged on this radial and concentric zone plan.

It is highly significant that whilst the radial type of multi-cellular growth was among the very first to appear, and was evolved many millions of years ago, it has never produced any known animal, retaining this plan of structure and method of growth, more highly organized than a polyp, or colony of polyps. This certainly cannot be due to lack of time, nor environment, nor opportunity, for in a very much shorter time, and in much the same kinds of external environments, all the higher forms of animal life, such as crabs, molluscs, fishes, and mammals, have been evolved.

While the mere association of cells is a wonderfully creative process, it is clear that there must be some inherent conditions in the radial method of growth which prohibit the attainment of the higher possibilities of life; and that all the agencies of time, environment, natural selection, and heredity have been powerless against them. 
Some of these inherent obstacles to progress are manifestly of a purely physical or economic character: ( $\mathrm{I}$ ) the presence of a common alimentary entrance and exit which creates confusion and prevents uninterrupted linear streaming, serial treatment, and graded distribution of alimentary materials; (2) the lack of internal diversity, due to the fact that in a typical radiate, or in a truly spherical body, there is the maximum volume relative to surface, and the minimum diversity in internal relations. Every point on the same circumference is potentially like every other point on it, and for every point on a given radius there is a homologous point, under like conditions, on every other radius; (3) spherical bodies offer excessive resistance to locomotion and internal exchange; and (4) a radial arrangement of receptors and affectors is not capable of a highly discriminating response to the agencies of the outer world.

With growth and increased demands, these disabilities increase so that, ultimately, equitable conveyance, to meet all the varied requirements of supply and demand, becomes impossible.

\section{Spiral Growth and False Radial Symmetry}

If this radially symmetrical system, for any reason, becomes structurally unbalanced, it may lead to some form of spiral growth, which cannot again attain a balanced symmetry, except the ends unite in the same plane to form a ring. This may, in effect, then give rise to a false, or secondary, radial type with the same disabilities as before.

Spiral growth is common in the great class of mol- 


\section{IO GRAND STRATEGY OF EVOLUTION}

luscs; and false radial symmetry is peculiar to the great class of echinoderms, fig. 4 .

These two methods, as well as the pure radial type, inevitably lead to serious mechanical difficulties in vital

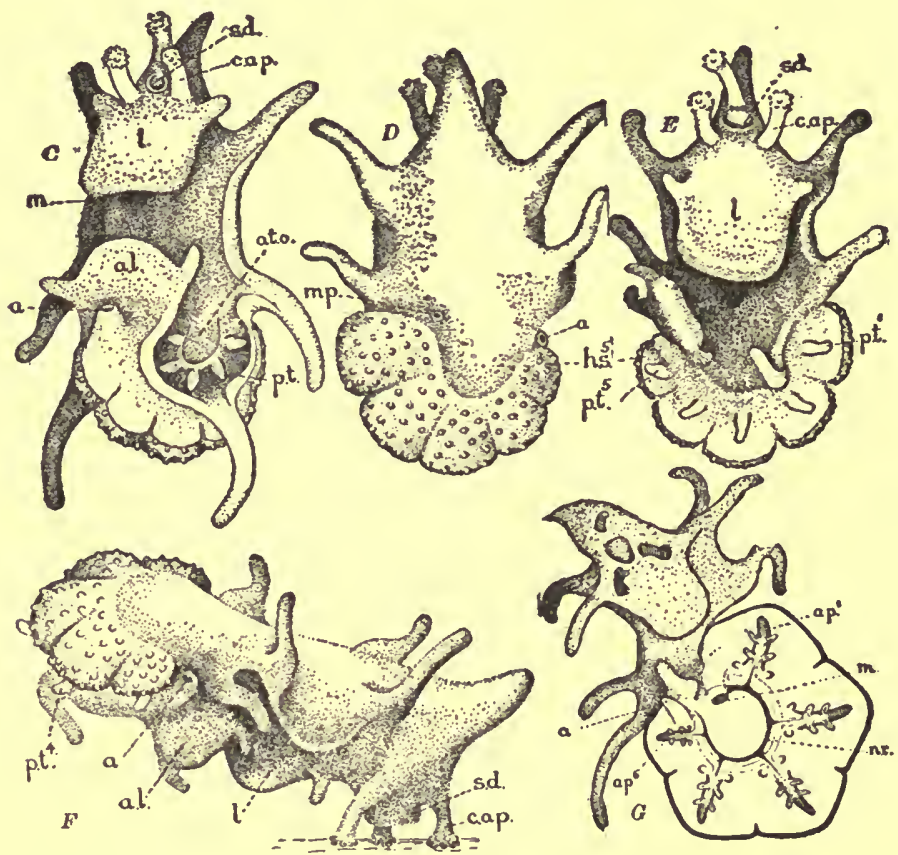

Figure 4. Diagram of the Metamorphosis of a Star-fish Larva, to illustrate unequal bilateral growth and the conversion of an initial bilateral symmetry into spiral symmetry and ultimately into the false radial sym. metry characteristic of the echinoderms.

administration, and it is not surprising that, in spite of their immense antiquity, these three great classes of animals remain on a low level of organization, forever handicapped by their constructive methods and materials. ${ }^{1}$

"See "The Evolution of the Vertebrates and Their Kin." 


\section{THE TRIAXIAL SYSTEM AND THE GREAT HIGHWAY OF ANIMAL EVOLUTION}

The Triaxial System of Structural and Functional Gradients-Its Methods of Internal Readjustment and Betterment-The Material and Functional Register of Vital Betterments: the Old Mouth and the New; Gills, Lungs, and Heart; the Blood; the Nervous System -The Decline of Metamerism and the Centralization of Functions-Architectural Tropism, or the Orientation of Triaxial Organic Gradients to the Triaxial System of Gradient Action in the Outer World: the Asymmetry of the Outer World; the Orientation of Triaxial Vital Architecture to World Architecture; Tropic Action; Triaxial Architecture as a Tropic Reaction System and as a Product of Tropic Action-Other Registers of Constructive Action, Instincts, Intelligence, Cultural Implements-Cultural Registers.

IN "The Evolution of the Vertebrates and Their Kin," we have shown that man is the culminating product of a long genetic line called The Great Highway of Animal Evolution. It emerges from the coelenterate stock, probably as a special modification of the radial mode of growth, and in successive adaptive increments leads by way of the more primitive arthropods, such as the phyllopod crustacea and marine arachnids, up to the ostracoderms (a wholly extinct class of animals forming a paleozoic connecting link between the invertebrates and the vertebrates) through them to the fishes, amphibia, reptiles, and mammals, to man, where it culminates in its logical constructive limitation, figs. 7 and 8 .

Throughout this great phylogenetic line, there is a common architectural plan and a consistent method 


\section{I2 GRAND STRATEGY OF EVOLUTION}

of differential growth, which we call the system of triaxial gradient increment, or briefly the triaxial system. The progress of this growth system, in its main outlines, may be followed historically through the great geological eras where each notable organic increment is coincident with, or has its returns in, the appearance of a new class of animals, and a new measure of vital freedom.

And today, in the embryos of all the higher animals belonging to this system, we may see how they rapidly retrace the same self-constructive ways, and repeat, one by one, in due order, the main architectural innovations which were chiefly characteristic of their ancestral classes.

It is evident that a growth system which can consistently produce such results as these must contain within itself some constructive principle of great significance, not found elsewhere in the organic or inorganic world.

In this chapter, we shall discuss this method of growth and try to point out wherein this constructive principle lies.

\section{The Triaxial System of Structural and Functional} Gradients

A constructive vital system, to attain the maximum results, must be able to meet the increasing demands of its own growth as they arise, and at the same time keep in profitable conformity with the permanent demands of the outer world.

These demands from within and from without are voiceless, it is true, but they are forever insistent, and they must be fulfilled, if the system is to endure. 
There is apparently but one way to meet these basic demands and thus overcome those narrower constructive limitations so characteristic of the inferior types of vital organization. That way is the triaxial (or apico-quadrilateral) system of growth.

In this constructive system, as in the other systems we have considered, growth begins by the successive divisions of an initial cell, or ovum; but the multicellular body thus produced always grows unequally in the three planes of space, producing a more or less cylindrical body with six unlike sides, progressively upbuilt on three right-angled, gradient axes.

The two opposing ends and four opposing sides are radically different in structure and function, and become respectively head end and tail end, right and left, neural and hæmal sides. These basic architectural and functional distinctions never change, and they can be easily identified in all animals of this structural type, down to the lowest invertebrates, to their earliest embryonic stages, and in some cases to the egg itself, figs. 5 and 6.

This architectural system meets the basic demands of growth in ways that no other conceivable system can do, more particularly in the following respects: ( $\mathrm{I}$ ) It may be permanently and profitably oriented to the three great systems of world action in which it lives; first and foremost, to gravity, the one universal, direct acting constant in the world at large; to light, second only to gravity in its straight line action and the constancy of its source, even though the angles of incidence may vary, and the flow be intermittent; and finally to the great terrestrial, tangential planes in which are variously distributed, or move in horizontal directions, 


\section{I4 GRAND STRATEGY OF EVOLUTION}

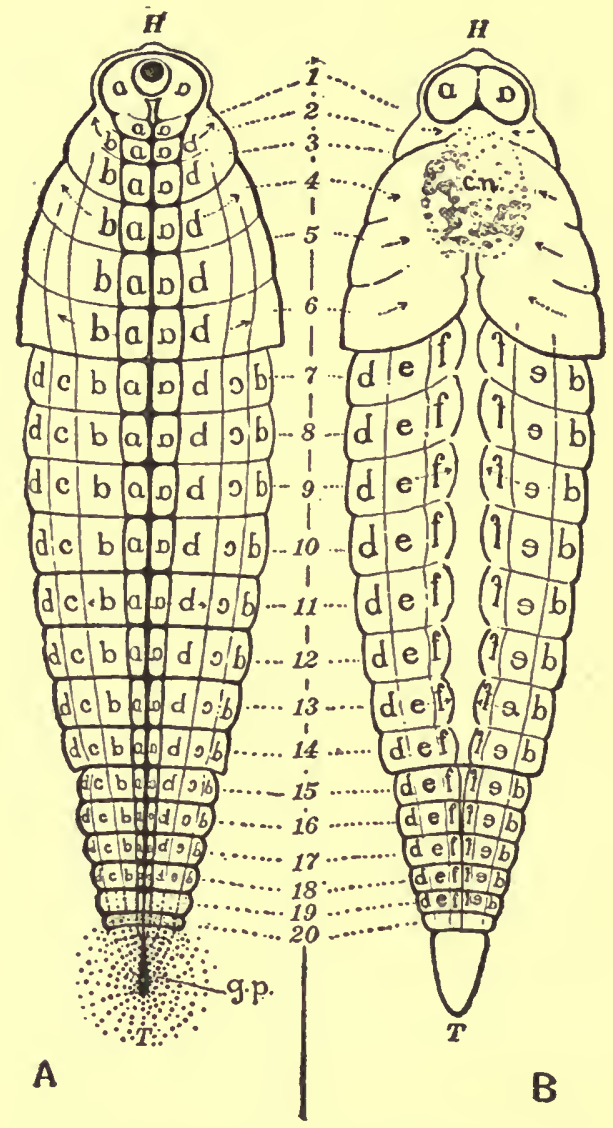

Figure 5. Diagram to Illustrate Triaxial Growth. $A$. seen from the neural side, $B$, from the haemal. The metameres formed at the growing point. g. p., (blastopore, teloblasts, telopore) a re indicated by numbers: Growth to right and left of the median neural line is indicated by arrows; serial homology and bilateral symmetry, by letters, those on one side being the mirror image of those on the other. Cephalization, or the specialization and breaking down of metamerism at the head end, has already begun. The figure is based on the arachnid type of triaxial growth.

the chief sources of life's constructive supplies, and the chief sources of danger. (2) It provides maximum economy in the grouping of all the great organic systems of conveyance and support, such as nervous, ali- 


\section{HIGHWAY OF ANIMAL EVOLUTION 215}
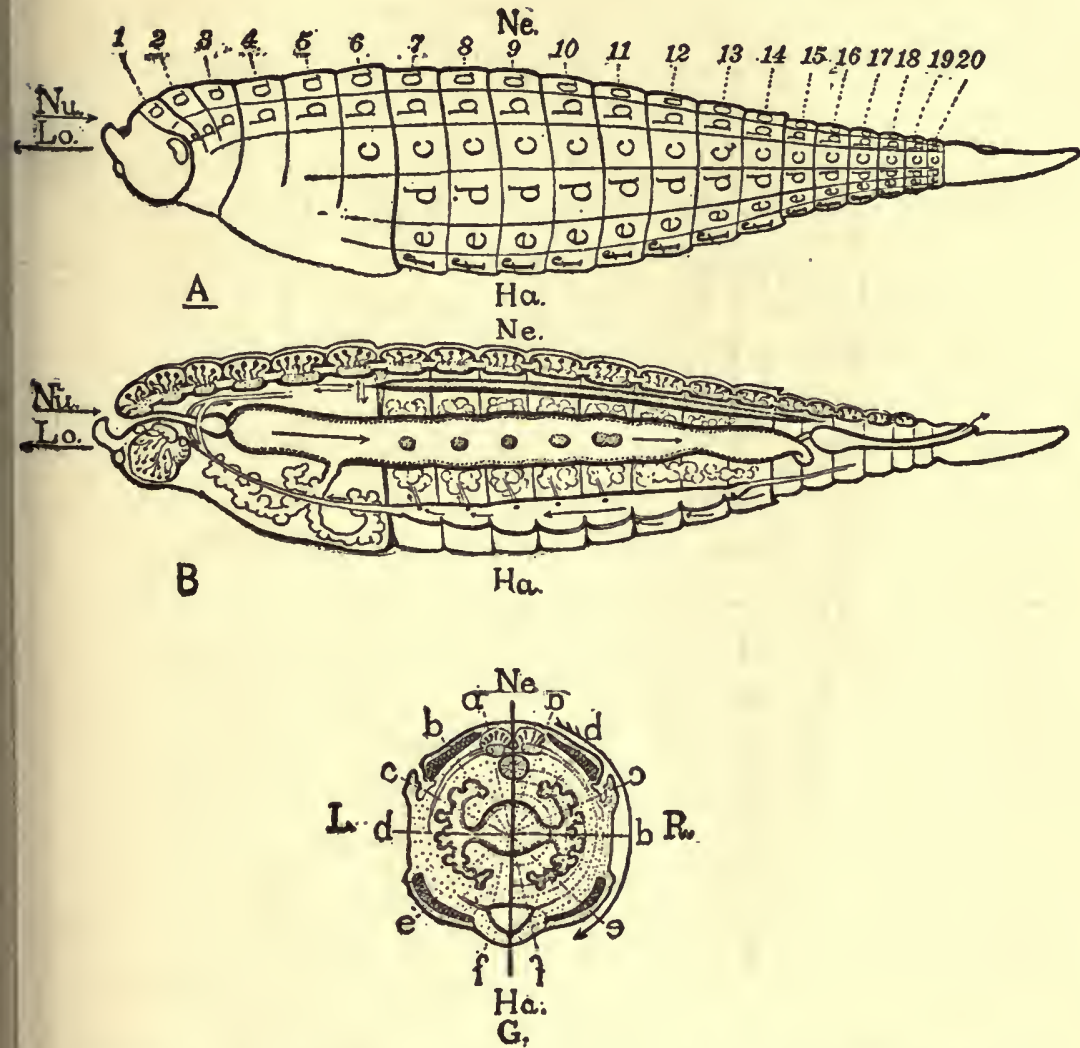

Figure 6. Diagram of Triaxial Growth. $A$, from side; $B$, in median longitudinal section; $C$, in cross section in the region of the ninth metamere. Letters and numbers as in fig. 4. Arrows indicate main lines of conveyance, locomotor, vascular, alimentary, and nervous. In $B$, the chief systems of medianly located organs are indicated, showing their linear arrangement. In $C$, bilateral symmetry, the lines of concentric growth, and the relation to gravity are indicated. Note the repetition of metameric organs in the middle region of the body and the decline of metamerism on the haemal surface at either end. The figures are based on the arachnid type of growth.

mentary, vascular, excretory, muscular, and skeletal. (3) Maximum economy of locomotion. (4) Maximum internal diversity. (5) Maximum opportunity for increase in volume without loss of these attributes, or serious detriment to them. (6) Maximum opportu- 


\section{I6 GRAND STRATEGY OF EVOLUTION}

nity for readjustments and repairs without serious interruption to life.

In general, the body, in animals of this type, is more or less cylindrical, larger toward the head, and tapering toward a growing point at the tail end. It is divided transversely into a series of similar compart. ments, or segments, or metameres, each of which may contain a complete set of all the more important vital organs, unless, it may be, some of them have been locally suppressed by secondary changes. These organs, such as eyes, legs, muscle-blocks, and kidneys, or nephridia, appear in pairs, one member on the right side of the metamere, the other in a corresponding position on the left, figs. 5-8.

In typical cases, the paired organs of various kind: extend in graded, linear series over the whole body, $a$. at least over very considerable portions of it. Th: members of a given series are often referred to as identical, or homologous organs, serially arranged.

The alimentary canal, for the reception, consecutive treatment, and distribution of food materials, runs lengthwise through the middle of the body; the mouth, or the entrance to the canal, at the head end; the exit, or anus, at the tail end.

Along one surface of the body is formed the double chain of ganglia and nerve fibres, or the brain and spinal cord, a.a. which constitutes the chief architectural landmark in animal morphology, and serves to identify this surface, as the so-called neural surface, whatever position, in reference to gravity, the body may assume in active life. From the pair of ganglia in each metamere are given off, right and left, the pairs of 
nerves which supply the various parts and organs within that metamere.

On the opposite, or hæmal side of the body, running parallel with the alimentary canal and spinal cord, is the great vascular distributing canal, or primitive heart tube. Its paired blood vessels, with the paired nerves, form approximately parallel, hoop-like, conducting channels around the alimentary canal between it and the outer surface of the body.

We recognize in this type of animals, a wholly new architectural unit; the metamere, each one approximately complete in itself. The whole body primarily consists of a chain of similar metameres, organically united, each link in the chain subject to the local conditions of its bodily position, and ultimately expressing them in the varying development of its component parts.

While growth may take place at any point in this system, the system is chiefly remarkable for the fact that organs around the head end are the first to be formed; and each new metamere makes its appearance as a distinct entity at the tail end, just behind the one previously formed. No basic alteration of this order of precedence is known to occur.

Hence the body always consists of a graded, linear series of metameres, in one, two, three, order. Whether there be two or three, or several score, the one nearer the head end is the older, the one behind it, the younger; and each metamere retains its serial identity throughout life.

On the other hand, the neural axis is always more precocious than the hæmal, so that differential growth 


\section{I8 GRAND STRATEGY OF EVOLUTION}

in each metamere proceeds in a, b, c, d, order, to the right and left of the median neural axis, the older stages being nearest the median line, the youngest, farthest away, or nearest to the hæmal surface; see diagram (figs. 5 and 6). Thus with growth in volume, there is a longitudinal, gradient increment from head to tail; transverse gradient increments to the right and left of the neural axis towards the opposite hæmal side; and a radial gradient increment from the centre to the periphery. Hence the name, triaxial gradient increment.

It is evident that no two points in such a growing system can ever be alike, either in their historical, or spacial relations; or in their functional conditions; or in their potentialities. For every cross section will display a condition a little younger than that in front of it, and a little older than that behind it; and in every cross section the lines drawn from a central point to all the peripheral points will be divided into two mirror-image sets, right and left; each set forming a graded series of radial lines extending from the neural to the hæmal side, and each line representing a series of points at graded distances from the centre of the body, or from any object in the outside world, fig. 6. $C$.

We may regard this triaxial system, if we choose, as a system of points, graded in their potentialities, in accordance with the geometric properties of that system and in accordance with their functional relations to a permanent asymmetry in the outer world. In the living body, these potentialities are expressed in architectural details arranged in right and left longitudinal series, in right and left transverse series, and in overlying concentric strata. Hand in hand with these dis- 
tinctive local structures and conditions, necessarily go distinctive local functions.

Thus the features which distinguish this system from all others are: (I) the multiplication of similar, but not identical sets of organs in longitudinal and in transverse series (metamerism); (2) The formation of concentric strata and intervening spaces around a central axis (germ layers and coelomic cavities); and (3) the extension of the three great systems of conveyance throughout the body, parallel with the main axis of growth, the alimentary in the middle, the nervous system on one side, the vascular on the opposite one, with various other organs arranged in symmetrical pairs on the right and left. A more perfect system for differential functioning is inconceivable, for all agents, contents, or commodities of each system are inevitably subject to gradational treatment, selection, or distribution, along each one of the infinite number of gradient lines in the system, no two of which are alike.

As growth proceeds, it is always possible to modify or improve cooperative action by local increase, or diminution, at such points as the increasing exigencies of supply and demand may call for.

It should be noted that on the basic necessity of this point for point correspondence in different individual organisms having similar architectural plans, rests the whole science of morphology and physiology, making it possible for us to "identify" corresponding structures and functions in different kinds of individuals, and at different periods of their development. 


\section{GRAND STRATEGY OF EVOLUTION}

\section{Its Methods of Internal Readjustment and Betterment}

In this system of growth, as well as in every other, the vital problems of a large body cannot be solved in the same ways as those of a small body. Hence growth cannot go on unless concurrent local readjustments and betterments are made within the sytsem to meet the new conditions created by its own growth. The criterion of the rightness of these readjustments is their creative returns. Here, as elsewhere, in accordance with the universal constructive law, those organs which better cooperate with one another, or serve one another, and thereby the whole, the longer endure and grow so much the more; those which do less than that, diminish, or give way to other organs more happily situated on their respective gradients.

To the morphologist, or to the student of animal architecture, the evolution of the great arthropod-vertebrate stock, where this method of growth and organic readjustment prevails, is therefore the age-long history of more or less intermittent increments in bodily volume and organic power due to the successive addition of new groups of metameres at the posterior end of the body; the local rise, decline, or combination of metameres; the localization of certain functions and organs, or the apparent transfer of them from one position in the body to another; the up-building of new and the down-breaking of old partitions, and the consequent opening, closing, diverting, dividing, or enlargement of the channels of exchange:

Whenever these local readjustments are of exceptional cooperative value, just as in commercial or po- 
litical affairs, sudden eruptions of growth ensue, accompanied by still other readjustments which necessarily follow in their train; and great classes, orders, or families of animals may arise therefrom, differing among themselves in countless details, but all of them upbuilt on some particular modification of this basic architectural plan.

In some of the lower forms of bilateral animals (clams, oysters, and certain worms) the entire body may consist of but a single metamere, and although, in some instances, such animals may become very voluminous, no one-compartment animal, highly organized, or with great freedom of movement, has ever made its appearance.

There are also certain worm-like animals (annelids) whose body may consist of a long array of metameres, all very much alike, and each one supplied with a complete set of the more essential vital organs, such as eyes, legs, kidneys, germ-cells, ganglia, etc. No animal of this kind ever attained a high grade of organic efficiency, no doubt because of the very multiplicity of parts doing essentially the same things, and because one part either does not, or is unable efficiently to serve the other.

On the other hand, in the long series of animals which lead more directly up to man, figs. 7,8 , the body may consist of from two or three metameres to a hundred or more; but with each addition, there is generally a marked local diversity of parts in the older, more cephalic ones, and better centralization of organic services. To follow these changes, even in the barest outline, one must make a careful comparative study of the anatomy, physiology, and paleontology of all those 


\section{GRAND STRATECM OF EVOLUTION}

Figure 7. Diagrams, Correlated with the Grological Time Table, illustrating the growth of the triaxial system of gradient functions. The chief architectural innovations are indicated as they successively appear in the different classes of animals which probably form the more direct ancestral stock of the higher vertebrates, these innovations attaining their logical conclusion in man.

The main events indicated are: $(\mathrm{I})$ the rise and decline of metamerism, or the increase in the number of metameres successively developed at the tail end, their increasing destinction in the middle region of the body (arachnids) and their gradual break down, or fusion with one another, toward the head end and haemal side; (2) cephalization, or the concentration of a large number of bodily metameres, about $15-20$, to form the "head" in the higher classes $(y . y . \& z . z$.$) ; and (3) the coincident centrali-$ zation and redistribution of the great systems of bodily functions. Note the persistent reduction in the number of metameric organs performing similar functions, or their combination into a single system, and their shift of position to more fitting locations with the general increase in growth. The chief functions centralized toward the head end are the nervous and sensory ones (gustatory, visual, auditory, and olfactory). The locomotor, $L$, excretory, $e x$, and sexual, centralize at the opposite end; and the respiratory, $R$, digestive, $D$, and circulatory, $C$, toward the centre of the body. The assumed duration of geological time is indicated in ratios of million year periods, $M$. 


\section{HIGHWAY OF ANIMAL EVOLUTION}

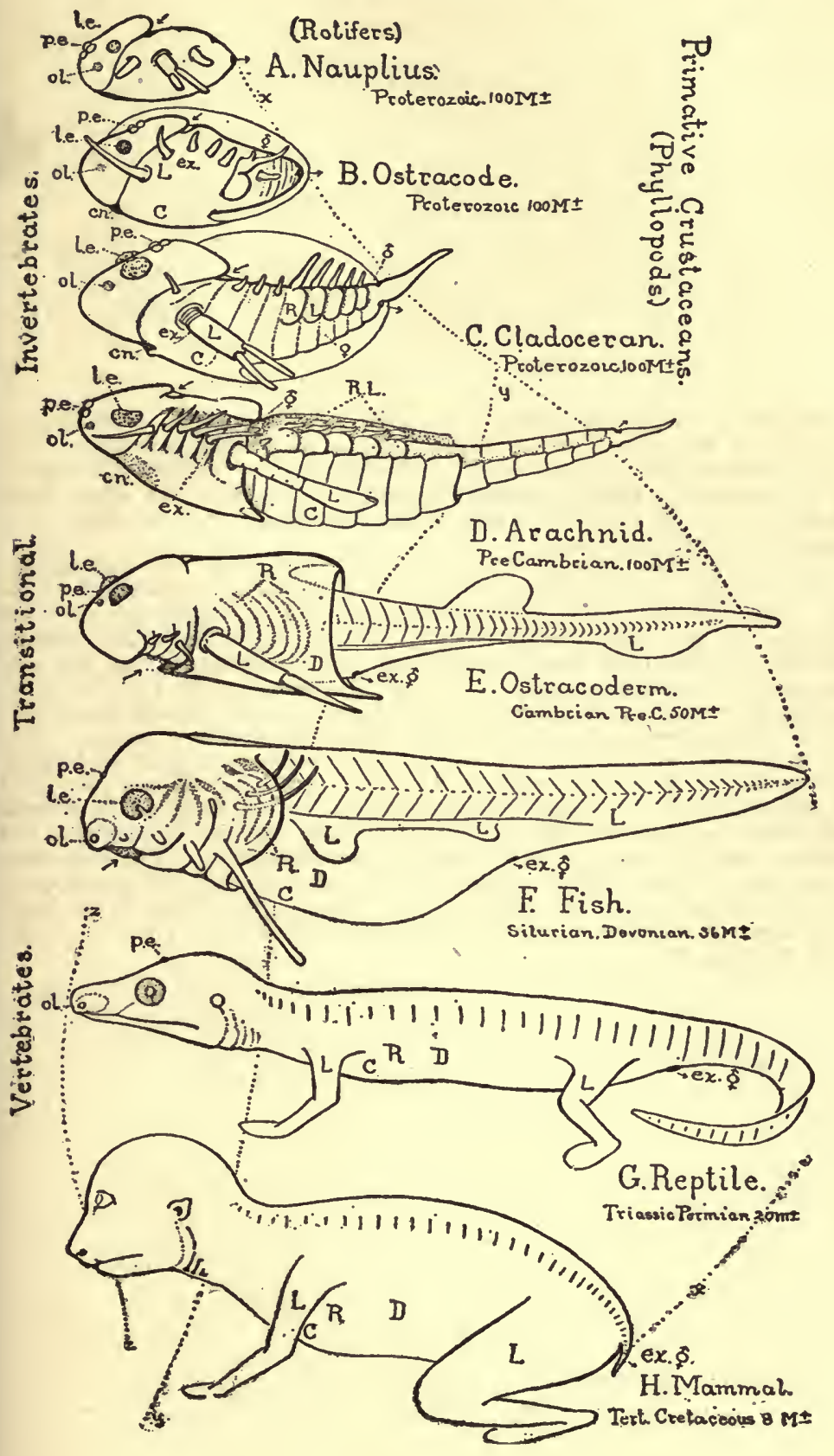




\section{GRAND STRATEGY OF EVOLUTION}

Figure 8. The Same as Figure 7, seen in Median Section. The chief events indicated are: $(x)$ the closing of the old gateway to the gut and the opening of a new one in the region of the cephalic navel, c.n.; (2) the infolding of respiratory appendages of the phyllopod to form arachnid gill sacs, or lung-books; their rupture into the alimentary canal in fishes, their subsequent atrophy and finally the substitution of lungs to take their place; (3) the origin of the chief ductless glands, the pituitary body from the remnants of the old oesophagus, and from an ancient excretory organ, $p t^{2}, p t^{2}$; the pineal gland from the median eye, p.e., and the thyroid gland, th, from a segmental outgrowth of the alimentary canal; (4) the metanorphosis of the primitive heart tube into the four chambered heart; (s) the metamorphosis of three pairs of arthropod appendages into the mandibles, maxillae, and pre-maxillae of vertebrates; (6) the rise of the notochord, nch, neural arches, n.a., and cartilagenous cranium, $c r$, in the arachnids, and their further growth into the vertebrate column and skull of vertebrates; $(7)$ the rise of excretory and genital organs and their ducts in the anterior end of the body and their successive transfer toward the posterior end; (8) the establishment of the main divisions of the brain in the phyllopods and their persistent growth into the characteristic subdivisions of the brain in the higher vertebrates. 


\section{HIGHWAY OF ANIMAL EVOLUTION 225}

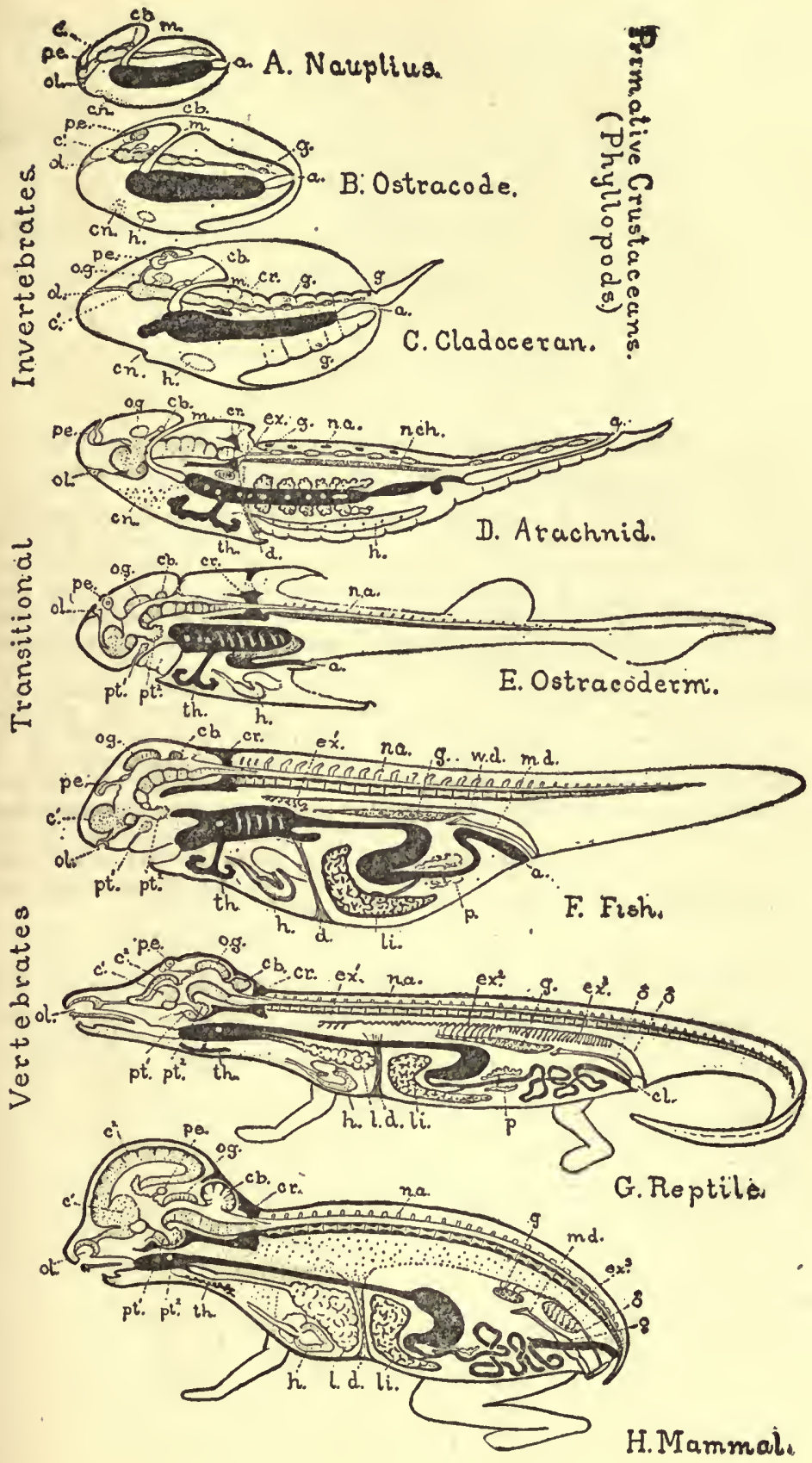




\section{GRAND STRATEGY OF EVOLUTION}

classes of animals which constitute this great trunk line of organic evolution.

The structural gaps which here and there divide this long genetic series into classes, phylla, or orders, generally represent relatively rapid organic improvement in some particular which has quickly gained a new stability and yielded large returns in minor variations of it.

For this reason we seek in vain to bridge them, especially the more creative ones, with the same degree of completeness we do elsewhere, for these gaps are probably real ones, accentuated by perspective, not necessarily fortuitous gaps in our records, or in our knowledge.

These forward movements are rarely due to the formation of new chemical substances, or to the acquisition of essentially new powers by individual cells, for the fundamental properties of life are very much alike in all cell communities, high or low, large or small.

Sense cells and nerve cells, for example, may not be appreciably more delicate in their individual responses, or essentially different in their modes of action, in the higher classes of animals than in the lower; and there is apparently little difference in the actual processes of digestion, in the making of new living materials, or in the production of bodily movements through the agency of muscle, and nerve, and sense organ. On the other hand, improvements in the social life of cells, due to their cooperative organization, may be very great indeed, and they afford the biologist the most striking evidences of progress. 
III. The Material and Functional Register of Vital Betterments

A few examples will serve to illustrate some of the different ways in which these organic readjustments are actually made, the creative results which spring from them, and the ways in which they are registered.

I. The Old Mouth and the New. The closing of the old invertebrate mouth and the formation in the vertebrates of a new one to take its place is a case in point, fig. 8 .

In the arachnids, the stomodæum, or the oral end of the gut, passes through the nervous system, between the right and left roots of the forebrain. In the vertebrates, it always lies outside the nervous system, and wholly in front of the forebrain. What has doubtless happened is this. In the immediate ancestors of the yertebrates, the old mouth became practically useless, owing to certain cumulative growth factors, and a new one was formed out of an ancient, but transitory, entrance to the alimentary canal, which originally served a wholly different function. Many subsidiary factors were involved in the event, and we can still see some of them in actual operation in modern arachnids. For example, the progressive constriction of the œsophagus, by the growth of the surrounding brain, ultimately compels all those with relatively larger brains to suck their food in liquid form through the narrowest possible opening, or give up eating altogether. This clearly indicates that in this class of animals further enlargement of these two vital functions has reached a mechanical impasse. On the other hand, this now wholly useless oral opening still survives in 


\section{GRAND STRATEGY OF EVOLUTION}

all modern vertebrates, including man, as an otherwise meaningless passage-way through the floor of the brain (infundibulum and saccus vasculosus), a permanent register, in its proper place, of this great creative event. $p t^{1}$ and $p t^{2}$.

It is evident that immediate and far-reaching results are contingent on an open or shut factor of this nature. It is not surprising, therefore, that the ultimate shutting up of this passage-way should be coincident with the onset of a great organic reformation, and the abrupt appearance of a new class of animals, such as the fish-like vertebrates. But it had still further creative significance, for without this closing up of what had come to be a very inconvenient gateway to the gut, the growth of the brain, as we see it in the higher vertebrates and in man, would have been a physical impossibility. ${ }^{1}$

2. Gills, Lungs, and Heart. The rupture of gill chambers into the alimentary canal was another similar event, of immediate and far-reaching importance in the evolution of fishes; and it still dominates their internal economy, as well as that of the embryonic stages in all their more modern descendants.

But the gills of fishes, so long as they are retained in their characteristic form and place, are an insuperable barrier to further evolution. Their position is fundamentally wrong, from a mechanical standpoint, both in relation to the heart and the alimentary canal, and seriously restricts their further functional dev 21 opment. For the delicate respiratory capillaries of the gills are directly, and dangerously, interposed between Kin."

"For furthes details see "The Evolution of the Vertebrates and Their 
the heart, which supplies the driving power for the circulation of the blood, and the main arterial channels which supply the body. On the other hand, the respiratory currents of water, entering the mouth and passing out through the necessarily large gill clefts, seriously interfere with the passage of foods through the mouth to the stomach, and with the usage of this part of the alimentary canal for digestive purposes.

But when new and larger blood channels were opened up, leading into the air bladder, a new respiratory organ, the lungs, was established in a safer and better functional position. Lungs were then substituted for gills; a double circulation for a single one; and the heart and the general arterial system thereby acquired greatly increased powers of service. This relatively simple readjustment in the direction of the blood current which, with other accompanying changes, made it possible separately to regulate the blood pressure in the lungs, and in that of the general arterial system, was of great functional importance. It is the chief cooperative event which marks the transition from fishes to the amphibia and reptiles; and the register of this change is still preserved in the embryos of all their descendants. But its effects did not stop there; it also opened the way for a terrestrial, airbreathing life, and for the hot, even-tempered blood of the higher vertebrates. The subsequent changes in the direction and volume of the blood currents, and the influence of the new mode of impact on the walls, valves, and openings of the heart, were doubtless important physical agencies in completing the four chambered heart which came later, making it possible to deliver the rich supply of arterial blood directly to 


\section{GRAND STRATEGY OF EVOLUTION}

the head, an essential condition to the growth and nutrition of the brain in man and in the higher vertebrates.

When we consider this sequence of events and conditions in the evolution of the vertebrate heart, as revealed to us by comparative anatomy and embryology; observing in it the structural changes which follow one another in due and logical order, as though in response to physical forces; when we consider the gradual rise of chambers and valves, inlets and outlets, mechanically correct in form and place for their specific services; and the correlated rise and decline of gills, the growth of lungs, and many other organs, who shall say that we are not at the same time passing in review the very cooperative agencies which bring them about, if we only had the sense to discern them.

How futile then it is, and essentially unscientific in spirit, to ignore such factors because they are structural, or merely morphological, or phylogenetic; and to assume, as some apparently do, that it is simpler, or easier, to explain them by the far-away god "vitality" or "heredity," or by counting the beads on a rosary of chromosomes!

3. The Blood. Blood is one of the most important vital agencies of conveyance. Its constructive, or creative, power is dependent not only on the arrangement of its conducting channels, their nervous, muscular, and physical attributes, but on what the blood itself contains, its rate of movement, and its volume, the direction in which it flows, and the way it ultimately affects the life of the various kinds of cells it serves. Here the improvements in service are not expressed in such obvious architectural features, but 
rather in chemical and physical changes and in many remote functional adaptations, the result of which is obvious enough, but the contributory agencies exceedingly difficult, or impossible, to locate, or analyze.

Briefly, and speaking in very broad terms, one of the first great improvements affecting the social life of the cell was in limiting the free access of sea water to the interior of the cell community, using in its stead a very similar chemical fluid, as a vehicle for its products.

At first this forerunner of true blood was driven aimlessly to and fro through irregular body cavities by spasmodic bodily contractions. After a long period of evolution, this service was performed by a rhythmically contractile tube, or primitive heart, which drove the blood in definite circulatory movements through specially constructed channels leading to and from definite stations.

A common system of internal transportation was thereby established, which supplied each cell with nourishment from a common store and removed its waste materials. These obvious improvements in the circulatory system, with many others, finally delivered these primitive animals from the limitations of the sea and made life in inland waters, on land and in the air, a possibility, and ultimately a reality.

During other periods of evolution, covering many millions of years, counthess other improvements from time to time were made, to meet the increasing demands of the growing body. New kinds of blood cells, chemical agents, and organized bodies of the most varied and subtle character were contributed by different bodily organs to the basic fluids of the blood, mak- 


\section{GRAND STRATEGY OF EVOLUTION}

ing the blood itself a veritable physical and chemical laboratory.

Finally the common blood stream was divided qualitatively into venous, lymphatic, and other special carriers; old stations of give and take were cut off and others provided with increased facilities. And with all these betterments in service, the pressure, the local rate of flow, the nutritive contents, and the temperature of the blood were at last so artfully regulated as to provide for each one of the countless millions of bodily cells, according to their individual necessities, the optimum conditions, apparently, for the performance of their functions.

Many of these improvements were purely mechanical devices, gross architectural readjustments of purely material things, yet they are no more, or less, significant in their constructive rightness, than the less tangible nervous and biochemical devices, or the altogether intangible "vital" ones.

It was through the agency of all these achievements in internal conveyance, and many other contributory services of a similar character, that the higher phases of life, as we see it in birds and mammals, became a possibility and then a reality; a life capable of the most sustained, strenuous, and varied activities; one that had freed itself from the dominion of the sea and shore, and was now freed from the dominion of the tropics, and of the changing seasons; for at last life had created within itself an approximately right environment for its constituents, and the freedom of the earth and the air was opened to them.

4. The Nervous System. In the long history of the arthropod-vertebrate stock, there has been a per- 
sistent improvement in the two great systems of conveyance, vascular and nervous, which is very impressive; but the material, or anatomical, evidences of these improvements are very different. In one case, it is very largely a visible increase in the relative volume of the nervous system and the number of nerve units; in the other, the rise of a multitude of striking architectural, mechanical and chemical devices.

That is to say, the evolution of nervous conveyance, of reflexes, instincts, and intelligence, is not evidenced so much by striking architectural changes in the brain itself, as by the steady increase in the number of those particular coordinating cells which unite all the other systems into one, and which facilitate and supplement their cooperative actions. This in itself is a very significant fact, and stands out in sharp contrast with the evolutionary history of all other functions. For every other system has its own formal, or material register of progress, chiefly in its anatomical structure. The nervous system alone is a material register of the cooperative actions of all the other systems.

Hence the increase in volume of the cerebral hemispheres, where these coordinating cells are chiefly located, gives us a single tangible measurement of the evolution of organic cooperation and constructive rightness. For the hemispheres represent, like any other representative body, the functioning of the whole organism. Their more special function is to discrimievil, and to direct and regulate the services of each nate between what is good for the whole, and what is part in the best interests of all.

The cerebral hemispheres are the chief intermediaries between the administration of the inner and of 


\section{GRAND STRATEGY OF EVOLUTION}

the outer life, and their mere increase in volume, whatever may be the cause of that increment, rather than the arrangement, or the architecture of individual cells, most easily and surely measures the march of organic cooperation from class to class, throughout the whole gamut of animal evolution, fig. 8 .

It is not surprising, therefore, that the great difference between man and the anthropoid apes is not so easily measurable in terms of vital energy, bodily form, keenness of sense, or the efficiency of any one organic function, as it is in purposeful directive power, and in the volume of nervous material in which that directive power is registered.

That directive power, in cooperation with the wholly different powers of tongue, and eye, and ear, and hand, derived from a multitude of wholly different organic sources, is the chief creative agency of social institutions.

IV. The Decline of Metamerism and the Centralization of Functions

We have selected these special cases to illustrate the ways and means of organic progress in the arthropod-vertebrate stock. Any of the other vital functions, protective, excretory, sensory, or locomotor, might have been used for this purpose, and would have shown the same mingling of mechanical, chemical, and "vital" innovations.

But while, for the sake of convenience, the improvements in a single system may be considered separately, it must not be overlooked that each bodily system is wholly dependent on, and influenced by, all the others. 
In fact, in any forward step in evolution, it is hardly possible for the biologist to determine which is cause and which is effect. We are rarely, if ever, able to decide whether improvements in any one system of functions precede or follow those in the others. The

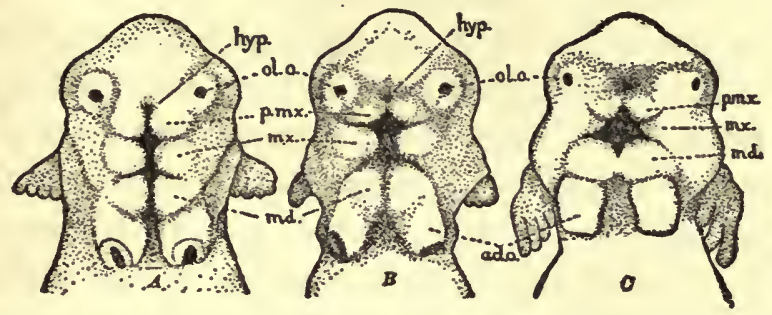

FIGURE 9. FACE OF AN EMBRYo FroG, showing the three pairs of primitive jaws derived from their invertebrate ancestors, and their union to form the jaws typical of the vertebrates. (From Patten, Evolution of the Vertebrates and Their Kin.)

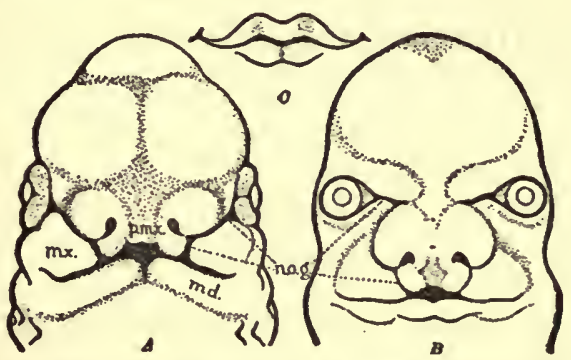

Figure 10. Figures Illuustrating the Mode of Growth of the Human FACE. $A$, human embryo, a little more than a month old, showing the traces of invertebrate jaws in the mandibular, m.d., maxillary, m.x., and premaxillary, p.mx., arches. $B$, embryo a little less than two months old, with the preceding parts nearly united. $C$, mouth of adult, the cupid bow contours showing its elemental structure. From Patten, A Problem in Evolution, Pop. Science, 1913.

very dependence of one on the other makes their respective changes appear to be coincident. But we cannot doubt that whenever any improvement in the service of one part takes place it demands and receives some compensating service elsewhere. 


\section{GRAND STRATEGY OF EVOLUTION}

When we survey the evolutionary process as a whole, we see all along this great genetic line the expression of these demands; and we see their ultimate fulfilment expressed in: (I) a consistent increase in bodily volume; (2) in centralized organic power, and (3) in a self-constructive adjustability to the more varied and subtle agencies of the outer world. It is not difficult to recognize those cases where considerable attainment has been made in some one of these three respects, but without corresponding attainment in one, or both, of the other two.

Measured by these three standards, no other animal can compare with man in perfection of bodily organization. And it is very doubtful whether the physical and chemical properties of protoplasm, under the prevailing terrestrial conditions, would to advantage permit the further evolution of a physical body notably different from what is generally regarded as the ideal man.

In the concurrent race between mere growth in volume and better organization, the general tendency is to produce more like metameres at one end of the body, only to be progressively specialized by the diverse conditions towards the other end, where special demands are made for service, and better returns are given for service rendered.

In accordance with this developmental law of supply and demand, the principal sense organs and the main centres for nerve control grew up at the oldest anterior end, rightly clustered around the main entrance to the body; and the three longitudinal systems of conveyance became more firmly established in their respective positions. As the body grew in volume, the 
heart, locomotor, respiratory, sexual, excretory, and digestive organs became greatly altered in relative size and relative position, and all of them gradually withdrew from their primitive centres of activity in the head, leaving that important region almost exclusively to the receptive functions and to the main centres of nerve control. Some of them, such as the heart, lungs, and locomotor organs, centralized their activities at such points as the services to be performed demanded; the kidneys, reproductive and other organs, where functional location is not so imperative, taking their positions at otherwise unoccupied regions of the body.

The general effect of all these organic readjustments was to transform the growing series of more or less independent metameres into a more unified body wherein each important function was performed by that one set, or pair of organs which was so situated as to give the maximum bodily service. It was like changing a long row of tenement houses into one residence, with centralized systems for the receipt, preparation, and distribution of common necessities.

The ultimate location of each centralized function is determined by various factors; chiefly by priority of origin, which in turn is determined by the necessity of prior activity in primitive or in embryonic life; by the imperative demands for a special location, in order rightly to perform its work; and by the universal organic law that the main lines of growth coincide with the most available channels of conveyance.

I have described these changes more specifically in "The Evolution of the Vertebrates and Their Kin." A careful consideration will show us that in man no further morphological or functional changes of this kind 


\section{GRAND STRATEGY OF EVOLUTION}

are possible, for this long series of organic adjustments has reached its logical conclusion.

It is evident, for example, that the chief segmental sense organs, such as the visual, auditory, and olfactory organs, cannot be reduced to less than a single pair, for a single pair, bilaterally symmetrical, as we shall presently show, is absolutely essential to the performance of their orienting functions. Nor can they be more centralized around a common point of intake, or in a position more suitable for head-first locomotion.

On the other hand, organs like the locomotor appendages, which in primitive invertebrates may be situated at the anterior end of the body, or arranged like many pairs of oar-like legs on either side, or as two pairs nearer the centre of the body, as in fishes, reptiles, birds, and mammals, cannot be advantageously reduced to less than a single pair, nor moved farther back than they are in man. The same is true of the excretory and reproductive organs. And finally the necessarily voluminous lungs, heart, liver, and digestive organs cannot be more centralized, or have their dead weight better placed, or balanced, for safety and economy of locomotion than they are at present.

I have tried to show the chief events in this rise and decline of metamerism in a series of diagrams, figs. 7 and 8 .

V. Architectural Tropism or the Orientation of Triaxial Organic Gradients to the Triaxial System of Gradient Action in the Outer $W$ orld

We have indicated in preceding sections some of the exceptional advantages which give triaxial growth its impressive aspect of constructive rightness. Or, other- 
wise stated: the utmost degree of organic evolution can be attained by the triaxial method of growth, and by no other; or, triaxial growth is the only way in which maximum organic development is possible.

But constructive rightness must have its external as well as internal aspect. That is, any architectural plan, to have superior constructive value, must conform in a superior way to the influences of the outer world from which all its constructive supplies are drawn.

The triaxial system fulfils both these basic requirements: (I) In its unequalled power of growth and progressive internal organization; (2) In that, architecturally and functionally, it is the only system which can be oriented in a profitable way, on the one hand, to the more constant, and on the other, to the more variable lines of gradient action in the outer world. Ultimately it does become so oriented.

More specifically, this architectural rightness is manifest: (I) In the coincidence of the axis of locomotion with the main axis of growth, and with the three longitudinal trunk lines of organic conveyance, nervous, alimentary, and vascular. (2) In the location of the chief directive receptors, such as the visual, chemotactic, and auditory organs, in single pairs centralized at the anterior end of the body; with the affectors, such as muscles, appendages, and other organs, arranged in graded linear series symmetrically paired, and apparently with definite functional connections, point for point, between these receptors and affectors. This functional connection is made by means of paired conductors (neurones, nerve fibres) extending longitudinally, as well as right to left and left to right, which 


\section{GRAND STRATEGY OF EVOLUTION}

offer graded resistance to the passage, or outlet, of nervous impulses.

I. The Asymmetry of the Outer World. Fully to appreciate the significance of this organic architectural system and the way it acts, we must know something of the architectural system of the outer world to which it must, and does, make a profitable response.

In the outer world of gradient action, all the actors are very unequally and asymmetrically distributed, not only in time, but in the three planes of space. Their ways and means of acting across time and space are very different; their directive influence, and their constructive power, of very unequal value. Hence, first of all, life must be permanently adjusted, or oriented, to the major directive influences in this outer world of action, and be free to respond to its minor, or more variable influences, good and evil, as they arise.

The most dominant and constant actors in the outer world are the sun and the earth; one chiefly acting on life by means of gravity, the other by means of light; both agencies are propagated practically instantaneously, and along essentially radial lines, or lines at right angles to the earth's surface. All the innumerable other actors, so far as life is concerned, are more variable in power and more intermittent in their action, and are distributed with great irregularity within the tangential terrestrial plane, between the solid earth and its more fluid envelopes. There they act either directly on life, as physical or material bodies in motion, such as circulating air and water with their transported contents; or as independently moving objects, such as other plants or animals; or they may act indirectly on life by means of individually transmitted vi- 
bratory action, or chemical emissions, such as sound, odors, color, etc. All these influences, in the main, are propagated in this horizontal plane, in north and south, east and west, or intermediate directions, at gradient rates and with gradient momentum.

2. The Orientation of Triaxial Vital Architecture to World Architecture. The definite orientation of the triaxial system to this world action system is seen in the stable relation of the neuro-hæmal axis to the two most constant directive agencies of the outer world, that is, to gravity, the more constant and dominant one, and in a lesser degree, to light, the less constant one.

While in the arthropods the normal, or functional, position of the body during locomotion is such that the neural side may be directed either upwards or downwards (depending largely on whether the animal is in a walking, or swimming, position) in the vertebrates, it is almost without exception directed upwards, or away from the earth's centre of gravity. In either case, the whole body is architecturally and functionally balanced, other things being equal, only when the neuro-hæmal axis is parallel with the lines of gravity. This force is universal; it casts no shadows, and all bodily actions are subject to its unvarying influence. Hence this architectural and functional orientation should be, and is, the most universal and stable of all morphological and physiological phenomena.

Light has less pronounced architectural influence on the body than gravity; for while light, in the main, comes on rectilinear paths from above, it is subject to many local and periodic variations, due to terrestrial motion, incidental reflection and refraction, and complete absorption. It is in the extraordinary variation 


\section{GRAND STRATEGY OF EVOLUTION}

in absorbtive area, in location, in fixation, and in movability of the visual organs, that a fitting architectural response to these more specific demands is chiefly manifest. Hence, when the body is in its normal position, whether its neural side is up or down, the windows of the body are generally turned toward the chief sources of light, or can be so turned, without rotating the body on its longitudinal axis. But while the dimensions, dioptric properties, and other attributes of the eyes may readily change in response to the demands of the

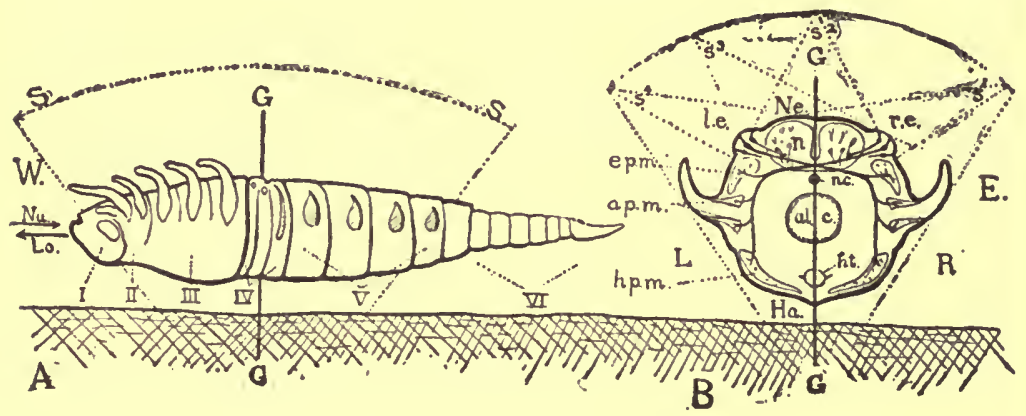

Figure i i. Diagram to Illustrate the Functional Orientation of the Balanced Triaxial System of Vital Architecture to the Unbalanced System of Nature Architecture. $A$, side view of an arachnid-like animal. $B$, cross section of the same in region III, but with the paired eyes of region I, and the paired trunk muscles of region V and VI projected onto the same plane. Both figures are structurally oriented to the dominant actors light, $S$, gravity $G$, and to the compass points of the great tangential plane with its irregularly distributed minor actors.

In $B$, the balanced effects of a luminous point at $s^{2}$, are indicated and the unbalanced effects when the point is shifted to $s^{1}, s^{3}$ and $s^{4} ;$ l.e., and r.e., right and left eyes; ap.m., paired appendicular muscles; ep.m., and $h p$, epaxial and hypaxial trunk muscles (myotomes.)

outer world, the inner ends of the optic nerves never change their relative points of attachment to the brain throughout the whole vertebrate and arthropod stock.

But when the neuro-hæmal axis is parallel with 


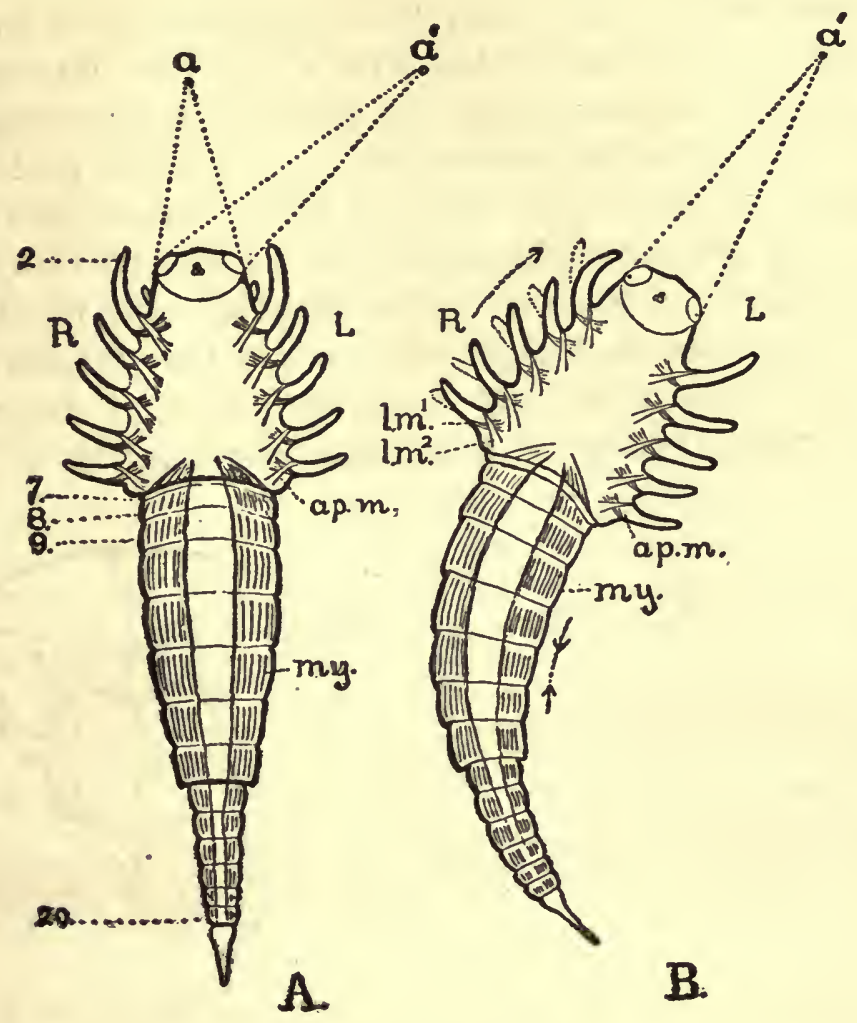

Figure 12. Diagrams of an Arachnid-like Animal seen from the HAEMAL SIDE, to illustrate the mechanism of reorientation in the triaxial system. In $A$, the balanced effects, right and left, of a luminous point at $a$, are indicated, and the unbalanced effects of a luminous point at $a^{\frac{1}{3}}$. In $B, a$ balanced condition is automatically reëstablished in relation to the point $a$, by the more vigorous action it has produced in the left appendicular muscles of the head region, and in the myotomes on the right side of the trunk and tail regions.

Note the difference in the action of the head and trunk muscles necessary to bring about this bodily reorientation to an asymmetrically placed stimulus.

the radial lines of gravitational action, as it normally is, all the paired receptors and affectors are then, and only then, rightly oriented to the great horizontal plane 


\section{GRAND STRATEGY OF EVOLUTION}

of life's terrestrial environment, whence radiate from countless individual centres, right and left, the intermittent influences of light, sound, and chemical emissions, to which life must for the moment adjust itself in order to live with them in profitable relations.

Owing to this gravitational orientation and to this symmetrical structure and arrangement of right and left receptors and affectors, balanced cooperative action, or rectilinear locomotion inevitably follows, other things being equal, so long as both right and left sides are subject, from without, to the same influences. But when that outward symmetry is disturbed, bodily reorientation, or various degrees of rebalancing action necessarily follow, such as swerving, or circus, movements to right and left, toward or away from the momentarily dominant actor.

A waltzing body, like a rifle bullet, might move faster, it is true, or straighter, or have greater stability, or greater power of penetration, but it could not keep its "eye on the ball" or on its objective, nor could the objective remain in that constant regulative touch with the living body, which is so essential to directive control.

Exactly mated pairs of organs, acting either against each other, or in unison, are in many other ways capa-. ble of the highest degree of cooperative action, an essential factor in their functioning being their right and left symmetry.

In many coelenterates, worms, and molluscs, where directive locomotion, or even any locomotion at all, is little in evidence, there may be an extraordinary number of visual organs (two hundred, or more, in some cases), either irregularly distributed over the 


\section{HIGHWAY OF ANIMAL EVOLUTION 245}

surface of the body, or located on radial axes. But if we bear in mind the necessary correlation between vision and precisely regulated locomotion, we can readily see why, with evolution, there has been a progressive reduction in the number of eyes, while an exact right and left symmetry in the one remaining pair is persistently retained. In exact locomotor reactions to light, it is apparently essential to establish a point for point correspondence, right and left, between the outer world and the internal system of response. This result can be obtained with one pair of symmetrical image forming visual organs, but not with several pairs, nor with asymmetrically, or radially, distributed organs (Fig. 3).

Thus when animals built on the triaxial plan are normally oriented to the outer world of action, the body, like a weather-vane, is always impaled on some one of the vertical lines of gravity; but it is relatively free to turn its face toward any actor on the horizon, and to move like an arrow, head-first into the winds of circumstance.

We can now, perhaps, see more clearly the necessary correlation between vital architectural plans and world architecture. For any animal built on this structural plan, in order to be in its most effective position for purposeful action, must have its two major axes of organization, neuro-hæmal, right and left, rightly oriented to the two major axes, radial and tangential, of terrestrial organization. We can also see that this triple polarization of the triaxial vital system is nothing more or less than the expression, in architectural terms, of a threefold qualification of life's freedom of movement (radial, tangential, and compass 


\section{GRAND STRATEGY OF EVOLUTION}

turning) and the definition of its field of opportunity for self-constructive action.

Here again, the dual sovereignty of life is expressed in its own architecture, and in that of the external world of action to which it responds, and in which it has its opportunities, and its limitations.

3. Tropic Action. Conduct often appears to be the expression solely of an internal sovereignty, acting independently of external conditions.

But the sovereignty of the external world is clearly seen under controlled experimental conditions, that is when a given organism is subject to one predominating influence, all others, so far as possible, being neutralized, removed, or duly accredited.

External sovereignty is then manifest in a definite vital response, commonly called a tropism, which may be immediately expressed in terms of motion, or locomotion, or less immediately in terms of growth. Many kinds of tropism are recognized, such as geotropism, heliotropism, chemotropism, etc.

By means of these prearranged experiments, the biologist seeks, as it were, to dissect the action of the environment, or to analyze the behavior of an animal, for much the same reasons, and in much the same ways, that the chemist seeks to analyze, quantitatively and qualitatively, a chemical compound; that is in order more clearly to reveal its constituent actors.

Under such specific conditions, vital structures may definitely orient themselves to what, for the time being, is the dominant line of external action; or the organism moves, or grows, in very different ways in 
respect to them. It may grow, for example, directly away from the earth's centre of gravity, like the stem of a plant; or towards it, like the roots; or, like many animals, it may move in straight lines, up, or down, the invisible lines of gravity; along a beam of light; or along a radiating line, or trail of chemical emission, or diffusion, etc., either toward, or away from its source. Or it may be made to swerve from a balanced attitude, or straight line action, one way or the other, in gradient response to gradient changes in direction, or relative intensity of the source, or sources, of influence.

These measurable vital responses to measurable external agencies are very convincing, and from them it would appear that behavior, or conduct, even in the most highly organized animals, is the resultant of many mingled external influences each acting in definite ways, on definite organic structures. And that is doubtless true. But we may not assume that conduct is merely the algebraic sum of certain constituent acts. We cannot measure conduct wholly in that way, any more than we can measure the action; or quality, or behavior, of water, as a world agent, by the acts of its separate chemical constituents.

There is a creative attribute in the cooperative operation of organic acts, as there is in the cooperative action of chemical elements. For that reason the experienced biologist, while he always welcomes the information which may come from the experimental dissection and analysis of animal behavior, does not cease to look on the living animal, on the one hand, as an organic unit having a special value of its own in its unity, 


\section{GRAND STRATEGY OF EVOLUTION}

and on the other, as a unit which is inseparable from the environment which created it and which it helps to create.

For every animal, like a bank, a college, or an automobile, is both a product and a producer of its time. As a created and creative agent, the constructive value, or quality, of each one of them is manifest only when all its parts are in cooperative action and when it is itself in action as a creative agent within the social environment which created it.

4. Triaxial Architecture as a Tropic Reaction System, and as a Product of Tropic Action. The most striking attribute of the triaxial system of growth, in contrast with all other organic systems, is its supreme structural fitness for the discriminating receipt of influences from the outer world, and for moving from place to place in profitable response to them.

Among the imperative requirements for this freedom of movement are: head-first locomotion, parallel both with the main axis of growth and with the three longitudinal systems of internal gradient treatment and distributions; a stable neuro-hæmal balance in respect to gravity; and a bilateral symmetry in reference to a changing asymmetry in its chief plane of action.

From a historic standpoint, the gradual evolution of this architectural system, which attains its logical culmination in man's bodily structure, may be regarded as a special form of tropic growth, or as a progressively adaptive response to the more insistent actors of the outer world. The constructive process includes both the agencies to that end and the products, for it derives its accumulating constructive profits from 
greater freedom of action, and greater freedom from more profitably responsive structures.

\section{Other Registers of Constructive Action; In- stincts, Intelligence, Cultural Implements}

In addition to the triaxial organization essential to this basic orientation and guidance, there must be some internal means of modifying, or reversing tropic action from positive to negative, and negative to positive, when a constructive stimulus is intensified to a point where it becomes painful, or injurious, or destructive, or where it has fulfilled its purpose, and thereby ceases, for the moment, to be constructive. That is, conduct, like growth, must be constantly readjusted to itself, and to that good and evil which changes the more, the more active the organism is; and it must be rightly readjusted, otherwise freedom of movement would not be more constructive than sitting still and waiting for something to happen.

We do not know how this is done, but we cannot doubt it is done, as may be easily demonstrated in the laboratory; and besides, all about us are the living witnesses to its accomplishment. All, the more highly organized animals, for example, invariably react constructively, or rightly, to gravity, and on the average they react rightly to many of the countless minor influences to which they are subject. The register of one is in the architectural plan of the whole organism and in its constant orientation to gravity. ${ }^{1}$

${ }^{1}$ See also the remarkable orientation of nerve fibres within the visual rods of arthropod ocelli, in reference to the direction of the incoming rays of light, and also in reference to three perpendicular planes. "A Basis for a Theory of Color Vision." W. Patten, Am. Nat. Vol. 32, 1918. 


\section{GRAND STRATEGY OF EVOLUTION}

The register of the other is in supplementary structural details, chiefly, no doubt, in the nervous system. These structural details are not so easily measurable; many of them are wholly inaccessible. They may be manifest only in supplementary reflex actions, in instincts, or in the more immediately purposeful acts called intelligent actions.

In all these cases, the rightly moulded organic structures and the rightness of their responses to the outer world are the product of what we call experience.

Cultural Registers. But to go beyond mere instinct and animal intelligence, and rightly to respond, in a comprehensive way, to the less insistent warnings, and to the less frequent invitations of the outer world, demands something more than the fleeting memory, and the limited experience of the individual organism.

It demands some means of gaining an approximate equivalent of personal experience though communication with other individuals. These equivalents of experience must then themselves be recorded, or symbolized in some enduring architectural form; averaged and expressed in what we call natural laws, or customs, and made, so far as possible, immediately available for the usage of every individual.

But no one individual, or one generation, can do that. That is a social function of mankind; one which demands for its accomplishment the cooperation of countless individuals, for many successive generations, and the usage of more enduring and more powerful physical agencies than naked protoplasm. And so far as that is accomplished, animal life passes over into the more distinctive phases of human life and social 


\section{HIGHWAY OF ANIMAL EVOLUTION 25I}

organization. Man's creative action, his constructive response to his outer world, is then registered and preserved in rituals and social pageantry; in the material agencies of commerce, art, literature, and science. His constructive egoism matures in cultural benevolence; the profits of his labor and of his experience become a social heritage, and the constructive rightness in nature action is reembodied in the works of man. 


\section{THE ARCHITECTURE AND COHESIVE POWER OF SOCIAL LIFE}

Limitations to the Growth of Man as an Individual, and the Physical Limitations to his Organic Instruments-The Distinctive Organs of Social Life, Manual, Visual, Vocal, Auditory, a Mental, and their cooperative Unification-The Merging of Man's Sense of Self with his Physical Instruments and Material Properties -The World-wide Unification, Physical, Organic, and Mental, of the Nineteenth Century: the Completion of the Social Blastoderm; the Increment of Power; the New Receptors and Perceptors; the New Ways and Means of Conveyance; the Orientation to a New World and the New Mental Freedom-The Compulsion to Social Cooperation-The Consciousness of Social Possessions as the Compelling Creative Power in Social Construction and Social Preservation -Summary of Chapters VII-X.

I. Limitations to the Growth of Man as an Individual, and the Physical Limitations to His

Organic Instruments

WE have seen that there are very definite limitations to every system of growth, physical or organic. When those limits are reached, further growth is possible only by the production of more individuals of the same kind (either by repetition, de novo, or by division, or by self-reproduction) and by their cooperative union to form new systems on a higher level. In this respect, human beings are not different from celestial bodies, or from atoms, molecules, cells, plants, or animals. In man, these distinct but overlapping 
phases of growth are: growth, or development, of the individual man; increase in population by his multiplication, or reproduction; and growth, or development, of social units; their division, or multiplication, growth, cooperative union, etc.

There is reasonable assurance that the triaxial system of growth has practically reached its limits in man. No notable modification in man's architectural plan, in his physical dimensions, organic structure, or vital power, is likely to take place, even in the very remote future. It seems probable, however, that the general average of attainment in the most characteristic human traits will be much improved, and the duration of human life greatly increased, and with relative rapidity. It is also quite possible that the impending functional segregations of social life, with their special trainings, common interests and mutual understandings, will tend more and more to minimize racial and mental distinctions, and accentuate functional types.

The inherent limitations to man's further evolution, as an individual organism, lie in the fact that no further readjustments, or increments, of his chief vital organs, such as have taken place in his more remote ancestors, are possible. Those changes have clearly reached their logical conclusion. And as for his purely muscular and nervous powers, so essential for locomotion, internal circulation, and discriminating response to external agents, further increase of power in these directions is definitely prohibited by the limited conductivity and tensile strength of living protoplasm and its products; by its limited powers of assimilation and response to physical agents; its limited ability to 


\section{GRAND STRATEGY OF EVOLUTION}

transmit these influences, and to distribute its commodities to the various parts of the body.

These basic limitations of life, well known to the biologists, but often wholly ignored by the layman, are not peculiar to man alone, but to all animals, and to all protoplasmic structures.

Man's freedom of action, as a naked animal organism, and his profitable response to his environment, is therefore strictly limited by the purely physical limitations of his organic instruments. They limit his experience to those world influences which can reach him through his naked senses; confine him to whatever territory he may be able to reach with his unaided hands and feet; and limit his sources of power to those foods his unaided digestive organs can assimilate.

Man might multiply indefinitely and his progeny gradually spread over all the habitable portions of the globe, but without something more than mere increase in numbers the individual man would remain practically as before. He could not greatly increase his native powers without increasing the physical power of his organic instruments, and without the aid of his fellow-man; it was in these cultural increments to the power of his vital organs, and in the mutual aid and cooperative fellowship of unarmed, ape-like men that human society had its origin.

II. The Distinctive Organs of Social Life; Manual, Visual, Vocal, Auditory, and Mental, and Their Cooperative Unification

Man's peculiar fitness for social life was already established by (I) a considerable measure of intelli- 
gence, greater probably than in any of his animal predecessors; (2) an extremely elaborate visual, vocal, and auditory equipment, readily adaptable to communication and cooperative social action; and (3) a pair of appendages (arms and hands) relatively free from locomotor demands, and themselves rightly constructed for constructive purposes. How, or why, all these organically distinct sets of structures and functions, so essential to social life, happened to exist in primitive man, and which one of them, if any, preceded or exceeded the other, we do not know; nor is it pertinent to our present discussion. There they undoubtedly were, and they, with practically all their subsidiary parts, were initiated very far back in the arthropod-vertebrate stock, millions of years before the mammals, to say nothing of man himself, existed; and long before they could be utilized in social life as they are today.

Thus each of these important organic systems, after an immeasurably long constructive period, came to man essentially as they are today, rightly modeled beforehand, and with all their great social potentialities ready for exploitation, and so they are likely to remain. What these potentialities are we may better realize, perhaps, if we try to imagine what the result would have been if some one of these conditions had been otherwise. Suppose, for example, that primitive man, though endowed with the intelligence of a Greek or Hindoo philosopher, had inherited a hand like a horse's foot, or an eye like an ant's, or vocal and auditory organs like those of a grasshopper. Intelligence of that order, even if it could under those conditions have come into being, with such instruments to work with would have little or no constructive social value. 


\section{GRAND STRATEGY OF EVOLUTION}

Even with mutual aid and dawning intelligence, man could not greatly increase his native power, or raise his social organization much above that of animal life, until his hand, eye, ear, vocal organs, and intelligence were brought into better organic cooperation, and their potential constructive power made a reality. These great constructive functions, visual, manual, linguistic, auditory, and mental, must march abreast on approximately the same front; neither one, without inviting disaster, can greatly surpass, or greatly fall behind, the other; for they must all act together, and act cooperatively, to act constructively. Their constructive power is in their unity of action and purpose, and the progress of man, as an individual and as a social animal, was, and still is, dependent on the equitable development of each function.

What we may call the preliminary period of man's social evolution was devoted largely to the improvement and unification of these organic instruments. For it was only after that was in some measure achieved that his hand, guided by his senses and by his intelligence, could put material things to rights, and his articulated words-expressing inward emotions in the architecture of outwardly propagated sounds-could join anarchistic wills in one, and direct the conduct of widely separated human bodies into cooperative social action.

III. The Merging of Man's Sense of Self with His Physical Instruments and Material Properties

Meantime man was gradually learning that the material things in nature have a constructive power of 
their own, and that when rightly combined with his own native powers they become virtually a part of himself, supplementing the power of his own vital organs, and extending his sense of self, and of personal ownership, farther and farther beyond himself, into the outer world of usable things.

This merging of his living, organic self with external properties, inevitably extended to whatever things in nature man could lay his hands upon and bend to his self-constructive ends, including his fellow-man. And there was the source of his mental confusion as to the limitations of his personal rights, initiating endless conflicts to define and stabilize them. Man could not sharply distinguish between the constructive and saving power of his usable personal properties, such as material objects, domestic, or wild animals or plants, and human beings, and those of his own vital organs, because in reality there is no such distinction. Hence there could be no final solution to his problems of ownership, personal rights, and the delimitation of domains, or spheres of constructive action, except the recognition that the right to use nature's properties constructively, even man's right of self-usage, is not restricted to any individual thing. That right is universal.

The evolution of cultural architecture was a very slow process, covering a period of something like fifty thousand, or it may be five hundred thousand years. It comprised the invention, discovery, and utilization of many distinct and separate things, beginning with the rudest implements of wood, or stone, or bone. They were constructed, or invented, either de novo by different primitive races at different times and places, or 


\section{$25^{8}$ GRAND STRATEGY OF EVOLUTION}

conserved, increased, and transmitted by them in a process of social inheritance, from one race, or generation, to another.

There was, of course, no formal continuity, or architectural unity, in all these material things, or in their constructive usage, like that for example in the organs of a living body; but their basic elements, or properties, such as fire, heat, and light; the elasticity of the bow, vibrating strings and membranes; the principles involved in the hammer, the wheel, and the axle, lever, arch, and sail; and the application of power in pull and thrust, the automatic adjustment, or response, of material things to gravity, atmospheric pressure, and to other physical agencies, were everywhere the same. The more complex mechanisms, that were evolved at a later period, such as a watch, engine, or microscope, were merely more complex cooperative combinations of them "organized" for some particular end, or purpose.

In all this cultural evolution, the real gain, as in all other phases of evolution, was in constructive rightness. The evidence of that rightness was both in the things so constructed, and in their constructors, human and otherwise. Somehow, or in some way, there has been registered and conserved in the architecture of the individual man, as the regenerative power of the race is registered and conserved in the architecture of the egg, the power to reconstruct in a few hours what had taken his ancestors many thousand of years to construct. The most essential element of that new cultural power was rightness, or the "knowledge" of the right way to do things. 
Thus a most significant factor in cultural evolution is the enlarged sense of personality that goes with every increase of man's personal properties, or possessions. When man made a club to reinforce his fist, or teeth, shaped a log to improve his locomotion, or cleared a place to plant a root, or seed, helping it to grow in order to insure the continuity of his own food supply, it was in effect a larger process of self-construction, in which the growth of his own individuality was extended beyond his organic self, into those properties which he appropriated from nature, or which with his own hands, instead of his digestive organs, he constructed out of nature's own constructive materials.

His instinct of self-preservation then widened to embrace his larger self, compelling him to preserve and protect his possessions, as he would a part of his own body, or his own offspring.

That is, the conscious possession of these self-constructing cultural properties carried with it the mental compulsion to protect and save them. This is merely another instance of the compulsion of possessions that we have seen in operation in the organic and physical world.

Another significant factor is that these cultural properties can be detached, or alienated, from their producer, or creator, without destroying their constructive power, or usefulness. For a well-constructed club is as impartial in its impact, a plot of ground, in its returns, and a canoe, in its buoyancy, for the man who buys them, or steals them, or in any other way gets possession of them, as they were for the man who put his labor into them. But the head, or hand, cannot be so separated from the body and still preserve its con- 


\section{GRAND STRATEGY OF EVOLUTION}

structive power, either for the producer, or for any one else.

This more obvious and more permanent usefulness of detachable possessions is an essential condition for barter, or commerce, or for that mutually profitable exchange of constructive properties across the larger reaches of time and space, which separate one individual from the other. The viability, or conveyability, of these constructive properties is an essential condition to the functional unity of separate human beings, or, in other words, to social metabolism.

While the growth of these cultural properties led to endless conflicts for their possession, they were not wholly destroyed by the change of ownership, but accumulated to form the foundation of future social life on a still larger scale.

For as slaves, retainers, domesticated animals and plants, cultivated lands, dwelling places, weapons and utensils of all kinds grew in constructive power and durability; as man's knowledge of the right way to use them increased; and as their saving and constructive value extended beyond the nominal owner, to the many, the initial limitations of the more primitive individual man were widened, his sense of personality enlarged, blending with that of his more helpful fellows, and so into that of the social group and its common store of cultural possessions. The social unit then virtually became the property of every individual in it. For each one could then rightly refer to it as my clan, or my village, or in later stages of social evolution, as my city, my college, or my country.

From time to time, the hearthstone, the totem, the college color, the cross, the crescent, or the flag, became 
the symbol of this social unity; something that signified, in a simple, tangible form the history and traditions, or the common body of constructive agencies, which produced that unity, and its common purpose.

Such symbols are the material agencies of mental compulsion in these various social groups. As occasion may demand, they are effectively utilized to mobilize the vital resources of all their individual members, to summons them to augment and preserve their possessions.

But with better understanding, the sense of ownership extends far beyond even these broader limits, for it then becomes sufficiently obvious, at least to the so-called idealist, that the scientific and political achievements of the French, German and English peoples, the art, literature, and philosophy of Greek and Roman, of Hebrew, Hindoo, and Mongolian, and the cultural inventions of the American, are practically immortal human possessions, a common social heritage open to the usage of all mankind, and having essentially the same constructive value for one race or nation as for the other. It is also obvious that the characteristic quality in each local cultural product, and the most valuable one to other peoples, is something which can have its origin only in some particular social group, with its own peculiar antecedents and surroundings.

The consciousness in one people of this ownership in the constructive attributes of all the others, and the recognition of the common source of these attributes, is the only power which can hold mankind together in social unity, and compel man to mobolize his resources in order to augment and preserve his common possessions. 


\section{GRAND STRATEGY OF EVOLUTION.}

We may see in all this cultural growth the same constructive strategy and cumulative benevolence we have seen in other phases of evolution. For man's mere bodily growth, supplemented by his external, or cultural, constructiveness, while enlarging his egoism, also enlarges his altruism. It thereby enables the individual man to give the body social something of more permanent constructive value; and it is these personal profits, to him no longer usable, which are ultimately redirected to his future self, or offspring, as a germinal, cultural heritage.

We need not review the evolution of man's extrabodily constructions, such as tools, clothing, utensils, material instruments, etc., whose architecture is always the expression, in some one or more particulars, of the peculiar constructive power of his bodily organs. All that is sufficiently familiar, or easily accessible. What we wish to emphasize is that every new cultural invention, or construction, every new discovery in constructive rightness, was virtually an extension of the powers of some one or more of his vital organs, and yielded its returns in social growth, according to the constructive value of the invention to the individual man. And, to some extent, these inorganic cultural instruments reacted constructively on man's vital organization, as though they actually were new vital organs.

The rate of cultural evolution was, therefore, no more uniform than organic evolution. It was spasmodic and divergent; now rapid, now slow; now in one direction, now in another, until the full creative 
power of each construction was realized; and checked when a new level of stability was attained.

Nevertheless, when we compare the new things constructed by man during this long proto-cultural period, with the progress of his own bodily organization, it is evident that cultural growth was very rapid indeed.

Man's cultural constructiveness was first exercised to increase his own individual possessions, for his own personal usage, or at most for that of a comparatively small group of individuals, such as the family, band, or class. But whatever man himself may have thought, or believed, or intended, all of his cultural achievements, such as.utensils, weapons, and housings, and the territories delimited and preempted by cultivation, roadways, and defenses were in reality possessions in common, for immediate or future usage of all mankind.

This early cultural period may be regarded as a sort of protozoan cultural age; that is, an age of more or less isolated, or independent, elemental cultural instruments. It was a necessary preliminary stage to their cooperative union, or combination, to form the more complex machinery of modern life, and through its instrumentality, to tie the larger social groups into organic unity.

IV. The World-wide Unification, Physical, Organic and Mental of the Nineteenth Century

But when this proto-cultural age, which we shall not attempt to review, attained its maturity, and the elements, or principles, of many separate inventions were 


\section{GRAND STRATEGY OF EVOLUTION}

variously combined, making them more comprehensive in their utility, serving not only one man, or one village, but many millions of human beings, for all time and all places, as the printing press, telegraph, and engine, man was unwittingly compelled, in spite of himself, to think and act constructively for all mankind.

Many factors contributed to this result, but all of them seem to have been slowly marshalled in secret, like the different organs of a growing embryo. In the nineteenth century, to use roundly a convenient unit of time, they seem to come into cooperative action all at once, making that century the most creative period in the history of organic evolution; setting it distinctly apart as the quickening period of a world-wide, social entity; and making, at least in a physically united humanity, the philosopher's dream a reality.

We can do no more than barely outline the cultural movements of the nineteenth century, and in so doing we shall not rigidly restrict ourselves to the literal meaning of the term, for many of these movements may be traced back, historically, hundreds, or thousands, of years. But in the cases specified the movements attained well within that period a quickening momentum and a unity of action befitting the birth of a living body of world-wide dimensions.

It will best serve our present purpose, if we project these events in bold relief against the general background of organic evolution. We may then more clearly see what it was that so quickly widened man's mental horizon, increased his freedom of action, and made his organic unity a reality. The events we have in mind may be grouped as follows: 


\section{COHESIVE POWER OF SOCIAL LIFE 265}

I. The Completion of the Social Blastoderm. With increase in population, migrations, and colonizations, man had at last, within the nineteenth century, covered all the habitable surface of the globe with a virtually continuous blastoderm, to use an embryological term, or at least with an anastomosing network of human beings, which were everywhere within reach of one another; all of them moving more or less freely to and fro, and mingling. with one another in social and reproductive intercourse.

It is true that the discrete elements in this streaming human plasmodium, its individuals, families, tribes, and races, are separated by countless cleavage planes of habits, prejudices, and long established customs; by arbitrary territorial boundaries rupturing, or bending in and out, under the varying osmotic pressure of rising and declining populations; by semi-permeable rivers, plains, and forests; or by impassable nature-barriers, oceans and mountain ranges, ancient and forbidding. But on the other hand, between the larger blood-islands of social life, lie the open gateways of ter restrial architecture, permanent channels, and standing invitations to social and commercial circulation. No animal in the history of organic evolution, nor man himself, has ever before attained this world-wide distribution and this degree of freedom in social intercourse.

2. The Increment of Power. The increase in the amount of energy at man's command, or that he was able to utilize for moving, or conveying himself and his properties from place to place, was chiefly due (I) To greater food supplies derived from domesticated 


\section{GRAND STRATEGY OF EVOLUTION}

animals and plants, drawn from all quarters of the globe; and from better agricultural returns. (2) To the use of mineral fuels and water power. (3) To the use of machinery. During the brief period of the nineteenth century, the resulting increase in man's constructive power, and in his power of transportation, was far greater than in all the preceding cultural eras, and is without a parallel in any animal, for any length of time whatsoever, in the whole history of evolution. The chief creative value of this accomplishment lies in the fact that, for the first time in evolution, it provided a living organism with sufficient power for a continuous, world-wide, vital circulation, comparable in its functional and social significance with the initial circulation of the blood in a growing embryo.

3. The New Receptors and Perceptors. Sense organs are living resonators, or receptors tuned to particular kinds of physical action. The range of action to which they respond, that is, wave-length, energy, and frequency, is in each organ very limited; they are either mute to actions outside that range, or destroyed by them.

In their respective functions and limitations, the sense organs of man are much like those of other animals. In both cases, there is a vast world of natureaction all about them, to which they do not, and cannot, make an adaptive response. To them, this other and greater world does not exist.

Man alone is able to construct supplementary sense organs, or perceptors, or measurers, of external events; that is, he alone is able to select certain objects which are highly sensitive to particular external acts, or conditions, shield them from other influences, and 


\section{COHESIVE POWER OF SOCIAL LIFE 267}

then, by observing their reactions, to obtain from them more trustworthy testimony to nature-action, unprejudiced by previous opinion, conflicting vital influences, or human emotions.

This mental humility, or the willingness to appeal to the democracy of nature and to submit to the unbiassed testimony of her humblest constituents, definitely initiated the delivery of man from the dominion of his own senses. During the eighteenth and nineteenth centuries, probably for the first time in history, this mental attitude became the chief characteristic of intellectual leaders, and the means by which they made their most important discoveries. It was the chief factor in the rapid evolution of modern science, and at once revealed to man a new world of architectural realities, to which he was compelled mentally to orient himself, whether he would or no.

By means of these new physical instruments, practically all of them constructed, or greatly improved, during the nineteenth century, the precision, range, and capacity of human sense organs was magnified many hundred, thousand, or even million fold. The microscope, telescope, and camera became a new eye; the stethoscope, seismograph, and phonograph, a new ear; and physical, astronomical, chemical, and biological laboratories, with all their machinery for measuring, analyzing, and recording nature-action, became new balancing, temperature, olfactory, and gustatory organs. But even more than that, they were building a more stable and more comprehensive register of human experience, in fact, a new social memory, and a cloud of ready witnesses that were partisans of no theory, no race, no government, and no religion. 


\section{GRAND STRATEGY OF EVOLUTION}

We can grasp the magnitude and the significance of this almost instant achievement of man only when we realize that there had been no notable inventions or consistent improvements in animal sense organs in many millions of preceding years.

4. The. New Ways and Means of Conveyance. Broadly speaking, vital response is expressed in the ways and means of conveyance: (I) In organic acts, or motion, such as movements of appendages, heart-beat, peristaltic action, etc.; in locomotion, or bodily transportation in air, land, or water, or along definite roads, or pathways in such media; and in circulation, or the internal movements of vital commodities and waste materials through definite channels, blood vessels, canals, and tubules. (2) In communication, or the transmission of impulses through amorphous media, such as air, or water, or soil ; or through specially constructed conductors, such as nerve fibres. (3) In the impulses and commodities themselves, and in their conductors, receptacles, records, and other architectural containers. (4) In the regulation of conveyance in response to variations in supply and demand.

Commerce, science, literature, and art, in a word, culture, is merely an extension, or enlargement, of these organic systems of conveyance, utilizing more power and other instruments, and which at one and the same time serve the same functions for many, that the vital organs do for one.

Man was the first animal to construct a cultural system of this character. In the nineteenth century, its great trunk lines of conveyance extended completely round the earth, for the first time in evolution, defi- 
nitely uniting and regulating the supplies and demands of a world-wide social life.

Within that period, its roads and pathways grew from provincial, or national ones, to oceanic and continental highways, rightly oriented to terrestrial architecture and human service. The stored-up energy of a nature-life, long since extinct, became its chief source of power. Primeval vehicles of vital commodities grew to steel-clad ships and cars, swift couriers of agelong hostile peoples and their products. The feeble signals of cell to cell and man to man, calling for aid and offering aid, grew to the call of empires and continents flashed around the world in advertisement of their surplus and their necessities; and accepting these invitations to exchange, protoplasmic, cultural, and international metabolism were joined in one.

In approximately this brief period, many household functions grew into municipal and state functions; and domestic architecture into municipal and state architecture; into reservoirs, parks, conservatories, granaries, and warehouses, and into communal heating, lighting, cooking, cold storage, and sewerage systems. The unstable mental records of countless individuals were fixed, summed up, tabulated and recorded in material symbols; memorialized in ledgers of metal and stone; in libraries and museums; in science, literature, and art, the great communal banks for the conservation of human profits, world reservoirs of spiritual power, subject to draught at all times, by all peoples.

All these great cultural systems, which came to life with such extraordinary rapidity in the nineteenth century, are for social life precisely what the living, or- 


\section{GRAND STRATEGY OF EVOLUTION}

ganic systems of the body are for the living individual, - receivers, conveyors, containers, metabulators, and regulators of constructive supplies; sustaining and quickening social life, the world over, by their mutually serviceable action.

5. The Orientation to a New $W$ orld and the New Mental Freedom. The world in which an animal lives is limited to those things to which it is rightly oriented, and to which, for that reason, it makes a profitable response. To react unprofitably is to die. The profit is in avoiding those things which are evil and in taking possession of those which are good. In its ultimate analysis, this vital response is a process of exploration and experiment, conscious or unconscious, measurable in the power used for conveyance in exploration, and in the constructive rightness of the response, mental or physical, to the good and evil discovered.

So it is with men. We have witnessed the enormous increment of man's physical power and constructive rightncss in the nineteenth century, and how his world, and his freedom of action in it, was enlarged with every increment in his usable power, and with every new invention of physical instruments for better exploration and discovery, and for the better measurement of what was really going on in the world of action all about him.

If we try to picture the typical man of two hundred, or ten thousand, or even fifty thousand years ago, and compare him, merely as a human being, without his cultural implements and social atmosphere, with the man of today, we shall find little or no reason to suspect that in naked physical and mental capacity he would be the one to suffer from the comparison. But 
how great the difference when their respective cultural instruments and social atmospheres are thrown into the balance!

Consider for a moment the man of today in his altered mental relations to natural phenomena. How his knowledge of the physical and organic, large and small, has grown! How his mental attitude, or his mental orientation in reference to them, has been readjusted and progressively stabilized with that growth! Consider geography, and celestial architecture; spiral nebulæ and radio-activity; spontaneous generation, contagious diseases, surgery, sanitation, bacteria, heredity, and the architecture and functions of cells, plants, and animals; slavery, and the social relations of man to man. How this world of his has been enlarged in the nineteenth century! How he has been compelled to reorient himself to it in mental tropic response. How his vision has been clarified, his wild guesses and superstitions rectified. How his resources have been increased, and his ability to distinguish between reality and phantasy, good and evil, right ways of thinking and acting, and wrong ways. Then consider his profits therefrom in terms of mental and physical growth, mental and physical freedom. His old world of thought and action appears small, indeed, and tragically confused, but only because a larger, more lawful world of thought and action has been revealed to us, and our life has been brought into cooperative action with it.

But this new heritage of man was not merely an endowment of physical power and material instruments; it was also a spiritual endowment, and the greatest of all was the new concept of world growth. 


\section{GRAND STRATEGY OF EVOLUTION}

Evolution was, in effect, a mental emancipation from an imaginary immutable world order. It released man from the dominion of a fixed idea, and revealed him to himself, not as the degenerate paralytic offspring of a fallen angel, the imprisoned scourge of an implacable and incompetent experimenter like himself, but as a living growing part of a living growing universe; product of the sun and soil, blood relative and next of kin to his meanest servants. This revelation, at first so staggering and repulsive to his childish imagination, ultimately inspired him with its real significance, and gave to his newly-won manhood, and to his new concept of animism, a new dignity. It was a rousing challenge to the dawning consciousness of his physical and intellectual powers; and under its influence the dominion of age-old myths, and fables, and superstition, passed rapidly away. The long night of baseless terror and grotesque imaginings was past and a new day was dawning. His multitudinous enemies vanished with the dark, and in the new light appeared as friends and coworkers. Man was at last conscious of his real self; conscious of his unity with his fellow creatures, and conscious of his creative mission. He heard nature speaking to him in friendly tones, and at last realized - that her gestures were not threats, but invitations to creative acts. The students and lovers of nature, walking with nature in the field, the hospital, workshop, and laboratory, were no longer, in their own estimation, or in that of their fellows, social outcasts, or harmless lunatics, or sacrilegious sorcerers and workers of witchcraft, or magic, in dens of secret iniquity, but self-respecting and respected ministers of a new order; new instruments of nature, seeking, not indeed to conquer 
nature, but to discover the will of nature, the better to obey it.

This growth period, then, that we have had in mind was doubtless the most remarkable constructive period in the history or organic evolution. No known geological era, representing many millions of years, shows anything comparable, either in actual accomplishment, or in potential significance, with this world-wide functional unification of physical, organic, and spiritual powers.

\section{The Compulsion to Social Cooperation}

It is evident that the source of man's motor power is not in man himself. The real source of the great wealth of life and treasure, which not only provides him with the means to action, but the motive for action, is in the past; in the sunlight and in the soil; in moving and standing waters; in the forests, mountains, and plains; in their products, and in their inhabitants. It is from this accumulated capital of nature's constructive labor that man derives his vital power. It is the common heritage of life from nature, held in trust by life, for life and its posterity.

But the dawning consciousness that he, Aladdinlike, could command these vast sources of power; that at the touch of his hand and the impulse of his will these monstrous genii of good and evil could be summonsed to his aid, spurred him on to gain possession of them. They became indeed the common objectives of national and imperial endeavor. But the questions, what shall be done with them, or how shall we use 


\section{GRAND STRATEGY OF EVOLUTION}

them, brought the old militant, selfish doctrines of church and state into conflict with the new doctrines of democracy; not merely with the democracy of mankind, but with nature's kind; with that universal equality of right to be served, the obligation to serve, and the equitable sharing of profits and losses, upon which all constructive, or creative action depends.

This conflict cannot be confined to any time, or place, or people; it cuts across every phase of life, high and low, young and old, domestic and foreign. It is, in fact, not merely a question of national, or racial, or class growth, it is a basic question of organic evolution, or the right constructive usage of all nature's resources.

There was, and there is today, little or no consciousness of the real social significance of evolution among the most cultured peoples, or even among scientists themselves, to say nothing of the outspoken political and theological champions of the old régime. Too late for the rack and the stake, evolution was tolerated with a grimace and a joke, and became an impalpable atmosphere and an agency of intellectual compulsion. The monkey saved it from academic oblivion. All unconsciously, the basic idea in evolution took root in the popular mind, and through the agency of science and the press penetrated all social and mental strata, in countless subtle disguises; widening the general perspective, clarifying social vision, undermining ancient shams and privileges, weakening the old bonds of authority, and equalizing the power of individual men for good and evil.

Dominion and equality, over lordship and democracy, are irreconcilable ideals. In a universal egoistic 
struggle for power, where everything must get what it can, and defend what it has, there is no escape but to rob, or be robbed, or to remain stationary. In a world that is not, and cannot be stationary, there are but two alternative vital policies, or goals of vital endeavor, and in reality but one of these goals is attainable; either a perpetual life and death struggle of the stronger against the weaker, making dominion and slavery the ideal, or progressive cooperation, making equality of rights and mutual service the ideal. At the beginning of the twentieth century, the time had come in the social evolution of man when a decisive conflict between these two ideals was inevitable. For the first time in human history, this alternative, openly expressed, and so clearly formulated that the meanest intelligence could not fail to grasp its import, became for every race, and class, and nation, and individual, not merely an academic question, but the practical question of the moment, demanding immediate action.

The rapid growth of the preceding century, the complete preemption of the world's habitable territory, the contiguity of alert, hostile entities, gigantic reservoirs of power surcharged with pent-up energy and cris-crossed with wires hot with inflammable lies, and the deep-rooted conviction on all sides that the impending struggle was to be one of life and death, made the war that followed a fitting expression of the magnitude of the forces set in motion, the issues at stake, and the unity of world interests.

But it was also a most significant testimonial to the uncompromising bitterness and heroism, with which man will fight for his convictions, right or wrong; the willingness with which he gives up his life in the de- 


\section{GRAND STRATEGY OF EVOLUTION}

fense of his ideal of justice, and of what he believes to be right. That testimonial is not an assurance. It is a warning.

The social turmoil of today is in part the result of the destruction of life and property, and the loss of constructive momentum due to the war itself; but in the main it is the expression of the very same causes that brought on the war-that is (I) The attainment of a world-wide physical unity, expressing itself in social vitality, in national and in class consciousness; and in vigorous self-constructive purposes. (2) The universal struggle, individually and collectively, for the possession of territory, of land and yet more land, with all its sources of power, as a means of self-preservation and growth. (3) The conscious command of vast sources of power by organized social groups, constituting both a threat of mutual destruction, and an invitation to mutual service. (4) The conflict of ideals within these groups as to the right ways and means of using their power.

Reduced to its lowest terms, the problem in every national, as well in every individual, life is how to get power and how to use it. It is the problem of egoism and altruism applied to cultural constructiveness or cultural growth.

All problems concerning the use of power, in nature or in any phase of human life, are the same; they are architectural problems; problems in self-construction, or growth, old as life and nature itself, yet always appearing in new forms. They can never be permanently solved as long as life and growth endure. The inevitable new conditions produced by growth, create new 
supplies, new reactions, and new demands, and these demands must be supplied if growth is to continue.

But there is obviously only one way in which that can be done, and that way is always the same; better cooperation, better egoism and altruism, better mutual services, and better fulfilment of mutual obligations. Therein lies the compulsion to social cooperation.

Standing on this basic axiom, all constructive problems in social life may be resolved into secondary problems of ways and means of extending the principles of cooperative action to larger and larger groups, or conditions, for longer and longer periods. To that end, correspondingly larger experience, more comprehensive vision, and greater tenacity of purpose are essential. But the constructive method will always remain the same.

\section{The Consciousness of Social Possession as the} Compelling Creative Power in Social Construction and Social Preservation

In cultural constructiveness, the new agent used to direct, or to control power is the human will, which is itself an expression of intelligence. Intelligence is a highly discriminating constructive response of the individual man to his outer world. But the very attribute which makes intelligence one of the most constructive agents in social evolution, at the same time constitutes its inherent weakness. As a form of energy, its power is immeasurably small. Its discriminating irritability and instability are defects as deadly as these qualities are vital, or essential.

In physical and organic evolution, progress is made 


\section{GRAND STRATEGY OF EVOLUTION}

by stabilizing and conserving, in some architectural form, the gains in constructive rightness and coherent power. In cultural evolution, the problem is to stabilize and conserve the gains of constructive intelligence; that is, to reinforce the will to create and to preserve social institutions. That is the function of education.

But that education must be fundamentally right, and consistent with itself. If the educators themselves are not rightly educated, or if they are teachers of conflicting social ideals, fundamentally incompatible, the more elaborate and extensive the education, the greater the disaster when the social structures built upon these ideals collapse.

There is no hope in an education, however, technical or elaborate, which does not stabilize a basic sense of social righteousness; nor in one which serves more deeply to entrench antagonistic wills in opposition on fundamental principles, strengthening their respective convictions, increasing their respective powers, and perpetuating a conflict which becomes more and more bitter and mutually destructive.

Human society, large or small, national or international, is a living, growing organism with attributes peculiar to itself. Its unity and vitality is expressed in the cooperative actions of all its constituent parts.

There is no physical power that can hold these heterogeneous social structures together save the human will, acting in self-preservation under the guidance and compulsion of intelligence. That will to preserve social life, that common compulsion to defend it and contribute to it, can exist only in the conviction that social life is a vital part of every individual life, and that the whole architecture of society, physical and or- 


\section{COHESIVE POWER OF SOCIAL LIFE 279}

ganic, national and international, is a personal possession of every one of its constituents. With this conviction, which is broadened and stabilized with broadening intelligence, self and society are automatically merged in one organism, and the compulsion of these cultural possessions provides the motive to social selfpreservation and further social growth.

\section{Summary to Chapters VII, $X$}

We may summarize our conclusions as to constructive action and world architecture as follows:

Every individual thing in nature is a resultant product of cooperative action between itself and its outer world. The influence of these cooperative agencies, great and small, on one another is mutual, but not equivalent. The effect is profitable, or cumulative, and tends mutually to direct, or mould, the world's content into more and more diversified architectural forms, which are themselves more and more unified by the cooperative action of their constituent parts, subject to directive external control. Therein lies the source of their increment in power. The resultant constructive and conserving action is what we call growth, or progress, or evolution, or creation, or constructive rightness.

Man's bodily structure is the final product of individualized cell growth, cell multiplication, and cellular socialization, in which the cooperating cells and their products are either definitely localized or conveyed, so as to form a symmetrical, triaxial system of 


\section{GRAND STRATEGY OF EVOLUTION}

gradient action, in which the actors have the most profitable functional relations, both to one another and to the asymmetrical system of gradient action in the outer world.

The consistent architectural growth of this particular action system throughout the whole range of geologic and embryologic history is what we call The Great Highway of Animal Evolution.

The evolution of this system is the resultant of a cumulative directive restriction and compulsion, which is expressed architecturally in a progressive upbuilding, or growth tropism, wherein the organic architectural elements react to nature's content in a more and more self-constructive, or profitable, way.

The basic difference between the life of a single cell leading an independent existence, and the life of a human being, lies in the fact that in man there are many millions of cells united in a common constructive service; each cell leading its own individual life, yet serving all the others, and in turn served by them; all contributing something to the sum total of what we call the individual man, and all cooperating to make him a more effective servant to other individuals, human and otherwise.

No one cell in the human body, so far as we know, does anything essentially better, or more difficult, than the others, or than the things a single vagabond cell may do. But when millions of cells are united to form one organic body, with common interests and common dangers; a common origin and a common destiny; with justly divided labors duly performed and welfare mu- 
tually assured, how different are the powers so created! How great the possibilities!

In man, as an individual organism, an absolute, or natural, constructive limitation to the power of terrestrial organic growth, has been attained, which neither man, nor any other form of animal life, is at all likely to surpass, unless it may be in better mental adaptability to a cooperative social life. In the arthropodvertebrate stock, the great trunk line of animal evolution which runs through the whole gamut of geologic eras and finally culminates in man, the consistent progress of organic growth, with its concomitant adaptive readjustment to itself and to the outer world of action, reaches its logical conclusion. Moreover man's chief vital organs, sensory, digestive, circulatory, and motor, have practically reached a natural limitation to the physical powers of protoplasmic response.

Man's further evolution is possible, up to the limit of nature's available constructive capital, only by multiplication, or increase in population; by raising the general average of man's physical and mental power; by further individualization, or specialization; and by better social cooperation, aided by the evolution of those cultural agencies which extend, reenforce, and communize man's purely bodily functions.

During the last century, these wholly involuntary phases of social growth, radiating from many independent social foci, have met and joined forces around the world, producing a new, critical stage in organic evolution, where social cooperation, or cultural organization, irrespective of race, class, or nation, has be- 


\section{GRAND STRATEGY OF EVOLUTION}

come compulsory, and now awaits only a more "voluntary" human guidance, before further social evolution can be realized.

The cohesive power of social life is the will to create social institutions. Acting under the compulsion of self-preservation, man is compelled to provide that power out of his own resources as soon as elemental intelligence dictates to him that social institutions are his personal possessions usable in self-construction and self-preservation. 


\section{PART IV}

THE ARCHITECTONICS OF MENTAL EVOLUTION 



\section{CHAPTER XI}

\section{THE ORIENTATION OF MENTAL IMAGERY TO NATURE-ACTION AS A MEANS TO CONSTRUCTIVE CONDUCT}

The Cooperation between Conduct, Cosmic, Organic, and Mental Action-The Egoism and Altruism of Mental Life, Learning, and Teaching-The Parallelism between Mental and Physical Evolution-Mental Imagery as a Self-Constructive Function-The Evolution of Mental Imagery-The Imagination as an Instrument of Conveyance-The New Freedom and the New World-Basic Concepts: Creation, Growth, Obedience, Service, Profit-The Tests of Veracity.

\section{The Cooperation Between Conduct, Cosmic, Organic, and Mental Action}

CONFIRMED evolutionists, unlike introspective philosophers, prefer to approach their problems from without, and, so far as possible, to treat them in a purely objective way. At the very outset, therefore, of any comprehensive treatment of social life, we must clearly recognize that man is one of the more recent products of a unified system of cosmic growth, in which physical, organic, and mental evolution have played and still play their respective rôles. We must also recognize that all the agencies of this system, including man, can endure and grow only so far as they rightly conform to one another and act in a mutually profitable way.

Starting with these basic assumptions, analysis of 


\section{GRAND STRATEGY OF EVOLUTION}

social growth at once reveals four main categories of phenomena whose constructive relations to one another must be considered. (I) Nature-action, or the cosmic action system itself, as expressed in the growth, or creation, of physical and organic bodies. (2) Man's reactions, as a purely animal organism, to the cosmic system. (3) His mental imagery of nature action. (4) His conduct in reference to his outer world, as influ enced by his imagery, or by his so-called intelligence. The first two categories we have considered in the preceding chapters.

As man's mental imagery is a prime creative factor in the newer phases of cosmic evolution that we call social life, giving man a new footing in the world different from all the other products of nature, it is necessary for us to consider how this mental imagery has grown up in man, and how it has influenced his conduct. In this way we may, perhaps, better understand the architectural relations between these great action systems, for it is evident that, at least in some measure and in some way, they must become more rightly fitted to one another before they can act more cooperatively, or profitably, or before they can become progressively creative and saving agencies. As an intelligent animal, man's life and growth is contingent on the rightness both of his mental imagery and his conduct, or upon the maintenance of profitable relations between his mental imagery, his conduct, and his outer world.

Sometime, perhaps, the evolutionist may be able to trace in broad perspective, the growth of man's mental life into those more specific systems of mental imagery called religious, scientific, and philosophic thought, and to trace their concomitant morphological expres- 


\section{ORIENTATION OF MENTAL IMAGERY 287}

sion in bodily acts and bodily structures, or in conduct, art, and social procedure. That, needless to say, cannot now be done. However, some tentative generalizations, indicative of the cooperative relations between these different systems, may be permissible. Broadly stated, they seem to be somewhat as follows: (I) Man's mental imagery, reflecting directly or indirectly natureaction, tends to become unbuilt and organized into logically coherent sequences by the same self-saving and creative methods that have produced nature's evolutionary streams of form and structure. (2) Hence, no matter what their racial sources may be, or their instrumentalities, science, religion, and philosophy are driven by the same logical compulsion toward the same elemental conclusions. (3) Hence these psychic-action systems, when outwardly expressed in material constructions, in organic action, conduct, art, or cultural constructions, must be expressed in similar architectural forms, and in similar modes of social procedure.

In this indirect way, man's mental imagery, bodily actions, and social procedures are individually unbuilt by mutual adaptation, and in functional unison, as members of a common growth system, and in accordance with the same saving and constructive methods universally used in nature architecture.

\section{The Egoism and Altruism of Mental Life, Learning and Teaching}

In the evolution of these three great currents of constructive thought, we see the same basic imagery, the same attempts to discover corresponding realities in nature, and the same attempts to test, or interpret, the 


\section{GRAND STRATEGY OF EVOLUTION}

validity of their imagery in terms of conduct. There is the same trial groping after truth, wherein saving rightness and eliminating error ultimately yield some abiding sense of mental well-being, self-saving satisfaction, and new creative power in a cooperative or logical explanation, and in profitable conduct.

All of them have had their martyrs to truth, and in all their leaders there is manifest the same constructive egoism, the same insatiable acquisitiveness of the student, or investigator, which overflows into idealism, whose receptive goal lies somewhere outside of self, beyond the constructive limitations of individual life. This missionary spirit of idealism, this mental benevolence, or mental altruism, is the characteristic teacher instinct of mankind. It is, in effect, the germinal, or reproductive, attribute of the mind, constituting the basic factor in a system of mental heritage, by which the accumulating profits of mental rightness are given vital continuity. What man learns today and teaches tomorrow is the chief, if not the only source of man's mental capital. This mental overflow, through whatever channels it may find its way, is in fact, a dower of mental mother-yolk for future generations to utilize and build upon, but unhampered by parental, or racial restrictions. This dower of mental loaves and fishes, multiplied in the giving, is a mental possession, over and above that essential, or usable, for the welfare of the parent, giver or teacher, and which by right of dower becomes a common germinal property, held in trust by mankind for mankind.

The ripening of mental leadership to its reproductive act is ever expressed in the exuberant mental power 


\section{ORIENTATION OF MENTAL IMAGERY 289}

that drives the virile intellectual leader to day-dreams, to playful explorations and mental foragings which ultimately blossom into self-assertion, but bringing no other profit to the forager save the joy of discovery and the pleasure of mental procreation in mental giving. Indeed his best gifts may be most unwelcome, and their sowing the cause of his undoing; but they will be very precious to those he can never know and from whom he can receive no returns.

\section{The Parallelism Between Mental and Physical Evolution}

The self-saving and self-constructive methods of the mind are therefore truly comparable with those of the physical world, and the results are measured in similar terms. We may say, for example, that an hypothesis, theory, or explanation, is right, or true, or good, or workable, or creative, if its component elements are mutually confirmatory, cooperative, self-preservative, or self-constructive; that it is wrong, or false, or evil, if they are mutually conflicting, non-cooperative, or destructive. And we may say that mental processes are benevolent, or altruistic in effect when the mental profits, or possessions, of the individual are transmitted to other individuals through the instrumentalities of education.

That is to say, every mental image, every thought, theory, or system of thought, to exist, must in some measure sustain, or confirm, some other image, or images, thought, or theory, and be sustained, or confirmed by them, just as every physical thing, or system 


\section{GRAND STRATEGY OF EVOLUTION}

of things, and all their parts, to exist, must move, hold, or sustain, something else, and be moved, or sustained, by them.

The serviceability of any system, mental or physical, is its power to save itself, and give itself, as an altruistic agent, to the construction of something else. To grow in stability and serviceability, it must increase the number, variety, continuity, and rightness of its self-sustaining services, draw to itself new servants, and perform for them more and better services.

\section{Mental Imagery as a Self-Constructive Function}

Intelligence may be regarded as a constructive response, not of any one organ, but of the whole organism, to its outer world.

As this functional response expresses the cooperative action of discrete physical and organic systems, it must await the creation of the various parts and instruments of those systems before it can itself be manifest. Intelligence becomes more and more manifest with the growth of these physical instruments and the increase of their creative returns.

The purpose of intelligence, like that of every other function, is manifest in what it does, or accomplishes. In this case, it is to discover the right ways to do things in order that the body may do them rightly, or self-constructively; in other words, in order to find, appropriate, and rightly use what is good, or selfcreative and self-saving, and to avoid what is evil, or destructive.

Those things, therefore, which do possess a measure of intelligence, in some way must have conserved in 
their architecture the summed-up profits of righteous action. Their basic purposes, to that extent, have been achieved, and from that level new constructive ends may be attained by more direct, or economic, methods.

\section{The Evolution of Mental Imagery}

Animal life, as we have already seen, is a cooperative and adaptive response to the outer world. But no living thing responds to all its environments, nor can it adapt its life to all the things to which it responds. In this adaptive response to its environment, an animal may move from place to place wherever protoplasm may endure, or wherever it finds the physical conditions essential to its activities. No animal can live, in the past or in the future, or for one instant outside the established sanctuary of physico-chemical conditions essential to its being; nor, so far as we know, can it consciously utilize the past to establish more profitable relations with the future.

Animal life, therefore, in the final analysis is a serial response, or a moving picture if you will, of a particular part of the present external world of reality expressed in terms of protoplasmic activity. This animal life, even though it be a reflection, or reaction, to something else, is itself a reality just as much as the world external to it is a reality. It is, however, not the same reality any more than the vibrating string is the same thing as the moving bow, air waves, or the nervous reactions they produce in man. Nevertheless each reality may be interpreted in terms of the other.

In man, a new vital factor has been introduced. In addition to this older animal machinery of direct neu- 


\section{GRAND STRATEGY OF EVOLUTION}

romuscular response to the outer world of the present, man has acquired a mental or spiritual power that enables him indirectly to picture and interpret the past by means of the present, and thus to explore those regions of the outer world which lie outside and beyond the physical sanctuary within which his body is confined. This "retroactive cognition" lies largely in memorizing, or in approximately repeating a part of the nervous reactions produced by previous experience, as though the events that first produced them were themselves present, or repeated. This new power is apparently resident in an over-nervous tension, released and expended in the repetition of the older sequence of nervous acts, without the presence of the original outer stimuli, and without the other bodily acts that normally accompany them.

This supplementary nervous activity initiates a new kind of vital action that may be largely independent of the external world it tends to portray. With its aid, it is possible for man to construct image chains which tend to follow the same order as those produced by experience, and which thus tend to correspond with the actual order of external events. These retrospective images are tested, readjusted, and approved or disapproved by supplementary experience to form a broader and more secure basis for prospective action.

These mental pseudopodia, this halo of mental outreachings into the past and future, into history and prophecy, enable man to project himself as it were into the limitless expanse of universal time and universal space in search of those more comprehensive truths, or realities, which he calls natural laws.

This constructive usage of the imagination, ever 
checked and reoriented by observation and experiment; this matching of the inevitable logic of growth and evolution in the outer world with a logical sequence of selfsustaining mental processes, is the very essence of science and of spiritual freedom. It is the only means we have of reconstructing the unwritten past, and anticipating or prophesying the future. It is our only escape from the narrow prison in which the physical body is confined, to universal freedom and to larger fields of profit.

The chief purpose, therefore, of the imagination is rightly to orient mental and bodily growth to world growth; rightly to picture the world as it was, and shall be, in order to fit life more profitably to the world as it is.

Fantasy may create its own pictures, real enough it is true, and true they may well be. But if these mental creations have no corresponding realities in the outer world, they cannot be used for constructive purposes. Organic life cannot build itself up and preserve itself by acting in accordance with them, because in that way life cannot receive cooperative support, or service, from the outer world.

The free usage of both fantasy and the imagination may be regarded as mental play, serving the same purpose as physical play, in that it exercises important vital functions, and leads to the discovery of the ways things may or may not be done.

VI. The Imagination as an Instrument of Conveyance The New Freedom and The New World

The lives of plants, animals, and man, are dependent on three different orders of conveyance, each 


\section{GRAND STRATEGY OF EVOLUTION}

order, in its own way, providing the means to profitable exchange, or growth.

The plant in the main lives in, and on the larger circulation of inanimate nature, and the chief materials and forces essential to its being are carried to its very doors by a benevolent, cosmic circulation of light, and air, and water, and soil. The continuity of the relatively simple life of the plant is assured by the wide distribution and inexhaustible abundance of these supplies and by the stability of their sources.

In the animal, these larger, more fundamental methods of the plant are supplemented by individual freedom of movement. By means of its adaptive neuromuscular responses, and by means of its complex internal system of transmission and exchange, the animal may move bodily toward more specialized sources of supplies and thread its way between more particularized sources of danger. With ever increasing profit, it is conveyed along the more localized food lines to their source and along the more localized danger lines, away from their source, uniting with what is good for it and avoiding what is evil. The progress and continuity of this more subtle life is automatically insured by a more and more elaborate organic cooperation within, and by better bodily conduct in reference to the outer world, which constantly tend to reduce the percentage of errors, to substitute certainties for probabilities, to increase the rate and the volume of cooperation and exchange.

In man, the chief mechanisms of plant and animal life are still utilized, but they are heavily reinforced by his new instrument, the imagination, the eyes and legs of his spiritual body, the real seven-league boots 


\section{ORIENTATION OF MENTAL IMAGERY 295}

and the helmet of invisibility with which he annihilates time, and space, and matter, and with which, in effect, he may project himself far beyond the narrow confines of his physical sanctuary into realms his physical body may not enter.

Imagination opens the gates of the universe. It is life's open sesame to world freedom and to the accumulated treasures of the world's experience. In his search for wisdom, it gives man the instant power to look over the edge of yesterday and the top of tomorrow into the abyss of universal time; to fly through and beyond all physical barriers into the infinite expanse of universal space; to explore the dead past and invade the germinating future.

Ever checked and corrected, ever stimulated by its increment in power, it is the common agency by which man is perpetually upbuilding, renovating, and systematizing his science, his philosophy, and his religion; short circuiting the roundabout methods of chance, and hastening the discovery of the constructive way.

\section{Basic Concepts: Creation, Growth, Obedience, Service, Profit}

As man grew in bodily organization, his world enlarged, that is, he was influenced by a larger number and greater variety of things; and as he grew in power rightly to form mental images of this larger world, he grew in knowledge and in wisdom. His wisdom consisted not merely in the more profitable regulation of his own conduct in reference to that of other men, but also in reference to the conduct of plants and animals and to that of the great world of inorganic things. 


\section{GRAND STRATEGY OF EVOLUTION}

Apparently man's earliest and most fundamental concept was that of profit, or progress, or growth; the vague notion that all things had some kind of a beginning, and moved toward some end, for some purpose. The dawning consciousness of progress was doubtless due to its insistent influence on the whole gamut of organic life. It was but another expression of the compulsory adaptation of life to universal progress; for life could preserve its own constructive relations to the outer world only so far as its own acts fitted cooperatively into these larger movements of the outer world. Hence this idea of progress has been the chief motivethought of man, persistently expressed in a more or less crude way, in his science, in his religion, and in his conduct, at every stage of his mental evolution.

Man's earliest questioning, the underlying motive of all his seeking, has ever been to discover:- How the familiar things of the world begin, where they come from, how they "carry on," and how man may keep on the right side of things as they are. Or to put these questions in a more modern form: What creates, what preserves, and what destroys the products of nature and how man may profit thereby? Or still more comprehensively: How does nature act and how must man act in order to live and to grow?

The asking of these questions and the attempts to answer them marked man's dawning recognition of rightness and his obligation to obedience; the germination of his ethics and morality, as a counter expression of the ethics and morality of nature action. Out of these very practical, every day problems, with no system of formulating questions and answers; no distinction between fantasy and reality, and no separa- 


\section{ORIENTATION OF MENTAL IMAGERY 297}

tion of nature into the great domains of the organic and inorganic, the living and the dead; always conscious of his own weakness, and of the larger world forces which must be avoided, or enlisted in his own services, or in some way bribed or propitiated; always moved by fear of destruction and by the greedy appetites that ministered to his own growth and preservation, grew the first vague outlines of man's organized knowledge that we call science, religion, and philosophy, and the attempts to regulate his acts in harmony therewith, that we call social conduct, social laws, and social discipline.

These more or less independently organized systems of thought and action have a common origin in vital experience. Their roots penetrate every phase of organic life, extending even beyond instincts and purely organic reactions, into the domain of the inorganic world, where life itself has its origin, and from which it still draws its working materials and powers.

The more immediate basis of these great physicopsychic systems was an elemental, but a very practical nature-science; the ethics and morality of plant and animal life, the self-constructive action of the cat, the mouse, and the nut, of the ape, the fruit, and the tiger, whereby, in varying degrees, the duration and well being of each life was insured by its conformity to the exigencies of the other, and to the chemical and physical properties of a multitude of other agencies. The cat is of necessity a practical student of the physics, chemistry, and biology of the mouse, just as the mouse, of necessity, is a practical student of the dangerous ways of the cat, the attributes of moving bodies, the physical properties of nut-shells, and the chemical 


\section{GRAND STRATEGY OF EVOLUTION}

properties of their contents. Its life is ordered in such a way, whatever the means of ordering it may be, that on the whole the mouse avoids the cat, discovers the nut, circumvents the nut-shell, gets to the meat it contains, and rightly uses it in self-construction. On the whole, the mouse successfully avoids what is evil, and gets what is good by rightly conforming its acts, or behavior, to its own inner and outer world. To that extent it is obedient to itself and to its outer world: its science is true, its art constructive, and its morality right or profitable, for they rest on the saving and creating basis of cooperative realities; otherwise the mouse could not exist. So also with the cat, the ape, the fruit, and the tiger. And also so with man.

But this primordial science and art, ethics and morality, of organic life was either so familiar, or so fundamental to man's very existence that he did not, or could not, recognize it as such till after the methods and instruments of science had taken on newer and less familiar shapes.

When broader concepts were formed, and more generalized rules of conduct formulated, this primordial nature-science passed over into what we may more properly call the common basis of man's science, religion, philosophy and art.

Religion was the first of the great physico-psychic systems to emerge from this common basis and to assume a form peculiar to itself, partly because of the growing remoteness of its subject matter from the innumerable practical problems of every day life; and partly because imagination and fantasy, speculation and theory, always outrun experience, and extend far beyond the realms where the more immediate tests of 


\section{ORIENTATION OF MENTAL IMAGERY 299}

veracity can be made and answered in terms of life and death, into realms where the more deliberate methods, peculiar to science are not available, or cannot be applied.

But perhaps the chief reason was the crystallization of its imagery into simple formulas, and because of the urgency and the democracy of its message. Religion could preserve its form and continuity through the simplicity of its fundamental concepts, as well as through the intelligibility and durability of its symbols, such as amulets, material images, monuments and temples, and its fixed ceremonials, dancing, incantations and rituals. Man's intangible mental concepts were thereby preserved in wood, clay, bone, and stone, in pigments, and in music, through the pleasurable exercise of his highest artistic faculties. Above all his religious messages, and their accompanying regulations of conduct, were essentially unselfish, democratic, and universal, for the obligations of service and obedience were laid on all alike.

This was not, and could not be the case with science. Science, so far as it was distinct from religion, had no temples of its own save the great temple of nature itself; no processionals, save the moving pageantry of world-life; no simple message intelligible to the great masses of humanity, and no immediate compulsion to action in prospective profits, or in fear. It had no means of preserving the form, or continuity, of its imagery till a more exact verbal language had developed, more enduring verbal symbols were created, and the physical instruments and materials for more numerous tests and records invented.

When its messages did come, they came as mists 


\section{GRAND STRATEGY OF EVOLUTION}

of the morning, or in intermittent clouds and torrents, which slowly raised the general level of human knowledge unnoticed by mankind. The great majority were unconscious of the storms of scientific controversy, or the continuous patter of discovery, but they utilized their accumulating power, nevertheless. Always eager passengers of science, they sailed its rising tides to ever more distant realms, viewing in wonder the otherwise inaccessible works of nature, but as unconscious as were their ancestral apes of the means by which their vision had been enlarged.

These discoveries of science were too intricate and numerous to be apprehended by any one individual. They had continually to be unified and summarized, expressed in ever simpler and more comprehensive terms, called "natural laws," to carry any message whatever. That was necessarily a slow process.

\section{The Tests of Veracity}

The basic, or initial test of veracity, in religion as in every other domain of mental life, is human authority, or the concrete evidence afforded by the bodily presence and well being of him who claimed to have profited by his own experience. The older, stronger, and more successful men being the larger, more enduring vessels of experience, were therefore rightly regarded as the chief sources of evidence.

Science separated from religion and philosophy as soon as it began to seek out and to utilize new and larger sources of evidence than human authority in order to test the veracity of its mental imagery. The mutation in human thought and action out of which 


\section{ORIENTATION OF MENTAL IMAGERY zoI}

modern science evolved, was man's purposeful usage of more stable objects, and of more measurably responsive physical instruments to supplement or enlarge the limited powers of his senses, and to check, or control, his estimates of sensory response. These objects and instruments enabled man to broaden his experience by observations and experiments in new fields; to increase the accuracy and capacity of his memory by the use of records and statistics from countless sources other than himself. Human authority then lost its supremacy and surrendered to the democracy of common things.

To distinguish the true from the false, science submitted man's imagery to the supreme court of nature, resting its cases on the evidence of the yardstick, the balance, and the clock, and upon the total testimonies of the multitudes. On these multiplied verdicts of nature, confirmed and reconfirmed by nature herself, is based man's supreme contribution to his own salvation and welfare. Man was thereby able to verify his trial guesses. And it was but yesterday that man, for the first time, could confidently affirm that his imagery of progress was indeed a reflection of reality.

The reality of this world progress, this lawful action of nature, under whose directive discipline man upbuilds all his edifices, is called Evolution. It is but another way of saying that nature grows, and grows in a self-regulated, profitable way. 


\section{CHAPTER XII}

\section{THE COMPULSION OF NATURE-ACTION IN SCIENCE, RELIGION, ART, AND GOVERNMENT}

The Compulsion of Intelligence-The Expression of Nature's Self-Constructive Ways in Man's Self-Constructive Social LawsMental Reorientation-The Militant Phase of Intelligent ActionFear as a Counter Evil-The Conservation of Mental Rightness through Education-The Creative Value of Truth as the Expression of a Natural Creative Law-The Cooperative Factor, Mental and Moral, in Antmism-The Tendency to Unify and Simplify Natural Phenomena-Rightness as a Saving and Directing Agency in Mental and Physical Action-The Community of Purpose in Science and Religion.

WE have seen that science, religion, and philosophy are more or less coherent systems of thought and conduct, growing out of man's conscious attempts to utilize nature-action in self-construction.

Man's first glimmer of "truth" was the discovery that some ways were good and others bad; some things helped, others hindered; that in order to prosper he must appropriate to himself the helpers and avoid the hinderers, or else subordinate his ways to their ways.

In spite of all his longing for freedom of action, mysterious forces constantly hedged him about, limiting the scope of his enterprises, and determining the outlets to his purposes.

These limitations and compulsions made his errors manifest; they were the chief sources of his terrors, and the compelling instruments to his persuasion; for 
man has ever feared the actual tiger and the storm less than the unknown menace behind them.

Man's impulse was primarily to avoid; then to conquer or to destroy either by the display of force or by the application of force; that unavailing, he endeavored by gifts, supplications, or education to modify or reform these obstacles to his purpose. Failing in that, and his failures were ever competent to make him pliable, his last resort was to reform himself; to learn the will, the ways or the purpose, of these mysterious forces, the better to obey them.

\section{The Compulsion of Intelligence}

This desire to understand, the better to obey, is a self-saving impulse common to all phases of science, religion, and philosophy. When man does understand, the truth thus revealed to him then becomes a new leader and a new instrument to his compulsion. He may resist an unwelcome truth, or he may not immediately honor it by responsive action; but he cannot evade his own convictions. He cannot escape the compulsion of the truth he has discovered, whether he would or no. Its ultimate triumph over him is certain.

With the recognition of acquisition and obedience as primal necessities, came man's recognition of freedom and compulsion; of impulse from within and restraint from without, and of right and wrong. With them developed his power of self-control, or his power of adaptive self-inhibition and self-acceleration, which in turn was expressed in his conduct, his social laws and customs. These laws and customs, written or 


\section{GRAND STRATEGY OF EVOLUTION}

otherwise, formulate more or less accurately and fully what he believes he ought to do, and what he ought not to do, to insure his self preservation and profit, individually and collectively. Just as man's mental imagery was gradually fitted to outward realities by the profits of rightness and the disasters of error, so his conduct, by the same process of addition and subtraction was gradually fitted to his imagery. Hence man's social procedures are the legal symbols of his intelligence. His prosperity and happiness are the proofs, as well as the profits, of his mental and moral rightness; they measure the truthfulness of his imagery and the extent to which he has rightly, or constructively, conformed his conduct to realities.

Intelligence, therefore, is the recognition of these demands of nature-action, and voluntary submission to them. To act intelligently and profitably, man must be disciplined in mind and body into conformity with these realities of the outer world. He must distinguish between his limitations and his opportunities, and recognizing them, deny himself the one, and mould his thoughts and acts to the other. The discipline to which he then voluntarily subjects himself is the same discipline to which nature herself is subject in the possible and the impossible.

Here we may see nature's directive strategy in operation on the field of mental life. For her warnings of disaster and her invitations to profit bend man's anarchistic will to constructive rightness for his own self-preserving and self-creating ends. And the clearer, more comprehensive his vision is, the more imperative are its demands; the more willing he is to obey them, and the more he thrives in his obedience. 
Thus the compulsion of nature-action has its ultimate organic outlet in the compulsion of intelligence. Here, as elsewhere, the directive saving and creative agency is rightness.

\section{The Expression of Nature's Self-constructive Ways in Man's Self-constructive Social Laws}

If every individual thing in nature were made of materials wholly peculiar to itself, and each thing acted wholly in its own way, there would be no natural laws, and there could be no science; there could be no ethics or morality, right or wrong, or intelligent action. Man, even if he, or anything else, could exist, would bump his way through the world with less regularity and less chance of profit than an amoeba, or an atom of hydrogen.

But since man has discovered a very large degree of material uniformity and of mutual regulation in nature, foresight and intelligent conduct on his part, or the preparation for coming events in accordance with past experience, is possible. His ways of acting, especially when they are self-creating and selfpreserving, or when they are more general in their application rather than particular, then become in some measure a replica of nature's self-constructive ways; we then call them social laws, or customs, rather than natural laws.

When man became conscious that his ways were good, he appropriated them to himself; called them his own laws, and in self-preservation demanded their observance. The evil, or bad ways, in self-defense, he rejected, or forbade, or tabooed. As his vision of good and evil became clearer, and his ways and means of 


\section{GRAND STRATEGY OF EVOLUTION}

self expression increased, he attempted to formulate more exactly and permanently these constructive and destructive ways into both more general and more specific rules, or laws, of social conduct. Obedience to his laws he then counted a virtue, called it morality, and guarded and cherished it in others as a useful property to himself.

Written social laws are therefore but verbal formulas to express man's mental imagery of right and wrong within a limited field of nature-action. Because they are so limited, they are not immutable. In fact they must be perpetually remodelled the better to adapt them to the new conditions created by social growth, to the growth of man's intelligence, to the increase of his properties, to larger numbers, and to the ability of the masses to understand more elemental, more comprehensive truths.

We have seen that creative power in the purely physical and organic worlds depends on the cooperative action of various architectural agents, on their enduring physical or chemical attributes, on their distribution in time and space, and on the way in which each one moulds and directs the other into constructive rightness.

In human social life these same factors still play their necessary parts in the creation and preservation of the individual man and his properties. But beyond and above this substratum of unconscious physical and organic cooperation, intelligence enters as a new selective and directive agent, moulding human beings, as intelligent individuals endowed with a new constructive attribute, or a will of their own, into cooperative action. 
Individual acts, or social procedures, are then subject to the inspection of intelligence, repeatedly made to determine their saving and constructive value. According as they withstand or dissolve under these corrosive tests they constitute a crumbling or an enduring foundation for further social growth. And these tests are not merely the occasional tests of the ultra wise ones, but the every day tests of the common tissues of mankind.

The elemental virtues of social life, such as the cooperative safeguarding of life and property, and the recognition of mutual rights and obligations within the circle of the family, tribe, and nation, have withstood these tests so long and so often, that these virtues are everywhere recognized, even by peoples of very limited intelligence, as self-saving necessities.

\section{Mental Reorientation}

It is evident that this mental rightness must be a more or less stable attribute of the controlling majority if cooperative social conduct is to endure, or extend to larger groups, or a higher kind of social life be built upon it within the limits of any group whatsoever.

Nevertheless intelligent action may quickly reverse itself, like an unconscious tropism under changing temperature, whenever man clearly recognizes that the further application of his methods would ultimately defeat his self-constructive purposes. The reversal of man's mental attitude and conduct toward slavery is a case in point.

Slavery was once an approved social institution. It was as old, perhaps, as human society, and was uni- 


\section{GRAND STRATEGY OF EVOLUTION}

versally honored as a necessary part of social life, as much so as marriage and loyalty to the state. But well within a century, it has been stricken from the statutes of every civilized nation, not so much because it had failed to work in the past, or had failed to serve its initial purpose, but because it could not, in practice, stand the stress of further development, and because it could not be intellectually justified as a means to further social progress. Slavery, indeed, primarily had its creative and cooperative values in the mutual services of master and slave; in that respect it was less slavery in reality than in name. It was only when actually carried by its own growth to its logical and inevitable conclusion, and the repeated attempts to build upon it a larger and more elaborate social system failed, that its mutually destructive character was clearly recognized.

The gain in constructive mental rightness thereby achieved was absolute and permanent. But this gain was not so much in the destruction of formal slavery -for social slavery still exists, no less pernicious for its lack of recognition-as in the fact that the philosophy of slavery had lost its intellectual defense.

In recognizing the self-destructive character of slavery, mankind made a discovery in constructive rightness of elemental magnitude. As one of the possible methods of social construction and social growth, slavery was thereby stricken from the mind of man. As a creative social factor, it was as dead as cannibalism. A better way to social growth was opened, the old one closed forever, and an old virtue had become a crime. 


\section{COMPULSION OF NATURE-ACTION 309}

\section{The Militant Phase of Intelligent Action}

The recognition that elemental social truths are saving virtues provides not merely a new means to social life, it also creates the will to cherish and protect these virtues as social properties and guarantees of personal safety.

Thus the abolition of slavery does not in itself represent the whole gain to humanity. This discovery of the way in which things could not be done produced a veritable intellectual mutation, or mental reorientation, of permanent value, whereof the fruits as yet are in the bud.

The sharper, clearer vision of personal peril in slavery created a haunting, ever present fear of it; and out of that fear the purpose grew and the will power was born to seek out the spirit of slavery wherever it lurked, in order to destroy it. When that militant phase was reached, slavery needed but show itself to be attacked as though it were an assassin, or a common enemy of mankind. Here man was evidently acting under the compulsion of a truth clearly visualized; while acting intelligently and consciously, he was nevertheless unconscious of the compulsion under which he was voluntarily acting.

This is a good illustration of the growth of mental.imagery into truth and constructive vital action, showing the usual way in which a mental concept passes through its earlier embryonic phases to the altruistic phase of its maturity. In this case, as in prohibition, woman's suffrage, militarism, and so many others of a similar character, we may see how slavery, as a 


\section{IO GRAND STRATEGY OF EVOLUTION}

problem in social philosophy, passed from an inchoate, sporadic phase to a purely academic question, then into an urgent practical problem, and thence into militant constructive action.

Just such an intelligently aggressive attitude must be created in respect to the philosophy of dominion, the elder brother of slavery, before more enduring foundations for social cooperation can be laid and a broader, more profitable system of social life securely built upon them. The compelling vision of a personal peril must be created within man by every form of social tyranny; a mental vision, clear and sharp as the image of a physical weapon aimed at him and his children, before the will to combat that particular evil can exist, and before the obligation to destroy it can be fulfilled.

\section{Fear as a Counter Evil}

But the vision of truth must still further grow in breadth and clearness, for in every birth of truth is resident a new born evil to test the youthful vision. For once created, fear begets fear, distorts and multiplies its images; sees friends in foes, and danger where danger long since has passed away.

If slavery and dominion are self-destructive, and permanent barriers to social growth, so are the counter evils, freedom, independence, and anarchy. Society cannot exist without mutual services. No one can be free, or independent, and at the same time be an organic part of any society. One must be either a serviceable, or striving to be a serviceable part of the society wherein one is placed, using one's social priv- 


\section{COMPULSION OF NATURE-ACTION 3 I r}

ileges, and performing one's social obligations as best one may to a common end, or be a dead-head passenger, a parasite, or a wilful enemy of society, with no right to exist there, save social negligence.

Social freedom is merely the right to select, or be selected, for the service one is best able to perform. In return for, or in anticipation of that service, society must provide ways and means whereby that service may be effectively and happily performed, or itself suffer self-destructive penalties. Here, as elsewhere, the obligation to serve, and the right to be served, is the categorical imperative to existence.

\section{The Conservation of Mental Rightness Through} Education

Social life derives its power largely from voluntary services intelligently performed. In self-protection, society may justly use its power to eject from, or refuse admission to itself; but the human will, acting under the compulsion of egoistic intelligence is the only agency that can bring social power into action, or preserve the organic cohesion of social life. As society grows in volume and diversity, a more and more elaborate cooperation is necessary, and more intelligence in both leaders and followers is required to direct it and keep it in self-sustaining motion.

This new kind of mental rightness, and the understanding of these larger social purposes, so essential to intelligent action, is not inborn or transmitted through the usual channels of germinal inheritance. It must be reacquired by each leader and follower, either by the slow and costly method of trial and experiment, 


\section{GRAND STRATEGY OF EVOLUTION}

or by personal intercourse, imitation, or communication.

This mental egoism and altruism of teacher and learner, that we call education, is the system of mental inheritance, and the only one, by which society conserves its mental profits, augments its capital in mental rightness, and stabilizes its purposes. It is the great saving and creating factor in social evolution; the most vital spot in social life, and the one most difficult to fortify. A nation, stumbling into ignorance, must be bandaged with restrictions, and propped up with the crutches of force. Pricked by the poisoned shafts of propaganda, it may dissolve in anarchy though the armies and navies of the world have failed to break it. Its vital powers can be mobilized only in a common self-saving purpose, clearly recognized as such, and approved by a common fund of intelligence.

VII. The Creative Value of Truth as the Expression of a Natural Creative Law

The creative value of truth is measured by its mental candle power, or its power to reveal creative ways. The harvest of constructive returns which flow from every great discovery, springs from the revelation of a fundamental unity and similarity in phenomena that appeared to be different in method, or in domain. That all celestial bodies are moved and regulated by a common force; that physics, chemistry and biology have a common basis in atomic and ionic mechanism; that all organic life is upraised on common structural units, or cells, which are activated by common vital processes; and that all social life is based on mutual 
rights and obligations, common to all its constituents, are discoveries of this character.

If man could go further than this and discover that there is one essential, underlying method common to all the creative processes of nature, that discovery would at once give him the creative power of a great fundamental truth. It would give him a more trustworthy historic and prophetic vision than he had before; a more compelling reason for modifying his own acts, and a more certain means of directing the creative acts of nature to his own profit. In all his own creative acts, it would be this creative way of nature that he was actually following, even though he knew not what the forces and materials were with which he was dealing. This truth would be to him the "law" which he must obey, willingly or unwillingly, if he is to succeed in his efforts further to upbuild his own life individually and socially.

Progressive creation through better mutual service, is such a truth and such a law. It is a still broader expression of the basic unity and similarity which pervades all natural phenomena. It is the most comprehensive truth man has discovered for it is applicable to all the serially constructive processes of physics, chemistry, and astronomy, as well as to those of organic and social life. It is more comprehensive than evolution itself, for progressive cooperation is the agency that everywhere produces evolution. Or, stated in another way, evolution is the architectural manifestation of the cooperative law, expressed in graded products serially created. While the progress of evolution within the various realms of nature may be temporarily checked, or accelerated, or its direction 


\section{GRAND STRATEGY OF EVOLUTION}

diverted by local events into minor currents and eddies, neither its underlying power, nor its methods, nor its forward drift, as a whole, are thereby sensibly changed, or evaded.

The dawning consciousness that all these minor constructive processes of nature are but different phases of one universal creative process is pregnant with all that man may hope to realize; for the revelation of nature's basic strategy, of the enduring unity and similarity of her creative methods is what gives man his peculiar powers of retrospection and prophecy, his constructive influence over nature, and over himself.

His discovery of nature's way of destroying, creating, and preserving her products, thereby, in some degree endows him with her own constructive rightness, and to some extent with her own creative power. For an intelligent act is one wherein, for his own profit, man seeks merely to guide nature's existing agents into their own ways of cooperation. There is no measure of its increase in value save the increase of constructive returns.

Man has no creative power of his own save rightness; none save the will to direct and short-circuit nature-processes, till a more constructive way is found. When that is rightly done, things make and preserve themselves. But man, more than any other animal, knows how things may, and may not, be done. Therein lies his distinguishing attribute; in the use of it, his happiness. Therein is he dedicated to a service beyond himself, moved by that missionary instinct of super-service which animates all discoverers and givers of profits. 


\section{COMPULSION OF NATURE-ACTION 3I5}

When man became conscious of this power in himself, he became an organic, creative will; a new instrument of nature to constructive rightness, and a new means to a new era in evolution. The moving power behind this will to create is the compulsion of his possessions in mental rightness.

\section{The Cooperative Factor, Mental and Moral, in Animism}

In man's earlier attempts to interpret nature, no fundamental distinction was drawn between animate and inanimate things, and he rarely recognized a constant relation between cause and effect.

Having no written language to symbolize his mental imagery, he had no stable means of mental conveyance from man to man; no reservoir of memory-symbols in which to store up the fruits of his experiences neither for his own future use, nor for that of succeeding generations. He therefore had little or no means, beyond his own personal experience, of correlating one event with another, especially the ones of less frequent, or more irregular occurrence. Being without these means, he was compelled to invent them the easiest way on the spur of the moment. It is not so surprising that his first inventions were so varied or that his trial explanations of natural phenomena were so wide of the mark, as that he should have felt compelled to make any at all.

The Papuans, a primitive race of New Guinea savages, it is said, do not recognize that there is such a thing as natural death, or death by inevitable internal causes. However that may be, the Papuan is always 


\section{I6 GRAND STRATEGY OF EVOLUTION}

ready with some self-satisfying explanation for anything that may happen to himself, or to others. If he sickens, or is about to die, it is due to the superior power, or witchcraft, or absent-treatment, of some invisible human enemy, or of some offended plant or animal totem, or of some other nature-personality, who to him may be very present and very real. If he stubs his toe in the forest, he is little likely to count it his own fault; rather will he attribute his disaster to some stick or stone lying in ambush for him, which with devilish malignity rose up in the nick of time to accomplish its purpose.

Like many other primitive people, and indeed like many educated persons in our most civilized communities, he attributes miraculous powers to curiously shaped sticks and stones and other oddities, which are carefully sought for, treasured, and reverently worn as protective charms, or amulets. Even the more cultured races have pictured the great forces of nature, such as the sun, moon, and stars, thunder, wind, etc., as living things, or as man-like beings, but on a larger scale, and have persistently interpreted their acts and motives in terms of human life.

The Greeks and Romans, in certain periods of their evolution, endowed practically every familiar object, or event, even the more trivial ones, with a presiding, or controlling, spirit.

All these amulets, totems, and personified physical forces, are supposed to have peculiar powers of their own, and to be animated with some good or evil purpose. In effect, it is believed that by due respect, by submission to their "will," or ways, or by appropriate gifts and ceremonials, or even by threats to withdraw 
allegiance, their purposes may be, so to speak, adaptively modified, or they may be in some way induced to preserve or augment the petitioner, and to nullify, weaken, or destroy his enemies.

This primitive attempt to obtain desired results by obeying, yielding, or giving up something of one's self to an unwilling power, and thus by means of these gifts, or additions to it, helping, inducing, or compelling that power to modify itself, or to make up its own mind how to act, is an important step toward bringing about that mutual adaptation which is so essential to all cooperative action. The creative principle utilized is right, for it is the only method that can give creative returns. The specific application may be largely, or wholly, wrong.

IX. The Tendency to Unify and Simplify Natural Phenomena

But we need not further recall the familiar facts of animism and anthropomorphism. They are easily accessible. What I wish more particularly to emphasize is that as man, consciously, or unconsciously, tried to find cooperative explanations of natural phenomena, explanations that would work together to strengthen one another and at the same time strengthen and preserve himself, or serve as guiding principles in the better conduct of his own life, he gradually reduced his legions of warring gods and devils to a smaller number; that is, he unconsciously classified natural phenomena into larger and larger groups presided over by more powerful "spirits," or more comprehensive agencies. 


\section{I8 GRAND STRATEGY OF EVOLUTION}

In Persia, in India, and on the shores of the Mediterranean, we may see these preeminent agencies slowly emerging from the mists of ancient thought, each taking a form and sovereignty somewhat apart, and each reigning over all the minor agencies of a similar kind under a broadly significant term, or title.

Thus in Persia, in the religion of Zoroaster, the dominant thought is the universal conflict of constructive and destructive forces, of good and evil, of Ahrimet and Ormazd. In Hinduism, the great mother religion of the East, there is Brahma the creator, Vishnu the Preserver, and Siva the destroyer. And in the Christian religion, the thought is focussed more and more clearly on Jehovah, the one God, who is the creator of all things and the source of all that is good; on one supreme devil, or Satan, the destroyer and the source of all that is evil; and on Christ, the saviour of the world.

This reducing and embracing tendency in the cleavage of religious thought is the same phenomenon we see so clearly in the development of science and philosophy, where, under the increasing compulsion of larger experience and broader intelligence, man sees more and more clearly the fundamental unity of the universe, and absolutely refuses to subdivide his concepts of nature, where no division in nature exists.

But religion could reach this more advanced stage more quickly than science, because she was primarily concerned with the larger, more comprehensive necessities of life. She was temperamentally incapable of seeing the multitudes of confusing details in the physical and organic world immediately about her; with them she was not concerned, and by them the course 
of her conscious life was little perturbed. On a free and easy logic, and without mental compunctions, she rode rough-shod over minor obstructions straight for her goal.

Science, although not necessarily more cautious, took the longer and safer way to reach her conclusions. She had from the outset the stolid, neuro-muscular temperament of the artisan, rather than that of the master, the singer, or the spinner of alluring verbal webs. She was intensely interested, and wholly absorbed, in the beauty and perfection of the mechanical details of nature; perpetually losing herself in the endless mazes of purposeful adaptation of form and movement to definite constructive ends; watching in dumb and lingering amazement the big and little elements of the living and non-living world lose themselves in one another and free themselves again; or turn and halt, rise and march, and fall and separate, in an endless swirl of music, color, and pattern, apparently with no other cause or reason than their own good will, or inherent impulse.

Science could not logically unite the elements of nature into distinct mechanisms, and these mechanisms into one living, self-sustaining system, until she was better able to estimate the capacity of nature's resources, and to visualize the connecting links, the reservoirs, and the pathways through space and time, over which the driving power of nature was received and delivered, or held in reserve.

She was unable convincingly to summarize in general terms her multitudinous impressions, or to visualize the physical and organic universe as a unit until her discoveries of more comprehensive laws, such as 


\section{GRAND STRATEGY OF EVOLUTION}

thellaw of gravity, the corpuscular structure of matter, the unity of heat, light, and electricity, evolution, the cellular structure of living bodies and the mechanism of heredity, broadened, and clarified, and steadied her vision, and forced her to reduce her own gods and devils to a smaller number.

Thus science, like religion, under the compulsion of a growing intelligence, has been forced to abandon, one after another, her older deities, or to unite them into larger, and again into still larger categorical fractions with smaller denominators. She now calls them matter and energy, or merely an infinite "something" acting lawfully and serviceably in time and space, which without that "something" could not exist.

These magnified and unified gods of modern science are as impalpable, as indefinable and all embracing as those of modern religion. They are indistinguishable from one another. In their saving and creative attributes they are identical.

It was, therefore, inevitable that in the blindness of their youthful ardor, science and religion should come into conflict, for each saw in the other a deadly enemy intent on destroying all the other held most true and precious. Today, with clarified vision, and with the relics of a barbarous youth eliminated, each will see in the other only a collaborator.

Philosophy, in so far as she was able to stand on her own feet in a province of her own, has generally had more intimate, perhaps more friendly relations with religion than with science.

Philosophy occupies an intermediate position, and as a medium of intellectual assimilation and exchange has served to unite and adaptively modify the two ex- 


\section{COMPULSION OF NATURE-ACTION 32I}

tremes. She is chiefly concerned with the larger problems common to the whole domain of constructive thought, rather than with the formal, dynamic, or architectural processes of nature, and as an ostensible neutral has often served as a court of appeal in religious and scientific controversies. But philosophy could not rightly perform her functions till the natural sciences brought her to earth, and in the architectural realities of a physical world provided a substantial footing for her metaphysical abstractions.

\section{$\mathrm{X}$. Rightness, as a Saving and Directing Agency in} Mental and Physical Action

Thus the upbuilding of all constructive mental processes, like the upbuilding of cooperative organic structures, necessarily develops along definite phylogenetic lines. Like living things, they expend their resources in protozoan mental wanderings, or in haphazard trial explanations, in pursuit of profit. Finding profit in rightness only, they are gradually stabilized in rightness and oriented by directive realities, as zigzaging swarm-spores are stabilized and oriented to rectilinear light. Because they are saved by truth and grow by the acquisition of truth, they progress on converging lines toward a universal truth, with the same purposes, the same increment of illuminating thought, and with the same creative results.

Thus, whatever his ethnic, or geographic origin may be, or along whatever lines his mental activities may specialize, man is always drawn in the same direction; and compelled to face the same basic problems. What is good and evil, right and wrong? How may 


\section{GRAND STRATEGY OF EVOLUTION}

the one be found, the other avoided? How may man live profitably?

Has not that been the history of science, that breaker of false images and unwelcome intruder on the domains of religion and philosophy? Are not those also her ultimate thoughts and purposes? Does not science aim to follow, step by step, link by link, the chain of cause and effect, backward into history and forward into prophecy, in order to discover, as nearly as may be, how things are created, or "happen," or come into being; how they endure, or survive, or are saved; how they are constructed, or organized; how they grow, or profit; how their growth is checked and accelerated; how they are disorganized, or destroyed; and how man himself may profit thereby? Or, in still simpler terms, how can science help man to attain that which is good and avoid that which is evil?

To these basic questions the same answer always comes back, clothed in similar meaning, if not in similar terms: Mutual service creates and preserves. The profit is in rightness.

Fitness and adaptation, those conjuring words with which the biologist so blandly performs his tricks, and conceals the way he does them, are but other names for rightness. In any particular case, adaptation, in action, is the finding of the right way of doing that particular thing, and avoiding the wrong way. Fitness, or adaptation, as an accomplished fact, is the manifest evidence that in that case, and to that extent, the right constructive way has been successfully found. Science first points out these facts and then seeks to discover how these ways are found.

And science finally reveals to us that nature's way 
of self-construction and self-conservation, although exceedingly intricate and variable in detail, is very simple and invariable in principle. It is a universal cooperative system of mutually profitable give and take; a system of reciprocating egoism and altruism, whereby more serviceable agents are created for use in larger creative enterprises.

When once a right way is found, a more secure foundation is laid for further construction. That is the reason why there are such things as great lines of evolution, or progress. That is the reason they are so continuous, direct, and cumulative in some one or more particulars, or as the biologist would call them, orthogenic. These lines of progress may be called, with equal propriety, the pathways of constructive rightness, in so far as that particular way, or condition, is concerned. The limitations to progress in that particular individual thing are reached, sooner or later, according to its own degree of constructive rightness and that of its environments.

Thus in their broader aspects, the evolution of human thought and the evolution of the world's physical architecture follow comparable, or corresponding courses, making it possible to establish profitable cooperative relations between psychic action and organic action, conduct and environment.

The subtle compulsion which moves and guides psychic evolution, leading it persistently toward the recognition of a threefold directorate: creator, preserver, and destroyer, is due to the fact that these three terms symbolize three fundamental attributes, or actual processes, or realities, of nature. These three attri- 


\section{GRAND STRATEGY OF EVOLUTION}

butes are rightly the chief subjects of all man's religious, scientific, and philosophic thought. Rightly to know and to utilize the saving and creative ways and to avoid the destructive ones is the goal of all his endeavors.

XI. The Community of Purpose in Science and Religion

Thus when we analyze the intellectual life of man, we find that its motive is everywhere the same. Man's motive is profit, or growth. Science, which is the organized intellectual life of mankind, has three chief functions, all serving the same purpose,-profit. First, to explore and to chronicle. To that end science aims to discover what things are contained in nature, where they are, what they do, and what the order is, step by step, of their coming in, their growing up, and their going out. Second, to compare, to explain, and to distinguish right from wrong, or how things may, or may not be done. To that end, science aims to discover why things are as they are, in what respects they differ, what they have in common, how one thing influences another, for good or evil, constructively or destructively. Her third function is to act constructively, or to create. To that end her purpose is to regulate man's conduct in profitable accordance with nature's way of doing things. In the execution of this purpose, Science completes its functioning by passing, over into Art, as thought passes over into constructive action.

Thus three qualifying motives pervade science: the acquisitive, the ethical, and the moral. She seeks 
knowledge through experience, wisdom through understanding, and profit through obedience.

But that profit is small indeed that cannot be compounded, added up, rightly placed, conserved, and handed on from life to life, for life again to supplement. The vital power of science is so compounded. Science lives and grows only so far as her profits are conserved, and transmitted through her own peculiar instruments of conveyance to fertile soil, from generation to generation. She shelters no self-corrupting secrets. In the very catholicity of her altruistic give and her egoistic take, in her incoming endowments of truth, and in her educational outgivings of truth, is the warm vital power of an unsatiable appetite and an unstinting benevolence. Science, like life itself, freely gives to fructify, and herself is fructified through her receiving.

In the same way, religion and philosophy blossom into art and constructive action wherever there is this vital reciprocity of egoism and altruism. In the subtle religion and philosophy of the ancient East, and in the religion and philosophy of the modern West, the underlying motives and questions were and are the same as those of science: How was the world created? Why do things live and grow? What is good and evil, right and wrong? What creates, what preserves, and what destroys? What must man obey? How may man profit by his obedience, and what shall the profit be?

While science answers in terms of exact measurements and natural laws, rather than in terms of an anthropomorphic will to create and a will to destroy, she contributes nothing more to the answers, nor can 


\section{GRAND STRATEGY OF EVOLUTION}

she do so, than a greater volume of precise and organized knowledge, based on experience in her chosen fields.

The chief distinction, then, between science, religion, and philosophy, is in the domains of their mental activities, and in their methods of testing the veracity of their imagery. Their basic purpose is the same. And now their methods are losing their distinctive characters; the boundaries of their old domains are mutually over-run, binding the three more closely together in cooperative action. Religion has become more cognizant of present physical realities, more tolerant, and receptive; science more spiritual, humanitarian, and social in its benevolence; and philosophy, like the middle man it really is, gives and receives from both. There is no conflict between the basic teachings of science and the instinctive dictates of humanity expressed in broad religious terms.

Science seeks truth and discovers rightness. Religion seeks righteousness and discovers truth. Both have acquired knowledge of creative and destructive ways, of right and wrong, and both point the same way to right living.

In religion, there is an instinctive desire for truth, benevolence, and righteousness. Nature's way is the truth man seeks to discover, and her way is benevolent: and righteous. Science takes cognizance of it in measured terms.

In religion, there is a formal expression of wonder, adoration, gratitude, and humility. It is justified and satisfied by the contemplation of nature through science.

Religion demands service. Nature is a growing 
fabric of cooperating services. Science surveys the process, shows man the way to service, and provides the ways and means to perform the service.

In religion, there is a formal recognition of our imperfections and a desire for perfection. Natureaction is a conflict of imperfections. Science shows that the conflict is aimed at, and moves toward, perfection. Both serve that end the more the better their own services are organized. Each, in its own way, through progressive adaptation of thought and act to creative ends, reflects the universal ways of naturegrowth and evolution, the way nature herself moves toward perfection.

Science and religion, therefore, always have asked, and doubtless always will ask the same fundamental questions, and they must ever seek the answers to them in constructive action. The answers, whatever they may be, will come to them from the same source, in the same way, and ultimately must be expressed by them in essentially equivalent terms. And their purpose in seeking these answers is to enable man, the man in the streets of commerce, in the study, and in the wilderness, the leader and the follower, rightly to use the lessons of human experience in self-constructive acts to ulterior creative ends; and to mitigate the inevitable tragedies of a life which has become conscious of its aspirations and its compulsions, and which is valiantly seeking to satisfy their demands.

But creative art is never wholly subject to established laws and precedents. Nature's inexhaustible secrecy, that defies all prophecy and rewards all trials, is the source of man's undying hope and faith, his abiding impulse to endeavor. 



\section{PART V}

THE ARCHITECTONICS OF SOCIAL EVOLUTION 



\section{MENTAL IMAGERY AS A FACTOR IN SOCIAL GROWTH}

Conflicting Social Philosophies, Old and New-The Distorted Philosophy of the Biologists-Business Philosophy-Germany's Militant Kultur-The Permanent Mental Incentive in Social Regeneration-Mental Limitations and Unadaptive Social Growths: Primitive Social Life of the Australians; Christianity, Buddhism, and Hinduism; the Cultural Inequalities of the Greeks-Science and the New Democracy-The New Demands of the New Freedom.

\section{Conflicting Social Philosophies, Old and New}

IT is not surprising that the subjęctive and objective interpretations of nature were at first so generally regarded as mutually exclusive. The problem was complicated by a general lack of sympathy with nature-action, a narrow interpretation of evolution by all the disputants, and above all by a bitter struggle for mental supremacy between the leaders of the new science and the old religion.

For countless ages man had pictured natural phenomena as vital processes, or as living processes dominated by living agents endowed with human powers and animated by capricious human motives. Science and evolution dealt a mortal blow to this fictitious universe and set up in its place a dead and empty mechanism. But scientists, theologians, and laymen alike quite generally overlooked the fact that the vital creative power of nature was not destroyed by evolution. On the contrary in all the domains of the physical and organic world, so far as they were accessible to scien- 


\section{GRAND STRATEGY OF EVOLUTION}

tific inquiry, evolution made that creative power more clearly manifest; and made it more intelligible for it was seen to be more lawful in action. It was also quite generally overlooked that man derives his creative power from some kind of benevolent action, from mutual service and rightness; and that the methods by which he attains his ends are the same as those by which he himself was created.

\section{The Distorted Philosophy of the Biologists}

One of the chief causes of his misunderstanding was the common error of failing to distinguish between evolution, as a universal phenomenon, and the various attempts to explain some particular phase of evolution.

A period of calm was necessary after the more violent discussions, before even the more sagacious evolutionists could clearly perceive that natural selection, the most generally accepted explanation, was not in itself a true creative process, but merely a name for a multitude of interacting agencies by which things already created were selected for preservation. But long after this period of mental reaction, for some unaccountable reason, biologists persistently magnified the goddess of chance and exalted the reign of force. They persistently exaggerated the selfishness and failures, the "wanton destruction" and the tragedies of life, and minimized the gains that were so manifest in a benevolent order. The shallow philosophers, statesmen, and sentimentalists were not slow to catch the dominant note, and to join in a noisy chorus, wherein the reiterated thought of a warring, hostile nature, "red in tooth 
and claw with ravin," was the recurrent lash in their poetic frenzy. Many good souls joined in the chorus out of pure imitativeness, others because it helped to soothe an uneasy sense of social unrightness, or appeared to justify whatever special privileges and immunities they possessed, or eagerly sought to acquire.

It is evident to every thoughtful biologist, I believe, that this cynical view of nature-action is superficial, morbid, and absurdly tragic. Much of it, very much indeed, is wholly fictitious and imaginary, and has done incalculable harm. It has produced an insidious pseudo-scientific philosophy of life, based on a wholly false biological foundation. It has fortified a false social philosophy which sees in social parasitism, in self-aggrandizement, in measureless acquisition of arbitrary power, the goal of a successfull lifé, and one which seeks to justify itself by an appeal to the struggle for existence, the elimination of the unfit, and the survival of the fittest.

The philosophy of robbery is difficult to combat because it is always easier to point to a successful thief than to prove that honesty is the best policy. In the great world of nature-life, it is all the more difficult to combat this half-witted philosophy of unadulterated egoism because animal robbers and animal parasites flaunt their ephemeral successes even more conspicuously and shamelessly than man, while nature's more basic system of cooperation and mutual service, interwoven as it is in the most intricate manner through age-long periods, is not so easily understood, and its results are so commonplace they fail to attract attention.

Thus in this new world of intellectual freedom 


\section{GRAND STRATEGY OF EVOLUTION}

which man was invading guided by his first visions of evolution, his age-old standards of ethics and morality were rapidly destroyed. The more remote sources of creative power were forgotten, or concealed in the ruins of his anthropmorphic religions, or overgrown with the poisonous thickets of his new doctrine of selfishness. His belief in the supremacy of force, and the necessity for complete freedom of action, grew apace; his sense of obligation and restraint, his recognition that it was necessary for others to have the same freedom of action, and that he was under obligations to insure it to them through his own services, slowly atrophied.

\section{Business Philosophy}

It was this one-sided, or half-witted philosophy of egoism, fortunately now in disrepute since its pathological nature has been so clearly recognized, which characterized the business ethics and morality of the past generation, or more. "Business was business," for no other than purely selfish ends, and any ways or means within, or beyond, the written law was justified so long as it brought immediate returns that could be measured in money and social power. That business is also an altruistic, public service, and commerce, a system of cooperative social conveyance, was but dimly recognized, if at all.

But this philosophy was not more characteristic of Americans than of other peoples, many critics to the contrary notwithstanding. At any rate, if the accusation is justified, the lavish gifts of American business men to education, to medicine, and to other social institutions, has amply demonstrated that their business 
philosophy and their social philosophy were not the same. They evidently recognized, more clearly, perhaps, than their critics, that a cumulative system of social benevolence is an essential factor in all social growth and social preservation.

\section{Germany's Militant Kultur}

It was this false, shortsighted philosophy of the biologists which was so largely responsible for the world war. German scientists were among the very first freely to accept the Darwinian theory of evolution; and German leaders were the first frankly to incorporate into their politics, their business, their philosophy, and their religion, the most pernicious teachings of the struggle for existence and the survival of the fittest.

Germany's concept of world politics was the result of her deliberate application of scientific principles, particularly of biological science, to international life. Her international policy was a purely scholastic effort to profit by a clearer understanding, and better imitation of animal life and natural laws. In that respect her purpose was wholly justifiable, and her efforts commendable. That her concepts of nature-action were false is pardonable; in that she did not, and does not, stand alone. But the practical application of her theory of social life, with all its sordid, heartless, and criminal details, could have been possible only by an unimaginative people, whose moral instincts and social idealism were too immature, or too firmly suppressed, to rebel against the logic of its demands.

Germany is the unfortunate victim of her own policy, faultlessly executed. She has proved the falsity 


\section{GRAND STRATEGY OF EVOLUTION}

of her own concept of world life by the elaborate way in which she has dissected and exposed her own mental attitude toward life, and by the unflinching manner in which she has executed the preposterous demands of her own logic.

She would not be convinced by the mere "reductio ad absurdum" which was the manifest outcome of her moral system. She must have it actually demonstrated on her own person, by her own disasters. This moral corruption, like a running sore, poisoned her whole intellectual system, nullified her physical powers, and led them to inevitable disaster. The fetor of her dissolution already pervades the house of man, and moves man, as death always does, to fear and foreboding.

But the world will be the better for this practical lesson, for it can now more clearly see the inevitable results of this policy. For Germany, with scientific precision, has demonstrated to the world, using in the experiment all her incomparable resources of power, physical, intellectual, and administrative, that selfishness, for nations as for individuals, is self-destructive.

It must be conceded that in her internal administration, Germany made good use of cooperative principles and succeeded in creating a powerful empire. But she lamentably failed in her larger purpose, because the scope of her cooperation was narrow and self-limited. She lacked the missionary spirit which must animate all social units, if they are to live and grow; a spirit which aims to create social power in order to use it in cooperation with other people and other nations for mutual welfare and world-service.

It is commendable to put one's house in order for 
its own sake, but it is all the more detestable if the real purpose is deliberately to create power in order to insure efficiency in the robbery and destruction of some other household. This larger criminal purpose of Germany has been revealed. It was doomed to failure because it was sure to destroy the very qualities upon which its whole life depended.

Militant kultur is a very simple and a very old philosophy. It is the philosophy generally defended and practised by those people who have achieved some measure of so called success. It runs somewhat to this effect. Progress is the creation of more intelligent and powerful people. It is accomplished by providing for them better servants and helpers to do the necessary, but less important things in life. The servants are the weak and the stupid, the unfortunate, barbarous, or undeveloped members of the human race, whom nature benevolently provides for the born master and leader of men. His function is to herd and housebreak these helpless ones, force them to feed out of his hand, man his machines, and drive his chariots.

Germany's militant kultur was the application of this type of philosophy, on a magnificent, international scale. It aimed to make German citizens more docile and capable servants for a dominant ruling class; and to make the world at large a fatter and easier prey for Germany. It was an automatically self-destructive process, because it tended to destroy the very instruments and sources of her own social power. Like all forms of parasitism and slavery, and "militant kultur" is nothing more than that in principle, it inevitably results in a disastrous unbalancing of the giving and receiving processes, leading to the undue weakening 


\section{GRAND STRATEGY OF EVOLUTION}

of the citizen host and to the degeneration of the parasitic ruler. The more efficient the system, the more deadly its effects, and the greater the catastrophe when it breaks down under the final test.

One of the chief sources of Germany's growth in power was the development of her science; her deliberate prostitution of science was one of the many causes of her destruction.

The egoistic and altruistic spirit of science, the craving for truth for truth's own sake, and the impulse, when once it is found, freely to convey truth to those who have it not, is man's most precious possession; for truth is the only creative attribute which by right of conquest he may justly call his own.

But when the trained scientist, the dedicated disciple of truth, is deliberately perverted into an artful propagandist, or a scientific instrument of intrigue, whose chief purpose is to scatter lies and create confusion and anarchy abroad, the better to fish in troubled waters, the very spirit that created him is poisoned at its source, and science itself is destroyed. The spirit of science and the spirit of intrigue are mutually exclusive and mutually destructive. They cannot flourish in the same soil. For no man, or nation, can be an effective conveyor of lies and truth at the same time; success in the one attempt automatically excludes success in the other.

Or consider the egoistic philosophy itself. A purely predatory system must live and grow on the exploited, hence it is limited in its growth to their resources. When those admittedly inferior resources are exhausted, but two alternatives are available, each ending in self-destruction; that is, either the system must 
radically change its character, or turn inwards on itself, and consume itself.

When, for example, the exploited race, or class, or nation, is weakened, or threatened with destruction, it cannot be restored by any effort on the part of the exploiter, except through some form of assistance which, to serve its purpose must end in the transformation of the predatory system into a benevolent, or cooperative one.

On the other hand, in times of stress, external sources failing, the true disciple of a predatory system cannot logically deny the right of each member of that system to attack and consume the other, since all the reasons for friendly cooperation in the robbery of the common enemy have disappeared. That way also, madness lies. His system, therefore, contains no ultimate refuge in an enduring, self-saving principle. It must either dissolve in internal anarchy, robbery, or social cannibalism, or change itself into a cooperative system.

A house divided against itself cannot stand; a government cannot endure, half slave, and half free; a system, of any kind whatsoever, cannot be upbuilt on antagonistic principles, part militant, part cooperative. It will ultimately break down into separate antagonistic systems; or one part will destroy, or neutralize the other, or be to the other a non-contributory burden, a foreign element in the system, not an organic part of the system.

A cooperative system may be destroyed by a militant one, but there is no power that can destroy the creative principle in cooperation, for that is indestructible; or that can make a militant system creative, save 


\section{GRAND STRATEGY OF EVOLUTION}

only so far as it is not militant, but mutually serviceable within itself, like a gang of thieves living on the profits of other people.

A social system, mutually serviceable to its constituents and to its foreign colleagues, embodies within itself the principle of perpetual growth and immortality.

But that saving principle will not become a compelling incentive to cooperative, self-saving action till that fact is clearly recognized, or becomes intelligible, or becomes for man what we call truth, or reality.

In balancing the constructive value of contingent profits and losses, the more immediate demands must necessarily take precedence over the more remote, otherwise there would be no saving basis to build upon.

\section{The Permanent Mental Incentive in Social Re- generation}

A fundamental attribute of man, underlying all his variability as an individual, is his sociability, or his tendency when in contiguity like atoms to combine in social molecules. For each human atom, according to his personal peculiarities, finds thereby a larger saving usage for his strength and a better servant to his weakness.

The immediate result of association is a self-reinforcement, that may, or may not, be recognized. But as this result is one of man's most frequent and impressive experiences, it is one of the first truths to be impressed upon his conscious life.

Hence when this fact, or truth, or certainty, is 
recognized, the prospective gain in this elemental cooperation then becomes the incentive, or the compelling motive to social cooperation, a motive as immortal, or enduring, as elemental human intelligence. All the existing social systems of man have been upbuilt, consciously or unconsciously, willingly or unwillingly, by the use of these cooperative methods.

They fail, as every other growing system fails, when the limits of cooperative coherency are reached; when the mutual give and take become unbalanced or unjust; when the currents of profit, duly earned, persistently set in one direction and there are no compensating returns from obligations elsewhere duly performed; when the will to service is fattened by parasitism to inaction, and poisoned by privilege to insensibility; when the channels of service are hardened by conservatism and clogged by formalities which destroy the power of adaptive response; and when the instruments of conveyance, to and from the outlying and submerged, are unable to fulfil their elemental functions. When any one or more of these social conditions arise and are not adaptively rectified, a pathological condition is produced comparable with organic disease, or senility, in animal life. Something then breaks, or fails duly to perform its functions. Social atrophy, hypertrophy, or paralysis, may then ensue; or some vital social organ falls, or rises in rebellion. Death then mercifully enters, followed by dissolution, and clears the ground for a new attempt.

Dissolution may be gradual or catastrophic, but in any case the surviving fragments, like swarm spores, or ovum and sperm, then reunite to form new struc- 


\section{GRAND STRATEGY OF EVOLUTION}

tural patterns, or redissolve in one another to form new social mixtures which grow again and reproduce new social generations in new environments.

This indestructible social attribute of man is the hereditary germinal factor in society which endows society with its immortality. The repeated attempts to find a better way cooperatively to unite diverse human individuals supplies the diversifying factor in social development analagous to sexual reproduction. Ultimately these fertilizing unions provide new means of social salvation, and direct the subsequent social cleavage and the upbuilding of social institutions throughout the embryonic and youthful stages of sociiety to a new maturity.

This repeated dissolution and regeneration of social life does not differ in any essential respect from the death and reproductive regeneration of individual life.

But no living organism in death normally disintegrates into its ultimate elements. Some of its gains are permanent. Besides the more specific germinal elements of life, other parts survive after the parent organism dies, or has severed its connection with its offspring, such as egg-yolk, foods, and various administrative provisions supplementary to the living germ. They enable the new life safely to bridge over the more precarious initial stages of growth, insure its welfare in youth, and its guidance into right developmental channels. The longer these renewed developmental journeys are, the more bounteous and righteous these ancestral provisions must be. And so they are.

So also it is with social death and regeneration. The culture of social life is seldom, if ever, wholly extinguished. Through many winters of discontent it 
may dormant lie, and come to life again long after its social parents have passed away. New civilizations incorporate the more stable elements of its constructive rightness into themselves, revitalize them and utilize the accumulated profits contained in its literature, arts, and sciences, for the upbuilding of a new social life.

A new race, or a new social system may then feed, vulture-like, on the carcass of a dead, or moribund, civilization, but it cannot rise to the former level by those means alone. It will itself die when its resources in the dead are exhausted, unless it holds within itself the elements of a self-sustaining, creative power.

Or the life of a social system may be prolonged by sacrifices, by self-control, and by the corrective medicine of equal justice. But good will is not enough, nor equal justice, to enlarge the scope of life and insure its further growth and continuity. For a social system cannot grow beyond its powęrs of conveyance to and from the sacrificial altars of individual life. To extend that power, the vision of the truth must be more exact and comprehensive; the instrumentalities of the physical world must be enlisted in its service. Social inheritance can have no constructive value if the heritage makes no effective appeal to the intelligence, for unless that appeal is heard there can be no compulsion to save its heritage and utilize it in self-construction.

\section{Mental Limitations and Unadaptive Social Growths}

In small social groups, cooperative aims are easily attained. In larger groups, where social undertakings 


\section{GRAND STRATEGY OF EVOLUTION}

involve larger factors in time, space, and numbers, broader vision and more intelligence are demanded. But the cooperative instinct then becomes confused, or divided into opposing motive currents which neutralize, or ultimately defeat one another. Man becomes wholly impotent to accomplish these larger purposes when he reaches the limits of his ability to utilize nature's resources, or when he becomes unable rightly to interpret and adapt himself to the internal social conditions created by his own social growth. In these respects society is subject to the same constructive limitations as a growing multicellular organism.

Man's moral instincts, his desire to do the right things, his willingness to make sacrificial offerings, may be ever so strong, but if through sheer stupidity, ignorance, or intellectual confusion in the handling of his larger problems, he does not know what is right, what really is helpful and constructive, his acts are more likely to be suicidal than self-saving, because there are always more wrong ways of doing things than right ones.

We have seen that in organic evolution every forward step in the structural upbuilding of the living animal body has been due to the local enlargement of some organ, or to some functional improvement, followed by compensating adjustments elsewriere.

But these local increments, or improvements, may become pathological and disastrous, if carried too far. They may lead to some form of giantism, or acromegaly; to purely acrobatic specialization; to superfluous ornamentation; or to some form of organic parasitism, all of them of a confiscatory nature. Such monstrous overgrowths, or functional inequalities, 
must be checked, or rectified by adaptive changes and compensating services elsewhere, before the organism as a whole can proceed on its evolutionary way. Similar unadaptive growths are constantly arising in human societies, correlated with some mental limitation, or mental peculiarity.

No one, however, can accurately diagnose all the contributory causes to the rise and decline of these unadaptable social growths; they are many and varied. But from the biologist's viewpoint, it cannot be doubted, I believe, that every great social upbuilding has its impulse in some new birth of social vision, and the finding of new ways and means of social cooperation. We may call them religious, scientific, or artistic revivals. In reality, they are ethical and moral growths; enlarged visions of social rightness, and enlarged powers to act in a socially constructive way. The real source of this impetus to growth, we can no more discover than we can discover why a carbon molecule builds itself up into complex structures, or how a blade of grass grows. All we can do is to observe, as best we may, what conditions are right for growth, help to make and keep them right, and draw our dividends.

The germinal idea within the seed coats of every religious regeneration has been some phase of mutual service between man and man, or between man and his gods, reiterated and reemphasized as a new way of salvation better adapted to more complex social conditions, or to a society wherein the impulse to mutual service and self-sacrifice has become neutralized, confused, or evaded, or wherein, for some reason, rights 


\section{GRAND STRATEGY OF EVOLUTION}

were unequally recognized and obligations unequally fulfilled.

These larger social obligations can not be recognized without clearer vision, nor fulfilled without better instruments. Hence, wherever they have been fulfilled, it has been through some accession of ethical insight and constructive power; some increase in the knowledge of, and command over nature's constructive resources. In other words, through some profitable application of science, which enabled man to preserve himself, and to add to his possessions by such means as shelters, weapons, flocks, and agricultural products, or by enlarged reservoirs of constructive profit, and by better ways and means of conveyance, mental and physical.

But every one of these great social functions, such as science, art, religion, education, government, militarism, intellectualism, industrialism, and capitalism, tends to become more and more self-centred and parasitic on social life. Cultivated for its own sake only, each tends to overgrow and to ramify into countless blind pockets of futility. Its basic, altruistic function drops out of sight, and its organic usefulness as a social servant is gradually suppressed. The social organ is then cut off from its bodily support, and the body social is deprived of an essential function. Degeneration and death follow in the wake of these changes.

I. Primitive Social Life of the Australians. The naked, protozoan simplicity of the social life of the aboriginal Australians, for example, is apparently not due to a lack of sense perception and logic, for he is marvellously acute as a tracker of man and beast, and he can draw surprisingly unerring and most signifi- 
cant conclusions from his observations; nor to his lack of a practical knowledge of animal and plant life, for his knowledge of them is extraordinarily full and accurate, enabling him to live in safety and abundance, where a very capable white man could not, unaided, survive; nor to his lack of a spirit of mutual service and self-sacrifice, for his education in numerous exacting ceremonials, his attempts to augment natural resources through his cooperative totem system, and his elaborate sexual and property regulations, make demands upon his mental powers and self-control which few white men would be willing, or able, to meet. On the other hand, in marked contrast to these capacities, is his total lack of fixed dwelling places, of cultivated crops, of other domestic animals than the $\mathrm{dog}$, and of all but a mere trace of constructive arts. But above all, he has what, to us, is an appalling and unfathomable stupidity and superstition in regard to many of the most familiar and most elemental natural phenomena, and a more than childish inability to fit his life cooperatively to that of his fellow men.

This very primitive social life, like the primitive organization of the jellyfish, was evidently not due to the lack of time or opportunity for development, because, so far as we know, the Australians as a race are as old as any other human race; or to their physical and bionomic environment, for while it is extremely severe and exacting in some regions, in others it is as favorable to human life as any the world affords.

The thing lacking was apparently some subtle mental quality, mental rightness is the only word, to express it, which is essential to social growth and cultural evolution. 


\section{GRAND STRATEGY OF EVOLUTION}

2. Christianity, Buddhism, and Hinduism. No religion has more clearly expressed the idea of universal unity, the equality of social rights and obligations, and the necessity for fraternal love and mutual service, than Christianity; and few religions have been less insistent on the practical application of their ideals. It grew up out of a decaying, pantheistic religion, in a militant social system rich in material constructiveness. But Christianity was slow to eliminate the relics of its primitive anthropmorphism and became overabsorbed in theological disputations and ecclesiastical formalities; it feared and vigorously opposed the growth of the scientific spirit of inquiry and was unable to correct the growing menace of militarism, of industrialism, and capitalism, when they made their appearance in social life.

Hinduism and Buddhism, ${ }^{1}$ with similar precepts, nobly clothed in poetic language, sprang from a more

1 "The great... complex of writings which bears the name of Veda, that is '(theological) knowledge' . . . exceeds that of the Bible more than six times over."

"The most ancient monument in this extensive circle of literature (and perhaps also the most ancient literary monument of the human race) is formed by the Hymns of the Rigveda, since, as regards the great bulk of them, they go back to a time when their possessors were not yet in the valley of the Ganges, but lived among the tributaries of the Indus, had as yet no Castes, no privileged worship, no Brahmanical system of government and life, but belonged to small tribes ... enjoying a primitive life. The Hymns of the Rigveda unfold a graphic picture of all these relations, but especially we can follow in them the genesis of the primitive nature religion of India through its different phases, in part even from the moment when the gods are crystallizing under the hand of the poet out of the phenomena of nature, to the point at which belief in them for the thinking part of the nation begins to grow dim, and is being replaced by the first stirrings of philosophical speculation."

"Parallel with this development of the Vedic theories, there early arose side by side in India, from the germs contained in the Brâhamana's and older Upanishad's, a whole series of philosophic systems .... in which we can trace every shade of philosophical concept of the world, from the crass and cynical materialism of the Cârvaka's up to the orthodox faith in the letter of the Vedas. Six among them were able to obtain the reputation of orthodoxy; ..... the others, and among them Buddhism, were held to be heterodox and heretical."-Deussen. The System of the Vedânta, 19r2. 
comprehensive religious philosophy, cosmic in its creative concepts, rather than theistic. But they ultimately lost contact with the constructive material world and grew into empty mysticism and inaction.

Christianity needed the infusion of the scientific spirit, which it is now receiving, in order to increase its sympathy with nature-action, and to broaden its cosmic concepts. Buddhism and Hinduism need it to draw their thought to present terrestrial realities, and to arm their self-constructive purposes with material instruments.

3. The Cultural Inequalities of the Greeks. Greek culture, rooted in a primitive social soil, narrowly circumscribed geographically and minutely subdivided by political barriers of mutual distrust and rivalry, nevertheless blossomed into social life with a splendor unsurpassed. But her towering art and intellectualism were ultimately sterilized by the limited scope of her social instincts. Greek art lost its regenerative motive with the decline of her religion, which her growing intellectualism devitalized and destroyed, but could not replace. Her intellectualism was selfcentred and top-heavy; its inlets and outlets unduly constricted. It lacked catholicity of receipts and the altruistic spirit of out-going social services. Cut off at the roots from the lower strata of society, and from real communion with the great world of nature-life, it became over-humanistic, aristocratic, acrobatic, and ornamental. Her semi-parasitic philosophers, not more familiar with the intimate life of plants and animals than an Australian black-fellow, rarely sharpened their wits on the whetstone of hard realities, or 


\section{GRAND STRATEGY OF EVOLUTION}

utilized them constructively for compensating plebian betterments. Her intellectualism could not, or did not, test the veracity of its imagery by an experimental appeal to the democracy of nature, and would not submit to the correction of its conduct by humiliating experience with little things and homely.

When her creative resources were exhausted, there was no sufficient motive for mere repetition. She could not, in self-sustaining labor, pay the price of freedom with the unproductive freedom she demanded.

The Greeks, in other words, were unscientific in the constructive usage of their thought and action. Their culture lacked the creative metabolism of a universal give and take, the vital catholicity which gladly receives from all and freely gives to all. It was not impregnated with the regenerative lure of the scientific spirit, which ever leads to new exploits and creates new means to new delights; which ever satisfies and never satiates; which ever calls to new adventures in fields unhorizoned and unexplored, where achievement flows through its countless outlets of employment to the ocean of created things and back again to the sunlight and the soil.

New social systems sprang from the prostrate remnants of Greek and Roman culture, not from quickened parent seeds, but from storm-swept foreign spores that like fungous growths on fallen tree-trunks could never blossom into fruit like theirs.

The remnants of these moribund civilizations gradually broke down into their less perishable elements of rightness. But for centuries their decomposing remains provided an easy living for pale mental parasites and 
patched-up pensioners of progress-grotesquely fashioned in protective patterns of the dead-that flourished on the lifeless body of this red-blooded past. When at last they crawled away into the obscurity of ineffective action, the ground was cleared for a new life, more independent and self-sustaining.

\section{Science and the New Democracy}

After twenty centuries or more, this new life ma. tured, not as a mere renaissance of the old, but as a veritable social mutation; it was a new physical growth in a new environment, using different material agencies under the guidance of a new mental imagery.

The great impetus came with the new concept of nature-growth contained in the doctrine of evolution. When this concept finally ripened into conviction, as it were overnight, the old garment of thought which, like a larval envelop had encased the mind, was ruptured and cast aside. It had served its purpose. Man was no longer a mere imitator of a past that was dead and gone forever; or the slave of a fickle imagination, but the master of it. He forfeited, indeed, his claim to a fictitious kingdom, but gained his rightful place as master builder in the great kingdom of terrestrial life. In the revelation of evolution, man had a new birth of physical and mental freedom. He entered a new world of boundless possibilities, free from baseless terrors and self-imposed restrictions; free to experiment with his treasures, and to appropriate therefrom to his own pleasure and profit; free to taste what is evil and to avoid it; free to seek out the good and to make it a part of himself. 


\section{GRAND STRATEGY OF EVOLUTION}

The incubus of uncorroborative authority, which like a nightmare had pressed so heavily on his mind, was thrown off, and all his vital activities were impregnated with the quickening spirit of experimental inquiry. The liberated agencies of mind and body at once found access to new sources of creative power, and new physical and spiritual growths followed with extraordinary rapidity.

With this broadened vision came a clearer recognition of mutual rights and obligations, penetrating far deeper into the lower strata of life than ever before, revitalizing social life from below, under the far reaching compulsion of this new increment of intelligence.

The emancipation of his mental imagery from superstitions, from classical and theological dogmatism, for the first time in evolution gave free play to his motor impulses, and ripened his thought for its reproductive act. It delivered him from all paralyzing fears, save the fear of a futile life; kindled within him the lust for truth, and set him afoot with his vision.

Armored and armed with the courage of righteousness, he bravely courted nature and won the lovers' sanction to explore the forbidden mysteries of creation. He broke down the phantom barriers of the flesh between man, and beast, and flower; bridged the canyons of the living and the non-living worlds; beheld their protean shapes merge with one another and emerge again, and saw that they were one. All the social institutions of man, however hallowed by custom and antiquity, were subject to his questioning and his renovation. The silent sanctuaries of the dead were robbed of their ghostly terrors; the hiding places of the gods 
ransacked and despoiled; and the whole household of nature, sweetened and illumined by his love, was thrown open to public pleasures and profitable usages.

At last the dreadful fictions of the waning mental night vanished in the white light of realities, and the narrow womb of time and space, which hemmed in man's endeavors, opened wide delivering him into a world of unlimited opportunities.

The new-born man was deeply humiliated by his self-revealed nakedness; by his poverty in godliness, and by his infinitesimal insignificance as part and parcel of the material universe. He was deeply chagrined by the discovery that he was but one of nature's countless products, privileged solely by his flickering vision of right and wrong, and wholly dependent on his knowledge of nature and himself for his support. Henceforth his burnt offerings and propitiatory dividends to the gods were to be the sacrifices of a selfconsuming labor on the altar of his fellow-creatures. On him fell the heavy obligation to deliver himself from evil, and to quench his thirst for constructive rightness from the well springs of rightness all about him.

All unconsciously the methods of science demonstrated to man's unwilling mind the universality of his democracy, and his kinship to nature. Neither arrogance, nor pride of place, the humility of misfortune, nor the bitterness of defeat, could long survive the knowledge that man, and beast, and flower, and sun, and soil, are made of the same universal stuff and moved by the same universal forces. That kings and paupers, black, and yellow, and white, are born in the same way, fed with the same foods, respond phys- 


\section{GRAND STRATEGY OF EVOLUTION}

ically to the same stimuli, have the same hopes and fears, pride and prejudice, joys and sorrows; the same rights, the same obligations, and the same end.

When man turned his thoughts away from human life to nature-life, the old values vanished, never to return, and new ones took their places. For science knows no barriers, and fosters no spirit of propagandism. She permits no proprietorship in sun, or moon, or stars; instills no prejudice in poison, and forbids all privilege with death. There is no racial bigotry in heat, or cold, or gravity. The microscope, the balance, and the test-tube speak the same language to all mankind; they tell the same story to England, Germany, and Japan, they tell to me, to you, and to yours.

\section{The New Demands of the New Freedom}

With man's new mental and bodily freedom, and his new discoveries of constructive rightness, all the physical and organic fibres of society surged with expanding life, and with a more profitable social metabolism. The new returns created new demands, and the new demands impelled man to seek, and to find, new ways and means to satisfy them. Mankind intermingled, bred, and multiplied, and with the same basic motives spread their racial rootlets and commercial tendrils into every nutrient nook and corner of the earth, distilling their peculiar qualities into one another, and exercising their mutually adaptive influences on one another, wherever they came in contact.

The physical machinery and the mental vision necessary to sustain this world-wide social organization, put into the hands of social children the most terrible de- 
structive instruments the world has ever seen, and gave them unlimited opportunities to use them for good or evil, as they saw fit. It was not merely that the ancient implements of social conveyance had grown into steel-clad cars, battle-ships, submarines, and airships; into newspaper, cinema, and international postal service. Far more significant than these events, great as they were, was the fact that the vital spots of the whole social system were left open to mental and physical attacks capable of at once destroying countless human beings, and of reducing the survivors to the old levels of barbarism. For the cohesion of this new system was no longer resident in a rigid mental conservatism, or in stable chemical affinities, or in long established social relations of man to man, or to his physical environment; but to good will, to mutual confidence, and to a clear understanding of the new conditions that had brought this new social life into existence and which were essential to its endurance.

And meantime social officers virtually, if not in reality, had been degraded to the ranks because they had lost that distinctive saving power which sanctions authority. The divinity that hedged about the king and priest had disappeared; the gaudy covering of paint and feathers, and the coating of tinselled tradition that served to conceal and protect the social parasite and profiteer, became as transparent and penetrable as air to the newly armed and bespectacled masses. The modern political and business barons, and the lawclad knights of militarism and diplomacy, for their own selfish purposes, had put the all powerful instruments of science into the hands of their retainers in place of the flail, the hammer, and the scythe; and had 


\section{GRAND STRATEGY OF EVOLUTION}

given to them understanding in place of the bludgeons of ignorance. The disciples of physical and intellectual dominion thereby unconsciously fashioned the means to their own destruction, and raised mankind to a higher level of equality in social opportunity, in offensive and defensive power.

The ability to move the masses to united purposeful action vanished when these time-honored leaders lost their authority. They fell from their physical and mental supremacy to the levels of the rank and file, because they no longer inspired a compelling fear of their power to destroy, nor an abiding faith in their power to save.

To construct and control the exacting machinery of modern social life, and of modern warfare, demands long and careful training, and the exercise of the highest intellectual faculties by a large number of individuals. But these mental attributes are the very. ones which enable men to visualize with greater clearness the horrors and futility of war, thus compelling them to cooperate with one another in their common interests, rather than fight one another to their common disadvantage.

The growth of these mutually nullifying factors automatically inhibits the development of any comprehensive system of mental and physical dominion, and will ultimately reduce the danger from great international wars to the vanishing point. For you cannot educate men to the command of physical forces, and at the same time make them insensible to moral forces. A time must inevitably come when there will be no motive sufficiently strong to mobilize these growing intellectual powers for purposes of destruction. Either 


\section{IMAGERY IN SOCIAL GROWTH}

a moving fear will not be there, or the possible profits will manifestly not be worth the sacrifice.

It is only the sharp compelling vision of an impending common disaster, or the vision of common salvation and immediate profit, that can produce in all the members of any social group the same motive for action; and that motive alone can compel cooperative action to a common end. Such a motive for international wars does not and cannot, exist. The clearer man's constructive vision becomes, the more evident it is that the salvation and growth of nations, as well as of individuals, lies in peace, not in war; in mutual service, not in mutual destruction. 


\section{CLASS FUNCTIONS AND VOLUNTARY SUB- MISSION TO LEADERSHIP}

Class Differences a Necessary Condition to Social CooperationSocial Metabolism and the Conveyance of Social Power-Social Cleavage and the Delimitation of Social Units-Social Motives and the Compulsion of Achievement-The Constructive Usage of Intelligence in Social Growth: Mental Dominion; Mental Democracy, or Equality of Authority-The Delegation of Functional Authority and Voluntary Submission to Leadership.

THE inhibitory mental factor in social evolution which automatically tends to suppress great international wars, is less potent to suppress minor, or internal, conflicts. Here the divergence of interests is more fluctuating, the relative difference in individual profits greater, and apparently more easily accessible to correction. It is therefore easier to mobilize antagonistic purposes for prospective gains; and the prospective losses in the struggle for rightness, being less appalling, are not so deterrent to action.

\section{Class Differences a Necessary Condition to Social Cooperation}

Without the structural and functional differences in human beings on which class distinctions are mainly based, no social organization would be possible. For cooperation is contingent on differences not likenesses. Like the various tissues and organs which make up a 
living animal, these differences in human individuals indicate not only the manner in which society actually has grown up and acquired its organization but, in a general way, the direction in which further growth and organization must take place, if at all. Class differences are primarily due to inevitable differences in the time and place of birth of different individuals, and to personal differences in their physical structure and mental powers. They inevitably increase with every stage of social growth. Further social growth, or progress, is possible only by increasing these differences and by finding new and better ways to utilize them cooperatively.

Class interests are those things which are concerned with the growth and preservation of these functional, or class, differences. They are therefore of paramount importance, secondary only to those of individual life. They are essentially the same in every social group in corresponding stages of social evolution.

To understand and to react intelligently to these internal conditions is of more immediate importance than the solution of the larger and more remote problems of internationalism; for when they are understood, and not till then, internationalism will take care of itself in due time and sequence, through the outward extension of the same methods of cooperation to larger groups.

For social growth and organization proceed from the small to the large, not from the large to the small. If man is not at heart truly democratic; if he still preserves the spirit of uncompromising arrogance and the ultimate hope of any kind of dominion over others; if he is not willing to pay the price of social coopera- 


\section{GRAND STRATEGY OF EVOLUTION}

tino in personal sacrifices and self-subordination to the whole, no enduring social or national structure can be upbuilt by him that can sustain the more comprehensive sacrifices of internationalism.

\section{Social Metabolism and the Conveyance of Power}

The really vital problems of state, of empires, or of humanity, are precisely the same kind of problems as those of a family of human beings under one roof, except that in the former instances the households are larger, more enduring, and contain more children.

The only way in which any social group can increase in numbers, in security, and welfare, is through the improvement or extension of the elementary cooperative machinery of smaller social groups; that is by increasing the range, or volume, or speed, of mutual services. All these social services ultimately resolve themselves into problems of the conveyance of power, mental and physical, to and from social constituents, past, present, and future.

The more social life does grow in numbers, the more complex these time, and space, and load, and quality factors become; the more danger there is from the rise of antagonistic, or of non-contributory groups; from over-absorption in local, or class interests; from the loss of social perspective and unity of purpose.

Thus in social life, as in a growing animal organism, all the problems of mutual service necessarily become more intricate with the progress of growth; more difficult to synchronize and readjust in order to preserve that sequence and equality of give and take essential to the maintenance of social metabolism. 


\section{Social Cleavage and the Delimitation of Social Units}

Whenever for any reason, geographic, racial, or psychic, these problems become insoluble, and with growth they always tend to approach that point, social cleavage, or fission, or subdivision into smaller, more centralized groups takes place. These new social groups may then enter into cooperative relations with one another on a different level. The process is similar to that which takes place in living and non-living things when they reach the limits to their power of growth. For, as we have already seen, every system, or individualized thing, such as an atom, nucleus, cell, animal, or plant, has these definite limitations to its size and coherency. They can become larger only when their cooperative instruments have sufficient power to cover those increased dimensions, or to act constructively under those new conditions. The dimension of any system is the expression of the cooperative action of its constituent parts, as well as the measure of their power to cooperate.

In any case, the greater the progress of social growth, the more intelligence, the more toleration, the more sense of obligation, confidence, and mutual service is required to preserve that which has been gained by mutual service. Not only a higher order of intelligence in the social leaders, to solve the more technical problems of life, but a better and more universal understanding in the masses that will make it possible to reach, and to keep some underlying agreement, however elemental it may be, as to the basic purposes of life, and the basic ways and means of achieving them. 


\section{GRAND STRATEGY OF EVOLUTION}

That community of understanding, that agreement in acts and purposes, is the mental basis of social ethics and morality. It is the power which holds individuals together in organic unity. The varying degrees and extent of that agreement determines the cleavage lines of social units, and the union of those units into larger or smaller social bodies.

\section{Social Motives and the Compulsion of Achieve- ment}

Needless to say those social acts and purposes are always two-fold, and reciprocal in their action: (I) to increase the security, happiness, and creative power of the individual through the constructive usage of all the available social agencies; and (2) to increase the security and creative power of the social group, or state, by increasing the creative and cooperative power of all its constituents. The state and the individual citizen are alike involved in this reciprocating altruism and egoism.

On this understanding, vague, narrow, or even semiconscious as it may be, social life has gone far on its constructive way. To retreat now, to repudiate this unwritten covenant, would be suicidal. Death would be as certain for both state and its citizens, as it would be for the body and all its organs, if the heart and brain refused to act cooperatively.

Therein lies the directive agency of acquired possessions, and the mental compulsion of achievement; the inevitable tragedy, as well as the challenge of social life and growth. In the consciousness of these 
social possessions, lies the intellectual compulsion to self-denial and self-saving cooperative action.

As the leaders in social life become more conscious of what man has achieved, they feel more keenly the sense of ownership in social institutions; recognize the constructive value of their heritage, and the dangers that threaten it. They are terrified by their new responsibilities and by the conviction that their own welfare, their own lives, and those of their nearest and dearest, depend not on themselves alone, but on countless scraps of good intentions; on countless vacillating purposes, feeble intelligence, and physical incapacity in other human beings in whom, of necessity, they must place their trust. Therein lies the new and henceforth ever present motive which, in self-defense and selfpreservation, will compel these leaders to serve and strengthen their fellow men, physically, intellectually, and morally.

The old terrors of the unknown, of superstition, witchcraft, and of nature's countless evil doers, which once served as directive agencies, rounding up mankind with a common fear into terror-stricken flocks, compelling him to seek the shelter of familiar haunts and the encouragement of familiar faces, vanished under the reassuring bounty of larger experience, only to be replaced by the new terrors of modern social life. That is, by the fear of overwhelming numbers whose faces are seen but whose motives are unknown; fear of drowning in a storm-tossed ocean of humanity, swept from a sustaining purpose, or smothered into helpless inaction; fear of the instability of his own intentions, and above all fear of the insincerity and incompetency 


\section{GRAND STRATEGY OF EVOLUTION}

of his fellow-man, or that his co-workers will suddenly let go, or change their purpose, and leave him helpless on the brink of disaster. For he now knows that he and his fellow-man have long since embarked on a common enterprise; mutiny and incompetency, no longer mean mere disbandment and a return to the independent life of primitive man, but a terrible common disaster.

The industrial life of to-day is in very truth a perilous voyage of romantic adventurers; a motley company of Ulysses, Jasons, and Sir Galahads, seeking in untried worlds the golden fleece of some new experience, the fountains of perpetual youth, or the sources of creative power. It has ventured far into unsustaining realms, trusting to a slender thread of relays for its support. It can neither move forward, nor stay where it is, nor yet retreat to its base of supplies, if any one of the sustaining links of its support breaks down through stupidity, or treachery, or physical incapacity.

No physical force, or dictator-ship, can preserve the coherency of this social system. Its constituents are held to their services solely by established habits; by satisfaction in the right performance of social functions; by a common understanding of social purposes; and by that compelling sense of responsibility which comes with the knowledge that failure on their part means immeasurable disaster to one and all.

This social cohesion can be no greater than the moral compulsion of intelligence, and the physical ability to obey its dictates.

It will not be denied, for example, that the force of gravity compels more respect, more unqualified obedience in one who is up a tree than in one whose 
feet are firmly planted on the ground. But if obedience, however willing, is physically and organically impossible, disaster is in no wise delayed. In that case, one can live only on the ground; for such a one, to climb is suicidal.

So it is with social life in respect to physical and biological laws. They may be of little consequence to barbarians drawing their sustenance directly from an easily benevolent environment. But to the builders of modern states, and to all those who today depend on the due performance of great social functions, these laws are of vital importance. The superstitions of barbarism, the ignorance of elemental, natural phenomena, are then manifestations of criminal negligence; for in the present stage of social evolution, obedience to an amazing multitude of natural laws is absolutely essential to social life and growth; disobedience means death and social disintegration.

Or to change our simile, modern society is no longer comparable with the traditional ship of state; nor is it like an ocean liner, safely moving on a substantial ocean, its familiar course prescribed from port to port. Rather is it like a giant air-ship drifting in unstable airs, and they who are in it know not where, or how, or why, the ship is moving. Among them all there is no unity of purpose, or desire; no agreement on the course that must be followed, or the rate of progress. Only this they know, and they that know are few indeed: the social ship is riding dangerously high, and drifting farther and farther away from sustaining earth and familiar shores. Supplies are rapidly diminishing, and unequally divided; the officers are incompetent, the crew is mutinous, and there is perpetual 


\section{GRAND STRATEGY OF EVOLUTION}

quarreling over the right ways and means of doing obviously necessary things. Some believe in science, some in religion; some in freedom, others in discipline; some rely on humanity, others on brutality; some follow Wilson, others Aristotle; some put their faith in the things of today, others in the things of yesterday. But no one is able to convince the other of his error; and no one is quite sure whether it would be better to go up, or down, or forwards, or backwards; whether the social ballast is in the gasoline tanks, the parachutes, or the refrigerators.

Who knows how far this bubble may yet expand before it bursts? Who can say when, or how, or where, the countless forces that have produced this over-century industrial growth must be checked, or stimulated, in order to preserve a righteous balance of give and take and the requisite margin of safety?

But it is sufficiently clear that we cannot now retreat. We cannot now go "back to nature" and a primitive life, except through cataclysmic death and dissolution. To live, we must hold fast to what we have, and add more constructive rightness to it. There is no other option, and no opportunity to delay; for complacent death ever thrusts its insistent challenge in the face of life, and defiant life promptly answers the challenge, stands alert to its guard and willingly throws its whole self into the struggle.

There again lies the secret, compelling agency which guides all steps to progress. There again is the inevitable compulsion to still greater service and larger sacrifice which achievement itself creates. Social life has raised itself to what it is by its intelligence, and now must use all its intelligence to save itself. 


\section{The Constructive Usage of Intelligence in Social Growth}

The existence of a physical object, or a living organism, is dependent on the compelling powers which regulate the action of its constituent parts. In social life, these powers are supplemented, or extended, by the compulsion of intelligence.

There are apparently three alternative methods of using that compulsion constructively: (I) By mental dominion, or the compulsion to constructive action of the mentally weak and stupid by the mentally strong; (2) By mental democracy, or the compulsion to constructive action by an equal degree of intelligence in all the social constituents; and (3) By a combination of the first two methods; or by the delegation of authority.

In any case, the underlying intellectual compulsion that drives the individual man to purposeful action is always essentially the same; fear of destruction, loss, or injury; the desire to save himself $\cdot$ and the desire to profit, to increase, or to grow.

I. Mental Dominion. Of these three alternative methods, the first one is definitely excluded as a permanent means of progress, because no class, or group, or nation, can go on growing in intellectual power and in dominion over others, and at the same time deprive its own constituents of the intellectual instruments by which that dominion is created and maintained. The command of these constructive agencies must be general, or diffused throughout the dominant group, else no enduring system of social power can be created. If this command is general, dominion within the group, 


\section{GRAND STRATEGY OF EVOLUTION}

however large, vanishes with the equalization of mental power, and any individual, or minor group of individuals, can then use these agencies as their interests may demand.

There is no way to compel anyone knowingly to act to his own disadvantage when he has the physical power to prevent it; no way to hold back the rising tide of intelligence which, as it sees the way to its own salvation, beats down all artificial barriers to the attainment of its desires.

Hence, if interests lie apart, the system falls apart when that is recognized. If they lie in common, and that is recognized, all the available constructive agencies will be voluntarily utilized to that larger end. In that case, the system automatically ceases to be founded on dominion and becomes a voluntary cooperative system.

2. Mental Democracy. The second method cannot be the way to unlimited social progress because it is impossible for all individuals, young and old, male and female, to be equally intelligent, or to have equal moral responsibiities and equal ability to fulfil them. Moreover a period is soon reached in social growth when no one individual can comprehend all the problems that arise in that social life, and who will have more than an even chance of acting constructively in reference to them. If it soon becomes impossible for one, it will become impossible, at a much earlier, or more primitive stage of social evolution, for a controlling number of individuals to do so. When that stage is reached, consistent progress will be automatically checked at a fluctuating zone where chance alone will be the controlling factor. Further progress can 
be achieved, and consistently maintained at that higher level, only through greater diversity of mental powers among individuals, and a corresponding subdivision of authority between them. In other words, through mutual submission to the guidance of delegated experts.

If that is done, social organization and growth passes over into the third alternative method, which we will now consider in somewhat more detail.

VI. The Delegation of Functional Authority and Voluntary Submission to Leadership

The third method is a combination of the first two. That is, it is a method of growth based on cooperative mental action, or mutual guidance and mutual submission to direction. It is, in fact, an extension into the social group of the familiar principle of functional acceleration and inhibition which governs the selfconstructive action of the living body. It is the only method of social growth that is practically unlimited in its creative possibilities.

Social growth is governed by the same creative law that controls all other constructive processes in nature. This law may be expressed somewhat as follows: Growth always creates progressively diversified conditions within the growing structure. These conditions tend to create, or demand, corresponding diversity in the constituent parts. Hence more diversified constructive agents, and more elaborate cooperation between them, are essential to every additional step in the constructive process. Growth will continue as long as these 


\section{GRAND STRATEGY OF EVOLUTION}

demands are fulfilled; it stops when they are not fulfilled.

In human society, therefore, an essential condition for social evolution, or growth, is a progressive diversity in the mental and physical qualities of human individuals, no matter how it is created, whether by social position, environment, education, or by heredity; and the opportunity, or freedom, to exercise the directive influence of those qualities on other individuals.

In physical and organic things, the directive powers of the elemental parts and organs, or of the whole system created by them, we call physical attributes, or functions. They are relatively fixed, or stable, quantities dependent on the chemical and physical laws which regulate their being. The mutual give and take of these individual qualities and quantities is what, in the broadest sense, we call cooperation.

In the intelligent human individual, acting as a living social unit, this cooperative quality is not fixed, or constant in quantity. It fluctuates widely and rapidly; or, as we say, it is "voluntary," changing with experience, and as intelligence, in self interests, may demand. Broadly spealsing, its constancy can be preserved only so long as the intelligence of the individual, rightly or wrongly, wisely or foolishly, dictates that it is self-saving, or profitable, so to act.

These impalpable forces of the will-as impalpable as those which hold atoms and molecules in cooperation together, but unlike them acting far and wide across time and space-give to social life its sole cohesive power. On this labile basis, the cooperative mental metabolism of social life is founded. 
This new factor in evolution, that we call "will" or "intelligence"-new only in that it has now become manifest to us in social architecture, even as atoms are manifest in material bodies-is a terrible constructive and destructive instrument, almost as potent for evil as for good. It is a growing, benevolent factor, whose gifts are augmented by the receiving, and whose demands are ever more terrifying and exacting.

Education, in its broadest sense, is the constructive influence one thing exercises over another. For society to obtain these constructive results, or as we say "to give them a chance," human social atoms must be brought within the range of each other's influence and be given every opportunity to find that environmental stimulus which will give their peculiar powers the best chance to grow. That is the purpose of the educational chemist.

Those powers, however, will be wasted, developed to no purpose, unless they are themselves utilized; that is unless they also are free to exercise their controlling and guiding influence on others to a common creative end. They cannot be so utilized unless other individuals, in some one or more particulars voluntarily submit, eagerly and hopefully, to their leadership.

But to recognize that creative power in which leadership is rightfully resident requires a high order of intelligence in those who must choose their leaders and submit to their guidance. Not necessarily expert knowledge, but at least an elementary understanding of the ways in which creative power is acquired by others and the purposes for which it is utilized. In 


\section{GRAND STRATEGY OF EVOLUTION}

other words, that intellectual cooperation, or mental give and take, on which the preservation and improvement of our social life depends cannot be assured without a clear understanding on the part of the common people of those agencies which have created the social conditions in which they live.

For in mental, as well as physical phenomena, it is an essential part of the grand strategy of evolution that every new discovery of constructive rightness creates new possessions which make new demands and impose new obligations. These obligations must be fulfilled if the beneficiary would preserve his gains.

We have already shown that the most creative period in the history of evolution is the one in which we are now living. To match this cataclysmic outburst of creative power, we search in vain the whole gamut of geological records, where creative eras are measured in millions of years, and where the constructive gains are small indeed in comparison. These immeasurable achievements and new possessions, create our immeasurable obligations to science.

Nevertheless science is as yet in its glorious youth. It is possible still further to increase its creative power; but it can be done only by'extending more deeply and widely into the social body the mental attitude toward nature-action, and the mental methods which have created science.

That means primarily the abdication of intellectual dominion; the democratization of constructive thought as well as constructive labor; putting, not merely the physical machinery of social life and the instruments of physical power into the hands of the common people, but elemental truths and mental rightness into their 
heads, and the love of nature into their hearts. It means that in education there shall be no diplomatic evasions, no selfish secrecy, and no lying propagandism. That the masses shall be entrusted with all the power of knowledge they can receive and utilize to their own salvation and welfare. That to fight the battles of life they shall not be clad in superstition's rags, nor decked with falsehood's paper caps and make-believe arms of out-worn tradition; but clothed in wholesome truth, and armed with stern realities.

The obligation to give the common people these offensive and defensive weapons lies on the princes of scholarship; on science, and on the church!

Intellectual cooperation and the submission to intellectual leadership, can come only through this larger measure of intellectual democracy and larger measure of mutual confidence, whose source is the common understanding of a common purpose. This understanding must be based on a community of ideals; on an intelligent sympathy with the aims and methods of modern scholarship, using that term in its broadest sense. It must be based on a disciplined imagination growing out of a broader time and space perspective, and a stronger conviction of the benevolent neutrality and immutability of natural laws.

That kind of imagination can come only through some elemental concept of world-progress, physical and spiritual; some basic knowledge of cosmic, organic, and social evolution; of Astronomy, Geology, Chemistry, Physics, and Biology, and the parts they have played in the remote past, and are now playing in the great creative movements of today.

No man without these basic concepts has today a 


\section{GRAND STRATEGY OF EVOLUTION}

fair chance rightly to estimate his own value in the general scheme of nature; to act constructively himself, or rightly to estimate the constructive value of leadership in others. Nor will he, otherwise, voluntarily submit to the exactions which modern science, to an ever increasing degree, must impose upon his conduct in commerce, agriculture, public health and other phases of social life.

It is this kind of understanding our colleges must give to their graduates if they are to fulfil their social services. It is their chief social function to create an intelligent middle class, as a cooperative mental link between the specialists, created by the universities and higher technical schools, and the great body of citizens who cannot readily understand either the requirements for, or the value of, expert knowledge; and who instinctively fear the misuse of intellectual power.

The cooperative unity of social life is wholly dependent on the sanity and good common sense of this intellectual middle class. Without its approval, no progressive social measures can be initiated, or if initiated, cannot be effectively maintained. It regulates and stabilizes public opinion and social conduct; protects one class against the narrowness, selfishness, and over-zeal of the others; and bends the conservative will to new constructive purposes. Only through this voluntary service of one class for the other, and this voluntary submission to one another under the common compulsion of obvious self-interest, can society preserve its organization and continue its growth.

Such a mental social system is upbuilt, neither by freedom nor by dominion, but by both; by the reciprocal mental egoism and mental altruism of pupil and 
teacher. It is a self-regulating system, based on a combination of intellectual compulsion and the dominion of approved leadership. It is precisely the same kind of a system that regulates the conduct of every highly organized animal, or for that matter of every organized being. That is, it is a combination of free, or spontaneous, or voluntary actions in response to invitations to profit; and of self-inhibition in response to warnings of danger, or of destruction. The middle class is the clearing house where these social checks and drafts are balanced against one another, and the profits and losses, as nearly as may be, rightly distributed.

When it becomes perfectly clear that special knowledge, skill, talent, or genius, are social properties held in common, and that they are saving and creative social agencies, freely open to common uses, they then cease to be a source of disrupting envy, become uniting bonds, and a source of pride in their possession. Heavy sacrifices will then be made, eagerly and voluntarily, to preserve and augment these agencies. For then the scholar, or the mental leader, is clearly but an instrument of the other man. Each is then guide and follower in one, and each a source of saving power to the other.

Thus man, in his own selfish interests, will voluntarily submit to dictation and control so long as it is manifest that his leaders are raised to leadership by himself, as servants to himself. Both, then, are one, in will and purpose; the identity of the people is then merged with that of their officers and servants, and theirs with that of their creators.

This community of will, which can spring only 


\section{GRAND STRATEGY OF EVOLUTION}

from the consciousness of common possessions, common interests, common responsibilities, and common control, is the one condition essential to social unity. It is the sole element of compulsion in every intelligent, "voluntary" cooperative system. 


\section{CHAPTER XV}

\section{THE NEW LEVIATHAN}

Quickening World-Life-The Mosaic of World-Life, Functional and Morphological-The Evidences of Organized World-Life-The Ways and Means to a Purposeful World-Life-The State as Sphere of Cooperative Action-The Evolution of Social Covenants-The Government of the State: the Autocratice State; the Democratic State-Education as a Directive Agency to Social EgoismThe State as a System of Cooperative Functions: Social Reproduction; Social Metabolism; Social Betterments-The Extension of State Functions into International Functions.

\section{Quickening World Life}

MANKIND, together with the plant and animal colleagues that have been drawn into the circle of his influences, that thrive under his aegis and contribute to his welfare, constitute a new thing in evolution, which like a living organism is now assuming definite form and action under our very eyes.

The evolution of this New Leviathan out of the sordid, commonplace realities of today, dulls our sensibility to what is actually going on all about us. But we are both eye witnesses and active participants in the miraculous birth of this giant organism which now embraces the earth with its encircling arms. But yesterday, unconscious as a new born child, today it has come into conscious life; and you and I, the very atoms of its flesh and blood, and the instruments of its spiritual power, may calmly sit in contemplation of its inmost anatomy, and measure the ebb and flow of its vital impulses. 


\section{GRAND STRATEGY OF EVOLUTION}

This infant monster is not merely the formless aggregate we vaguely call humanity, although mankind constitutes the denser warp and woof of its social protoplasm. Intermingled with its substance are countless plants and animals, high and low, large and small, living symbiotically with man, guided by his will, and in turn, controlling him; pouring their nutrient and transforming products into these human microsomes, and exchanging their own vital commodities with those of mankind, on precisely the same cooperative basis that man makes his exchange with man.

But, it may be objected, man is a separate living thing; he has a definite form of his own, is made of coherent parts, and moves about at will from place to place, while "society" is stationary, an amorphous, sessile thing, tied to its native soil, and is made up of different things, widely separated, such as human beings, animals and plants, dead machines, books, and material edifices.

These differences, and many others, are obvious enough. But are they really significant, or vital differences? It depends on our standards of measuring time, space, and service values.

A human being starts life as a microscopic germ, and grows to man's estate and power by profitable exchange with the materials and forces of his outer world. His form is never constant, or his content; his materials and directive forces stream in from the outer world, and out again, in countless other ways than the grosser, more familiar ones of feeding, respiration, and excretion. And these same materials, forces, and influences may be used by other living things in a roundabout cannibalism, none the less real because it 
is roundabout. And when we attempt to follow up these vital processes, within the body, they break up into countless larger and smaller ones, mingling inextricably the living and the dead; into organs, cells, and molecules, each a system in itself, and yet interlocking with all the others in a common give and take, with merely nominal, or purely arbitrary boundaries between them, like different departments in one department store. And when the chemist, or biologist turns his sharpest scrutiny on the most vital fragments of life, the dead and the living appear not less mingled than before. Precisely what parts are "dead" and what "alive" does not appear. Only this is sure: what once was dead is now a part of life; and what was once a part of life, is now a part of things called "dead."

And the separating spaces between all these living bodily parts, down to their ultimate elements, appear to be no less real, and no more, in one case than the other, though the dimensions are smaller than those which separate the physical and organic elements in, for example, a great railroad system. But in both cases the action flowing out from all these disconnected, heterogeneous elements is continuous and selfsustaining, merging into larger common currents, and into unified, purposeful action.

What then is essential among all these apparently unessential, or equally essential, things? Evidently, it is the self-sustaining unity of the various systems of give and take; the measure of order, mutual service, and right constructive action within each minor system, and that which ties them all together into larger and larger systems of cooperative systems, which in 


\section{GRAND STRATEGY OF EVOLUTION}

their own peculiar ways are creative and self-sustaining entities.

A red blood corpuscle, for example, itself an organism, but small beyond our unaided powers to estimate, picks out in its own peculiar way its burden of oxygen from the air, or water; and driven by other bodily agents through a maze of capillary channels, delivers its combustion cargo to muscle, and nerve, and gland. And these, in terms of rightly administered bodily actions, feed the corpuscle and pay its transportation and deterioration charges to and from the consumer and the source of its supplies. Which one of all these separate and distinct agencies performs the more vital, or essential service, the oxygen, blood corpuscle, heart, arteries, veins, muscle, nerve, food, or habitat? Where does any one of these services begin or end? Which service could man best omit from his bodily make-up, or which one of these bodily servants could best live and endure without the other?

Does the yeast plant, which ferments the grape, do less for man than the laborer who extracts the wine and stores it in his cellar against the time of need? Does the lamb, which gives its wool to man, do less for man than the tailor that fashions it into a coat? Does the cow, which gives its milk to man, perform a less vital and sustaining service for man than the mother that nurses her own offspring? So also with rice, wheat, potatoes, farmer, miller, baker, birds, flowers, bees, ships, cars, iron, and coal. Do not all these things, and countless more, cooperatively serve to accomplish the common result we call social life?

Evidently, therefore, the existence of this New Le- 
viathan is not dependent on any fixed, morphological, or architectural contours; or on their location in any particular time or place: but on the persistency of their action, and on the continuity of their reciprocal functions. The fractions of time and space which isolate, and which give freedom and individuality to the labile units of social life, are indeed far larger, and perhaps more variable, than those which isolate the atoms of a chemical molecule, or the constituent parts of an ocean liner, or of a social institution, like a college, or university; but this same separating matrix is present in all these individualities, and so far as we may know, it is everywhere of precisely the same nature, immaterial and indefinable. Neither formal aggregation, nor contiguity of substance, is the basic attribute of unity and individuality, whether physical, organic, or social. True unity is always based on cooperative action across time and space, in variable measure; or on the mutual conveyance of directive influences from part to part, in a common creative act.

In this sense, then, the birth of humanity, of a great coherent, immortal organism, is an accomplished fact. In it are now securely embodied the unfailing promises of a vigorous youth. Although its utterances are as yet incoherent and its acts uncoordinated, it is animated by common spiritual impulses and possessed of the physical organs necessary to convey them to all its constituents, and to utilize their powers in purposeful action.

Justly to appreciate the significance of this period in evolution, to grasp the magnitude of current events, or to estimate even approximately their tremendous 


\section{GRAND STRATEGY OF EVOLUTION}

power to transform and to create new social institutions, one must view this critical period against the whole background of organic evolution.

Seen in this universal setting, the past century, to use a convenient unit of time, stands clearly apart as a period of unsurpassed intellectual revelation, of violent social paroxysms, and flocculent political precipitations.

Approximately within that period, an incredibly short time for such world-moving events, the morphological features of many systems of physical and intellectual conveyance, wholly new and world wide in range, have been definitely established. Through their instrumentality, utilizing agencies as intangible as air and as unsubstantial as a dream, but agencies which alone can hold free men together, as with hooks of steel, this formless Leviathan has attained to individuality, to structural unity, and to continuity of action. In this individuality is now resident a stimulating selfconsciousness; a consciousness that mankind has a common origin with other living things, common blood, and common purposes, and that he now possesses the physical and spiritual instruments to translate his purposes into self-preserving and self-constructive action.

It is, therefore, no mere trick of the imagination which pictures this social Leviathan as a quickening maelstrom of the most heterogeneous physical, organic, and spiritual, agencies. An omniverous world-wide plasmodium, greedily incorporating into itself the helpful instrumentalities of all nature life, from bacteria to forests, and from protozoa to man; extending its discriminating industrial pseudopodia into land and sea and air, and extracting from them its sustaining forces 
and constructive materials; metabolizing iron and coal, sunlight, and soil, and moving waters, into vital instruments; sending out its products, its messengers, and its demands to its far flung constituents, and receiving from them, over the crumbling barriers of time and space, and life and death, their reassuring answers.

The universe is its habitat, the earth its den, and the earth, like an egg, is a well provisioned residence. In the narrow cleft, between the more substantial earth and the blanket of its enveloping atmosphere, it lives and moves, and multiplies; riding free the currents of terrestrial circulation; creeping into inviting valleys; crossing nature's bridges as they emerge; and following up the favoring shores of ancient causeways; spreading out, where life is easier, in denser racial spots and larger sprawling patches; linked over no-man's land by thread-like filaments of interlacing traffic; or intermingling hostile bloods, and merging spots and patches into one, the living film at last grows around the world, shutting in its cosmic heritage. East then meets west, and north mẹets south on common territory.

Even so, in a growing embryo, the network of initial blastodermic cells spreads from its initial point over all the surface of its provisioning sphere, enclosing within itself its parental heritage.

\section{The Mosaic of World Life, Functional and Morphological}

But in spite of the basic uniformity of its human elements, the blastoderm of social life appears to our mind's eye as a labile mosaic pattern, an iridescent social checker-board, the architectural product of 


\section{GRAND STRATEGY OF EVOLUTION}

wavering social traits, physical and mental; of shifting geographic, climatic, and biologic conditions, where heredity, political history, and education, play their respective rôles. These agencies, in their all-together working, deflect the streams of social conveyance into specific channels, restrict, or stimulate, the play of social services, thereby outlining the areas of social cooperation, and their intervening cleavage zones.

Thus this terrestrial social film is broken up into specific functional blocks, called states, or nations, or empires. But the intervening walls, like semi-permeable membranes, are never stationary, or impassable, or wholly exclusive or inclusive. They waver from place to place, under the varying osmotic pressure of social metabolism; open or close from time to time, checking the passage of certain influences and allowing others to pass more freely through. The sum total of all these influences is what gives individuality to a given state, or province, marking it off from others as a more or less self-determining sphere of cooperative life, definitely qualified by one or more specific conditions. If we choose to press our comparison, these imperial, national, tribal and village spheres of cooperative social life may be likened to the organic placodes and unlike specific cell groups, or cleavage areas, of embryonic life; civic capitals and local governments are their representative and administrative nuclear centres; and manufacturing districts, or other centres of social metabolism, may be compared with plastids and other bodily organs, where specific industries are localized.

But we need not further press the parallel. Analogies serve a double purpose; for all analogies ultimately 
break down, and in the end better serve to demonstrate the existence of real differences rather than make the resemblances more intelligible.

The main point is that in both cases the individualities that we call cells, or organs, and those that we call social groups, or states, are merely localized spheres of cooperative life of various dimensions. They are situated, it may be, side by side, or surrounded, and wholly enclosed by many others, but in all cases separated and shut off from one another by fluctuating barriers of time and space that control and graduate the range, volume, and character of the mutual exchange between them.

\section{The Evidences of Organized World Life}

In the development of embryonic life, among the first evidences of vital action, and perhaps the most striking fact to the observer, is the unerring emergence of definite bodily structures out of apparent emptiness. For here life frankly displays before the critical, but ever baffled gaze of science, the translation of its invisible agencies into concrete forms.

Then other signs of vital action rise. Miniature lakes and streams of nutrient fluids form; and in them, acquisitive cells are presently launched which ride on swirling currents through guardian channels, trafficking with every shore. Along widening crevices, between more substantial structures, sense organs and nerves throw out their lines to myriad expectant terminals, bringing subtle impulses from abroad, and transmitting messages from cell to cell, in advertisement of present supplies and urgent necessities. 


\section{GRAND STRATEGY OF EVOLUTION}

And then the mystic embryo, apparently compounded of countless discordant parts, expresses its organic unity in rhythmic heart-beats and convulsive movements, and finally in more purposeful bodily actions.

In the worlds developing social life, the same mystery of embryonic phenomena is now being displayed before our very eyes. We may see there the same methods in action, utilized for the same purposes; and in a similar manner its emerging physical structures and coordinated vital actions reveal to us its growing unity and cooperative organization.

The larger features of this embryo Leviathan are seen in the checker-board of states and empires which are now taking on more coherent and stable form in response to their historic antecedents, their inherent qualities, and their local environments. These national units, once established, immediately express their individuality by the international exchange of their material commodities and spiritual influences. The human will cannot inhibit the flowing of these cross currents any more than atoms can suppress their affinities, or the ocean inhibit the flowing of its own waters. The mutual influences of man on man, and state on state, operate whether man wills it or not.

These vital influences are now taking on, in due creative sequence, the more substantial form of vessels, cars, and air-ships; they are the larger blood corpuscles of the growing international circulation, giving up and receiving their life sustaining cargoes, regardless of nominal boundaries, along the great channels and highways of terrestrial conveyance.

And the press, the post, the phonograph, and the 
"movies," the material receptors and transmittors of the new life, with their printed films and chiseled metal shields, their branching copper filaments, flash the feeble calls of man to man, and state to state, throughout the world; and black and brown respond to white, and white to black and brown, in reassuring flashes.

At last, the myriad vacillating atoms of world-life have emerged from the primordial chaos of futile isolation and conflicting motives, joined in ever larger groups to spiritual continuity, through steel clad cars and tiny dots and dashes. At last the west stirs uneasily to the call of the east, and the north to the call of the south. The heart of the world-life has begun to beat and her forces to act in unison.

The differences between all these quickening agencies of world-life and those of the quickening embryo are in dimensions, materials and agents, not in methods, purpose, or results. In both cases there is present the same element of inevitable progress, the same basic compulsion to growth and organization inherent in the "make up" of their constituent parts. In both cases, as in a Red Cross act, cosmic agencies, and the physical machinery of life, must be rightly utilized to establish cooperative continuity with the ultimate chemical and organic forces of the living body before growth can take place, and when that is accomplished growth takes place automatically. In both cases, all the essential processes involved are cooperative, mutually serviceable, saving and creative in their results if not in their "purposes."

We are now beginning to see more clearly something of the grand strategy of evolution, something of the purpose, or end, toward which world-life is mov- 


\section{GRAND STRATEGY OF EVOLUTION}

ing, and the agencies it is automatically creating within itself for its own upbuilding.

Man, with feverish activity, is forever striving to overtake his own purposes, like a cat chasing its own tail; when the speed and power to gain his ends are found, the ends are no longer there, but new ones are seen still just out of reach. His perpetual invention of better and more powerful instruments of conveyance multiplies his desires, feeds them but does satisfy them, and thus are means to a larger end than the mere acquisition of more speed, or physical power, or wealth, or comfort, or leisure, or knowledge, or art, or the dominion of man over nature's organic and physical forces. All these gains are but instruments to an evolutionary goal, not ends in themselves.

They but enable life to multiply the more, thereby laying still heavier compulsion on man's intelligence, and enforcing stricter moral discipline upon him, in order to preserve his increase. The multiplication of man is that growth in numbers necessary to give worldlife its bodily completion, its social unity and continuity, its volume and variety of human resources. Man's machinery of social conveyance, his commerce, science, literature, and art, his acquisition of vast sources of physical power, are but the necessary preliminaries to the upbuilding of the physical anatomy, the circulatory system, nerve centres, and sense organs, the sources and reservoirs of physical supplies and spiritual stimuli, essential to a world-wide cooperative life.

Man's intelligence, that new instrument in evolution, which primarily served, and rightly, his own selfish, individual ends, having accomplished its initial 
constructive purpose, became the unconscious, and now the conscious, directive and constructive agency in a new world-life. Intelligence, therefore, and her offspring, science, religion, philosophy, and art, like all other cosmic agencies, is primarily egoistic, self-creative, and self-saving, and then turns its new-born powers to super-service, to altruism, or to the still larger constructive ends of world-life.

The time is ripe for man to catch the spirit of this mental obligation now laid upon him.

\section{The Ways and Means to a Purposeful World-Life}

How can this embryonic world-life, now entering its conscious stage, accomplish its creative purposes? Solely by using present powers for future, altruistic ends. As in the parental benevolence of animal life, and as in all other phases of evolutionary strategy, provisions must be made for future usage, consciously or unconsciously, on a scale commensurate with the social purposes to be accomplished. It should not surprise us that all the pleasures and satisfactions in life, sensory and mental, consist in doing these very things.

But the creative powers in mutual service, whether expressed as reflex actions; or as sexual, or nutritive instincts; or as religious, scientific, or philosophic motives; or as the highest ideals resident in the masters only, are impotent as constructive social agencies without the machinery for their accomplishment.

To turn these potential agencies into realities, a larger, more controlling number must have these motives, or ideals, and themselves provide a permanent 


\section{GRAND STRATEGY OF EVOLUTION}

vehicle for transmitting them from man to man, and from generation to generation.

To act purposefully, with some measure of social unison and common profit, as for example in the way the bodily organs perform their purposeful actions for the frog, the physical, organic, and mental machinery of social conveyance must first be created, which will make it possible for great social groups to preserve their ideals; to advertise their supplies and demands; to store up, or transport their commodities; and to check, or stimulate, their activities as the common welfare may demand. All that means national and international cooperation, commercial and educational, resting on some common understanding; on some basic community of methods and motives.

The growth of such a system may be left to chance, or till the slow action of natural laws establishes an equitable balance in the flow of social give and take. But in that case, the human quality in intelligent cooperative action, and the fulfilment of man's moral obligations, would be absent. The process can be hastened, rectified, or regulated, given its human quality, only through the operation of the ordinary processes of intelligent action in self-interests; that is by foresight and self-denial, based on experience and on a knowledge of natural laws and conditions. That means what is commonly called "science" in its broader meaning; or some knowledge of world movements, the nature and volume of world resources, anticipation of the world's supplies and demands, and a knowledge of the right ways and means of utilizing one to satisfy the other. 


\section{The State as a Sphere of Cooperative Action}

We have seen that cooperative action is a universal attribute of nature, rhythmic in the wave-like rise and fall of its constructive impulses; and cumulative in the tidal rise of world organization its petty gains engender. It is the main spring to the growth and being of every individual thing; the compelling creative power which everywhere underlies the phenomena of evolution and progress.

While it has not before been recognized that progressive cooperation is a universal creative law, man has long been cognizant of the creative power in cooperative action. Within the narrower circles of his more familiar affairs, he first instinctively, or unconsciously, then deliberately, or intelligently, utilizes cooperative methods to augment his own powers and resources. Broadly speaking, his own profits and the dimensions of all his social institutions, by whatever names they be called, have been commensurate with the degree of intelligence utilized in directing existing agencies into cooperative channels.

But deliberately and rightly to utilize these creative methods on a larger and more enduring scale, or in projects that ripen in the more remote future, as in agriculture, science, or education, or in kindred affairs of state and nation, demands a far larger experience and a broader vision than that requisite for the exploitation of present opportunities. It demands at least a clear enough vision of prospective profits to constitute an abiding compulsory factor in the regulation of man's conduct, and so regulating it in a sufficient number of 


\section{GRAND STRATEGY OF EVOLUTION}

individuals as to produce concerted social action adequate to attain these more remote, less tangible ends.

The success attendant upon these larger cooperative enterprises, whatever the aims and agents may be, depends on the fulfilment, to and by the constituents, of definite rights and obligations in a definite sequence; and this aid must be conveyed over wider areas and longer periods, the larger and more comprehensive the enterprises are. But these rights and obligations can never be fulfilled in due time and equal measure, because social demands are never equally vocalized, nor immediate necessities equally manifest, nor the ways and means to execute them equally available to all.

Hence the cooperative egoism and altruism of social life, like the metabolism of protoplasmic life, can never attain to cooperative equilibrium, for the receipt of rights by one constituent cannot precede the fulfilment of obligations by the others; moreover the inevitable handicaps of time, and place, and capacity may outweigh the necessity for one, or obviate the performance of the other.

The rate at which cooperative social life actually is evolved depends on the extent to which the underlying growth-pressure, or the increase in population and the increasing exigencies of supply and demand, forces these divergent tendencies through common channels to their natural issues.

This growth pressure, which is itself evidence of an underlying accumulation of profits whose only outlet is through the discovery, or invention, of better ways and means of conveyance, compels men to seek out and utilize these better ways; preserves and strengthens them with increased returns when these ways are 
found; and compels them to see that the fulfilment of mutual rights and obligations in the attainment of these ends is a self-preserving necessity.

The state is one of these larger spheres of cooperative social action around which man has set up more or less arbitrary boundaries.

\section{The Evolution of Social Covenants}

It is evident, therefore, that men must come to some sort of agreement in conduct, tacit or otherwise, before they can live in association. These agreements are in effect mutual stimulations and inhibitions for united purposeful acts. They mean for each partner to the agreement some measure of self-sacrifice and service for a common gain; or a mutual surrender of individual sovereignty in return for services rendered, or to be rendered.

Whenever such agreements were mutually serviceable, the partners to them had a better chance to survive, the agreement a better chance to become a custom. Agreements that were not mutually serviceable, or profitable, ultimately ceased to be made; their authority then died, and new agreements, that were stronger and more enduring because they were more profitable, were formed instead. The framework of social life is upbuilt on countless agreements of this character that may or may not be formally expressed, or even recognized as an agreement. Municipal law derives its basic authority from a long line of such agreements whose origin vanishes in antiquity.

In any case, the agreement to be more constructive socially must give freer play to egoistic and altruistic 


\section{GRAND STRATEGY OF EVOLUTION}

action than independence, or complete freedom of action could give; that is, it must result in increased ability in each individual to render services to the other. In this sense, then, municipal law is an extension into social groups of the profitable system of organic inhibition and acceleration, so familiar to the student of animal life; its really vital growth represents the accumulating profits of socially constructive agreements, saved by their rightness, and saving those who use them rightly.

The life of the state is wholly dependent on the actual fulfilment of these mental agreements, however vaguely they may be expressed, or formulated.

Contained in, or underlying all these agreements in thought and act, is the principle of a cooperative covenant, involving the partial surrender of sovereignty and the assumption of obligations, for some ulterior end, or result, or purpose.

The covenant may be religious, as wherein it is understood that God is willing, or agrees, to save and magnify His people, if they are willing to believe in Him, or agree to obey and glorify Him. In effect, science enters into a similar covenant with Nature. For Nature virtually says to man: "Know me, obey me, and serve me, and I will serve you and augment you." And so she does. In the same way, the State virtually says to her citizens: Serve me, or serve one another, and all of us will serve you. And so on, down the whole category of written, implied, or wholly unconscious covenants of social life involved in law abiding citizenship, in family relations, business integrity, credit, neighborly conduct, and all that is implied in honor, and in the conduct of a gentleman. The contract always im- 
plies the expectation of profit, of self-betterment, augmentation, or growth, on the part of the contractors; and beyond that, a hope, less clearly defined, of attaining some ulterior, larger result. The fulfilment of the contract justifies that hope and keeps it alive.

We thus reach solid ground, on which to build a biological interpretation of the state.

The state is clearly not to be identified with the special privileges and immunities of a divinely appointed ruler and his satellites; nor is it a being whose interests stand apart, or on a different footing than those of its individual constituents. The state is rather a more or less arbitrarily circumscribed sphere of cooperative nature-action and human action; it is dependent for its existence on the inventions and discoveries, the mutual sacrifice and mutual services of individual citizens, whereby other citizens have attained greater freedom and greater power.

These servants constitute the state; their exchange of mutual services, conscious or otherwise, is its vitality; the conservation of their profits, its growth. In this respect, the state is like any other living organism. The thing, for example, we conveniently call a frog, is in reality a complex action-system, whose various material parts and organs constitute the physical body of the frog; their cooperative action with one another and with their outer world, is its vitality; the accumulating profits of its exchange is its growth.

Thus in spite of the nominal boundaries laid down by man, there can be no absolutely exclusive, or inclusive, boundaries to a state, any more than to any other living being. Its inner life merges imperceptibly into the life of its external environment. 


\section{GRAND STRATEGY OF EVOLUTION}

That which gives it an outstanding unity is the distinctive character of its more immediate physical, organic, and spiritual resources, and the degree of their organization. Its physical topography and climate, the history of its peoples, their education, and the fundamental unity of their thought and purpose, are decis-' ive factors.

With growth all these conditions change. The old methods of internal and external conveyance must be improved and extended in order to preserve these gains; this, when accomplished, merely serves to unite larger areas and larger groups of people into more intimate cooperation.

\section{The Government of the State}

One of the chief sources of social instability is the diversity of opinion as to the right points and sequence of attack in social betterment. These opinions reflect the different desires of the social constituents, their various degrees of experience and wisdom, and their unequal incentives to action.

The ostensible purpose may be immediately to improve the internal life of some individual citizen, or class, or race, or nation; or their external life, or, ultimately, both in all. But even though it may have been clearly recognized, here and there, that the welfare of each constituent individual is essential to the existence of the state, and the welfare of the state essential to each one of its constituents, at no time in human history has there been any notable equality of desire, or of purposeful action, to that end ; or any consensus of opinion as to the best ways and means of attaining it. These 
social aims and measures are indicated by the ways in which a state is governed.

The Autocratic State. In its internal organization, the autocratic state seeks to increase its power by the compulsory subordination of the weak to the strong. Force, being the instrument of compulsion, thereby becomes the chief end and aim of the state, the ideal of all its leaders, because it is the necessary means to all their ends.

In its external life, or in its relations to other states, autocracy seeks to utilize the same methods. In both cases, wherever it is possible to do so, rights are seized by force, and obligations sheltered by force, thus sacrificing the weak to fortify the strong in a vain effort to perpetuate the system.

The servant, whose will to endure is weakening, is threatened by his master with greater ills to come; bribed by the offset of prospective spoils, and stimulated by the promise of increased power to rob the common enemy.

The constructive principles frankly recognized in this unequal exchange, however they may be disguised by high sounding names, are those of the slave driver, the pirate, and the parasite. But all such one-sided systems, as we have seen, are ultimately self-destructive, because the more they are perfected, the worse it is for both master and servant; and the sooner the one is forced, in self-defense, to prey upon the other. $\mathrm{He}$ that takes something from his servant, and gives something less in return, tends to destroy the source of his own power, for the servant that is not rightly served 


\section{GRAND STRATEGY OF EVOLUTION}

ceases to exist. Hence, with growth, the system inevitably disintegrates, broken down by its unbalanced growths, the clearer consciousness of unequal justice, and the lack of mutual benefit.

The Democratic State. Democracy is the inevitable reaction to autocracy. It seeks to protect the rights of the individual, rather than force him to perform his obligations. But the resultant over-emphasis of selfishness and freedom, and the lack of a spirit of subordination and self-sacrifice, are incompatible with a cooperative organization. Rights and obligations a re theoretically equalized; in reality, they are not and can not be equalized, because the demands for rights and the ability and the desire to serve, are never equally strong in the same or in different individuals.

Moreover, the equality of social rights, and the maximum power of the individual citizen, are not attainable in an imperfectly organized state. And where civic service is voluntary and sporadic, its necessity obscure and unimperative, an efficiently organized state is impossible.

In its external relations, the democratic state may be tolerant of the rights of other states, but it is slow to meet its international obligations because it lacks both the vision essential to a sufficient motive, and the organized power essential to constructive action.

In democracy, great improvement is possible through better education and organization. Improvements in autocracy merely exaggerate its basic evils and hasten its inevitable collapse. 
In the recent war, the conflicting individualities were intellectual groups, chiefly antagonized by differences in education and ideals.

Prussia, the leading state of one group, was a political monstrosity, a reversion to embryonic, ancestral conditions, in that she still so largely retained, in her higher intellectual life, the nullifying vestiges of criminal purposes.

And Prussia preferred to capitalize her misfortune, rather than to cauterize it. She sought to save herself from an organic disease by combining the crudities of barbarism with the idealism of modern science and the spiritual forces of religion. She thereby destroyed the very sources of her greatness. For the spirit of truth and the spirit of service, the great creative forces of science and religion, cannot live in the same soil with barbarism.

For this insanity of purpose, the false interpretation of evolution by her biologists was very largely responsible. Her intellectual life had long been saturated with their pernicious teachings, impelling her leaders and laymen, in all walks of life, to justify their immoral ambitions by an appeal to the ruthless brutality of animal life, and to smother the instinctive outcries of outraged humanity by a pseudo-scientific interpretation of the "struggle for existence" and "the survival of the fittest," where, forsooth, such sentimentalism as benevolence and altruism does not exist! Never were science, religion, and philosophy, and the good common sense of the layman, jointly committed to a more palpable error.

This half-witted philosophy of dominion, that looks only inwards to self, never outwards beyond self, as we 


\section{GRAND STRATEGY OF EVOLUTION}

have seen, has no justification in the creative processes of nature. It is this very attribute of super-service, entering into all the constructive processes of nature, which demands the intelligent use of altruistic methods in international relations.

While this philosophy of international robbery was not peculiar to Germany, no other nation so deliberately made it the basis of all its policies, or in its name so cunningly organized its educational system for destructive purposes; so knowingly prostituted the precious heritage of its scientific fervor, its religion, and its love of truth, to shameless propagandism; so cheaply sold its honor to opportunity; or whose people have been so intoxicated by the momentary success of its criminal doctrines.

\section{Education as a Directive Agency to Social Egoism}

Germany's power to accomplish her purpose was destroyed, or temporarily nullified, by force. But there is no force that can destroy her purpose. That purpose will live, as well elsewhere, as in Germany. For "militarism" is a protean spirit, assuming many physical disguises. It is the abiding egoistic attribute of progress; a recurrent organic disease, proclaiming in the delirium of its excesses some increasing unbalancing of the cooperative system, due either to environmental changes, or to the rise or decline of internal resources. It is as permanent as life, as incurable as death; a perpetual menace to every social organism, which a better education can better direct, but can never destroy. That education must be ever in large excess of present needs. 
The mental feelers of society, like the tentacles of a crawling animal, must be fully extended to the outer world, coming into intelligent contact with nature at every possible point, in order that man may rightly find his way through her mazes of constructive and destructive agencies. Like visceral nerves, the sympathetic agencies of social life must extend their observant communicating lines into the very vitals of the social body, in order to receive and distribute the reassuring messages of well being, and the warning pangs of social maladies. In this way only can society acquire the vision adequately to foresee impending evils, and the saving motive rightly to readjust itself to new conditions. For the insane spasm of pain, the red flag of revolt, and the leaden pallor of inaction, are symptoms of some local disturbance in the flow of cooperative action; the outcries of outraged constituents demanding vital aid; the warning signals of approaching social death and dissolution.

The motive behind all these demands for aid, and the "right to exist," is the lure of service. The root of the lure, expressing in vital terms the tendency of every physical body to modify every other body, is the desire to accomplish something; to exercise one's influence creatively over other things and thereby gain selfapproval, merit in the eyes of others, and added influence. The growth-motive is always there, even though the purpose may be narrowly limited or misdirected. Only in the freedom of self-expression can that desire be gratified. To capitalize this creative power, to awaken the service-motive into consciousness, and to give it wider opportunity for constructive action, is the function of education. 


\section{GRAND STRATEGY OF EVOLUTION}

Against this growing menace to freedom of action, and in order to meet the larger demands for service incident to a growing population and a narrowing world, man must minister to himself by building his offensive and defensive armaments of intelligence and human sympathy on an ever deeper, broader, and more enduring scale. For it is not against one another that men are insanely struggling for existence, but against ignorance and superstition and a diseased, or unbalanced, social condition, due to the fact that social life has rapidly outgrown its power to correct its self-created ills.

In this insane struggle for power, man is still led by the same medicine-men, witch-doctors, and sorcerers of old; the still older dog-ape chiefs of the pack, thinly disguised as divinely appointed masters and heirs to privilege; who with malign whisperings of magic influences, with modern substitutes for tom-toms and bladder-rattles, still incite their witless brothers to fratricidal frenzy, vainly hoping by sacrificial offerings to tribal gods, by pageantry and a loud noise, to cure the belly-ache of social indigestion, or the birth pangs of social revolution, and still preserve their ancient privileges.

To save himself, to live and grow in his new environment, man must shed these outgrown garments of the past, and as one new born in a new world, face the future with the youthful hope and naked courage of one who knows his task is set and his happiness assured in its performance. He must reconstruct his social life on a far deeper and broader cooperative purpose than ever before; a purpose simply and frankly expressed in words and deeds which every normal individual can 
see, and feel, and understand, and all work joyfully together in its accomplishment.

Labor and capital, art and science, must be frankly recognized as social increments, and as social properties. They are the social organs which create and preserve the body social. They are to society as reserve fats to the human body; as muscles and nerves, eyes and ears, skeleton and gland, skill and intelligence; all of which are both producers and products, the common profits of bodily experience and bodily labor, held in trust by man for present and future uses. Each belongs to each and all to one. No one can survive without the other. Each must receive its rights from the others, and must fulfil its obligations to the others, or cease to exist. That is the categorical imperative of social evolution.

Science and religion, the elder brothers of social life, must draw closer together in cooperative social action; science absorbing the more hopeful and spiritual qualities of religion, and religion the more progressive and frankly intellectual qualities of science. Every phase of man's education must emphasize the creative law of cooperative egoism and altruism, or the universal obligation to self-aggrandizement for the purpose of self-giving. This elemental creative law is the fundamental lesson of social life. Unless it is well learned, forming a basic part of man's personal character and of his social institutions, his intelligence will be devoid of its most essential human quality, his learning vain, and his social life a failure.

IX. The State as a System of Cooperative Functions

We have shown that the state is an organic being, territorially localized, and subject to the same basic 


\section{GRAND STRATEGY OF EVOLUTION}

laws that govern animal life. Intelligence, the new factor increasingly involved in its life and growth, does not release man from the action of these laws, but merely compels him to see them more clearly, and to use them more rightly. What we call the government of the state has been evolved out of many unconscious, or semi-conscious, attempts to restrict and specialize individual conduct, the better to protect and preserve the individual. So far as those attempts were successful, they also created and preserved the system of cooperative social functions we call the state.

But the individual can never solve all his social problems. Under the new conditions which arise in successive stages of social development, it is increasingly difficult for him to find an adequate outlet to his purposes. Under the compulsion of the ever new demands of growth, he can find that outlet only through a still more intelligent, or purposeful, organization of state functions. These directive and disciplinary phenomena of social embryology are precisely like those in a developing animal embryo, except that the unit actors belong to different dimensional orders.

The functions of the organic state are not less numerous and intricately interwoven than those of the human body. Nevertheless they may be conveniently grouped into three great categories which will, at the same time, serve to emphasize the three most important groups of vital functions, namely: reproduction, metabolism, and betterment.

Social Reproduction. In animal life the reproductive functions embrace all those conservational 
agencies which are included under the general terms heredity and parental altruism. These reproductive powers are wholly dependent on the endowment of the next generation with approved germinal materials supplemented by parental surplus in food materials, and by parental administrative contributions which insure the growth of their offspring and the production of another life similar to that of the parent organism.

Society extends and further enlarges these organic parental endowments, by means of all those educational provisions which insure the conservation and continuity of her mental and physical possessions. Among these provisions are included the exemptions of youth from productive labor; their shelter and nutrition out of social reserves; libraries, museums, and many other institutions, not restricted to the constructive usages of youth, and which embody in themselves the accumulated profits of human labor and experience and the enduring principles of constructive rightness.

Social Metabolism. In the animal organism metabolism includes all those upbuilding (anabolic) and consuming, or breaking down processes (katabolic) which constitute the give and take, the altruism and egoism, of protoplasmic life, and of internal organic exchange. The extension of these vital exchanges, so as to cover the larger reaches of time and space which separate plant and animal organisms, constitutes the social metabolism of nature-life. The more direct and more closely interwoven give and take of commerce and cultural life, providing power for its upbuilding, for the wear and tear of exchange, and for the directive 


\section{GRAND STRATEGY OF EVOLUTION}

agencies that keep it rightly moving, constitutes the metabolism of human social life.

Social Betterments. But no vital process can grow, or increase its possessions, without some provision other than that necessary for mere conservation, or the maintainance of the previous conditions. To grow, or progress, the whole transaction must yield a profit. In organic life, the provision for profit lies in a certain measure of leisure, or of experimental freedom; a playtime margin for adventure and exploration, which is always available, in every phase of life, over and above those compulsions necessary to machine-like maintenance.

From these opportunities, universally available for variation, for improvisation, or play, arise the chief betterments of life, or the discoveries of the right ways to do the new things which the new conditions always demand.

In social life, these provisions are supplied, although often grudgingly allowed, in the margins of life left open for wakeful rest, for contemplation, or study, or play, after the labor necessary to sustain life has been duly performed. Or more elaborate provisions may be made by the establishment and support of various institutions whose chief business is invention and research, or the intelligent effort to discover the right ways and means of meeting, or anticipating, the new demands of the growing social organism.

Whatever progress man may hope to attain can come to him only through due response to these vital 
demands of growth and to the discovery, or invention, of more equitable and more economic methods of conveying physical and spiritual commodities to the sources of these demands.

To give this new Leviathan of social life its necessary spiritual cohesion and mental stability, man must clearly recognize this basic growth purpose in social life, and the constructive value of these social functions to that end.

Formal agreements, or covenants, must therefore be entered into, covering the principal functional phases of world life, elementary in character they may well be, yet nevertheless explicitly recognizing the mutual rights and mutual obligations of the partners to the agreement, and the common purpose to be achieved by them. Chief and foremost among them, should be formal covenants between the citizen and the state; between the state and its institutions, and between the state and its sister states.

This will be man's work for the immediate future. It will demand something other than mere territorial, or numerical representation; something more than the shallow diplomacy of the "practical politician" or the makeshift wits of the middle man in statesmanship. It will call for the services of socially minded delegates from all the great vital functions of social life; delegates who derive their authority from their functional colleagues, and who are appointed by them to define their respective interests and purposes.

Such delegates can best foresee the requirements of those they represent, and the creative possibilities of their own social services. It should be their duty formally to demand the social rights of their constituents, 


\section{GRAND STRATEGY OF EVOLUTION}

and formally to express, and to assume, their social obligations.

The anlage of an organic government of this character, independent of the more formal government, exists within every modern state. It makes its appearance no one knows exactly when or where, as more or less informal, or supplementary methods of utilizing latent resources in more purposeful social action. These better methods tend to develop within every growing social group, whatever its social formulas may be; inevitably creating more unity and saving order out of a chaos of conflicting purposes.

The greater prevision and provision essential to the existence of larger and more enduring organic units make parental guidance, benevolence, and self-sacrifice the most characteristic attributes of such units wherever they exist. In the same way, social growth inevitably raises man above the lower levels of petty selfishness to higher levels of super-service and altruism. It automatically creates devotion to larger purposes, thereby creating the very agencies which are the instruments to social salvation. Therein lies the assurance of future progress.

In times of stress, and in great social emergencies, like that of the recent war, the sheer power of social service breaks down, or through all artificial barriers; spending itself in the attainment of its goal, it welds divergent wills together, shatters class distinctions, and differentiates anew the democratic masses; vitalizing with its energy all forms of society in a similar way, and creating in them similar organic structures.

Leadership, and the right of way, opens to him who best foresees demands, and to those who best supply 


\section{THE NEW LEVIATHAN}

them. Society thereby automatically reorganizes itself into more direct and more stable systems of cooperative conveyance.

Under the pressure of the rising floods of necessity, this shifting of social functions into broader and straighter channels may, rapidly assume revolutionary dimensions, as recently demonstrated in our own country. But this threatened metamorphosis in our national life created no destructive protest, because there was a sufficient capital of social intelligence to recognize the saving and creative way in that emergency. The manifest logic of rightness was the agent of compulsion.

Every successful revolution in the administration of animal life, and there have been a great many of them, is made in some such way as this. An essential condition is the existence of different systems of organic conveyance, growing up side by side in the same living organism, as, for example, the gills and lungs of a fish, or tadpole. The one system of conveyance ultimately supplants the other because it better serves the demands of the growing organism. And that better service then creates new growths, which make more demands, leading the whole organism, as fishes and tadpoles were led from water on to land, into a new world of light and air, of food and sound, of space and motion. The older system survives and serves, in diminishing measure, till the new birth of freedom is accomplished. It is then scrapped, or in part destroyed, in part reserved for more general usage, and the remnants incorporated into new instruments, such as male vocal organs and resonant auditory chambers, which then perform new and wholly different services. Thus this organic metamorphosis and the transfer of impor- 


\section{IO GRAND STRATEGY OF EVOLUTION}

tant bodily functions from one set of agents to another is peacefully accomplished without interrupting the flow of vital actions.

It may be that in our ultimate social metamorphosis, the older system of democratic government, based so largely on territorial and numerical representation, will not be wholly destroyed, but will be in part preserved as mutually stimulating vocal organs for both sexes, finding its chief usefulness in irritant oratory and in resonant congressional chambers.

\section{The Extension of State Functions into Inter- national Functions}

The functional agencies, which are so essential to the upbuilding of the state, cannot be restricted in their creative action to the internal life of the state. They inevitably extend, consciously or unconsciously, far beyond all nominal boundaries, and become cooperative international functions.

To give these international functions stability and the directive quality of human intelligence consciously acting in national self-preservation, international covenants recognizing mutual rights and mutual obligations, and thereby giving these international pledges the authority of international law, are as imperative as they are in smaller social groups.

But this more purposeful international cooperation is not likely to be realized through the instrumentality of existing political agencies, because the state is so largely organized for narrower selfish ends, and because its political agents are not the ones best fitted in spirit, training, or motives, adequately to recognize the 
extra-territorial interests and the creative potentialities of their constituents. A more hopeful source of leadership is in the great social functions of mankind, where there is greater unity of purpose; where common interests are more easily recognized; where vital supplies are more obviously drawn from world-wide domains, or at least from domains wider than the state; where the habit of thinking in terms of international cooperation is more prevalent; and where a cooperative organization, on an idealistic international basis, is already initiated.

Science, religion, art, education, commerce, and manual labor are social functions of this character. These great systems of vital exchange have long felt the impulse to international cooperation, and their instinctive response to it has already yielded results which demonstrate that, physically and spiritually, they are far better fitted to assume the judicial, legislative, and executive functions of international life, than the old political systems, with all their historic animosities. Their ability to perform these services will greatly increase with the fuller consciousness of their mission. And to accomplish this mission, their delegates, through the agency of international congresses, must endeavor to define the conditions essential to the regulation and control of constructive international relations, and summons their respective states to provide the necessary ways and means to translate their demands into purposeful action. 


\section{SUMMARY}

IN the preceding chapters we have surveyed the phenomena of nature from a purely objective point of view in order to discover, so far as we may, what they mean for us; whether it is for us as intelligent beings to "fight the cosmic process," or to use it according to our light and strength in our own constructive enterprises, and thereby become willing agents in its consummation.

We have seen that the one outstanding fact which now dominates the thoughts and acts of intelligent men is evolution, or nature-growth, embracing alike all physical, organic, mental, and social phenomena in its spontaneous constructive action, and using them all alike in the consummation of its creative purpose.

That sovereign outward fact, in all its elemental grandeur, is the immutable axial truth around which man must orient his inward purposes and to it conform his conduct rightly, or suffer self-destructive penalties. It compels man to accept nature's constructive rightness as his ethical standard, and to adopt her constructive methods as his moral code. It compels him to recognize in nature-growth the expression of a creative will; it reveals to him in nature-action the way to augment himself and the instrument to his salvation. His most ardent desire is then to know that will the better to obey it.

A limited perspective is always confusing, for the very reason that the diversity of nature-action is always unified. We instinctively resent the wanton destruction 
of creative values; we are appalled by nature's apparent carelessness of individual life and, to us, the unmeaning usage of her overwhelming power. But the wider perspective of the evolutionist tends to correct this mental confusion; and his mental attitude to natureaction, more rightly oriented, renews and fortifies his faith in nature's creative purpose.

In mental life our little tragedies are mostly of our own creation; they are mostly mental insurrections against the growing consciousness of external compulsion and hostile limitation to our purposes. But when the inevitable truth is clearly recognized, our mental subjugation is completed in the appetite of desire, and surrender to it becomes our pleasure and reward.

No accession of power can ever solve our problems, or the accumulation of possessions satisfy our desires; they are but new burdens which create new demands and impose new restrictions on us.

The constructive usage of what we have for that ulterior creative service we shall always crave is the source of happiness.

Our resentment of the world's injustice vanishes when we come to feel the sense of growth and ownership in the world about us, and in its growth participate. The strictest discipline and greatest hardships are no longer such, if we know that through them we better play the game; if as parent, patriot, explorer, artist, student, or as worker in any line whatsoevei of human endeavor, our ideals are still preserved and we truly seek and strive to satisfy our great desire. 



\section{APPENDIX}

\section{THE MESSAGE OF THE BIOLOGIST ${ }^{1}$}

IT is eminently fitting that we biologists, like virile swarm spores, should periodically come together in a holiday spirit of mutual exchange, and after giving and receiving our messages, go back to our life work, reinvigorated and reoriented, to prepare for another brief period of social conjugation.

The messages we send to one another will have little carrying power, and little influence on the receiver, if they are not specific in content, limited in scope, and securely wrapped up in the precise technical terms of our own familiar code.

On the other hand, the biologist would be wholly lacking in social instincts if he failed to recognize that he also has a more comprehensive message for the layman, who is largely dependent on the biologist for his working knowledge of the great domain of nature-life, and by whom the biologist is provided with the necessary means of existence.

This larger message must have a different vehicle. It must first be summarized, digested and metabolized into the vernacular, before it can circulate through the body of social life, reach its terminals, and there accomplish its strengthening and rectifying purpose.

We may well ask ourselves whether we have such a message to give, and if so, what it is, and who, or what, is our authority. And by "we," I now mean all of us, not merely the biologist, but the astronomer, geologist, chemist, physicist and psychologist, for we are what we are to-day because of the underlying community of our methods and purposes, and because, in our concept of evolution, we acknowledge the same mental sovereignty.

This concept, of which we are the trustees, initiated in man a veritable intellectual mutation, which is now rapidly expressing itself in new phases of social action, and in the emergence, like the parts of a growing embryo, of new types of social architecure. It is our duty to interpret this concept, and to see to it that its real significance is understood, and rightly used in social growth.

The social metamorphosis which historians call the renaissance was largely due to organic improvements in the system of educational circulation and the transmission of mental possessions from man to man. Learning was democratized by translating the bible and the classics into the vernacular, and by this betterment in transmission across time and space, the profits of a dead past were made to flow more freely into a living future, making those profits in some measure the mental heritage of the

${ }^{1}$ Address of the vice-president and chairman of Section F, Zoology, American Association for the Advancement of Science, St. Louis, January 31, 1919. "Science," N. S., Vol. LI, January 30, 1920.

See also two other papers by the author, of earlier date, expressing similar views:

The Evolution of Service by Union, Cooperation, Conservation and Exchange. Popular Science, Oct., r914.

Cooperation as a Factor in Evolution: Proceedings of the American Philosophical Society, Vol. XV. I916. Read April I5, I916. 
common people, and their enduring germinal possessions for self-constructive purposes.

In this accelerated social growth, the base line for the orientation of human conduct, and for the measurement of right and wrong, good and evil, was the bible, the classics, and the divine right of civic and religious leadership. The power and stability of these external directive agencies was universally acknowledged, the source of their authority unquestioned, and like radiant beams, their tropic influence was formally expressed in the prevailing architectonics of social procedure.

We are now witnessing, incident to a new birth of social vision, a new social convulsion, much more significant than that of the middle ages, in which science, and especially biological science, unconsciously played, and is still playing, a very important part. For when we recognized a new source of authority in lawful nature-action and in evolution, the old base line for the measurements of human conduct vanished, and many of the old bonds of social allegiance were destroyed; and now we are asked: What shall be the new compulsion to constructive social action, and on what authority can we stay the march of anarchy?

And you, as biologists and American men of science, may not shirk the grave responsibilities of social leadership now thrust upon you, for it requires little gift of prophecy to foresee that America is destined quickly to become the world's chief center of biological learning, as she is to-day the center of the broadest sympathy with human life and nature.

Perhaps it may clarify our vision if we first ask, not what biology is, but what science, as a whole, does, and what she tries to do. It will little help us to enumerate all the sciences, or be told there is "pure" science and applied science; science experimental, and descriptive. Behind and beyond all these varied aspects of science there must be common motives, and common purposes in the scientists, if we are rightly to include them as intelligent beings in the same class.

Let us therefore precipitate and remove these adjective purities and impurities, and you will then agree with me, I believe, that there still remain in science several over-lapping functions and purposes. First to explore and to chronicle. To that end, she aims to discover what things dre contained in nature, where they are, what they do, what the order is, step by step, of their coming in, their growing up, their going out. And then to memorize, to conserve her mental possessions, to register, in convenient and enduring symbols the result of ber explorations, for future usage. Second, to compare and explain. To that end, she aims to discover why things are as they are, in what respects they differ, in what they agree, how one thing influences another, constructively, or destructively, and to distinguish the right ways of doing things from wrong ways. Her third function is to do things rightly. In that respect, she is artistic, architectural. To that end, by conforming her ways of doing things to nature's ways, she aims to create, and to conserve, and to use her records and her knowledge of right and wrong profitably.

Thus three qualifying motives pervade science: the acquisitive, the ethical and the moral. She seeks knowledge through experience, wisdom through understanding, and profit through obedience. One purpose is selfconstructive, or egotistic, the other, self-giving, or altruistic. Both are cooperative functions; in action, continuous; in rightness, cumulative; in effect, creative.

The renaissance of to-day has its chief creative impulsive in the consciousness of evolution. This revelation of modern science, which we all acknowledge as our guiding star, has come to mean world-growth, or the progressive organization and architectural upbuilding of nature. Nature 
is now the source of our authority, and creative nature-action, as expressed in nature-growth, is the standard of all our values. Science is therefore compelled to express all her measurements in positive and negative constructive terms, which ultimately must be oriented in reference to this gradient base line of nature-progress, called evolution.

In this nature-growth, we fail to discover any gain or loss, either in basic constructive matter, or in energy. But gain there must be, if evolution is a reality. That gain is, in reality, a moral and ethical gain, or a gain in that creative action and constructive rightness which we call organization and directive discipline. There are no better positive and negative terms to express those gains, both relatively and absolutely, than the familiar terms, right and wrong, good and evil.

On this point, therefore, there need be no equivocation in our message. The profit in evolution is in better constructive action. By the conservation of these profits, nature augments her capital in constructive rightness.

But how is this profit made and conserved? That is the really vital question. Until it is answered there can be no underlying intellectual stability in human life, individually, or socially; no basic unity of purpose in human conduct. Here our vision is not so clear. Many of us believe that on this point we have no comprehensive message to give.

The most familiar attempts to explain how evolution takes place are restricted to special aspects of evolution, and are often epitomized in personal names, such as Darwinism, Lamarkism, Weismannism, Mendelism. Among us there are naturalists, morphologists, physiologists, and psychologists; breeders, experimentalists, and bio-chemists. And surrounding us on all sides are the physicists, chemists, geologists, and astronomers, with whom we must reckon, for their domains and their subject matter overlap ours in countless ways.

But unfortunately between all these workers there is little common understanding and much petty criticism.

Are we building out of aimless contributions to science a new Babel's tower of disjointed, slippery words, with nothing to hold them to constructive lines, and preserve the unity of purpose in our social architecture?

Perhaps the most comprehensive terms, although they have little meaning outside the organic world, are "natural selection," the "struggle for existence," and the "survival of the fittest." But granting their validity within the organic world, they have no definite moral significance. They convey no implication as to how man, or anything else, must act in order to exist, to say nothing of surviving. What is the fittest? Why is it fit? Why does it survive? If right combinations happen primarily by chance, why, or how, do they come to happen regularly? How can "right accidents" become cumulative, or lawful, or determinate, unless there is a saving, or more enduring, directive element in that something we call rightness?

When the layman makes his holiday call on his biological menagerie and points his umbrella at us, hoping to receive through that safety-first device a brush discharge of information, we fail to "come across" with illuminating answers to these very pertinent questions. But to conceal our low potential, and preserve our self-respect, we all resort to certain unintelligible sounds, or warning signals, according to the particular pen in which we have been bred and exercised, and which are guaranteed to scare away, or charm into inaction, the most intrepid questioner. One mumbles something about "environment" and "ecology," and crawls back into the bushes. Another wheezes something about "enzymes" and "vitality" and goes on with his experimenting. Another climbs to the top of his cage and yells "eugenics," while his mate in the corner faintly lisps "euthenics." Some particularly active youngsters jump into a revolving wheel, and 
every time it makes a complete revolution shout "chromosomes, chromosomes, chromosomes." A few old moss-backs, a rare variety, mournfully harp on "morphology." And one majestic megatherium comprising all in one, coughs up an "energy complex," followed by a prolonged roar, in several volumes, in which one can distinguish the words "action, reaction, and interaction." The clergymen, senators, and Bolsheviki, with their retinues of lady friends, exclaim "How wonderful, and so true." Life indeed is complex, energetic, and full of actions, reactions, and interactions! And all of them deeply impressed, go back to their deadly work, and act, and believe, if at all, just as they did before.

After they are gone, all the animals agree that no one has any right to bother real, simon-pure scientists with such fool questions. Let them go to-well, Where? To Germany? To Nietsche, Bernhardi, and Treitschke? To the militant philosophy of dominion; to a half-witted selfishness, in politics, commerce, and kultur, frankly upbuilt on the doctrine of the survival of the fittest; the fittest universally acknowledged, by themselves, to be the Germans and their system?

Or to the spiritualists, anthropomorphists, and sentimentalists, who see nothing clearly in the mirror of nature but a distorted image of themselves?

Or to Huxley and his "I don't know" followers, who can discover no ethics or morality in nature-action; neither warning nor invitation, nor directive discipline, but merely a drab, unoriented neutrality of "unmorality," leaving man nothing but himself with which to orient himself; leaving him to create. his own system of ethics and morality out of his own inner consciousness?

The biologist has found no evidence for the broad assumptions of these philosophers. In nature, he sees no one-sided dominion of the strong over the weak, or the weak over the strong; no special privileges; and no freedom from obligations. Neither does he see any warrant for puling sentimentality, nor any expectation of an unaggressive neutrality in natureaction.

Nature, so far as we have been able to discover, is an enduring, selfconstructive system, gaining and preserving her gains in a definite way, according to her own system of ethics and morality. In so far as naturegrowth is manifest in evolution, we can not deny that at least to that extent her ethics are constructive and her morals saving.

Man's constructive and saving principles can not be otherwise, without severing all his bonds with nature-action in a futile attempt, like that suggested by Huxley, to set up an anarchistic "imperium in imperio," or a Bolshevistic "microcosm within the macrocosm."

I can not believe we have reached that parting of the ways, for man's highest activities are all too clearly but extensions of nature's ways and means of creating and preserving her products, in which man uses whatever intelligence he may have, and the cultural implements he has constructed, as special instruments to attain his ends.

The specific gravity of the western variety of biologists will not let him float in a vacuum of cosmic mysteries with the Hindoo; and he does not care to wallow in a quagmire of metaphysics with the Greek. He gladly plants his substantial mental feet on the first firm substratum he can reach. And even though that substratum be nothing more than the molecular quicksands of physics and chemistry, it safely leads him to the rising shores of hard realities.

But now that we biologists, as evolutionists, feel reasonably safe in our storm-proof shelters of established facts, the spirit of adventure again leads us forth to wider excusions, and we ask ourselves whether it is possible to reduce all the constructive processes of nature to a simple formula, which can be expressed in familiar terms of universal human significance? This 
is a venture doomed apparently beforehand to defeat, for it takes us back again to the most ancient beaches of human controversy, strewn with the wreckage of all man's early and late attempts to launch a religion, or a philosophy, that will stand the test of experience.

And all these mournful wrecks are jealously guarded by marooned mariners of hope, and their beach-combing followers, who show no mercy to intruders. But modern science, which has wisely built on firmer, though drier ground, must ultimately extend the foundations of all of her outhousings down to the low water mark of this old shore, and while the attempt is fraught with danger, it will ever be an inspiring task for those engaged in the process of social reconstruction that now lies before us. I know of no other engineers whose occupation should better fit them for leadership in this task than the biologists, occupying, as they do, a central strategic position in relation to chemistry and physics, geology and astronomy, sociology and the humanities.

When to this end, we examine, as best we may, the attributes of these basic, chemical elements of nature's substance, we find in them, as in human social atoms, a potential constructive and creative power which becomes clearly manifest in the familiar processes of chemical action. In that process we are compelled to assume, if we are willing to assume anything, that some influence, or effect, we know not what, or how, is exercised by one element on another, the result of which may be the formation of a new unit, or compounded individuality, with a new style of architecture of its own. Coincident with this construction, the former attributes of the constituent parts vanish, and in the new unit a different attribute appears which was not there before.

We may profitably translate this constructive process into the vernacular, without, I trust, seriously offending the proprieties of the purest scientist, even though the words may'savor of morality.

We may say, for example, that when the right chemical elements are in the right relations to one another, or if they are moved into them, or placed there, or if these elements themselves find the right relations by chance, or otherwise, cooperative action between them then takes place automatically, or under a compulsion neither can resist, and something new is created. In this cooperative action, each element evidently does something, or gives something to the other, and receives something from the other. It is in fact apparently a clear case of creative action through mutual subjection and mutual service-not necessarily service for each other, because for all we know these elements may be the original anarchists and would much prefer neither to give anything to anybody, nor receive anything from anybody-but for the molecule so created.

In this creative process, the essential factors are, unity, mutual service, mutual discipline, and some sort of constructive rightness. When these conditions are fulfilled, something new is created, and these anarchistic elements then become, perforce, altruistic agents, or accessories, to some ulterior creative act, in which they may or may not be interested. In spite of themselves, by their mere existence, they are compelled to act for something beyond self, and in doing so they cease to be anarchists and become more or less orderly servants in a staid molecular society.

Mr. Molecule, therefore, is created by the mutual services and directive discipline of his constituent atoms, or elements, and by his home surroundings, all acting cooperatively to give him birth. In his creation, he becomes endowed with a sovereign quality of his own, subject to the sovereignty of his outer world. He endures as long as those cooperative services are rightly performed, and the discipline rightly maintained, and no longer. His existence, therefore, is contingent on the performance of these services, and on the existence of some degree of rightness within himself, and outside himself; and that molecule which does survive has preserved within 
its makeup some measure of that rightness. In that measure of cooperation and rightness lies the fitness of his constituents, and the selective agency in the evolution of the molecule.

But the molecule thus peremptorily set up in business for itself, and without being consulted in any way as to his own wishes in the matter, has his own work in the world to do, subject to his own specific attributes and external compulsions. This new anarchist, by force of circumstances, may be compelled to help in the construction of proteids to be used by some future plant or animal life, even if his anarchistic soul does rebel at the performance of such useless altruistic labor, and at such unwarrantable interference with his freedom of action.

If we now make a momentary excursion toward the other extreme of nature-action, into the domain of the astronomer, we apparently find the same constructive, selective, and saving agencies at work that are manifest in the upbuilding of the molecule, only the system and its component parts are larger, the time and space factors greater, and the unknowable movers have different names.

Here the cooperative agencies are the sovereign cosmos, and the sovereign individualities it contains. These solar systems, with their constituent suns, planets, and satellites, and their subordinate elements, are grouped in partially visible architectural entities, suggesting the wholly invisible molecular entities of physics and chemistry.

The gains in this cosmic action-system are formulated in sidereal architecture, and the continuity of its constructive services is manifest in the stability of its organization. The morphology of the heavens, like that of molecules and living organisms, is not only an index of past and present physiologic action, but an assuring prophecy of future action. Without this forward and backward aspect, along a gradient line of progressive nature-action, science itself could not exist, for there would be no base line for the profitable orientation of intelligent thought or action.

In each of these larger sidereal units, and systems of units, is embodied the summed up profits of past cooperative actions. In this self-construction lies the egoistic phase of these individualities. The ulterior altruistic services to which they are accessories are in some measure apparent in the terrestrial conditions under which, without our consent or approval, we now exist. So let us get back to earth again, where these agencies have made life and constructive thought a possibility, and have rigidly defined its impossibilities, whether we like these invitations, restrictions, and compulsion of nature's discipline, or not.

In the terrestrial world, the most convincing and familiar example of creative unity through cooperative action, is the living organism. But plant and animal life stand on, and in, the altruistic achievements of the physical world. They are pensioners of the past, using both the oldest and newest instruments of nature in their self-construction. The individual plant, or animal, is the product of its cooperating elements, cells and organs, and its environment, and is itself a cooperative agent in that environment. It is subject to its own sovereign attributes, as well as to those of its constituents and its habitat. The individual gain is everywhere contingent on the general. The plant can not long endure without the animal, the male without the female, and neither without their retinues of other servants. They exist, as they do, because of these mutual services, within and without, past and present. Their profit is in service betterments: their working capital, past betterments conserved.

In this phase of nature-action, the cooperative system is formless, elastic, and democratic. Plants and animals are the actor-units, widely separated 
it may be, in time and space, but everywhere intermingled regardless of high or low degree. And the system now assumes the familiar give and take of predatory life and reproduction, where consumer and consumed, parent and offspring, egoism and altruism, perform reciprocal functions in the universal metabolism of nature-life.

Consider, for example, the nut, the mouse and the cat.

If the mouse destroyed all the nuts, it would destroy itself. Its interests are best served when nuts are encouraged. If it had intelligence, it would cherish and preserve them. If it had the necessary cultural implements, it might profitably spend its spare time and energy in producing more and better nuts. Not even a "nut" could reasonably object to that. On the other hand, the cat is an efficient educator. It teaches the mouse to confine its attention to its own affairs, and both teacher and pupil are the better for that.

And when the mouse is about to die, and is brought to earth, it does not wholly go to waste. A percentage of him goes to make another nut, and a percentage helps to make another cat, which without the one and the other could not exist. And finally nature levies a tax upon the cat, and in due season the cat pays his taxes.

By virtue of this rigorous nature discipline, which prescribes when, and how, and where, the nut, the mouse, and the cat may act, and what they must, and must not do, each in its own way makes a living, as many others like them have done in similar ways before, a sufficient testimonial to the constructive and saving virtue of the system.

But this is only one part of this system of give and take. The plant, the mouse, or the cat, as an individual, not only gets, or receives enough income from all sources to pay his personal running expenses, but on the whole, each in his own way, makes a profit. Part goes into alterations, repairs and additions, or into what we call growth. But there is always a definite limit to individual holdings, or to the growth of every individual system, which is peculiar to itself. When that limit of cohesion is reached, or approached, the surplus overflows into other individualities and becomes their possession.

Much of this surplus of the profiteer, which for him is unusable, is scattered right and left with astounding prodigality, and this unwilling altruism on his part becomes one of the chief sources of income to life at large. But an adequate percentage becomes a special, entailed endowment to a new individual, similar to the first, thus setting up a substitute, or a direct lineal descendant in the business of life, giving him a fixed capital in germinal materials, quick assets in germinal food-stuffs, with containers and protective envelopes, all rightly constructed and arranged, and the whole package so located in time and space by the administrators of these estates as to insure for it, in the long run, a new life of adventure among the hazards and inviting opportunities of the outer world.

Thus in this larger spongeoplasmic fabric of nature-life, visible only to the more comprehensive instruments of the mind, kingdoms and classes, races and species, young and old, the physical and organic entities of the living and the dead, are unconscious partners in a common system of cooperative action. In this social metabolism across the larger reaches of time and space, each unit, in the reciprocal egoism and altruism of life and death, plays its respective anabolic and catabolic functions, and thereby gives the system, as a whole, its self-sustaining, vital power.

Through the shifting patterns of this growing fabric, we most clearly see the converging threads of genetic lineage, the long, gradient lines of alternating youthful egoism and parental altruism, on the one hand vanishing in the primordial life that has its issue in the terrestrial loom, and on the other, radiating into the abyss of future possibilities. Everywhere shot through and across these more rigid hereditary linęs are those which mark 
the sinuous course of predatory action, and other actions less discriminating. Thus the whole system is woven into that variegated plexus of success and failure, tragedy and comedy, joys and sorrows, good and evil, which makes up the cooperation functions of life and give it creative unity.

And then man, a new nature-anarchist, the most modern pattern in this moving-picture fabric, makes his appearance on the screen, and surrounded by his satellites of cultural instruments, and with both positive and negative poles of his very material self flaming with the auroras of intelligence, attempts to set this system which gave him birth to rights.

$\mathrm{He}$ is little conscious of the source of his own endowments, or that his ethics and morality, as manifest in his sporadic outbursts of social philanthropy and benevolence, are not his own institutions, but the compulsory application of world-old constructive principles to his own peculiar affairs. Nor is he fully conscious that his boasted material inventions and discoveries, his canoes and battleships, his ovens, highways and machinery, his microscopes, telephones, and telescopes, his commerce, literature, science, and art, are but improvements, or enlargements, outside himself, of his own internal organs and functions, and that he must use these cultural instruments, if he would use them constructively, in precisely the same ways his vital organs are used in his bodily growth and preservation.

In their functioning, these cultural instruments extend, deeper into time and farther across space, the power of his sense organs to discriminate between good and evil, and increase the range and velocity of the load his muscles, blood vessels, nerves, and other bodily organs can move, or carry. In other words they serve to increase the rate and diversity of the mutually profitable exchange, mental and physical, between the human molecules of social life, and between man and nature. They alone give man's social life its cooperative unity and power, just as the cooperative action of molecules, cells, and organs give unity and power to his body. Their saving and constructive action is contingent on the growth and right usage of intelligence, as the construction and preservation of his body is contingent on the evolution of right reflex actions and instincts.

And now, in this twentieth century of the historian's calendar-when the human blastoderm, for the first time in cosmic evolution, has practically enclosed the terrestrial egg, filling in all the habitable surface of this cosmic yolk-sphere, establishing its capillary network of highways, and its nerve plexus of communication, joining its racial blood-islands and national placodes into one organism-humanity has ceased to be a germinal potentiality, or a mere vision of the prophets. It has become a present and very obvious reality, and the academic flickerings of the philosophic auroras are now sufficiently luminous to be visible, as practical questions, to the politician. Indeed there is still hope that some rays may eventually pass the threshold of senatorial sensibility.

But the man of normal social instincts and average intelligence, in spite of himself, is now compelled to recognize this unity in human life and nature, and the dependence of that unity on the fulfillment of mutual rights, of mutual services, and mutual obligations. In this more humble state of mind, he does not now ask "What will I do?" but "What must we do?" to preserve social life and social structures. What is our protection against the will to destroy? With destructive agencies everywhere now at hand for those who have the will to use them, What shall be the compulsion to constructive action?

The answers to these questions can not be found in precedents, for there are no precedents in the whole history of evolution for man's present social conditions. The solution must be found in the intelligent application 
of the elementary principles of ethics and morality, principles which have their roots in the biological and physical sciences.

We must not accept Huxley's despairing assertions that "cosmic nature is no school of virtue, but the headquarters of the enemy of ethical nature," and that "the cosmic process has no sort of relation to moral ends." To do so we should have wholly to ignore the manifest creative power in cosmic action. We may surmise, from internal evidence, the irritation that provoked Huxley's brilliant but unconvincing dialectics; and it should be said that his point of view then, and the chief target of his attack, is not ours now.

And surely it is not for us "to fight the cosmic process" even under a fighting Huxley; nor on the other hand need we accept the stoical philosophy of protective mimicry and regard "living according to nature as the whole duty of man"; nor need we be horrified at the thought of ethics as "applied natural history."

Rather is it our duty to understand nature-action and to cooperate with it; to distinguish between the minor tactics of evolution and the grand strategy of evolution, and with our own peculiar instruments be willing and happy agents in its consummation. Man has but his animal organs, his cultural implements, and his intelligence, or his knowledge of right and wrong constructive ways to work with. The more those instruments are augmented, the better he can direct nature's constructive agencies to his own egoistic ends, and in so doing, man himself then unwittingly becomes a new and better altruistic agent in evolution.

We scientists, conscious of our purpose as constructive social agents, have three broad fields of activity open to us, as already indicated in defining the various functions and purposes of science. First, investigation, or the discovery of nature's ways and means of creative action. This is the ethical side of our work. Second, the constructive usage of these ways and means, or their application to the growing demands of social life, and their usage in the regulation of human conduct. This is the moral side. And, third, the conservation of our ethical and moral gains through education. The first two we may now ignore, for their significance is duly appreciated and their future is promising. But the educational side of our work is in a very serious condition, and it may even now be too late to avoid disaster. It little matters how much we may develop either our technique, or the spear-head of our research, if the so-called common people still have the ghost-hunter's paleolithic mental attitude toward natural phenomena, and their leaders a similar attitude toward social problems.

No social life can endure that is not under some common compulsion to united action. With the growth of the spirit of freedom and democracy, and the absence of any commonly recognized dictatorship in church or state, that compulsion can come only through a common understanding of the elemental necessities of social life, and through that sense of personal benefit and personal ownership in social institutions which alone can create the will to cherish and protect them.

The compulsion of elemental intelligence, acting in social unison, can alone provide the enduring directive and cohesive power essential to social cooperation. Man's will to create can be steadfast in purpose only when his intelligence becomes stabilized in its tropic attitudes, and rightly oriented to elemental realities. Man, stumbling in ignorance, must be bandaged with restrictions and propped up with crutches of force. A nation, pricked by the poisoned shafts of a lying propaganda, will dissolve in anarchy, though the armies and navies of the world have failed to break it.

In our education, we continually over-emphasized social rights and 
individual freedom of action, and ignore the obligations essential to partnership in any social or constructive compact. It is not without significance that ordinary people, like you and me, can discover no specific mandate in the Constitution of the United States. It broadly defines what the state does, or will do, in certain contingencies, and what its citizens may, or may not do, but says nothing about what the citizen must do in return for what the state does for him. The absence in citizenship ${ }^{2}$ of a formal and specific contract, defining a common purpose and recognizing mutual liabilities and mutual benefits in its attainment, is in marked contrast with modern business procedure, as well as with almost every other form of intelligent cooperation. It is, therefore, not surprising that an international covenant for the specific purpose of reducing the danger of international wars to a minimum, in which an attempt is made to define national rights and obligations in that undertaking, has a strange and unfamiliar sound.

The absence of this covenant principle is noticeable in almost every phase of modern education. Science, even, does not formally recognize a covenant with nature, although nature virtually says to man "Know me, and serve me, and I will serve you." Much of our biological teaching is like a shop window display of nature's competitive goods, with a varied assortment of human notions thrown in, but with no guarantee as to their significance, or quality, or usefulness. The pedagogical barker, seldom having convictions of his own, proudly displays the impartiality of his "purely scientific" attitude, and leaves the callow purchaser to decide for himself which trinket he will select for his mental adornment.

Perhaps all of us can get together again on common ground by putting our concepts of nature-action into simpler, more comprehensive formulas, universal in application, and somewhat as follows. In so far as we have a right to assume that purposeful action is involved in any constructive functioning whatever, or in anything that has been accomplished, we may assume that the purpose, or grand strategy in nature-action, is evolution, or self-construction, or growth. To that end, serviceable agents must first exist, or be constructed, in which is resident a basic right to receive service, and a basic obligation to give service. As all constructive action is contingent on the fulfilment of these mutual rights and obligations, the categorical imperative to existence is mutual service.

As corollaries to this categorical imperative, the following compulsions are laid upon these constructive agents. In all sustained constructive action there must be: (I) A mutual directive discipline, or mutual adaptation; that is, a mutual subjection, and yielding to one another's influence. (2) An individual freedom of opportunity for self-constructive, or egoistic action, within rigidly circumscribed limitations. (3) Mutual service or cooperative action, in which, sooner or later, the profits of egoism must be surrendered, through altruism, to some ulterior creative act. (4) Conservation of these profits as an accumulating capital in constructive rightness, and its endowment to other individualities for usage in further constructive action.

In that phase of cosmic evolution which we call social growth, science and religion are the outstanding cooperative agents. They better serve their ulterior purposes the better their mutual services, and the better their mutual adaptation of thought and act to creative ends.

\footnotetext{
${ }^{2}$ Every member of the community has a right to be protected by it in the enjoyment of his life, liberty, and property. He is, therefore, bound to contribute his share in the expense of such protection, and to yield his personal service, when necessary, or an equivalent."

BILl of Rights, Art. 12th, Constitution of the State of New Hampshire, "Colby's Manual," ז 902.
} 


\section{APPENDIX}

Science and religion always have asked, and doubtless always will ask, the same fundamental questions. What creates, what preserves, and what destroys the products of nature, and how may man profit thereby? The answers, whatever they may be, must ultimately be expressed by them in essentially equivalent terms, their verification sought in constructive action.

The large element of unpredictable returns resident in all phases of nature-action demands trial; creative turns justify the experiment.

These unsuspected potentialities are revealed in the triumphs of nature's creative art and thus reveal a measurable independence of established laws and precedents. Therein is the source of man's undying hope and faith, his abiding impulse to endeavor. 



\section{INDEX}

Acromegaly, 344 .

Adaptability, as a universal creative tropism, 76 .

Adaptation, 72; compulsory, 296.

Agreements, constructive, 394 ; social, 393.

Ahrimet, $3 \times 8$.

Altruism, 62; defined, 38 ; mental, 287; of metabolism, r3o; nature, r48; of organization, r34; parental, 148 ; social, 148 .

Amulets, 316 .

Animal life, architecture of, 204.

Animism, 315, 385 .

Anthropomorphism, 317.

Architectural plans, 1 88; problems, 195; tropism, 238; values, 78 .

Architecture and function, 172 ; and knowledge, I II; and nature action, $17 \mathrm{r}$; and philogeny, 188 ; and response, 176 ; of a nimal life, 182 , 204; of inorganic growth, 196; of organic growth, r 98 ; of plant life, 182,201 ; of social life, 252 ; orientation of triaxial, 24r.

Aspects of Nature, $2 \mathrm{r}$.

Assets of life, r4o.

Asymmetry of outer world, 240.

Attribute, 29.

Australians, social life of, 346 .

Authority, delegation of, 367,369 .

Autonomy, external, r14; internal, II4.

Balance, cooperative, 178 .

Behavior, defined, 58 .

Benevolence, defined, 38 , 129 ; mental, 287, 288.

Petterments, social, 406.

P.lastoderm, social, 268.

Blood, 230.

Brahma, 348 .

Buddhism, 348.

Business, 334; ethics and morality of 334 .

Cadence, creative, ro7.

Capital, mental, 288; organic, 13 r.
Categorical Imperative to existence, 50 ; in social evolution, 403 .

Centralization of function, 234 .

Chance, decrease of, 48 ; defined, 48 .

Christianity, 348 .

Circulation, international, 386.

Class, differences, $35^{8}$; functions, 358 ; interests, 359 .

Cleavage, social, $36 \mathrm{r}$.

Cognition, retroactive, 292.

Colonies, ror.

Commerce, 156.

Competition, ro6.

Compulsion, cumulative, XII; of achievement, 362 ; of established methods, 187; of intelligence, 302, 278,320 ; of nature action, 302 ; of self-preservation, 282 ; of social possessions, 277; of truth, 303 ; to growth, 387 ; to social cooperation, 273.

Concepts, basic, 295 .

Conduct, defined, 58; social, 297, 306.

Constitution of United States, 163 .

Constructive action, basic factors in, 21 ; agreements, 394.

Conveyance, 32, 35; cultural, 268; social, 268.

Cooperative covenant, 394 ; law, 3 I 3 .

Cooperation, bisexual, $146 \dot{6},{ }^{92}$; chemical, 29, 34; compulsion to, 277; defined, 33 ; law of, 33 ; of animal life, 148 ; of mass action, 34 ; of plant life, 182; of plants, 148 ; power of, 50 ; protoplasmic, 35 ; as universal attribute of nature, 39r; as universal creative law, 39r.

Cosmogeny, $3 \mathrm{r}$.

Cosmos, I8.

Covenants, cooperative, 393 ; international, 4ro; religious, 394 ; science, with nature, 394 ; social, evolution of, 393.

Creation, 295; defined, 28, 30.

Creative action, continuity of, 28 ; drift, 4r, 44; law, 403 . 
Cultural Evolution, 257.

Culture, Greek, 348.

Democracy, of common things, zor; mental, 368 ; new, 351 .

Development, 94.

Discipline, 128; civic, 16I; cosmic, 157; cumulative, 158; directive, 156 ; germinal, 158 ; in nature action, 26 ; in religion, 164 ; of nature, I16; of science, 165; social, 297.

Dominion, mental, 367 .

Education, I6o, $311,371,400$; function of, 278.

Egoism, 27, 133; mental, 287; of metabolism, 130; of organization, 134.

Endowments, 52; spiritual, 271.

Entail system, I36.

Entailed estates of life, 138 ; habitat, I38; principal, 139.

Evil, defined, 48,76 ; as centralizing agency, $76 ;$ as directive agency, 78.

Evolution, alturism of, 164 ; as a triumph of constructive action, $3 \mathrm{I}$, 97 ; categorical imperative of social, 403; collateral lines of, 190 ; influence on human conduct, 21 ; highway of, 279; main lines of, 190; of individuality, 40 ; of mental imagery, 29I; profit in, 46; purpose of, XII; essential process in XIII; rate of, 109 ; of social covenants, 393 .

\section{Fantasy, 293.}

Fear, 310,380 .

Fitness, 62 ; by design, 65 ; by mutual influence, 65 ; criterion of, 62 ; defined, 55 ; kinds of, 63 ; measure of, 68; permanent, 67; social, $71,7+$; temporary, 67 .

Forces, preparation for, 77 .

Freedom, growth of, 89 ; instruments of, 90 ; new, 354 ; social, 3 II ; world, 295.

Functional authority, delegation of, 369.

Functions, centralization of, 234; class, 357 ; international, 410; state, 4 IO.

Genesis, logic of, 108.

Giantism, 344 .
Gills, 228.

Good, defined, 48, 76 .

Greek culture, 316,349 .

Growth, 295; architecture of inorganic, 196; architecture of organic, 196; by combination, 99 ; checks and releases to, 93 ; compulsion to, 387 ; cultural, 261 ; demands of, 93 ; formal accents of, IOI; insistent power of, 91; limitations to, 97; by multiplication, 99 ; motive, 401 ; phases of, II2; pressure, 392; purpose, 47; rhythm, III; spiral, 20I; triaxial, 201 ; unadaptive social, 343 ; unicellular, 204 .

Habitat, entailed, of life, 138 .

Heart, 228.

Heritage, mental, 287, 288.

Highway of animal evolution, 280 . Hinduism, 318,348 .

Idealism, 54, 288.

Image chains, 292.

Imagery, evolution of, 29I; rightness of, 291.

Imagination, 292.

Individual, defined, $4 \mathrm{I}$; stability of, I 10.

Individuality, altruism of, $5 \mathrm{I}$; architecture of, . I96; components of, 59; egoism of, 51 ; evolution, of 40,45 .

Instinct, teacher, 288.

Instruments of animal life, 185 ; of plant life, 185 .

Intelligence, $57,155,290$; compulsion of, I61, 303, 364, 367; constructive uses of, 367 ; legal symbols of, 304 ; militant phase of, 309 ; purpose of, 290.

International covenants, 4ro; functions, 4 ro.

Knowledge, I7r.

Kultur, militant, 196, 335 .

Law, cooperative, 313; cultural, 269 ; elemental creative, 403 ; $\mathrm{mu}-$ nicipal, 393 ; social, 305 .

Leadership, germinal, ro7; mental, 298 ; orientation of, 54 ; voluntary submission to, 358 .

Learning, 387 .

Leviathan, new, 357 .

Life, administration of, 118 ; external, 120; federal, 120; internal, 
120; college, 123; cosmic formula of, 224; cosmic sanctuary of, 87 ; directive discipline of, 88 , 118; entailed estates of, rog, I38; habitat, 138; germinal principle of, 139; industrial, 364 ; quick assets of, I40; organs of social, 254.

Logic of science, 180.

Lungs, 228.

\section{Memorizing, 292.}

Mental benevolence, 288; capital, 288; democracy, 368 ; dominion, 367 ; freedom, 270 ; heritage, 288 ; imagery, 290; imagery, evolution of, 291 ; inheritance, 312 ; leadership, 298; limitations, 343; play, 293 ; procreation, 289 ; profits, 289 ; reorientation, 307 ; rightness, 288 ; rightness, conservation of, 3 II.

Mental life, altruism of, 287 ; egoism of, 287 ; strategy of, 304 .

Metabolism, altruism of, 133; cultural, 269 ; nature, XIII ; of mental life, r33; social, $360,384,405$.

Mergers, colonial, IoI; conjugal, Ior ; germinal, IOr ; parasitic, IOr ; profitable, ror ; sexual, ror ; symbiotic, ror.

Metamere, 219.

Metamerism, 219; decline of, 234.

Militant Kultur, 196, 335 .

Militarism, 400 .

Morality, defined, 58.

Motives, social, 362 .

Mouth, old and new, 227.

Municipal laws, 393.

Mutual service, increment of, 45 .

Nature-action, compulsion of, 302 ; ethics of, 56; morality of, 56 .

Nature, discipline of, II 6 .

Nature science, 297.

New Leviathan, 377.

Obligations, mutual, 50; to science, 372.

Orchid, 69.

Orientation of mental imagery, 285 .

Ormazd, 318 .

Papuans, $3 \mathbf{r} 5$.

Parasitism, I02.

Perceptors, 266.

Philogeny, I89.

Philosophy, 320; business, egoistic, $33^{8}$; of the biologist, 332 ; social, $33 \mathbf{I}$.

Plan, radial structural, 206.

Plasmodium, social, 382.

Possessions, mental, 288.

Procreation, mental, 289.

Profit, 295.

Profitable mergers, ror.

Profits, 53; in evolution, 46 ; in rightness, 322 ; mental, 289.

Progress, defined, 42.

Prophecy, justification of, 108 .

Protoplasm, 198; cooperation of, 35 ; social, 382.

Protozoa, 204.

Prussia, 399.

Purpose, in evolution, XII; in religion, 322 ; in science, 322 .

Radial structure, 206.

Reality, test of, 47 .

Receptors, 266.

Red Cross act, 37.

Regeneration, religious, 345 ; social, 340 ; incentive to, 345 .

Religion, 298, 318; discipline in, I64; purpose in, 324 .

Religious covenant, 394 .

Reorientation, mental, 307.

Reproduction, social, 404 .

Retroactive cognition, 292.

Rhythm, growth, III.

Rightness, conservation of, 3 II ; defined, 46,58 ; increment of, 45 ; inheritance of, 312 ; mental, 288, 321 ; pathways of, 322 ; profits in, 322 ; profits of, in evolution, 46 ; reciprocating functions of XIII, 78; serial order of, 108; social, 73.

Rights, mutual, 50.

Rita, 45.

Romans, 316.

Ruthlessness, 52, 53 .

Science, altruism of, $299,319,338$, 351 ; covenant of, 394 ; discipline of, 165 ; egoism of, 299,338 ; functions of, 324 ; logic of, 180 ; nature, 297, 319, 351; obligations to, 372 ; purpose in, 324 .

Selection, 62.

Selfishness in nature, 52.

Self-sacrifice, defined, 54 .

Sense-organs, 266.

Service, defined, 35 ; lure of, 401. 
Sex, attributes of, 143 ; properties of, 70.

Sexual cooperation, I45, 150.

Siva, $3 \mathbf{I} 6$.

Slavery, 106, 307.

Social agreement, 393; betterment, 405 ; cleavage, $36 \mathrm{I}$; conduct, 306 ; covenants, evolution of, 393 ; fitness, 71, 79; laws, 305; life, organs of, 254 ; metabolism, 360 , 405 ; motives, 362 ; protoplasm, $37^{2}$; reproduction, 404; rightness, 73 .

State, as a sphere of cooperative action, 391 ; autocratic, 397 ; biological interpretation of, 395 ; democratic, 398 ; functions of, 403,410 ; government of, 396 ; as sphere of cooperative action, 391 .

Sovereignty, external, II4; internal, II4; of individuality, Ir4; of nature, 114 .

Stomodæum, 207.

Strategy of evolution, XI; of mental life, 304 .

Super-service, 3 I 4 .

Symmetry, cooperative functions of bilateral, 403; false radial, 209.

System, entail in sexual reproduction, 136; nervous, 252; triaxial, 212.
Tao, 45.

Teacher instinct, 288.

Teaching, 287 .

Totems, 260, 316 .

Tragedy, in nature, 25 .

Tropic action, 246.

Tropism, a rchitectural, $77,237,248$; universal creative, 77 .

Triaxial architecture, 248; system, 212 ; orientation of, 241 .

Truth, biological interpretation of, 303; compulsion of, 303 ; creative value of, 312 .

Tunicates, 192.

United States, constitution of, 163 .

Veracity, tests of, 300 .

Vishnu, 3 I8.

Will, $37 \mathrm{I}$; creative, $3 \mathbf{I} 5$; to create, 315.

World life, evidences of, 385 ; mosaic of, 383 ; quickening of, 377 ; ways and means to, 389 .

Yeast, 69.

Zoroaster, 318 . 






\section{PLEASE DO NOT REMOVE}

CARDS OR SLIPS FROM THIS POCKET

\section{UNIVERSITY OF TORONTO LIBRARY}


